\title{
Assessment of the perceptions of principals about school performance in West Virginia
}

Connie L. Myer

West Virginia University

Follow this and additional works at: https://researchrepository.wvu.edu/etd

\section{Recommended Citation}

Myer, Connie L., "Assessment of the perceptions of principals about school performance in West Virginia" (2009). Graduate Theses, Dissertations, and Problem Reports. 2885.

https://researchrepository.wvu.edu/etd/2885

This Dissertation is protected by copyright and/or related rights. It has been brought to you by the The Research Repository @ WVU with permission from the rights-holder(s). You are free to use this Dissertation in any way that is permitted by the copyright and related rights legislation that applies to your use. For other uses you must obtain permission from the rights-holder(s) directly, unless additional rights are indicated by a Creative Commons license in the record and/ or on the work itself. This Dissertation has been accepted for inclusion in WVU Graduate Theses, Dissertations, and Problem Reports collection by an authorized administrator of The Research Repository @ WVU.

For more information, please contact researchrepository@mail.wvu.edu. 


\title{
Assessment of the Perceptions of Principals About School Performance in West Virginia
}

\author{
Connie L. Myer \\ Dissertation submitted to the \\ College of Human Resources and Education \\ at West Virginia University \\ in partial fulfillment of the requirements \\ for the degree of
}

\author{
Doctor of Education \\ in \\ Education Leadership Studies \\ Paul E. Chapman, Ph.D., Chair \\ Sebastian R. Diaz, Ph.D., J.D. \\ Richard A. Hartnett, Ed.D. \\ Ted Price, Ph.D. \\ Bonnie A. Ritz, Ed.D \\ Department of Education Leadership Studies
}

\author{
Morgantown, West Virginia \\ 2009
}

Keywords: Principals, Leadership, Institute, School Improvement, Framework for HighPerforming Schools, School Culture, Curriculum Management, Instructional Practices, Student and Parent Support, Effective Schools, $21^{\text {st }}$-Century Skills

Copyright 2009 Connie L. Myer 


\section{ABSTRACT \\ Assessment of the Perceptions of Principals About School Performance in West Virginia}

\section{Connie L. Myer}

This study compares the perceptions of two groups of West Virginia school principals about the performance of their schools. Six hundred principals were sent an online, 70-item survey instrument aligned with the seven domains of the state's Framework for High-Performing Schools. Of the total 600 principals in the study, half had attended the West Virginia Institute for $21^{\text {st }}$-Century Leadership, and the other half had not. Both the parametric $t$-test and the nonparametric Mann-Whitney $U$ were used to determine if there was a statistically significant difference between the mean scores of the two groups of principals. The results show a noteworthy influence by the Institute on school improvement efforts in West Virginia as perceived by 67 percent of its principals. 


\section{DEDICATION}

This work is dedicated to all those educators who have devoted their lives to serving children.

\section{ACKNOWLEDGEMENTS}

For their boundless support and encouragement, I thank my family, friends, students, past and present co-workers, and my committee members.

For His endless guidance, I thank the Shepherd. 


\section{CONTENTS}

Page

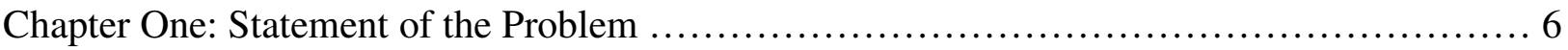

Background of the Study ............................................................

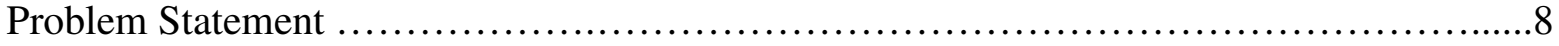

Professional Significance of the Problem ............................................11

Overview of Proposed Research Methods ........................................... 11

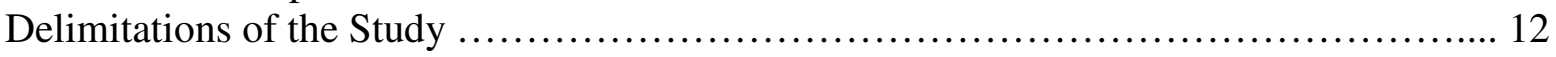

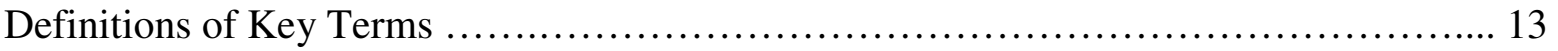

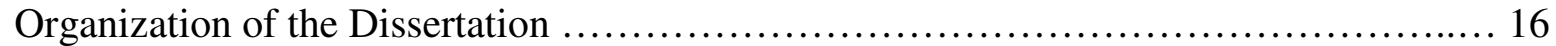

Chapter Two: Review of Selected Literature ......................................... 19

Domain 1: Culture of Common Beliefs and Values Dedicated to Learning for All ........ 19

Domain 2: Curriculum Management .............................................. 22

Domain 3: Instructional Practices .............................................. 25

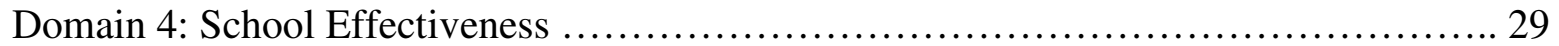

Domain 5: Student and Parent Support ........................................ 32

Domain 6: Systemic, Continuous-Improvement Process ............................ 37

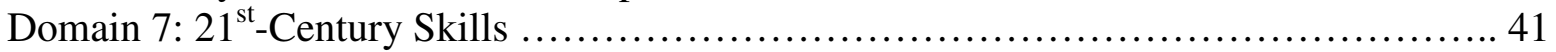

Chapter Three: Methods of the Study ................................................. 46

Research Questions and Hypotheses ......................................... 46

Sample and Population .................................................... 49

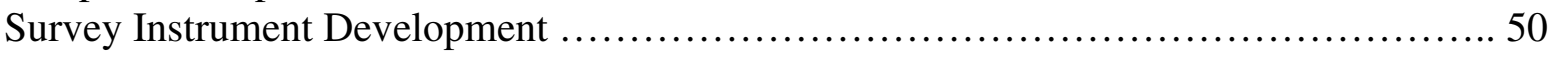

Panel of Reviewers .......................................................... 52

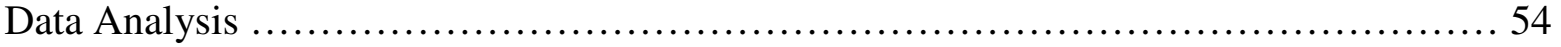

Pilot Testing of Questionnaire ................................................. 57

Considerations of Survey Dissemination ....................................... 57

Limitations of Electronic Survey ............................................ 58

Summary of Proposed Research Methods ......................................... 59

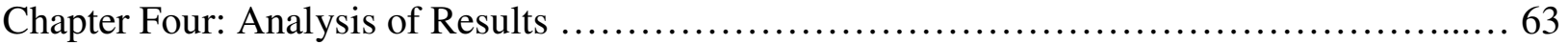

Descriptive and Statistical Analysis by Domain .................................... 65

Descriptive and Statistical Analysis by Question ................................... 78

Analysis of Narrative Responses ........................................... 145

Question 1 Responses ...................................................... 145

Question 2 Responses ...................................................... 154

Question 3 Responses .................................................... 159

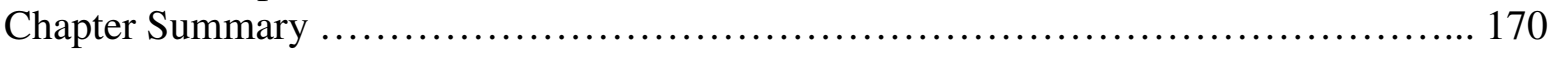

Chapter Five: Results ..................................................... 175

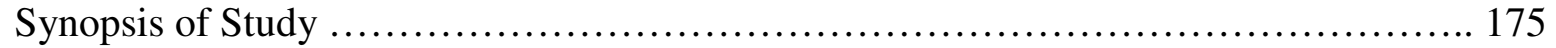

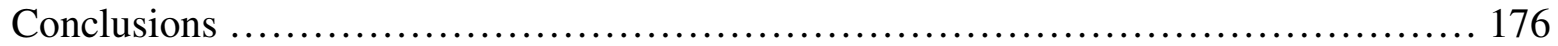

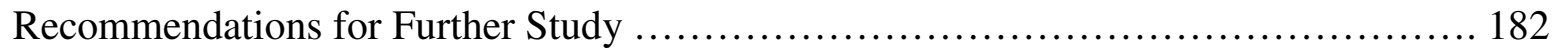

References ................................................................. 184 


\section{FIGURES}

Page

Figure 1. WVDE Framework for High-Performing Schools $\ldots \ldots \ldots \ldots \ldots \ldots \ldots \ldots \ldots \ldots \ldots \ldots \ldots$

Figure 2. Concept Map of Prospectus ...................................................... 18

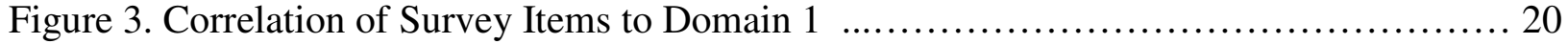

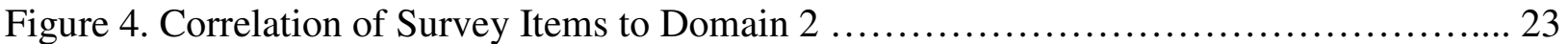

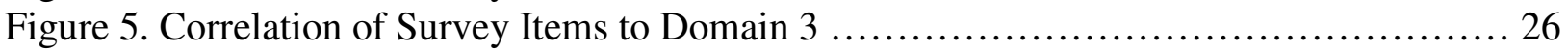

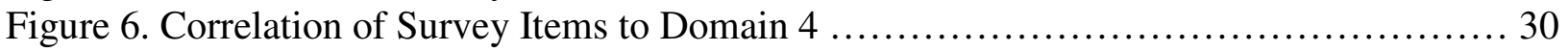

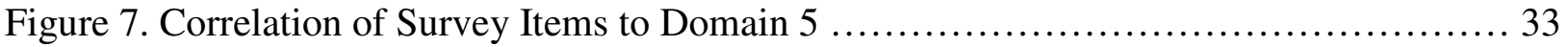

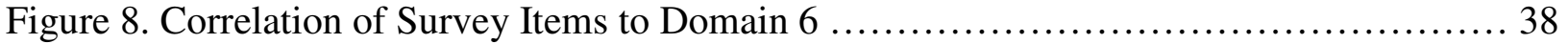

Figure 9: Correlation of Survey Items to Domain 7 .................................. 42

Figure 10. Proposed Time Line for Research, 2008-2009 .................................. 61

Figure 11. Comparison of Group Means by Domain ....................................... 67

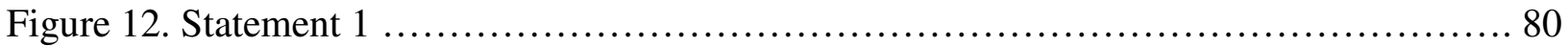

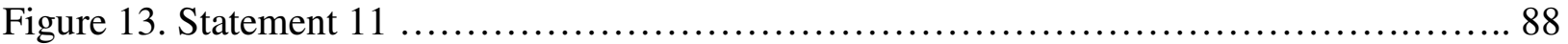

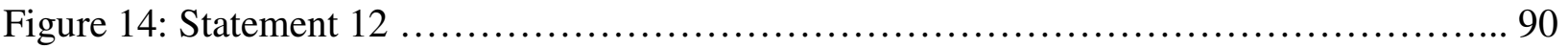

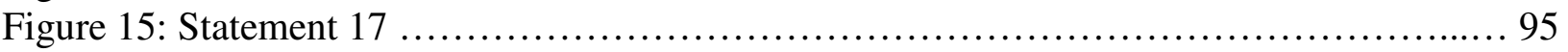

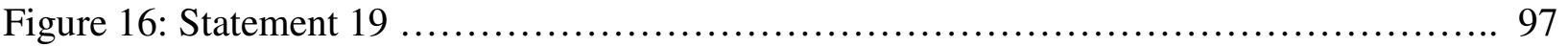

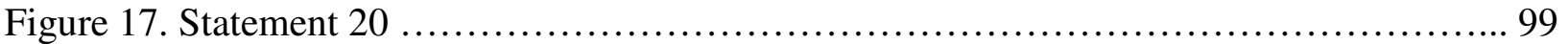

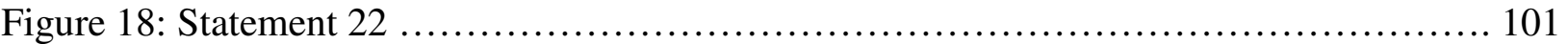

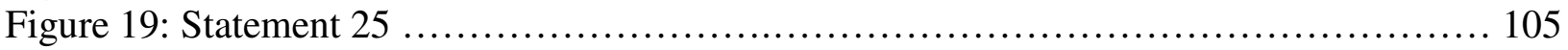

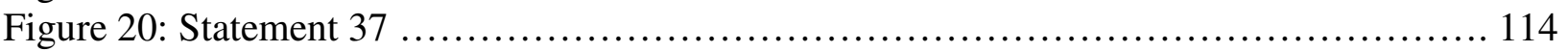

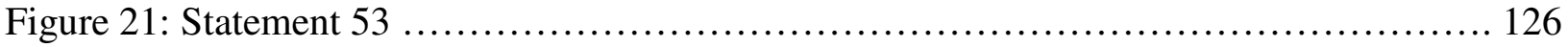

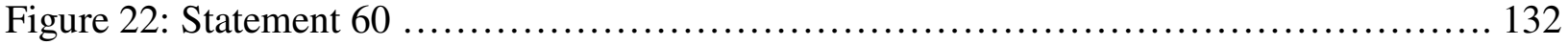

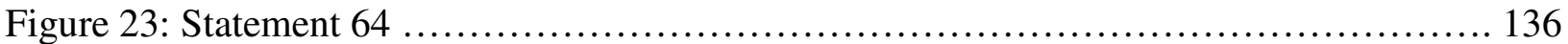

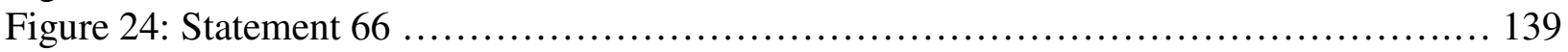

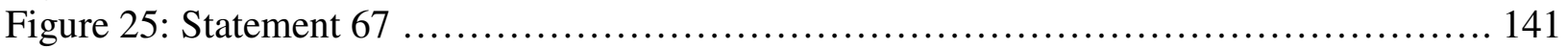

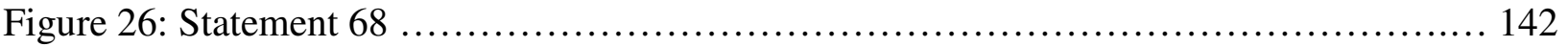

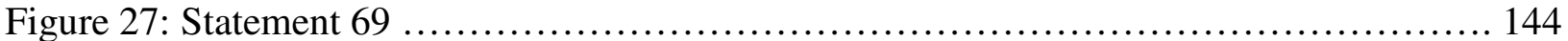

Figure 28: Question 1: Narrative Responses by Category ............................. 146

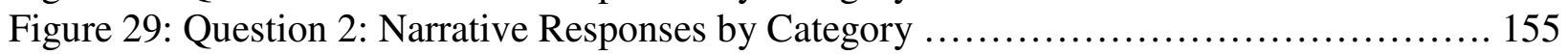

Figure 30: Question 3: Narrative Responses by Category .............................. 160 


\section{APPENDICES}

Page

Appendix A: Survey Instrument Items Correlated to Domain .......................... 189

Appendix B: Survey Statistics Summary by Survey Item .............................. 193

Appendix C: Domain Responses by Gender ......................................... 199

Appendix C: Question 1: Narrative Responses by Category (Comparison Group) ............ 200

Appendix D: Question 1: Narrative Responses by Category (Treatment Group) ...............203

Appendix E: Question 2: Narrative Responses by Category (Comparison Group) ............. 208

Appendix F: Question 2: Narrative Responses by Category (Treatment Group) .............. 213

Appendix G: Question 3: Narrative Responses by Category (Comparison Group) ............ 219

Appendix H: Question 3: Narrative Responses by Category (Treatment Group) .............. 224

Appendix I: Advance Letter for Survey via Regular Mail ................................ 229

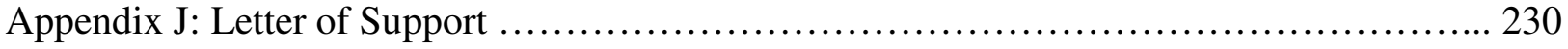




\section{CHAPTER ONE:}

\section{STATEMENT OF THE PROBLEM}

The research problem presented in this study is how to examine the perceptions of principals regarding the performance of their schools. This leads to the research question: Is there a statistically significant difference in the perceptions of two groups of principals regarding their schools' progress toward high-performing status as measured by an instrument aligned with the domains of the West Virginia Framework for High-Performing Schools?

One group to be studied consists of principals who have attended the West Virginia Institute for $21^{\text {st }}$-Century Leadership. The other group consists of principals who have not attended the Institute. The other group consists of principals who have not attended the Institute. The research hypothesis is that principals who have attended the Institute will perceive their schools as higher performing than the principals who have not attended the Institute.

What the school principal knows and does becomes critical to school improvement and student success (Waters, Marzano, and McNulty, 2003). If strong school leadership is related to improving schools and increasing student achievement, then it holds that high-quality professional development training for school leaders is essential. As a result, the work of attempting to answer this question becomes important to school leaders and, ultimately, to the students in the system. This proposal is an attempt to assess the effect on school improvement efforts of the professional development provided by the West Virginia Institute for $21^{\text {st }}$-Century Leadership.

This chapter provides the background of the study, the problem statement, the professional significance of the problem, an overview of the research methods to be used, delimitations of the study, definitions of key terms, and the organization of the dissertation. 


\section{Background of the Study}

The leadership abilities of the school principal can be used as a powerful force for improving schools (Fullan, 2003). Improvement requires different results, and different results cannot be expected from old leadership models. To implement a new leadership model in the state, West Virginia Department of Education (WVDE) personnel established the West Virginia Institute for $21^{\text {st }}$-Century Leadership. The Institute was integrated into a systemic reform effort called West Virginia Achieves.

West Virginia Achieves is a comprehensive series of interrelated programs and policies intended to bring all state public schools to high-performing status. To accomplish part of the mission of West Virginia Achieves, a 100-person committee was given the task of developing a conceptual framework to provide a guide for transforming schools into learning-for-all, highperforming organizations (WVDE, 2004). This committee was composed of personnel from the WVDE, Regional Education Service Agencies, the Office of Education Performance Audits, and the Center for Professional Development.

During nine meetings, committee members found significant commonalities in highperforming schools across the nation and in the current scholarly literature on successful education practices. They concluded that schools able to close the achievement gap and bring increasing numbers of students to mastery used many similar approaches. High-performing schools are proactive in promoting a culture of common beliefs and values dedicated to learning for all, managing the curriculum, enhancing instructional practices, improving overall school effectiveness, and supporting students and parents. All of this is done with an underlying philosophy of systemic, continuous improvement and an integration of $21^{\text {st }}$-century learning skills (WVDE, 2004). 
As a result of the committee's work, the West Virginia Framework for High-Performing Schools was developed (see Figure 1). Each of the first six of the areas common to highperforming schools became a domain of the Framework. These six areas were labeled (a) Culture of Common Beliefs and Values Dedicated to Learning for All; (b) Curriculum Management; (c) Instructional Practices; (d) School Effectiveness; (e) Student and Parent Support; and (f) Systemic, Continuous Improvement. The seventh domain, $21^{\text {st }}$-Century Skills, permeated the entire Framework and, therefore, was added as a seventh domain for the purposes of this study.

These seven domains formed the definition of high-performing schools in West Virginia. The Framework was reviewed by experts in school and school-system improvement, as well as by county superintendents. The use of the Framework was intended to help create systemic conditions, processes, and structures within the state's public school system that result in all students' mastery of the essential curriculum at a minimum, as well as closing the achievement gap among sub-groups of the student population (WVDE, 2004).

\section{Problem Statement}

This research problem deals with how to measure the influence of the West Virginia Institute for $21^{\text {st }}$-Century Leadership. This is important to the understanding of how to provide quality professional development activities. According to WVDE personnel (2006), previous professional development models for principals have been described as fragmented, piecemeal, simplistic, containing too many topics, lacking focus, and lacking school-related learning. In addition, they have made the claim that there has been no significant method in place to measure change in practice as a result of the professional development or whether it was even integrated into practice. 
Figure 1. WVDE Framework for High-Performing Schools

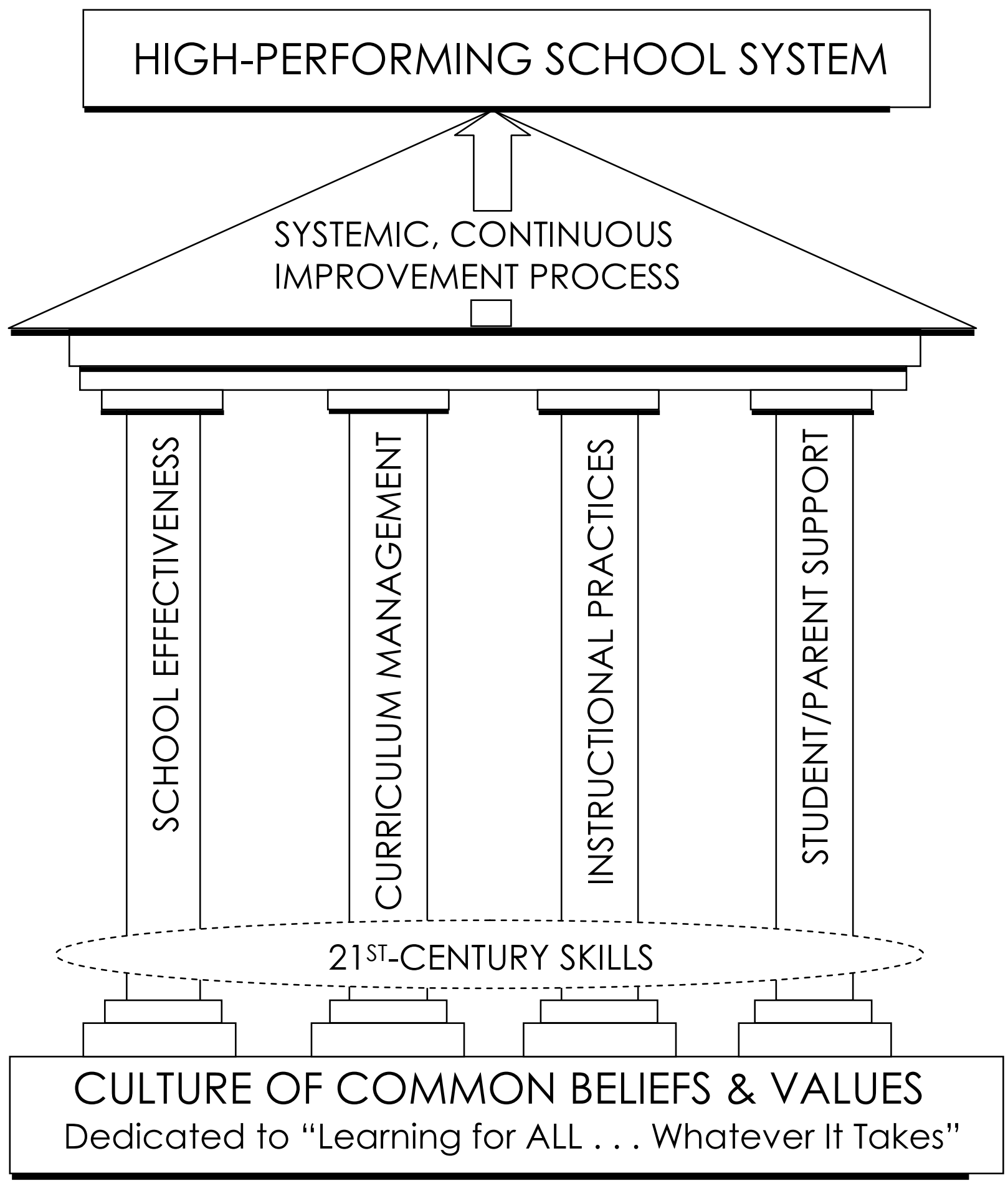


The evidence of the influence of professional development must be judged by more than a happiness quotient, which measures participants' satisfaction with the experience, and their offthe-cuff assessment regarding its usefulness (Sparks \& Hirsch, 2002). Good evaluation of programs provides information that is sound, meaningful, and sufficiently reliable to use in making thoughtful and responsible decisions about professional process and effects (Guskey, 2000).

This effort becomes especially urgent in southern states where student achievement generally lags behind the nation, and high-school graduation rates remain too low, despite many gains in recent years. West Virginia is among these states (Southern Regional Education Board [SREB], 2007). There are disturbing economic- and academic-related statistics that have emerged from other sources, such as the Alliance for Education Excellence (2007) and the U.S. Department of Education (2008), to support SREB's claim.

To add to the problem, it is expected that districts will have to replace more than 60 percent of all principals over the next five years. This new cohort of principals will lead their schools for some 15 to 20 years through the first quarter of the new century (Peterson, 2001).

Information such as this creates a sense of urgency to find answers to questions such as those posed here. If the school principalship can be used as a powerful force for improving schools, then the knowledge, skills, and dispositions the principal possesses have far-reaching implications for students and all those whose work is based on helping them achieve. Given this context, an attempt to understand the effects of the professional development training provided to principals become vital. 


\section{Professional Significance of the Problem}

Central to the task of reforming and improving the education system is what Murphy (2003) calls the need for re-culturing education leadership. Principals are viewed by some as playing a critical role in the successful transformation of the education system, because there are virtually no documented instances of troubled schools being turned around in the absence of intervention by talented leaders (Leithwood, Seashore Louis, Anderson, and Wahlstrom, 2004).

Considerable time, effort, public funding, and resources have been devoted to the West Virginia Institute for $21^{\text {st }}$-Century Leadership for school principals. Given the significance that has been attached to this work, the importance of attempting to understand how to assess its effects becomes more apparent. If principals are in a position to bring about successful transformation of the education system and increase the achievement of countless students, then the professional development they receive becomes extremely important. This study represents a way to begin the work of measuring the end product of the professional development provided for school principals through the Institute.

\section{Overview of Proposed Research Methods}

The research perspective of this study is primarily quantitative. It is descriptive, selfreport, survey research, which requires the collection of standardized, quantifiable information from all study participants (Gay, Mills, \& Airasian, 2006). The research hypothesis is that principals who have attended the Institute will perceive their schools as higher performing than the principals who have not attended the Institute.

A survey instrument was developed for the purpose of collecting data that will address the specific research hypothesis. This electronic survey contains 70 statements that reflect the dimensions of the six domains found in the WVDE's Framework for High-Performing Schools, 
along with the added domain of $21^{\text {st }}$-Century Skills. In the development phase, the instrument was analyzed for validity by a group of educators with expertise in education leadership and related research. A paper-and-pencil version of the survey was administered as a pilot for feedback on item readability and understandability.

The participants in the study are drawn from the pool of school principals in West Virginia. Half of the participants will be the 300 principals who attended the Institute. The other 300 respondents are to be chosen, using a random-number generator software program, from a list of the remaining principals in the state.

The statistical test to be used in the data analysis is the parametric $t$-test measure, which determines whether the means of two independent groups are significantly different at a selected probability level. The $t$-test determines whether the observed difference between two groups is sufficiently larger than a difference that would be expected solely by chance. The significance of the difference between two populations is also to be measured with the Mann-Whitney $U$ test, which is a nonparametric equivalent of the parametric $t$-test.

\section{Delimitations of the Study}

The boundaries of this study are confined to school principals in West Virginia. It is only in the sense that it may furnish propositions upon which to focus future investigations and debates that the results of this study might be generalizable to settings and contexts different from the one in which the findings were obtained (Best \& Kahn, 1998).

In an ideal situation, one might conduct a qualitative study of each principal in West Virginia to determine his perceptions about his school's progress in improvement efforts. The large number of principals in the state, however, makes such a study prohibitive. Also, in an 
ideal situation, every principal would have remained in the same school at the one he was in when he received the Institute training. In reality, this is not the case.

Although there are important advantages to using survey research, there are weaknesses that should be noted. A method relying on standardization forces the researcher to develop questions general enough to be minimally appropriate for all respondents, possibly missing what is most appropriate to many respondents. Surveys are inflexible in that they require initial study design (both the tool and the administration of the tool) to remain unchanged throughout the data collection period. In so doing, new emerging themes and ideas must be moved aside. The researcher must ensure that a large number of the selected sample will reply in order to have valid results. Those who do reply to the survey may have difficulty recalling information or telling the truth about a controversial question (University of Colorado, 2005). An inadequate response rate could render conclusions invalid.

There are also political sensibilities that must be considered in conducting a study about the Institute, which was developed by the West Virginia Department of Education; therefore, care must be taken to remain objective in analyzing the results. The reliability and validity of the survey instrument developed for this study have not yet been established. It is not within the purview of this study to determine the quality of the Institute curriculum or structure. It is, instead, an attempt to measure the perceptions of principals about the Institute training on their school improvement efforts.

\section{Definitions of Key Terms}

The definitions for the terms listed in this section correlate to the definitions provided for them by West Virginia Department of Education personnel. 
Benchmark. This term refers to pre-determined points during the instructional term when student mastery of specific instructional objectives is assessed.

Classroom Walkthrough. This process is a non-evaluative but focused classroom observation made for a brief period of time (three to five minutes) to observe specific classroom practices.

Core Subjects. Core subjects as outlined in NCLB include English, reading or language arts, mathematics, science, foreign languages, civics, government, economics, arts, history, and geography.

Curriculum Map. This term represents a graphic representation of the recommended instructional sequence for curriculum objectives during the instructional year and across the grades, pre-kindergarten to 12 , which is used as a management tool for enhancing curriculum continuity, communication, and coordination.

Formative Assessment. This term pertains to a periodic evaluation of the student's achievement level of the content standards and objectives used to adjust instructional time and strategies in order for all students to achieve proficiency.

Framework for High-Performing Schools. The meaning assigned to this is the conceptual model used by WVDE personnel to define the characteristics of high-performing schools. The dimensions of the seven domains of this Framework provide the definition of high-performing school status. These domains are: (a) Culture of Common Beliefs and Values, Dedicated to Learning for All; (b) school effectiveness; (c) curriculum management; (d) instructional practices; (e) student and parent support; (f) systemic, continuous improvement process; and (g) $21^{\text {st }}$-century learning skills. 
Culture. This term relates to the overall pattern of beliefs and values of an organization that manifests itself in policies, procedures, and organizational structures and ultimately shapes the behavior of personnel.

Performance Descriptors. These are narrative explanations of five levels of student achievement (distinguished, above mastery, mastery, partial mastery, and novice) used by the teacher to assess student attainment of the content standards and objectives.

Proficiency. This refers to the level of student achievement for students who achieve at the mastery, above-mastery, or distinguished levels.

Standards-Based Curriculum. This is a term used to describe a curriculum framework that establishes clear, comprehensive, exit learning expectations for all students, further defines the expectations through specific grade level and subject objectives, and provide performance descriptors for evaluating student levels of achievement relative to the standards and objectives.

Systemic Change. Systemic change is change that occurs in all aspects and levels of a system. Systemic change requires redesign of fundamental approaches within an organization, while considering the effect on all other aspects of the organization.

Transformational Leadership. This is a term used to describe the ability to affect the thoughts, feelings, and behaviors of a significant number of individuals through intentional actions and the creation of a body of work.

Twenty-First Century Skills. For the purposes of this study, this list of skills becomes the sub-categories defined by the Partnership for $21^{\text {st }}$-Century Skills. They are: (a) core subjects as outlined in NCLB, which include English, reading or language arts, mathematics, science, foreign languages, civics, government, economics, arts, history, and geography; (b) global awareness; financial, economic, business, and entrepreneurial literacy; civic literacy; and health 
and wellness awareness; (c) learning skills, comprised of the three broad categories of information and communication skills, thinking and problem-solving skills, and interpersonal and self-directional skills; (d) integration of learning skills and $21^{\text {st }}$-century tools, which comprises information, communication, and technology (ICT) literacy; (e) life skills, which include leadership, ethics, accountability, adaptability, personal productivity, personal responsibility, people skills, self direction, and social responsibility; and (f) authentic assessments that measure all the previously listed five components—core subjects, $21^{\text {st }}$-century content, learning and thinking skills, ICT literacy, and life skills.

Writing to Inform. This refers to any nonfiction writing assignments used to argue, criticize, define, describe, discuss, evaluate, explain, compare and contrast, or summarize topics in the classroom. This instructional strategy involves consistent use of writing-to-inform assignments in all content areas and consistent judging by a commonly used rubric correlates with high student achievement.

\section{Organization of the Dissertation}

The first three chapters of this dissertation represent the proposal for the intended research. Chapter One explains the research problem, the general background of the study, the professional significance of the problem, an overview of the methods proposed for answering the research question, delimitations of the study, definitions of key terms, and organization of the dissertation.

Chapter Two presents relevant research in order to provide the context for each of the domains of the West Virginia Framework for High-Performing Schools. Also included in the section related to each domain is a list of the descriptive elements, referred to in this proposal as dimensions, which were used as the basis for the survey questionnaire items to be used in the 
study. The chapter also includes selected research on school improvement and education leadership to show a broader context in which the research problem is set.

Chapter Three explains the proposed methods of the study. Survey research is the method to be used to answer the research question. The null and research (alternative) hypotheses are stated, along with the criteria for rejection or acceptance of the null hypotheses. The population and the sample for the study are described, and an explanation is given for how the survey instrument was developed. There is a section on characteristics of a good questionnaire and a section on the panel of individuals who reviewed and gave feedback on the questionnaire.

The final sections of Chapter Three provide an overview of how the survey questionnaire was piloted, how the questionnaire will be disseminated, how the data will be collected and analyzed, limitations involved in the process, and a summary of the proposed research method. The concept map shown in Figure 2 provides an overview of the prospectus. Chapter Four provides the analysis of the data collected during the study. Chapter Five presents the conclusions drawn from the study, as well as recommendations for further study. This research is set within an environment of educational and societal change. The next chapter sets the problem in the context of literature pertinent to the research question posed in this study. 
Figure 2. Concept Map of Prospectus.

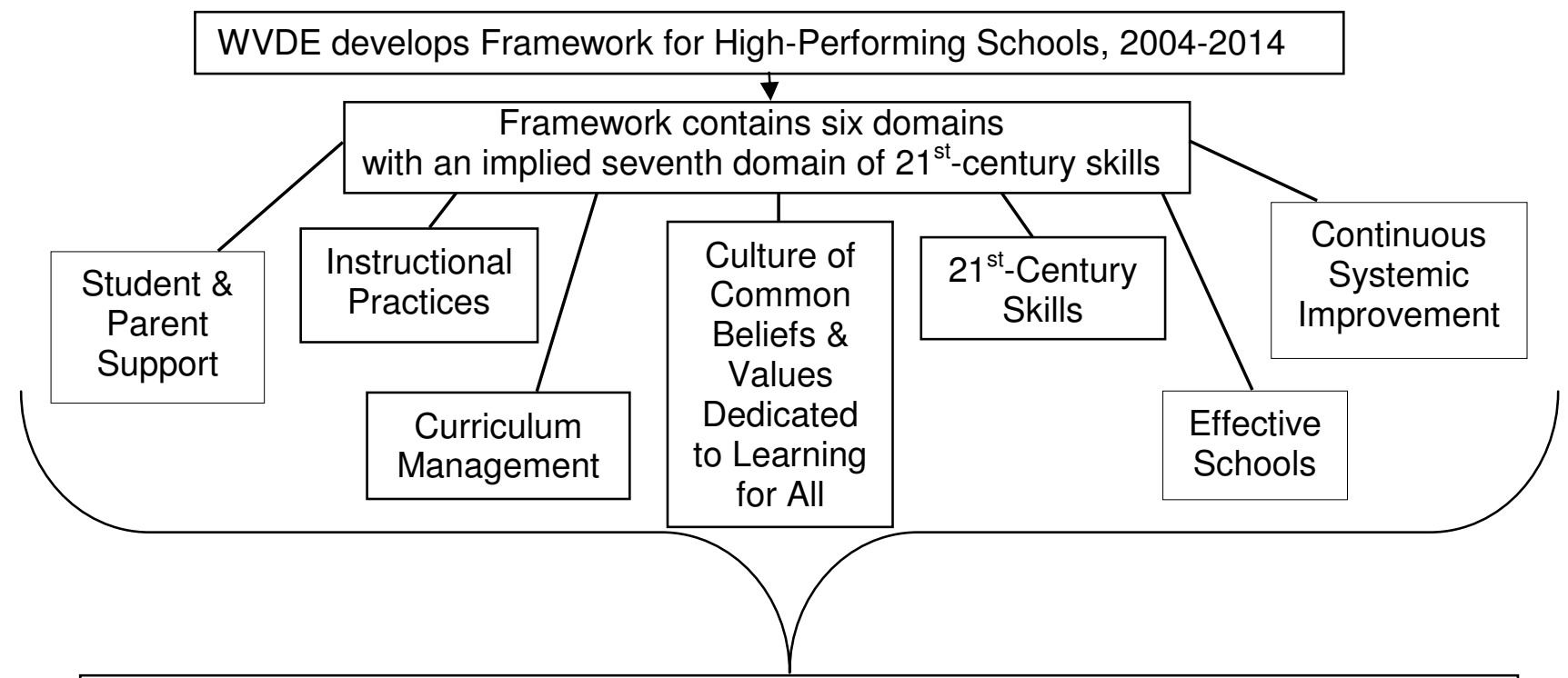

WVDE provides professional development training on the characteristics of highperforming schools to $275 \mathrm{WV}$ principals in the form of the WV Institute for $21^{\text {st }}$-Century
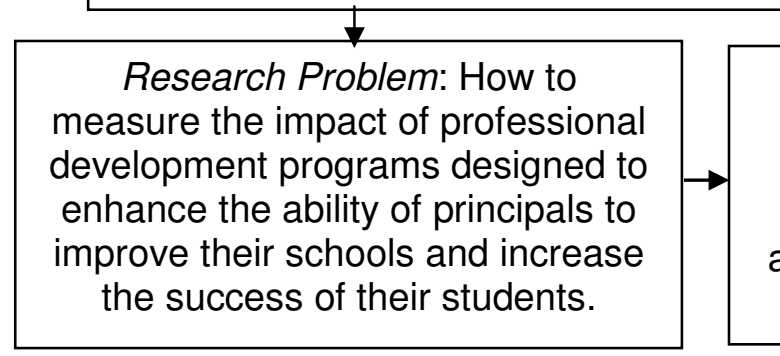

Research Question: Is there a statistically significant difference in the perceptions of two groups of principals regarding the progress of their schools toward highperforming status as measured by an instrument that is aligned with the domains of the West Virginia Framework for High-Performing Schools?

An online survey instrument was developed in the form of a 70-item questionnaire, using the dimensions of the seven domains of the Framework as declarative sentences. A respondent will select the choice on a Likert-type scale that most closely reflects his perception of the progress his school has made toward high-performing status.

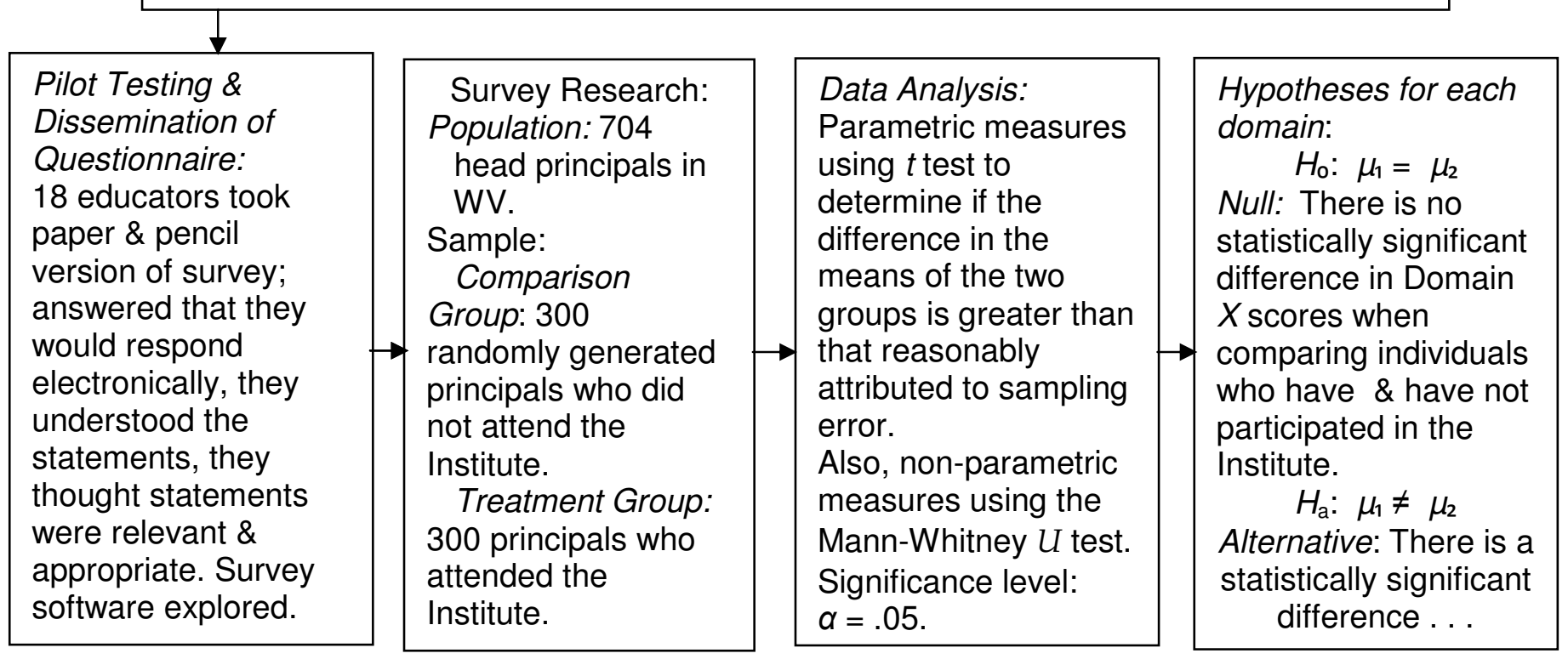




\section{CHAPTER TWO: REVIEW OF SELECTED LITERATURE}

Examining the perceptions of principals regarding the performance of their schools is at the heart of this research proposal. The specific research question addressing this problem is whether there is a statistically significant difference in the perceptions of a group of principals who attended the West Virginia Institute for $21^{\text {st }}$-Century Leadership and a group of principals who had not attended the Institute. The research instrument is a survey aligned with the domains of the West Virginia Framework for High-Performing Schools.

This chapter is a review of relevant literature selected to show the broader context of the proposed research question. The literature was viewed from the perspective of the school principal and the role she plays in education reform. It shows a complex interplay between timehonored learning practices and calls for change to meet the needs of future learners. It paints a picture of the dissonance naturally expected when such an institution as education, so strongly and integrally related to every aspect of society, is undergoing significant transformation.

The chapter begins with examples of relevant research that provides the context for each of the domains of the West Virginia Framework for High-Performing Schools. Also included in the section related to each domain is a list of the descriptive elements, referred to in this proposal as dimensions, which were used as the basis for the survey items to be used in the study. The chapter includes selected research that calls for education reform, and the final section of the chapter summarizes selected research on the importance of focusing on education leadership.

\section{Domain 1: Culture of Common Beliefs and Values \\ Dedicated to Learning for All}

The survey items for Domain 1 are correlated to the statements in the Framework for High-Performing Schools document (see Figure 3). What follows are some of the points made by 
Figure 3. Correlation of Survey Items to Domain 1 in the Framework for High-Performing Schools

\begin{tabular}{|c|c|c|}
\hline $\begin{array}{c}\text { Statement in the WVDE } \\
\text { Framework for High-Performing } \\
\text { Schools,2004-2014 } \\
\text { (Document page number) }\end{array}$ & $\begin{array}{c}\text { Survey } \\
\text { Item } \\
\text { (Part } \\
\text { Number - } \\
\text { Question } \\
\text { Number) }\end{array}$ & $\begin{array}{l}\text { Correlating Statement on } \\
\text { Survey Questionnaire }\end{array}$ \\
\hline $\begin{array}{l}\text { All children will achieve mastery of the } \\
\text { essential curriculum, given appropriate } \\
\text { time and conditions (p. 5.) }\end{array}$ & $1-1$ & $\begin{array}{l}\text { I believe all children can achieve } \\
\text { mastery of the essential curriculum, } \\
\text { given appropriate time and } \\
\text { conditions. }\end{array}$ \\
\hline $\begin{array}{l}\text { Schools and school systems are } \\
\text { responsible for creating the conditions } \\
\text { necessary for all students to achieve } \\
\text { mastery (p. 5). }\end{array}$ & $1-2$ & $\begin{array}{l}\text { I believe that everyone involved } \\
\text { with my school has an important } \\
\text { role in creating the conditions } \\
\text { necessary for all students to } \\
\text { achieve. }\end{array}$ \\
\hline $\begin{array}{l}\text { Commitment to high standards in all } \\
\text { aspects of the organization is essential } \\
\text { to produce mastery for all (p. 5). }\end{array}$ & $1-3$ & $\begin{array}{l}\text { I believe that everyone at my } \\
\text { school sets high standards in all } \\
\text { aspects that are essential for all } \\
\text { students to achieve. }\end{array}$ \\
\hline $\begin{array}{l}\text { Strong instructional leadership is } \\
\text { required to build the systems and } \\
\text { develop the culture to achieve mastery } \\
\text { for all (p. 5). }\end{array}$ & $1-4$ & $\begin{array}{l}\text { I believe it is essential that the } \\
\text { school principal provides strong } \\
\text { instructional leadership in order to } \\
\text { achieve mastery for all. }\end{array}$ \\
\hline $\begin{array}{l}\text { Highly qualified personnel are required } \\
\text { to build the systems and develop the } \\
\text { culture to achieve mastery for all (p. 5). }\end{array}$ & $1-5$ & $\begin{array}{l}\text { I believe that highly qualified } \\
\text { personnel are necessary to } \\
\text { develop the culture to achieve } \\
\text { mastery for all. }\end{array}$ \\
\hline $\begin{array}{l}\text { Parents, treated as valued and } \\
\text { respected partners involved in the } \\
\text { activities of the school, enhance } \\
\text { student learning (p. 5). }\end{array}$ & $1-6$ & $\begin{array}{l}\text { I believe it IS NOT essential to treat } \\
\text { parents as valued partners in order } \\
\text { for all students to achieve mastery. } \\
\text { (Capital letters are used because } \\
\text { this survey item is written in } \\
\text { reverse construct style.) }\end{array}$ \\
\hline $\begin{array}{l}\text { The primary measures of school and } \\
\text { system success are the increase of } \\
\text { students who achieve mastery and } \\
\text { beyond and the decrease in the } \\
\text { achievement gap among student sub- } \\
\text { groups (p. 5). }\end{array}$ & $1-7$ & $\begin{array}{l}\text { I believe the primary measure of } \\
\text { school success is the number of } \\
\text { students who achieve mastery of } \\
\text { the essential curriculum. }\end{array}$ \\
\hline $\begin{array}{l}\text { Transforming a school system to } \\
\text { produce mastery for all requires a } \\
\text { systemic, continuous improvement } \\
\text { process (p. 5). }\end{array}$ & $1-8$ & $\begin{array}{l}\text { I believe there must be a school- } \\
\text { wide, continuous-improvement } \\
\text { process in place in order for all } \\
\text { students to achieve. }\end{array}$ \\
\hline
\end{tabular}


education researchers relating to building a culture of common beliefs and values dedicated to learning for all. According to Schein (1992), a culture is a set of basic tacit assumptions about how the world is and ought to be that is shared by a set of people and determines their perceptions, thoughts, feelings and, to some degree, their overt behavior. Leadership and culture are intertwined. It is nearly impossible to sufficiently address one without the other. "These dynamic processes of culture creation and management are the essence of leadership and make one realize that leadership and culture are two sides of the same coin" (p. 1).

It is only after an organization's deep, basic assumptions are learned, shared, reinforced, tested, and successfully repeated over time and tried under crisis conditions that a paradigm forms. An organization's paradigm, like a pair of strong prescription glasses, impacts the way members perceive and interact with the world around it. Finally, it is then that paradigms and cultural components become predictable, patterned, and strategically manageable (Schein, 1992). Barth (2002) simplifies the definition as “. . the way we do things around here" (p. 6).

Every school has a culture, and an added consideration is that some are hospitable; others toxic. A school culture can work for or against improvement and reform (Barth, 2002). Changing a toxic school culture into a healthy school culture that inspires lifelong learning among students and adults is what Barth calls the greatest, but most important, challenge of instructional leadership. Barth's work on school culture produced the idea that one, alone, cannot change the culture of a scho9ol, but one can provide forms of leadership that invite others to join in as observers of the old and architects and designers of the new.

Barth (2002) relays the idea that the school culture is a complex pattern of norms, attitudes, beliefs, behaviors, values, ceremonies, traditions, and myths that are deeply ingrained in the very core of the organization. This historically transmitted pattern of meaning "wields 
astonishing power in shaping what people think and how they act" (p. 6). A school culture can be the defining element in reaching the goal of bringing all students to mastery or beyond in core subjects.

The work of Reeves (2007) supports the position that cultural change is necessary, but adds the caveat that cultural change may be difficult, especially in organizations in which stakeholders use the word "culture" as a rhetorical talisman to block leadership initiatives, stifle innovation, and maintain the status quo. He makes the point that, in the last decade, the education standards movement has taught us that policy change without cultural change is an exercise in futility and frustration. Once a strong, supportive, and constructive culture exists in the learning community of a school, the strengthening of the curriculum may proceed.

\section{Domain 2: Curriculum Management}

The survey items for Domain 2 are correlated to the statements in the Framework for High-Performing Schools document (see Figure 4). What follows are some of the points relating to curriculum management made by education researchers. School leaders should be less about preparation for life and more like life itself. This was the sentiment expressed by Dewey (1937), who continued to write that the primary basis of education should be the child's ability to work along the same general constructive lines as those that brought civilization into being. Education must be conceived as a continuing reconstruction of experience. The process and the goal of education are one and the same thing. Dewey's notion was that the education curriculum should be determined by life itself.

School leaders must look outside the textbooks and walls to determine what the interpretation of life should be and how it relates to the curriculum. Life in the $21^{\text {st }}$-century is 
Figure 4. Correlation of Survey Items to Domain 2 in the Framework for High- Performing

Schools

\begin{tabular}{|c|c|c|}
\hline $\begin{array}{l}\text { Statement in the WVDE } \\
\text { Framework for High-Performing } \\
\text { Schools, 2004-2014 } \\
\text { (Document page number) } \\
\text { High-Yield Strategies: }\end{array}$ & $\begin{array}{l}\text { Survey } \\
\text { Item } \\
\text { (Part } \\
\text { Number- } \\
\text { Question } \\
\text { Number) }\end{array}$ & $\begin{array}{l}\text { Correlating Statement on } \\
\text { Survey Questionnaire }\end{array}$ \\
\hline $\begin{array}{l}\text { Implementation of a rigorous, } \\
\text { standards-based curriculum for all } \\
\text { students that aligns with the West } \\
\text { Virginia Content Standards and } \\
\text { Objectives (p. 6). }\end{array}$ & $2-1$ & $\begin{array}{l}\text { I have provided the means for my } \\
\text { teachers to develop a rigorous } \\
\text { curriculum aligned with the West } \\
\text { Virginia Content Standards and } \\
\text { Objectives. }\end{array}$ \\
\hline $\begin{array}{l}\text { Prioritization and mapping of curriculum } \\
\text { objectives, } \mathrm{K}-12 \text {, to assure articulation } \\
\text { and alignment (p. 6). }\end{array}$ & $2-2$ & $\begin{array}{l}\text { I have provided the means for my } \\
\text { teachers to prioritize and map } \\
\text { curriculum objectives. }\end{array}$ \\
\hline $\begin{array}{l}\text { Development of system-wide, grade- } \\
\text { level performance benchmarks for } \\
\text { student achievement (p. 6). }\end{array}$ & $2-3$ & $\begin{array}{l}\text { All the teachers in my school use } \\
\text { performance benchmarks to measure } \\
\text { student achievement. }\end{array}$ \\
\hline $\begin{array}{l}\text { Development of formative assessments } \\
\text { that align with district benchmarks and } \\
\text { curriculum maps (p. 6). }\end{array}$ & $2-4$ & $\begin{array}{l}\text { All the teachers in my school use } \\
\text { formative assessments that align with } \\
\text { county performance benchmarks. }\end{array}$ \\
\hline $\begin{array}{l}\text { Implementation of a K-12, system-wide, } \\
\text { cohesive, standards-based model for } \\
\text { assuring literacy (p. 6). }\end{array}$ & $2-5$ & $\begin{array}{l}\text { My school IS NOT using a standards- } \\
\text { based program to assure students are } \\
\text { proficient in reading. } \\
\text { (Capital letters are used because this } \\
\text { survey item is written in reverse } \\
\text { construct style.) }\end{array}$ \\
\hline $\begin{array}{l}\text { Implementation of a K-12, system-wide, } \\
\text { cohesive, standards-based model for } \\
\text { teaching mathematics (p. 6). }\end{array}$ & $2-6$ & $\begin{array}{l}\text { My school is using a standards-based } \\
\text { program to assure students are } \\
\text { proficient in math. }\end{array}$ \\
\hline $\begin{array}{l}\text { Implementation of a teacher support } \\
\text { system for enhancing curriculum quality, } \\
\text { such as peer unit development, } \\
\text { technology supports, content-specific } \\
\text { professional development, etc. (p. 6). }\end{array}$ & $2-7$ & $\begin{array}{l}\text { I have implemented a teacher support } \\
\text { system for enhancing curriculum } \\
\text { quality, such as peer-unit } \\
\text { development, technology supports, } \\
\text { content-specific professional } \\
\text { development. }\end{array}$ \\
\hline $\begin{array}{l}\text { Development of a curriculum-monitoring } \\
\text { process, such as Classroom } \\
\text { Walkthroughs, to gather information for } \\
\text { continuous improvement (p. 6). }\end{array}$ & $2-8$ & $\begin{array}{l}\text { I have a process in place to monitor } \\
\text { the curriculum in order to gather } \\
\text { information for improvement. }\end{array}$ \\
\hline
\end{tabular}


complex and nebulous, and, therefore, not easy to define. It is what Ford and Friederici (2007) call an inconvenient curriculum, addressing real-world issues. These researchers label this inconvenient curriculum as the work educators should be about if they are to live up to their responsibility to educate tomorrow's leaders. They write,

Today's students will find their world shaped by many complex issues, such as energy needs and costs, the role of religion in world affairs, the needs of changing populations for food and water, and the interaction between economic development and the natural environment ... understanding that no single discipline has the tools to provide all the answers to such problems is critical to tomorrow's decision makers (p. 297).

They further note that educators should not be asking themselves how difficult it would be to rework curricula, but rather what the costs—social, environmental, and moral—of not restructuring them would be. "Unacceptably great," is their answer (p. 298).

Rather than holding students accountable to minimum acceptable levels of competency, the national standards-based reform movement that emerged in the 1990 s called for high standards for all students oriented around challenging subject matter, acquisition of higher-order thinking skills, and the application of abstract knowledge to solving real-world problems (McLaughlin, 1995). Perhaps more important, however, is that standards-based reform has a process-driven conception of educational change that clearly links schooling and policy to what students should know in given subject areas (O’Day \& Smith, 1993).

National education leaders have strongly advocated the standards-based curriculum, and states have rapidly adapted the standards-based approach. Four policy drivers emerged as a result of this initiative: (a) Content standards—-detailed statements of the high-quality academic material students should learn; (b) Performance standards-established levels of mastery 
students should be able to demonstrate; (c) Aligned assessments-the statewide testing of students to measure their levels of performance on the specified content; and (d) Professional standards - training and certification requirements to ensure that teachers are sufficiently skilled as both pedagogists and subject-matter specialists (Swanson \& Stevenson, 2002).

Having a coherent, standards-based curriculum means having every goal in an accountability system clearly specified and measured without added irrelevance and that there are essential standards that are the basis for the curriculum. Standards-based reform has become the driving force behind most federal, state, and local education policies in the United States today. At the heart of a standards-based curriculum lie academic content standards, specifying what students should know at each grade level and, by extension, what should be taught. From these content standards emerges a framework, or blueprint, for schools to use to implement the state-adopted content standards. These standards and this framework should guide all classroom instruction (Cash, 2007).

Schools that implement a coherent, standards-based curriculum have five key behaviors in common. They do the following: (a) Align the written, taught, and tested curriculum; (b) Get student academic data to teachers in a format they understand and give them frequent opportunities to talk about it; (c) Provide high-quality professional development to build the capacity of teachers and leaders; (d) Intervene on behalf of students who don't get it; and (e) Have rock-solid leadership (Cash, 2007). This kind of leadership calls for a clear notion of highquality, $21^{\text {st }}$-century, instructional practices.

\section{Domain 3: Instructional Practices}

The survey items for Domain 3 are correlated to the statements in the Framework for High-Performing Schools document (see Figure 5). What follows are some of the points 
Figure 5. Correlation of Survey Items to Domain 3 in the Framework for High-Performing Schools

\begin{tabular}{|c|c|c|}
\hline $\begin{array}{l}\text { Statement in the WVDE } \\
\text { Framework for High-Performing } \\
\text { Schools, 2004-2014 } \\
\text { (Document page number) } \\
\text { High-Yield Strategies: }\end{array}$ & $\begin{array}{l}\text { Survey } \\
\text { Item } \\
\text { (Part } \\
\text { Number- } \\
\text { Question } \\
\text { Number) }\end{array}$ & $\begin{array}{l}\text { Correlating Statement on } \\
\text { Survey Questionnaire }\end{array}$ \\
\hline $\begin{array}{l}\text { Expectation that classroom } \\
\text { environments be nurturing and } \\
\text { supportive with respect for individual } \\
\text { differences and high expectations for all } \\
\text { (p. 6). } \\
\text { (Three points are covered in this item: } \\
\text { 1. nurturing and supportive classroom } \\
\text { environments, 2. respect for individual } \\
\text { differences, and } 3 \text {. high expectations for } \\
\text { all. Points } 1 \text { and } 3 \text { were covered in } \\
\text { Domain 1.) }\end{array}$ & $3-1$ & $\begin{array}{l}\text { The teachers in my school show } \\
\text { respect for all students regardless of } \\
\text { individual differences. }\end{array}$ \\
\hline $\begin{array}{l}\text { Identification of and consistent use of } \\
\text { research-based instructional } \\
\text { management practices that result in } \\
\text { focused, productive, and well-organized } \\
\text { classrooms (p. 6). } \\
\text { (Two points are covered in this item: } 1 \text {. } \\
\text { research-based instructional } \\
\text { management practices, and } 2 \text {. focused, } \\
\text { productive, and well-organized } \\
\text { classrooms. Point } 1 \text { is covered in survey } \\
\text { item } 3-5 \text { ). }\end{array}$ & $3-2$ & $\begin{array}{l}\text { The classrooms in my school ARE } \\
\text { NOT focused, productive, and well } \\
\text { organized. } \\
\text { (Capital letters are used because } \\
\text { this survey item is written in reverse } \\
\text { construct style.) }\end{array}$ \\
\hline $\begin{array}{l}\text { System-wide selection and pervasive } \\
\text { use of standards-based framework for } \\
\text { unit and lesson design to address the } \\
\text { West Virginia Content Standards and } \\
\text { Objectives (p. 6). } \\
\text { (This point was already covered in } \\
\text { Domain 2) }\end{array}$ & & \\
\hline $\begin{array}{l}\text { System-wide instructional approach that } \\
\text { develops students as self-directed } \\
\text { learners who understand performance } \\
\text { standards and use reflective practice for } \\
\text { improving their work (p. 6). }\end{array}$ & $3-3$ & $\begin{array}{l}\text { The students in my school are being } \\
\text { developed into self-directed learners } \\
\text { who are responsible for improving } \\
\text { their own work. }\end{array}$ \\
\hline $\begin{array}{l}\text { Use of a differentiated instructional } \\
\text { model designed to meet the needs of } \\
\text { varied learners (p. } 6 \text { ). }\end{array}$ & $3-4$ & $\begin{array}{l}\text { The teachers in my school use } \\
\text { differentiated instruction to meet the } \\
\text { needs of varied learners. }\end{array}$ \\
\hline $\begin{array}{l}\text { Use of research-based, high-yield } \\
\text { instructional strategies in all classrooms } \\
\text { (p. 6). }\end{array}$ & $3-5$ & $\begin{array}{l}\text { The teachers in my school use } \\
\text { research-based, high-yield } \\
\text { instructional strategies in all } \\
\text { classrooms. }\end{array}$ \\
\hline
\end{tabular}


Figure 5. Correlation of Survey Items to Domain 3 in the Framework for High-Performing Schools (continued).

\begin{tabular}{|c|c|c|}
\hline $\begin{array}{l}\text { Use of formative assessments to inform } \\
\text { instruction; greater use of performance } \\
\text { assessments to determine level of } \\
\text { student mastery (p. } 6 \text { ) } \\
\text { (Two points are covered in this item: } 1 . \\
\text { formative assessments used to inform } \\
\text { instruction and 2. performance } \\
\text { assessments used to determine } \\
\text { mastery. Point } 1 \text { was covered in } \\
\text { Domain 2.) }\end{array}$ & $3-6$ & $\begin{array}{l}\text { The teachers in my school use } \\
\text { performance assessments to } \\
\text { determine level of student mastery. }\end{array}$ \\
\hline $\begin{array}{l}\text { Adjustment of instructional time by } \\
\text { grade, class, school, and system to } \\
\text { meet the needs of varied learners (p. 6). }\end{array}$ & $3-7$ & $\begin{array}{l}\text { The teachers in my school adjust } \\
\text { instructional time by grade, class, } \\
\text { and subject to meet the various } \\
\text { learning needs of students. }\end{array}$ \\
\hline \multirow{2}{*}{$\begin{array}{l}\text { Integration of Writing to Inform and } \\
\text { comprehension development strategies } \\
\text { in all classrooms in all content areas ( } \mathrm{p} \text {. } \\
6 \text { ). } \\
\text { (Two points are covered in this item: } 1 \text {. } \\
\text { writing to inform, and 2. comprehension } \\
\text { development strategies. These two } \\
\text { points are covered in survey items } 3-8 \\
\text { and 9). }\end{array}$} & $3-8$ & $\begin{array}{l}\text { Writing-to-inform strategies are used } \\
\text { in all classrooms in my school in all } \\
\text { content areas. }\end{array}$ \\
\hline & $3-9$ & $\begin{array}{l}\text { Comprehension development } \\
\text { strategies are used in all classrooms } \\
\text { in my school in all content areas. }\end{array}$ \\
\hline $\begin{array}{l}\text { System-wide approach to student } \\
\text { acceleration through such practices as } \\
\text { scaffolding and previewing (p. } 6) \text {. }\end{array}$ & $3-10$ & $\begin{array}{l}\text { The teachers in my school use such } \\
\text { practices as scaffolding and } \\
\text { previewing to help accelerate } \\
\text { student achievement. }\end{array}$ \\
\hline $\begin{array}{l}\text { Implementation of a teacher } \\
\text { instructional support system that } \\
\text { provides time and assistance to } \\
\text { teachers for data analysis, cooperative } \\
\text { planning, observation and feedback, } \\
\text { reflective practice, and professional } \\
\text { growth (p. 6). } \\
\text { Use of an instructional monitoring } \\
\text { system, such as walkthroughs that } \\
\text { collects data for school and district } \\
\text { improvement, teacher support, and } \\
\text { school improvement (p. 6). } \\
\text { (This point was already covered in } \\
\text { Domain 2.) }\end{array}$ & $3-11$ & $\begin{array}{l}\text { In my school, there is a teacher } \\
\text { instructional support system that } \\
\text { provides time and assistance to } \\
\text { teachers for data analysis, } \\
\text { cooperative planning, observation } \\
\text { and feedback, reflective practice, } \\
\text { and professional growth. }\end{array}$ \\
\hline
\end{tabular}


relating to instructional practices made by education researchers. At the heart of school capacity are principals focused on the development of teachers' knowledge and skills, professional community, program coherence, and technical resources (Fullan, 2002).

The term "instructional leader" has been in vogue for decades as the desired model for education leaders, especially for principals; yet the term is "often more a slogan than a welldefined set of leadership practices" (Leithwood, Seashore Louis, Anderson, \& Wahlstrom, 2004, p. 4). Spence (2007) describes an instructional leader as a learning-centered leader.

A learning-centered school leader puts curriculum and instruction first. He understands what students should be learning, how they learn best, and how to assess their performance. He must also develop the capacity of teachers to use proven instructional methods (Spence, 2007). There are several well-developed models of instructional leadership that specify particular practices and evidence of the impact on both organizations and students. For instance, the model developed by Hallinger (2000) consists of three sets of instructional leadership dimensions: (a) defining the school's mission, (b) managing the instructional program, and (c) promoting a positive learning climate. While clear and compelling organizational directions contribute significantly to members' work-related motivations, they are not the only conditions to do so. According to Leithwood et al. (2004), people's capacities and motivations are influenced by the direct experiences organizational members have with those in leadership roles, as well as the organizational context within which they work.

Learning-centered leaders know how to create a professional environment where all the adults in the school are constantly improving their own skills and knowledge, and helping and challenging each other to serve the particular needs of every learner (Spence, 2007). The school 
leader who understands all facets of the pedagogical arts will understand the importance of the correlates of effective schools.

\section{Domain 4: School Effectiveness}

The survey items for Domain 4 are correlated to the statements in the Framework for High-Performing Schools document (see Figure 6). The components of Domain 4 of the Framework are strongly supported by effective-school research. High performance in various aspects of the education system became a focus of a significant body of research that began in the late 1970s and early 1980s. This work, known as the Effective Schools Movement had a significant impact on decisions education leaders made in the subsequent years.

The Equal Education Opportunity survey, known as the Coleman report, concluded that family background, not the school, was the major determinant of student achievement (Coleman, 1966). During the 1960s and 1970s, a group of influential social scientists launched work from Coleman's ideas. They worked from the premise that family factors, such as poverty or a parent's lack of education prevented children from learning, regardless of the method of instruction. The Coleman report, along with related literature, was the catalyst to the creation of compensatory education programs that dominated school improvement for decades. These programs focused on changing students' behavior in order to compensate for their disadvantaged backgrounds but made no effort to change school behavior (Lezotte, 2001).

By lending official credence to the notion that schools could not make a difference in predicting student achievement, the report set off a vigorous reaction and induced a number of studies that became the research base for the Effective Schools Movement. Without discounting the importance of the family's impact on student learning, this body of research supported the 
Figure 6. Correlation of Survey Items to Domain 4 in the Framework for High-Performing Schools

\begin{tabular}{|c|c|c|}
\hline $\begin{array}{l}\text { Statement in the WVDE } \\
\text { Framework for High-Performing } \\
\text { Schools, 2004-2014 } \\
\text { (Document page number) } \\
\text { High-Yield Strategies: }\end{array}$ & $\begin{array}{l}\text { Survey } \\
\text { Item } \\
\text { (Part } \\
\text { Number- } \\
\text { Question } \\
\text { Number) }\end{array}$ & $\begin{array}{l}\text { Correlating Statement on } \\
\text { Survey Questionnaire }\end{array}$ \\
\hline $\begin{array}{l}\text { Creation of a system-wide culture of } \\
\text { support, trust, and collaboration } \\
\text { among the schools and the county } \\
\text { office focused on creating conditions } \\
\text { for all students' success (p. } 7 \text { ). }\end{array}$ & $4-1$ & $\begin{array}{l}\text { We have a culture of support, trust, } \\
\text { and collaboration between our } \\
\text { school and the county office } \\
\text { focused on creating conditions for } \\
\text { all students' success. }\end{array}$ \\
\hline \multirow{4}{*}{$\begin{array}{l}\text { Development of a clear system } \\
\text { mission, core beliefs, performance } \\
\text { goals, and strategic plan to provide } \\
\text { focus to school improvement efforts } \\
\text { (p. } 7 \text { ). } \\
\text { (Four points are covered in this item. } \\
\text { They are covered in survey items } 4 \\
-2 \text { to } 4-5 . \text { ) }\end{array}$} & $4-2$ & $\begin{array}{l}\text { Our school has developed a clear } \\
\text { mission to provide focus to school } \\
\text { improvement efforts. }\end{array}$ \\
\hline & $4-3$ & $\begin{array}{l}\text { Our school has a set of core beliefs } \\
\text { to provide focus to school } \\
\text { improvement efforts. }\end{array}$ \\
\hline & $4-4$ & $\begin{array}{l}\text { Our school HAS NOT set } \\
\text { performance goals to provide focus } \\
\text { to school improvement efforts. } \\
\text { (Capital letters are used because } \\
\text { this survey item is written in reverse } \\
\text { construct style.) }\end{array}$ \\
\hline & $4-5$ & $\begin{array}{l}\text { Our school has a strategic plan to } \\
\text { provide focus to school } \\
\text { improvement efforts. }\end{array}$ \\
\hline \multirow{2}{*}{$\begin{array}{l}\text { Professional development for } \\
\text { school-improvement team members } \\
\text { on strategic planning, continuous } \\
\text { improvement, and the correlates of } \\
\text { effective schools (p. } 7 \text { ). (Three } \\
\text { points are covered in this item. They } \\
\text { are covered in survey items } 4-6 \text { to } \\
4-8 .)\end{array}$} & $4-6$ & $\begin{array}{l}\text { Our school-improvement team } \\
\text { members have had professional } \\
\text { development training on strategic } \\
\text { planning. }\end{array}$ \\
\hline & $4-7$ & $\begin{array}{l}\text { Our school-improvement team } \\
\text { members have had professional } \\
\text { development training on continuous } \\
\text { improvement. }\end{array}$ \\
\hline
\end{tabular}




\begin{tabular}{|c|c|c|}
\hline \multicolumn{3}{|c|}{ Figure 6. Correlation of Survey Items to Domain 4 in the Framework for High- } \\
\hline $\begin{array}{l}\text { Time for improvement team } \\
\text { members to collaborate, develop, } \\
\text { and annually revise the five-year } \\
\text { strategic plan (p. } 7 \text { ). }\end{array}$ & $4-8$ & $\begin{array}{l}\text { Our school-improvement team } \\
\text { members have had professional } \\
\text { development training on the } \\
\text { correlates of effective schools. } \\
\text { Our school improvement team } \\
\text { members have time to collaborate, } \\
\text { develop, and annually revise the } \\
\text { five-year strategic plan. }\end{array}$ \\
\hline $\begin{array}{l}\text { A data management system to } \\
\text { analyze data trends and establish } \\
\text { priorities (p. 7). }\end{array}$ & $4-10$ & $\begin{array}{l}\text { Our school has a data } \\
\text { management system to analyze } \\
\text { data trends and establish priorities. }\end{array}$ \\
\hline $\begin{array}{l}\text { Support for school-based learning } \\
\text { communities focused on strategies } \\
\text { to achieve school performance } \\
\text { goals (p. } 7 \text { ). }\end{array}$ & $4-11$ & $\begin{array}{l}\text { Our school has a learning } \\
\text { community focused on strategies to } \\
\text { achieve school performance goals. }\end{array}$ \\
\hline $\begin{array}{l}\text { School-based professional } \\
\text { development aligned with the } \\
\text { school's improvement plan (p. 7). }\end{array}$ & $4-12$ & $\begin{array}{l}\text { Teachers in our school are } \\
\text { provided professional development } \\
\text { training aligned with the school's } \\
\text { improvement plan. }\end{array}$ \\
\hline $\begin{array}{l}\text { A district monitoring system that } \\
\text { requires continuous progress and } \\
\text { accountability for results as outlined } \\
\text { in the school and district plan (p. } 7 \text { ). }\end{array}$ & $4-13$ & $\begin{array}{l}\text { Our county has a monitoring } \\
\text { system that requires continuous } \\
\text { progress and accountability for } \\
\text { results as outlined in the school } \\
\text { and district plan. }\end{array}$ \\
\hline $\begin{array}{l}\text { Support to schools for arranging } \\
\text { time prior to and during the } \\
\text { instructional term for meaningful } \\
\text { staff planning, collaboration, and } \\
\text { problem solving related to the } \\
\text { school's performance goals (p. } 7 \text { ). }\end{array}$ & $4-14$ & $\begin{array}{l}\text { Our teachers are provided time } \\
\text { prior to and during the instructional } \\
\text { term for meaningful staff planning, } \\
\text { collaboration, and problem solving } \\
\text { related to the school's performance } \\
\text { goals. }\end{array}$ \\
\hline $\begin{array}{l}\text { Development of a central office } \\
\text { school monitoring system to gather } \\
\text { information on quality of overall } \\
\text { school operations and the presence } \\
\text { of the correlates of effective schools } \\
\text { (p. } 7) \text {. }\end{array}$ & $4-15$ & $\begin{array}{l}\text { Our county office has a school } \\
\text { monitoring system to gather } \\
\text { information on quality of overall } \\
\text { school operations and the presence } \\
\text { of the correlates of effective } \\
\text { schools. }\end{array}$ \\
\hline
\end{tabular}


premise that all children can learn and that the school controls the factors necessary to assure student mastery of the core curriculum.

Over the years, the correlates have been refined and expanded to the following: (a) Instructional leadership, (b) clear and focused mission, (c) safe and orderly environment, (d) frequent monitoring of student progress, (e) positive home-school relations, and (f) opportunity to learn and student time on task (Lezotte, 2001).

Other aspects of the Effective Schools Movement have evolved over the years, moving to what has been called the second generation of correlates. The early definition of an effective school focused on children from different socioeconomic classes. As educators became concerned about other subsets of the population, gender, ethnicity, disabilities, and family structure were added to the mix. The early definition also was cast in terms of mastery of the essential curriculum, which included reading and math. Over time, other curricular outcomes, such as problem-solving ability, higher-order thinking skills, creativity, and communicative ability were added (Lezotte, 1991).

The early Effective Schools Movement emphasized the individual school as the unit of change. Eventually, it became clear that school improvement resulting in increased student achievement could only be sustained with strong district support (Lezotte, 2001). In the societal context of the $21^{\text {st }}$-century, the importance of one of the original correlates, positive home-school relations, has taken on an added importance.

\section{Domain 5: Student and Parent Support}

The survey items for Domain 5 are correlated to the statements in the Framework for High-Performing Schools document (see Figure 7). What follows are some of the points 
Figure 7. Correlation of Survey Items to Domain 5 in the Framework for High-Performing Schools

\begin{tabular}{|c|c|c|}
\hline $\begin{array}{l}\text { Statement in the WVDE } \\
\text { Framework for High-Performing } \\
\text { Schools, 2004-2014 } \\
\text { (Document page number) } \\
\text { High-Yield Strategies: }\end{array}$ & $\begin{array}{l}\text { Survey } \\
\text { ltem } \\
\text { (Part } \\
\text { Number- } \\
\text { Question } \\
\text { Number) }\end{array}$ & $\begin{array}{l}\text { Correlating Statement on } \\
\text { Survey Questionnaire }\end{array}$ \\
\hline $\begin{array}{l}\text { Creation of a system-wide culture that } \\
\text { values all students regardless of } \\
\text { background or previous achievement ( } p \text {. } \\
7 \text { ). } \\
\text { (This item is already covered in Domains } \\
1,3 \text {, and } 4 .)\end{array}$ & & \\
\hline $\begin{array}{l}\text { Use of research-based, innovative } \\
\text { approaches to meeting the specific } \\
\text { academic and social/emotional needs of } \\
\text { poor, minority, special education, and } \\
\text { second lanquage learners (p. 7). }\end{array}$ & $5-1$ & $\begin{array}{l}\text { Our school uses research-based, } \\
\text { innovative approaches to meeting the } \\
\text { specific academic and } \\
\text { social/emotional needs of all learners. }\end{array}$ \\
\hline $\begin{array}{l}\text { Implementation of a system-wide } \\
\text { developmental guidance program that } \\
\text { includes a strong character education } \\
\text { and career development focus (p. } 7 \text { ). } \\
\text { (This item covers two points: } 1 \text {. strong } \\
\text { character education, and } 2 \text {. career } \\
\text { development. They will be covered in } \\
\text { survey items } 5-2 \text { and } 5-3 . \text { ) }\end{array}$ & $5-2$ & $\begin{array}{l}\text { Our school has a developmental } \\
\text { guidance program that includes a } \\
\text { strong character education focus. }\end{array}$ \\
\hline & $5-3$ & $\begin{array}{l}\text { Our school has a developmental } \\
\text { guidance program that includes a } \\
\text { career development focus. }\end{array}$ \\
\hline $\begin{array}{l}\text { Assurance that all schools have } \\
\text { strategies for providing support to } \\
\text { address social/emotional and academic } \\
\text { needs (p. 7). } \\
\text { (This item was covered in survey item } 5 \\
-1 .)\end{array}$ & & \\
\hline $\begin{array}{l}\text { Implementation of an effective system- } \\
\text { wide process for successfully } \\
\text { transitioning students from one school to } \\
\text { the next ( } \mathrm{p} .7 \text { ). } \\
\text { Expectation that all personnel treat } \\
\text { parents as respected and valued } \\
\text { partners in the educational process (p. } \\
7 \text { ). } \\
\text { (This item is covered in Domain } 1 \text {, } \\
\text { survey item } 1-6 .)\end{array}$ & $5-4$ & $\begin{array}{l}\text { Our school has an effective process } \\
\text { for successfully transitioning students } \\
\text { from one school to the next. }\end{array}$ \\
\hline
\end{tabular}


relating to student and parent support made by education researchers. There are implications for education leadership to be found in the work of Henderson and Mapp (2002), who write that the evidence is consistent positive, and convincing_families have a major influence on their children's achievement in school and through life. These researchers conducted a meta-analysis of 51 studies, which they say document the profound and comprehensive benefits for students, families, and schools when parents and family members become participants in their children's education and their lives. They conclude that when schools, families, and community groups work together to support learning, children tend to do better in school, stay in school longer, and like school more. They also drew specific conclusions in the areas of student achievement, student behavior, culture, age, and school quality.

Student Achievement. Programs that engage families in supporting their children's learning at home are linked to higher student achievement. When parents are involved, students achieve more, regardless of socioeconomic status, ethnic or racial background, or the parents' educational level. When parents are involved in their students' education, those students have higher grades and test scores, better attendance, and complete homework more consistently. Students whose parents are involved in their lives have higher graduation rates and greater enrollment rates in postsecondary education. In programs that are designed to involve parents in full partnerships, student achievement for disadvantaged children, not only improves; it can reach levels that are standard for middle-class children (Henderson \& Mapp, 2002).

The opposite has also shown to be true. Students are more likely to fall behind in academic performance if their parents do not participate in school events, develop a working relationship with their child's educators, or keep up with what is happening in their child's school (Henderson \& Berla, 2004). 
Student Behavior. When parents are involved, students exhibit more positive attitudes and behavior. When students report feeling support from both home and school, the have more self-confidence, feel school is more important, and they tend to do better in school. Student behaviors, such as alcohol use, violence, and other antisocial behaviors decrease as parent involvement increases (Henderson \& Mapp, 2002).

School Culture. Children from diverse cultural backgrounds tend to do better when parents and professionals collaborate to bridge the gap between the culture at home and the culture at school. The school's practices to inform and involve parents are stronger determinants of whether inner-city parents will be involved with their children's education than are parent education, family size, marital status, and even student grade level (Henderson \& Mapp, 2002).

Successful schools are those that succeed in engaging families from very diverse backgrounds focus on building trusting collaborative relationships among teachers, families, and community members; recognize, respect, and address families' needs, as well as class and cultural differences; and embrace a philosophy of partnership where power and responsibility are shared. For low-income families, however, programs offered in the community, at church, or those that include home visits are more successful in involving parents than programs that require parents to visit the school. When these parents do become involved at school, their children make even greater gains (Henderson \& Mapp, 2002).

Age. The benefits of involving parents are not confined to the early years; there are significant gains at all ages and grade levels. Junior- and senior-high-school students whose parents remain involved are able to make better transitions, maintain the quality of their work, and develop realistic plans for their futures. Students whose parents are not involved, on the other hand, are more likely to drop out of school (Henderson \& Mapp, 2002). 
School Quality. Schools that have parent-teacher groups have higher student achievement than schools that do not. Schools that work well with families have improved teacher morale and higher ratings of teachers by parents. When parents and community members organize to hold poorly performing schools accountable, school districts make positive changes in policy and practice that lead to upgraded school facilities, improved school leadership and staffing, new resources for programs to improve teaching and curriculum, and funding for after-school and family-support programs. Schools in which parents are involved have more support from families and better reputations in the community. Schools with highly rated parent partnership programs make greater gains on state tests than schools with lower rated programs (Henderson \& Mapp, 2002).

Regardless of the framework used to make parent and family involvement in schools a reality, it is the principal who plays the pivotal role. Teachers and other staff sense the level of priority administrators give to involving parents. The climate in a school is created, to a large extent, by the tone set in the principal's office. If principals collaborate with parents, teachers will be more likely to follow suit.

There is a misperception held by some that partnering with parents, particularly in the decision-making process, will diminish the principal's authority. Yet, the top management models in America are open and collaborative, encouraging subordinates to share their concerns and engaging managers and workers in cooperative problem solving rather than making decisions through strict hierarchical systems. Such an approach need not diminish the principal's authority, but can lead to better decisions. Without administrative leadership, long-term progress in family-school partnerships is difficult to achieve, because genuine change requires systemic 
solutions and coordinated efforts with consistent leadership support. The program standards provide the vision; the school principal provides the leadership (Henderson and Mapp, 2002).

Strong leadership is not only a key component of genuine progress in building constructive family-school partnerships; it is a key component of genuine change throughout the system. Schools with principals not committed to improvement by challenging the existing system are doomed to become stagnant, and growth will become marginalized. The school principal is a vital component in systemic, continuous improvement.

\section{Domain 6: Systemic, Continuous-Improvement Process}

The survey items for Domain 6 are correlated to the statements in the Framework for High-Performing Schools document (see Figure 8). What follows are some of the points relating to systemic, continuous improvement made by education researchers. Learning-centered principals are the catalysts in school-based efforts at continuous improvement. They understand and communicate that complacency is the enemy of improvement, that the status quo is more tightly linked to decline than to growth. These leaders confront stagnation. They ensure that the school systematically reviews and adopts more productive strategies to accomplish important goals (Waters, Marzano, \& McNulty, 2005).

Clearly, the many steps and tasks involved in diffusing innovations through systemic change call for a high degree of commitment and relentless effort. Moreover, time frames for accomplishing institutional changes must be realistic. Major systemic changes are not easily accomplished (Adelman \& Taylor, 2003). Schools are open systems, acutely dependent on their external environment, making awareness of the myriad political and bureaucratic difficulties involved a necessity. 
Figure 8. Correlation of Survey Items to Domain 6 in the Framework for High- Performing Schools

\begin{tabular}{|c|c|c|}
\hline $\begin{array}{l}\text { Statement in the WVDE } \\
\text { Framework for High-Performing Schools, } \\
2004-2014 \\
\text { (Document page number) } \\
\text { High-Yield Strategies: }\end{array}$ & $\begin{array}{l}\text { Survey } \\
\text { Item } \\
\text { (Part } \\
\text { Number- } \\
\text { Question } \\
\text { Number) }\end{array}$ & $\begin{array}{l}\text { Correlating Statement on } \\
\text { Survey Questionnaire }\end{array}$ \\
\hline $\begin{array}{l}\text { Transformational leadership that creates a } \\
\text { "learning-centered" system (p. 8). }\end{array}$ & $6-1$ & $\begin{array}{l}\text { I use a transformational leadership } \\
\text { approach to create a learning- } \\
\text { centered school. }\end{array}$ \\
\hline $\begin{array}{l}\text { An expectation that change will be an } \\
\text { ongoing, continuous process (p. 8). }\end{array}$ & $6-2$ & $\begin{array}{l}\text { There is an expectation in my school } \\
\text { that change will be an ongoing, } \\
\text { continuous process. }\end{array}$ \\
\hline $\begin{array}{l}\text { Identification of system-wide core beliefs } \\
\text { that drive improvement efforts (p. 8). } \\
\text { (This item was covered in survey item } 4-3 \text {.) }\end{array}$ & & \\
\hline $\begin{array}{l}\text { A well-articulated mission that includes a } \\
\text { focus on learning for all (p. 8). } \\
\text { (This item was covered in survey } 4-2 \text {.) }\end{array}$ & & \\
\hline $\begin{array}{l}\text { A broad understanding and commitment to } \\
\text { the need for change based on internal and } \\
\text { external factors (p. 8). }\end{array}$ & $6-3$ & $\begin{array}{l}\text { In my school, there IS NOT a broad } \\
\text { understanding and commitment to } \\
\text { the need for change. } \\
\text { (Capital letters are used because this } \\
\text { survey item is written in reverse } \\
\text { construct style.) }\end{array}$ \\
\hline $\begin{array}{l}\text { A focus on systemic approaches to design } \\
\text { and implementation (p. 8). }\end{array}$ & $6-4$ & $\begin{array}{l}\text { There is a focus on the whole school } \\
\text { in the design and implementation of } \\
\text { our school's programs. }\end{array}$ \\
\hline \multicolumn{3}{|l|}{$\begin{array}{l}\text { Pervasive use of data both to target and to } \\
\text { refine improvement efforts (p. 8). } \\
\text { (This item is covered in survey item } 4-10 \text { ). }\end{array}$} \\
\hline $\begin{array}{l}\text { Change initiatives and processes that } \\
\text { address the interrelatedness of system } \\
\text { activities and resources (p. 8). }\end{array}$ & $6-5$ & $\begin{array}{l}\text { In our school, personnel understand } \\
\text { that change involves system } \\
\text { activities and resources that are } \\
\text { connected. }\end{array}$ \\
\hline $\begin{array}{l}\text { An implementation process that reflects the } \\
\text { cycle of "Plan, Do, Study, Act" (p. 8). }\end{array}$ & $6-6$ & $\begin{array}{l}\text { Before we implement a program in } \\
\text { our school, we first plan it, then } \\
\text { implement it, study it to evaluate its } \\
\text { effects, and act on our evaluation. }\end{array}$ \\
\hline $\begin{array}{l}\text { A collaboratively developed strategic plan } \\
\text { focused on results ( } \mathrm{p} .8) \text {. } \\
\text { (This item is covered in survey item } 4-5 \text { ). }\end{array}$ & & \\
\hline
\end{tabular}


Open systems, as defined by Katz and Kahn (1966), interact with and are affected by entities outside the system, as well as within it, through repeated cycles of input, transformation, output, and renewed input. In adapting to their environment, open systems will attempt to cope with external forces by ingesting them or acquiring control over them. They are not at rest, because of their conflicting needs to both maintain equilibrium and to change in order to survive (Katz and Kahn). Reforming education, then, means dealing with the paradox of a complex entity that must change in order to survive, yet one that inherently resists change.

As a result, it should come as no surprise that there are so few examples of sustained, systemic change in our nation's schools. We have had little real incentive to rethink the purposes of education since the Industrial Revolution, when schools had to be redesigned to prepare a largely immigrant labor force for new forms of work and citizenship. New industrial practicesnotably Taylor's principles of scientific management—pointed the way for the development of now obsolete factory schools.

Now, in another era of rapid economic and social transformation, the business world finds that it must adapt to new technologies, changing markets, and global competition. This new revolution in the workplace, in turn, suggests fundamental reforms for education (Wagner, 1993). Fundamental reform calls for reflective thinking and asking the difficult questions.

The real method for system change beings and ends with ongoing, authentic conversations about the important questions. Wagner (1993) lists five essential questions: (a) What are our schools' strengths and weaknesses? (b) What is our vision and what are our core values for a better school? (c) What are our priorities and strategies for change? (d) What structures do we need to reach our goals? and (e) What new skills and resources will we need? Answers to these questions can launch the strategies for system-wide change. 
It is rare to find situations in which a well-designed systemic change infrastructure is in place. More characteristically, ad hoc mechanisms have been set in motion with personnel who have too little training and without adequate formative evaluation. It is common to find structures, such as teams and collaboratives operating without clear understanding of functions and major tasks. This defies the basic organizational principle that structure should follow function (Adelman \& Taylor, 2003).

Major systemic changes are not easily accomplished. Awareness of the myriad political and bureaucratic difficulties involved in making major institutional changes, especially with limited financial resources, leads to the caution that a successful approach is not a straightforward, sequential, linear process. Rather, the work proceeds, changes, and emerges in overlapping and spiraling ways. For significant prototype development and systemic change to occur, the infrastructure must be geared to sustain it. Finances, personnel, time, space, equipment, and other essential resources must be made available, organized, and used in ways that adequately operationalize policy and promising practices. This includes ensuring sufficient resources to develop an effective structural foundation for prototype development, systemic changes, sustainability, and ongoing capacity building (Adelman \& Taylor, 2003).

Those who do not support positive change are not building negative entropy, or useful energy, into the school (Katz \& Kahn, 1966). The old paradigm for what successful $21^{\text {st }}$-century school leaders would need to know and do had not been broken as late as 1998. School leaders in the $21^{\text {st }}$-century would need a clear recitation and description of the standards and related skills they must master and apply in order to ensure staff and students are engaging in relevant, $21^{\text {st }}$ century learning, wrote Hoyle, English, and Steffy (1998). 


\section{Domain 7: $21^{\text {st }}$-Century Skills}

The survey items for Domain 7 are correlated to the statements in the Framework for High-Performing Schools document (see Figure 9). What follows are some of the points relating to instructional practiced made by education researchers. Hoyle et al. (1998) wrote that $21^{\text {st }}$ century school leaders will need to be visionaries with the skills and dispositions needed to lead others to peak performance. In addition, political skill will be of prime importance for school governance in a democracy. Proficiency in communication and community relations will be required for articulating a vision. Skill in organizational management, as well as insights on developing a curriculum design and delivery system for diverse school communities, will be needed. Expertise in instructional management, the development of a data-based student achievement system, and the related need to focus on staff development will be important. Future leaders will need to make the most of educational research; pay close attention to evaluation and planning; and modeling appropriate value systems, ethics, and moral leadership (.Hoyle et al.).

To some, this would appear to be a restatement of what is already known about school leadership. Convinced that something else was needed for the future, the Partnership for $21^{\text {st }}$ Century Skills (Partnership) stepped into the debate. The Partnership calls itself the leading advocacy organization focused on infusing $21^{\text {st }}$-century skills into education. They bring together the business community, education leaders (including those in West Virginia), and policymakers to define what they call a powerful vision for $21^{\text {st }}$-century education to ensure every child's success as citizens and workers in the $21^{\text {st }}$ century.

The Partnership defined six key elements of $21^{\text {st }}$-century learning: (a) core subjects, (b) learning skills, (c) $21^{\text {st }}$-century tools, (d) $21^{\text {st }}$-century context, (e) $21^{\text {st }}$-century content, and (f) $21^{\text {st }}$-century assessments. Originally, these elements were divided into three broad categories: (a) 
Figure 9. Correlation of Survey Items to Domain 7 in the Framework for High- Performing Schools

\begin{tabular}{|c|c|c|}
\hline $\begin{array}{c}\text { Sub-Categories of the } \\
\text { Partnership's } \\
\text { Definition of } 21^{\text {st }} \text {-Century Skills }\end{array}$ & $\begin{array}{l}\text { Survey } \\
\text { Item } \\
\text { (Part } \\
\text { Number- } \\
\text { Question } \\
\text { Number) }\end{array}$ & $\begin{array}{l}\text { Correlating Statement on } \\
\text { Survey Questionnaire }\end{array}$ \\
\hline $\begin{array}{l}\text { Core subjects as outlined in } \\
\text { NCLB, which include English, } \\
\text { reading or language arts, } \\
\text { mathematics, science, foreign } \\
\text { languages, civics, government, } \\
\text { economics, arts, history, and } \\
\text { geography. }\end{array}$ & $7-1$ & $\begin{array}{l}\text { I DO NOT believe students need core } \\
\text { subjects, such as English, reading, math, } \\
\text { science, and social studies, in order to } \\
\text { be successful. } \\
\text { (Capital letters are used because this } \\
\text { survey item is written in reverse } \\
\text { construct style.) }\end{array}$ \\
\hline \multirow{4}{*}{$\begin{array}{l}\text { Global awareness; financial, } \\
\text { economic, business, and } \\
\text { entrepreneurial literacy; civic } \\
\text { literacy; and health and wellness } \\
\text { awareness. }\end{array}$} & $7-2$ & $\begin{array}{l}\text { Awareness of happenings around the } \\
\text { world is important for students' future } \\
\text { success. }\end{array}$ \\
\hline & $7-3$ & $\begin{array}{l}\text { Understanding business and finances is } \\
\text { important for students' future success. }\end{array}$ \\
\hline & $7-4$ & $\begin{array}{l}\text { Knowledge of government is important } \\
\text { for students' future success. }\end{array}$ \\
\hline & $7-5$ & $\begin{array}{l}\text { Health and wellness awareness is } \\
\text { important for students' future success. }\end{array}$ \\
\hline \multirow{3}{*}{$\begin{array}{l}\text { Learning skills, comprised of } \\
\text { three broad categories: } \\
\text { information and communication } \\
\text { skills, thinking and problem- } \\
\text { solving skills, and interpersonal } \\
\text { and self-directional skills. }\end{array}$} & $7-6$ & $\begin{array}{l}\text { Information and communication skills are } \\
\text { important for students' future success. }\end{array}$ \\
\hline & $7-7$ & $\begin{array}{l}\text { Thinking and problem-solving skills are } \\
\text { important for students' future success. }\end{array}$ \\
\hline & $7-8$ & $\begin{array}{l}\text { Interpersonal and self-directional skills } \\
\text { are important for students' future } \\
\text { success. }\end{array}$ \\
\hline $\begin{array}{l}\text { Integration of learning skills and } \\
21^{\text {st }} \text {-century tools, which comprises } \\
\text { information, communication, and } \\
\text { technology (ICT) literacy. }\end{array}$ & $7-9$ & $\begin{array}{l}21^{\text {st }} \text {-century tools should be used with } \\
\text { learning skills in order for students to be } \\
\text { successful. }\end{array}$ \\
\hline \multirow{2}{*}{$\begin{array}{l}\text { Life skills, which include: } \\
\text { leadership, ethics, accountability, } \\
\text { adaptability, personal productivity, } \\
\text { personal responsibility, people } \\
\text { skills, self-direction, and social } \\
\text { responsibility. }\end{array}$} & $7-10$ & $\begin{array}{l}\text { Ethics, including personal responsibility, } \\
\text { is important for students' future success. }\end{array}$ \\
\hline & $7-11$ & $\begin{array}{l}\text { Self-direction and social responsibility } \\
\text { are important for students' success. }\end{array}$ \\
\hline $\begin{array}{l}\text { Authentic assessments that } \\
\text { measure all the previously listed } \\
\text { five components-core subjects, } \\
21^{\text {st }} \text {-century content, learning and } \\
\text { thinking skills, ICT literacy, and life } \\
\text { skills. }\end{array}$ & $7-12$ & $\begin{array}{l}\text { Student assessments should measure } \\
\text { thinking skills in addition to knowledge of } \\
\text { cores subjects. }\end{array}$ \\
\hline
\end{tabular}


Learning and Teaching, (b) Learning Skills and Learning Tools, and (c) Leading and Managing. Later, the categories were re-labeled as (a) Learning and Innovation Skills, (b) Life and Career Skills, and (c) Information Media and Technology Skills. The WVDE is a collaborative partner in the Partnership for $21^{\text {st }}$-Century Skills. Both the Partnership and the WVDE have espoused a unified, collective vision for $21^{\text {st }}$-century learning to strengthen American education (WVDE, 2006).

The basic concepts of $21^{\text {st }}$-century learning and teaching relate to helping students master core subjects in a contemporary context. Instruction should always include content in a contemporary context through the incorporation of relevant examples, applications, and settings. Extensive contemporary content, including global awareness, civic and business literacy, should be available and used by students. Where applicable, schools should create $21^{\text {st }}$-century content that is relevant to the economic needs of their region, such as biotechnology, manufacturing, or agricultural technology (Partnership, 2007).

The first component of the $21^{\text {st }}$-century skills consists of the core subjects identified by the No-Child-Left-Behind Act of 2001 (NCLB). NCLB identifies core subjects as English, reading or language arts; mathematics; science; foreign languages; civics; government; economics; arts; history, and geography. Several significant, emerging content areas, which are critical to success in communities and workplaces, have been designated as the second component. These are global awareness; financial, economic, business, and entrepreneurial literacy; civic literacy; and health and wellness awareness (WVDE, 2004). The $21^{\text {st }}$-century focus on core subjects is to expand beyond basic competency to the understanding of core academic content at much higher levels (Partnership, 2007). 
Learning skills are comprised of three broad categories: (a) information and communication skills, (b) thinking and problem-solving skills, and (c) interpersonal and selfdirectional skills. Education objectives and teaching strategies should emphasize the integration of learning skills and $21^{\text {st }}$-century tools, which comprises information, communication, and technology (ICT) literacy. Learning skills and $21^{\text {st }}$-century tools are used together to enable students to effectively build content knowledge. Through integrating learning skills and $21^{\text {st }}$ century tools, students are able to do such things as access and communicate information, manage complexity, solve problems, and think critically and creatively. Every student should have access to $21^{\text {st }}$-century tools (Partnership, 2007).

As much as students need to learn academic content, they also need to know how to keep learning — and make effective and innovative use of what they know-throughout their lives. Learning and thinking skills are comprised of the following: critical-thinking and problemsolving skills, communication skills, creativity and innovation skills, collaboration skills, contextual learning skills, and information and media literacy skills (WVDE, 2004).

Information and communications technology (ICT) literacy, the fourth component, is the ability to use technology to develop $21^{\text {st }}$-century content knowledge and skills, in the context of learning core subjects. Students must be able to use technology to learn content and skills in order to know how to learn, think critically, solve problems, use information, communicate, innovate, and collaborate.

The fifth component relates to life skills. Good teachers have always incorporated life skills into their pedagogy. The challenge today is to incorporate these essential skills into schools 
deliberately, strategically and broadly. Life skills include: leadership, ethics, accountability, adaptability, personal productivity, personal responsibility, people skills, self-direction, and social responsibility (WVDE, 2004).

The final component involves authentic $21^{\text {st }}$-century assessments, which are the essential foundation of a $21^{\text {st }}$-century education. Assessments must measure all the previously listed five components-core subjects, $21^{\text {st }}$-century content, learning and thinking skills, ICT literacy, and life skills. To be effective, sustainable, and affordable, assessments must use modern technologies to increase efficiency and timeliness. Standardized tests alone can measure only a few of the important skills and knowledge students should learn. A balance of assessments, including high-quality standardized testing, along with effective classroom assessments, offers students a powerful way to master the content and skills central to success (WVDE, 2004).

Given the vast differences between skills needed to be successful in the $20^{\text {th }}$ and $21^{\text {st }}$ centuries, educators will need leaders who can provide high-quality, relevant professional development programs. Considerable thought should be given to planning professional development in order to avoid the trap of doing the same kinds of things and yet expecting different results. 


\section{CHAPTER THREE: METHODS OF THE STUDY}

This study will use survey research is an attempt to answer the following question: Is there a statistically significant difference in the perceptions of two groups of principals regarding their schools' progress towards high-performing status as measured by an instrument that is aligned with the domains of the West Virginia Framework for High-Performing Schools? The survey instrument items are correlated to the dimensions of the domains of the Framework for High-Performing Schools, plus the added area of $21^{\text {st }}$-century skills (see Figure 1). For the purposes of this study, the seven areas have been labeled as such:

Domain 1: Culture of common beliefs and values dedicated to learning for all;

Domain 2: Curriculum management;

Domain 3: Instructional practices;

Domain 4: School effectiveness;

Domain 5: Student and parent support;

Domain 6: Systemic continuous improvement process; and

Domain 7: $21^{\text {st }}$-century skills.

Research Questions and Hypotheses

The research hypotheses for this study relate to each of the seven domains. The null hypothesis and alternative hypothesis for each research question follow.

Research Question 1:

$H_{0}$ : There is no statistically significant difference in Domain 1 scores when comparing individuals who have participated in the West Virginia Institute for $21^{\text {st }}$-Century Leadership with those who have not attended the Institute. $H_{0}: \mu_{1}=\mu_{2}$ 
$H_{\text {a: }}$ There is a statistically significant difference in Domain 1 scores when comparing individuals who have participated in the West Virginia Institute for $21^{\text {st }}$-Century Leadership with those who have not attended the Institute. $H_{0}: \mu_{1} \neq \mu_{2}$

\section{Research Question 2:}

$H_{0}$ : There is no statistically significant difference in Domain 2 scores when comparing individuals who have participated in the West Virginia Institute for $21^{\text {st }}$-Century Leadership with those who have not attended the Institute. $H_{0}: \mu_{1}=\mu_{2}$

$H_{\text {a: }}$ There is a statistically significant difference in Domain 2 scores when comparing individuals who have participated in the West Virginia Institute for $21^{\text {st }}$-Century Leadership with those who have not attended the Institute. $H_{0}: \mu_{1} \neq \mu_{2}$

\section{Research Question 3:}

$H_{0}$ : There is no statistically significant difference in Domain 3 scores when comparing individuals who have participated in the West Virginia Institute for $21^{\text {st }}$-Century Leadership with those who have not attended the Institute. $H_{0}: \mu_{1}=\mu_{2}$

$H_{\text {a: }}$ There is a statistically significant difference in Domain 3 scores when comparing individuals who have participated in the West Virginia Institute for $21^{\text {st }}$-Century Leadership with those who have not attended the Institute. $H_{0}: \mu_{1} \neq \mu_{2}$

\section{Research Question 4:}

$H_{0}$ : There is no statistically significant difference in Domain 4 scores when comparing individuals who have participated in the West Virginia Institute for $21^{\text {st }}$-Century Leadership with those who have not attended the Institute. $H_{0}: \mu_{1}=\mu_{2}$ 
$H_{\text {a: }}$ There is a statistically significant difference in Domain 4 scores when comparing individuals who have participated in the West Virginia Institute for $21^{\text {st }}$-Century Leadership with those who have not attended the Institute. $H_{0}: \mu_{1} \neq \mu_{2}$

\section{Research Question 5:}

$H_{0}$ : There is no statistically significant difference in Domain 5 scores when comparing individuals who have participated in the West Virginia Institute for $21^{\text {st }}$-Century Leadership with those who have not attended the Institute. $H_{0}: \mu_{1}=\mu_{2}$

$H_{\mathrm{a}}$ There is a statistically significant difference in Domain 5 scores when comparing individuals who have participated in the West Virginia Institute for $21^{\text {st }}$-Century Leadership with those who have not attended the Institute. $H_{0}: \mu_{1} \neq \mu_{2}$

\section{Research Question 6:}

$H_{0}$ : There is no statistically significant difference in Domain 6 scores when comparing individuals who have participated in the West Virginia Institute for $21^{\text {st }}$-Century Leadership with those who have not attended the Institute. $H_{0}: \mu_{1}=\mu_{2}$

$H_{\text {a: }}$ There is a statistically significant difference in Domain 6 scores when comparing individuals who have participated in the West Virginia Institute for $21^{\text {st }}$-Century Leadership with those who have not attended the Institute. $H_{0}: \mu_{1} \neq \mu_{2}$

\section{Research Question 7:}

$H_{0}$ : There is no statistically significant difference in Domain 7 scores when comparing individuals who have participated in the West Virginia Institute for $21^{\text {st }}$-Century Leadership with those who have not attended the Institute. $H_{0}: \mu_{1}=\mu_{2}$ 
$H_{\text {a: }}$ There is a statistically significant difference in Domain 7 scores when comparing individuals who have participated in the West Virginia Institute for $21^{\text {st }}$-Century Leadership with those who have not attended the Institute. $H_{0}: \mu_{1} \neq \mu_{2}$

A null hypothesis states that there is no significant difference or relationship between two or more parameters. It concerns a judgment as to whether apparent differences or relationships are true differences or relationships or whether they merely result from sampling error. If the difference between the mean score of the experimental and the comparison groups is too great to attribute to the normal fluctuations that result from sampling error, the experimenter may reject the null hypothesis, saying in effect that it is probably not true that the difference is merely the result of sampling error. Thus, the researcher may conclude that the experimental variable or treatment probably accounted for the difference in performance as measured by the mean scores. If the difference between means was not great enough to reject the null hypothesis, the researcher fails to reject it (Best \& Kahn, 1998).

The rejection or acceptance of a null hypothesis is based on some level of significance (alpha level) as a criterion. In psychological and educational circles, the 5\% (.05) alpha $(\alpha)$ level indicates that a difference in means as large as that found between the experimental and comparison groups would have resulted from sampling error in less than 5 out of 100 replications of the experiment. This suggests a $95 \%$ probability that the difference was due to the experimental treatment rather than to sampling error.

\section{Sample and Population}

The population of this proposed study is the group of 704 head principals in West Virginia schools. Although it is not designed to address principals outside West Virginia, 
this study may serve as a start in that direction. The Comparison group will be the 300 principals quasi-randomly selected from a list of principals who have not received the professional development training provided to principals who attended the West Virginia Institute for $21^{\text {st }}$ Century Leadership.

The quasi-random selection will be done using the random-number generator function in Microsoft Excel software. The treatment group will be comprised of the 300 principals who received the professional development training provided to principals who attended the West Virginia Institute for $21^{\text {st }}$-Century Leadership.

This proposed survey will look at the results of the data in the aggregate, not at individual responses. The survey method gathers data from a relatively large number of cases at a particular time. It is not concerned with characteristics of individuals as individuals. It is concerned with the statistics that result when data are abstracted from a number of individual cases. It is essentially cross-sectional (Best \& Kahn, 1998).

\section{Survey Instrument Development}

The purpose of the survey instrument is to measure the perceptions of principals regarding their school's performance. It then became necessary to determine how the WVDE defined school performance. The answer was gleaned from the Framework for High-Performing Schools document, which is the working document for principals from 2004 to 2014 (WVDE, 2004). The notion behind the survey was to determine the perceptions of principals in terms of their levels of agreement about their schools' status in the seven domains of the Framework.

Suskie (1996) pointed out that, all other things being equal, a long questionnaire will be more reliable than a short one (p. 53). A reliable questionnaire elicits consistent responses. A perfectly reliable questionnaire, however is impossible to create. Suskie (1996) noted some 
reasons a person's response might vary from one question to the next or from one survey to the next. These reasons include: (a) variations in the respondent's mood; (b) fluctuations and idiosyncrasies of human memory; (c) unpredictable fluctuations in attention or accuracy; (d) health; (e) fatigue; (f) room conditions, such as heat, light, and noise; and (g) momentary distractions.

The first questions of the survey instrument should be written in such a way as to hook the respondent into answering the survey and thus increase the response rate. Demographic questions, which ask the respondent to provide such information as age, gender, and major, should not be placed at the beginning of the survey instrument. Respondents will find them irritants at best and offensive at worst (Suskie, 1996, p. 61). For this reason, the three demographic items on the survey instrument have been placed at the end. They ask for the respondents' gender, grade levels at her school, and the number of years she has been a principal.

The initial attempt for developing the survey items came from the way the dimensions were worded on the WVDE Framework document (WVDE, 2004). This soon became unwieldy and could easily lead to response fatigue. The next step, therefore, was to review each domain to determine its key points, and each of these key points became a survey item.

The first draft of the survey was in paper-and-pencil format, using a Likert-type scale. This survey instrument requires the respondent to self-report along a continuum of choices (Gay, et al., 2006). The respondent should easily understand how to decide on an answer and how to record it. Reverse-construction items that included a negative were typed with the negative words in all capital letters to draw attention to them (Suskie, 1996).

Each domain was labeled, and its dimension items were listed below it in the form of declarative statements. A respondent would be asked to indicate the number on a Likert-type 
scale that best describes his level of agreement or disagreement with the statement as it pertains to his school. Each item on the instrument is scored on a scale of 1 to 5 . The score for a domain is the sum of the respondent's scores of all the items in the domain.

\section{Panel of Reviewers}

Changes to the survey instrument came as a result of feedback from a group of people who are generally viewed as education experts (Gay, et al., 2006). The word, expert, in this context is used to mean one who knows a great deal about some specialized thing (Scott \& Foresman, 1983). All reviewers expressed a great deal of interest in the study and offered their support in conducting it.

Reviewer No. 1 was a state-level education administrator who had served as one of the Institute directors. This reviewer expressed two concerns, one of which was that the survey items did not match the Institute curriculum. The other concern was the use of the term, "full implementation." Because of the amount of time required for full implementation of the initiative to have been achieved, this reviewer feared that principals would infer that they were not up to expected standards if their responses indicated they were at less than full implementation.

Further discussion with this reviewer clarified that the intent was not to measure the Institute curriculum, nor to imply that all schools should be at full implementation. Instead, the intent was to measure the perceptions of participants and non-participants regarding their schools' progress toward high-performing status as outlined in West Virginia Department of Education Framework document. It was this reviewer's feedback that appropriately resulted in the words, "progress toward high-performing status" to be added to the survey's directions.

Reviewers No. 2 and 3 were state-level education administrators, serving in the West Virginia Department of Education as department-level directors. Both these reviewers provided 
supportive and encouraging feedback without any specific recommendations for substantive changes. Reviewer No. 4, another state-level education administrator who served as special assistant to a chief state school officer, emphasized the importance of eliminating understood prepositions and unnecessary words. This is consistent with Suskie's (1996) recommendation to keep the vocabulary level of each item low and as simple as possible. This reviewer also strongly encouraged the use of online survey software to conduct the research and suggested contacting the staff-development coordinators in the eight Regional Education Service Agencies for assistance in getting participants' contact information.

Reviewer No. 5 was a national education consultant who has experience as a director of research and development in a county school system, as well as experienced as a county superintendent in two states. This reviewer, who received Superintendent-of-the-Year Awards in both states, was supportive and encouraging with only one recommendation. This related to the notion of determining the impact of a program in terms of student outcomes as opposed to only adult behaviors. The reviewer suggested that a statement, such as the following, be added under the Continuous Improvement domain: "Our school has produced significant improvement in student achievement as a result of our efforts to date." The statement was added to the survey as suggested.

Reviewer No. 6 was a county central office administrator with 30 years of experience in the West Virginia education system. The reviewer has not only a doctorate in education, but a Master's Degree in Business Administration, and teaching endorsements in both elementary education and special education. This reviewer provided supportive and encouraging feedback without any specific recommendations for substantive changes. 
Reviewer No. 7, who holds a doctorate in Education Leadership, has held a position of teacher, county superintendent, state-level administrator, and has served as a chief state school officer. The feedback provided by this reviewer was supportive and encouraging without any specific recommendations for substantive changes. This reviewer also offered assistance in carrying out the survey if needed.

Reviewer No. 8, a university professor with a background in statistics, made three recommendations: (a) Eliminate double-barreled items. Suskie (1996) explained that a doublebarreled item asks several questions at once, each of which might be answered differently by the respondent. (b) Eliminate redundancy. Some survey statements related to the same topics and were, in effect, unnecessary. The reviewer emphasized the importance of deciding specifically what information the investigator is trying to obtain, and eliminating anything unrelated. (c) Do not label the domains to avoid preconceived notions of the domain's questions. These recommendations were acted upon accordingly.

\section{Data Analysis}

The way to analyze Likert scales is a hotly disputed issue within the general field of social science research. Some researchers point out that the data yield ordered but not scaled data. There is no way to be certain that the degree of difference between the response choices, such as Strongly Agree and Agree, is the same as the difference between Agree and Not Sure. They, therefore, argue that Likert data should be analyzed using only nonparametric statistics for ordered data, such as the Mann-Whitney $U$ test Others, however, argue that many parametric data analyses for scaled data (the same distance between choices), such as the $t$-test, are sufficiently robust to be used with Likert data (Suskie, 1996). 
Suskie (1996) recommends conducting both parametric and non-parametric analyses. If the results are the same for both, the parametric results can be confidently reported. If they differ, the nonparametric reports should be reported. Both the $t$-Test and the Mann-Whitney $U$ test will be conducted on data collected in this proposed study.

Statistical power refers to the ability of a significance test to avoid a Type II error, that is, to correctly reject the null hypothesis. The three pieces of information necessary to determine the power of the statistical test: (a) the significance level of a study, (b) the sample size, and (c) the effect size. The significance level of a study and its sample size are likely to be known by the researcher. The effect size must be determined.

Effect size is a numerical way of expressing the strength or magnitude of a reported relationship, whether or not it is causal. Effect size is expressed as a decimal number, and although numbers greater than 1.00 are possible, they do not occur very often. An effect size near .00 means that, on average, experimental and comparison groups performed the same; a positive effect size means that, on average, the experimental group performed better; and a negative effect size means that, on average, the comparison group did better. For positive effect sizes, the larger the number, the more effective the experimental treatment is. Although there are no hard and fast rules, it is generally agreed that an effect size in the twenties (e.g., .28) indicates a treatment that produces a relatively small effect, whereas an effect size in the eighties (e.g., 81) indicates a powerful treatment (Gay, et al., 2006).

A mere quantitative superiority of the experimental group mean score over the comparison group mean score is not conclusive proof of its superiority. Because we know that the means of two groups drawn from the same population are not necessarily identical, any difference that appeared at the end of the experimental cycle could possibly be attributed to 
sampling error or chance. To be statistically significant, the difference must be greater than that reasonably attributed to sampling error (Best \& Kahn, 1998, p. 390).

The test of the significance of the difference between two means is known as a $t$-test. The four basic assumptions of the $t$-test: (a) independence, (b) scale of measurement, (c) normality, and (d) homogeneity. If these assumptions are met, then the $t$-test will provide the most powerful test of the hypothesis. If these assumptions are not met, another statistical test should be used (Best \& Kahn, 1998).

The question of independence deals with whether the means in the two groups are independent. In the case of this proposed study, there are two groups selected from the population to be studied, making the means of the two groups independent. One possible limitation, however, is that there is no guarantee that respondents in the two groups will not confer about how they respond to the survey items.

The scale of measurement in this case is ordinal, classifying and ranking responses in terms of the degree to which they possess a characteristic or area or interest Normality deals with the assumption of the approximately normal distribution of the measure in the two groups. The assumption of homogeneity is that the $t$-tests of the two samples are equal in size and also have equal variances (Gay, et al., 2006).

The significance of the difference between two populations is also measured with the Mann-Whitney $U$ test. It is a nonparametric equivalent of the parametric $t$-test, which may be considered a useful alternative to the $t$-test when the parametric assumptions cannot be met and when the observations are expressed in at least ordinal scale values (Best \& Kahn, 1998, p. 420). 


\section{Pilot Testing of Questionnaire}

A paper-and-pencil version of the questionnaire was given to a group of 18 educators in an Education Leadership class. The primary purpose of this pilot test was to study the procedural aspects of administering the survey and to gather anecdotal data from respondents about the instrument. Ten members of this group were females; eight were males. When asked (a) if they would have been willing to respond to the survey electronically, (b) whether they understood the statements in the survey, (c) whether they understood the procedure for responding to each statement, and (d) whether they thought the statements were relevant and appropriate, they all responded in the affirmative. The average survey completion time for females was 12.8 minutes; for males, 10.2 minutes.

\section{Considerations of Survey Dissemination}

Sending questionnaires by e-mail has recently become a popular alternative to questionnaires mailed via the postal service. In addition to being fast and efficient, this method shares both the advantages and disadvantages of mail questionnaires, with the additional disadvantage that not all potential respondents have e-mail service (Gay, et al., 2006). Despite the associated disadvantages, however, given the impetus for all educators to use $21^{\text {st }}$-century tools, this study proposes to use an online survey tool to disseminate the survey, collect responses, and analyze the data. Reminders will be sent to non-respondents, and participants may request a paper copy of the survey that could be returned in a self-addressed, stamped envelope.

An advance letter, indicating the importance of each person's responses, will be sent to all potential survey respondents (see Appendix I). Motivating the respondent is central to getting a reply with good data. The letter of transmittal is a major means of motivation (Krathwohl, 1998). The cover letter speaks in the researcher's absence. It says all the things you would say in 
person to establish and maintain a rapport with the respondent, convince the respondent to decide to complete the questionnaire, and do so quickly and succinctly.

Suskie (1996) recommends the following ways to persuade those who receive the survey to answer: (a) Make the study look important. (b) Give respondents a good reason for participating. (c) Try to give the respondent the feeling that he or she will make a real impact on something important. (d) Stress that the respondent is part of a carefully selected sample, and his or her response is needed. (e) Make the study look professional. (f) Engage the respondent with a lead sentence that arouses interest and draws the reader in. (g) Appeal to the respondent's selfinterest by answering the respondent's unspoken question of what is in it for them. (h) Address the issue of confidentiality by explaining that the respondent's questionnaire will be separated from any personal identification. (i) In addition, personalize the letter by signing it in contrasting ink, including contact information, and offering to send a copy of the results.

\section{Limitations of Electronic Surveys}

As with any research method, there are some weaknesses that should be acknowledged about using electronic survey methods for research. Population and sample are limited to those with access to a computer and an online network. Due to the open nature of most online networks, it is difficult to guarantee anonymity and confidentiality. Constructing the format of a computer questionnaire can be difficult for a novice researcher. More instruction and orientation to the computer online systems may be necessary in order for respondents to accurately complete the questionnaire. Computers are subject to the technology issues not present in oral or written forms of communication. Even though research shows that email response rates are higher, most of these studies found response rates higher only during the first few days; thereafter, the rates were not significantly higher (University of Colorado, 2005). 


\section{Summary of Proposed Research Methods}

Survey research is the method proposed to answer the research question: Is there a statistically significant difference in the perceptions of two groups of principals regarding their schools' progress towards high-performing status as measured by an instrument that is aligned with the domains of the West Virginia Framework for High-Performing Schools? In this case, high-performing school status is equivalent to statements written about the six domains of the Framework for High-Performing Schools plus the added domain of $21^{\text {st }}$-century skills. The dimensions of the domains were translated into declarative statements and incorporated into a 70-item questionnaire, which was reviewed by eight knowledgeable educators. The survey instrument was pilot tested to allow a study of the procedural aspects of administering the survey.

The population for this study is the group of 704 head principals in West Virginia's schools. The samples drawn from the population consist of (a) the 300 principals who received the professional development training provided in the West Virginia Institute for $21^{\text {st }}$-Century Leadership (experimental group); and 300 principals, selected through a random-number generator software program, who did not receive the Institute training.

After an advance letter has been sent electronically to each survey participant, he will be asked to respond via computer to each item on the questionnaire by indicating his level of agreement with it in terms of his own school. Electronic survey software will be used to disseminate the surveys and collect responses.

Both parametric (using the $t$-test) and non-parametric (using the Mann-Whitney $U$ test) analyses of the data will be conducted to test the null and alternative hypotheses for each domain. The null hypothesis is that there is no statistically significant difference in the domain's 
scores when comparing individuals who have participated in the West Virginia Institute for $21^{\text {st }}$ Century Leadership with those who have not attended the Institute. The alternative hypothesis is that there is a statistically significant difference in the domain scores when comparing individuals in the two groups.

Rejection or acceptance of the null hypothesis is based on the significance level $(\alpha)$ of .05 , suggesting that there is a 95 percent probability that the difference in the means of the two groups was due to the experimental treatment rather than to sampling error. A concept map of the proposed study was previously presented in Figure 2. The proposed time line for completion of the study is presented in Figure 10.

Research is a creative act. Researchers combine the elements of methods in any way that makes the best sense for the study they want to do. Their only limits are their own imagination and the necessity of presenting their findings convincingly (Krathwohl, 1998). The following chapter will provide a presentation of the findings from the analysis of the data collected in this study. 
Figure 10. Proposed Time Line for Research, 2008-2009.

\begin{tabular}{|c|c|c|c|c|}
\hline Month & Week 1 & Week 2 & Week 3 & Week 4 \\
\hline $\begin{array}{l}\text { January } \\
2008\end{array}$ & $\begin{array}{l}\text { Take Institution } \\
\text { Review Board } \\
\text { test. }\end{array}$ & $\begin{array}{l}\text { Begin } \\
\text { development of } \\
\text { survey } \\
\text { instrument. }\end{array}$ & $\begin{array}{l}\text { Continue work } \\
\text { on survey } \\
\text { instrument. }\end{array}$ & $\begin{array}{l}\text { Request letter of } \\
\text { support from } \\
\text { WVDE } \\
\text { personnel. } \\
\text { Begin research } \\
\text { and writing. }\end{array}$ \\
\hline \multirow[t]{2}{*}{ February } & $\begin{array}{l}\text { Survey } \\
\text { instrument } \\
\text { reviewed by } \\
\text { panel of experts. }\end{array}$ & $\begin{array}{l}\text { Obtain list of } \\
\text { study } \\
\text { participants from } \\
\text { WVDE. }\end{array}$ & $\begin{array}{l}\text { Pilot test survey } \\
\text { instrument for } \\
\text { administration } \\
\text { procedures and } \\
\text { timing. }\end{array}$ & $\begin{array}{l}\text { Chapter } 1-\text { first } \\
\text { draft completed. }\end{array}$ \\
\hline & \multicolumn{4}{|c|}{ Continue research and writing. } \\
\hline \multirow[t]{2}{*}{ March } & $\begin{array}{l}\text { Meet with } \\
\text { advisor to read } \\
\text { first draft of } \\
\text { Chapter } 1 .\end{array}$ & $\begin{array}{l}\text { Confirm } 5^{\text {th }} \\
\text { committee } \\
\text { member. }\end{array}$ & $\begin{array}{l}\text { Continue } \\
\text { refinements to } \\
\text { Chapter } 1 .\end{array}$ & $\begin{array}{l}\text { Begin first draft } \\
\text { of Chapter } 2 \text {. }\end{array}$ \\
\hline & \multicolumn{4}{|c|}{ Continue research and writing. } \\
\hline \multirow[t]{2}{*}{ April } & $\begin{array}{l}\text { Revise survey } \\
\text { instrument per } \\
\text { reviewers' } \\
\text { feedback. }\end{array}$ & $\begin{array}{l}\text { Make revisions } \\
\text { to Chapter } 2 .\end{array}$ & $\begin{array}{l}\text { Purchase } \\
\text { subscription to } \\
\text { online survey } \\
\text { software. }\end{array}$ & $\begin{array}{l}\text { Learn } \\
\text { mechanics of } \\
\text { online survey } \\
\text { software. }\end{array}$ \\
\hline & \multicolumn{4}{|c|}{ Continue research and writing. } \\
\hline \multirow[t]{2}{*}{ May } & $\begin{array}{l}\text { Convert survey } \\
\text { instrument to } \\
\text { electronic } \\
\text { version. }\end{array}$ & $\begin{array}{l}\text { Rewrite Chapter } \\
1 \text {; move parts to } \\
\text { Chapter } 2 \text {. }\end{array}$ & $\begin{array}{l}\text { Begin first draft } \\
\text { of Chapter } 3 .\end{array}$ & $\begin{array}{l}\text { Put reference list } \\
\text { in APA format. }\end{array}$ \\
\hline & \multicolumn{4}{|c|}{ Continue research and writing; continue to build reference list. } \\
\hline \multirow[t]{2}{*}{ June } & \multicolumn{4}{|c|}{ Continue research and writing; continue to build reference list. } \\
\hline & \multicolumn{4}{|c|}{$\begin{array}{l}\text { Continue research and writing; continue to build reference list. Reorganize } \\
\text { Chapter } 2 \text {. }\end{array}$} \\
\hline July & $\begin{array}{l}\text { Continue } \\
\text { research and } \\
\text { writing. }\end{array}$ & $\begin{array}{l}\text { Continue } \\
\text { research and } \\
\text { writing. }\end{array}$ & $\begin{array}{l}\text { Continue } \\
\text { research and } \\
\text { writing. }\end{array}$ & $\begin{array}{l}\text { Continue } \\
\text { research and } \\
\text { writing. }\end{array}$ \\
\hline August & $\begin{array}{l}\text { Build tables, } \\
\text { figures, and } \\
\text { appendices. }\end{array}$ & $\begin{array}{l}\text { Finalize Chapter } \\
\text { 3. Check for } \\
\text { proper headings } \\
\text { throughout } \\
\text { document. }\end{array}$ & $\begin{array}{l}\text { Send Chapter } 3 \\
\text { section on } \\
\text { statistical } \\
\text { methods to } \\
\text { expert for } \\
\text { review. }\end{array}$ & $\begin{array}{l}\text { Proofread and } \\
\text { make } \\
\text { corrections on } \\
\text { final prospectus } \\
\text { document. }\end{array}$ \\
\hline \multicolumn{5}{|l|}{ Continued. } \\
\hline
\end{tabular}




\begin{tabular}{|c|c|c|c|c|}
\hline Month & Week 1 & Week 2 & Week 3 & Week 4 \\
\hline September & $\begin{array}{l}\text { Conduct final } \\
\text { reading of } \\
\text { prospectus with } \\
\text { advisor. Request } \\
\text { pre-prospectus } \\
\text { meeting. Send } \\
\text { document to } \\
\text { committee. }\end{array}$ & $\begin{array}{l}\text { Prepare for pre- } \\
\text { prospectus } \\
\text { defense } \\
\text { meeting. }\end{array}$ & $\begin{array}{l}\text { Hold pre- } \\
\text { prospectus } \\
\text { defense meeting } \\
\text { with committee. }\end{array}$ & $\begin{array}{l}\text { Make suggested } \\
\text { revisions to } \\
\text { prospectus. }\end{array}$ \\
\hline October & $\begin{array}{l}\text { Continue with } \\
\text { prospectus } \\
\text { revisions. }\end{array}$ & $\begin{array}{l}\text { Continue with } \\
\text { prospectus } \\
\text { revisions. }\end{array}$ & $\begin{array}{l}\text { Obtain final } \\
\text { approval of } \\
\text { prospectus. }\end{array}$ & $\begin{array}{l}\text { Obtain email } \\
\text { addresses of } \\
\text { study } \\
\text { participants. } \\
\text { Run random- } \\
\text { number } \\
\text { generator } \\
\text { program to } \\
\text { determine } \\
\text { principals in } \\
\text { comparison } \\
\text { group. }\end{array}$ \\
\hline November & $\begin{array}{l}\text { Set up electronic } \\
\text { version of survey } \\
\text { and electronic } \\
\text { data collectors. } \\
\text { Set up SPSS } \\
\text { formulas. } \\
\text { Prepare the } \\
\text { advance letter. }\end{array}$ & $\begin{array}{l}\text { Send out } \\
\text { advance letter. } \\
\text { Launch survey. } \\
\text { Prepare email } \\
\text { reminders to } \\
\text { send to non- } \\
\text { responders. }\end{array}$ & $\begin{array}{l}\text { Monitor data } \\
\text { collection. } \\
\text { Respond to } \\
\text { questions. }\end{array}$ & $\begin{array}{l}\text { Monitor data } \\
\text { collection. } \\
\text { Respond to } \\
\text { questions. }\end{array}$ \\
\hline December & $\begin{array}{l}\text { Monitor data } \\
\text { collection. } \\
\text { Respond to } \\
\text { questions. }\end{array}$ & $\begin{array}{l}\text { End electronic } \\
\text { data collection. }\end{array}$ & $\begin{array}{l}\text { Begin data } \\
\text { analysis. }\end{array}$ & $\begin{array}{l}\text { Continue data } \\
\text { analysis. }\end{array}$ \\
\hline $\begin{array}{c}\text { January } \\
2009\end{array}$ & $\begin{array}{l}\text { Continue data } \\
\text { analysis. }\end{array}$ & $\begin{array}{l}\text { Continue data } \\
\text { analysis. }\end{array}$ & $\begin{array}{l}\text { Continue data } \\
\text { analysis. }\end{array}$ & $\begin{array}{l}\text { Continue data } \\
\text { analysis. }\end{array}$ \\
\hline February & $\begin{array}{l}\text { Begin writing } \\
\text { Chapters Four } \\
\text { and Five. }\end{array}$ & Continue writing & Continue writing. & Continue writing. \\
\hline March & Continue writing. & Continue writing. & Continue writing. & Continue writing. \\
\hline April & $\begin{array}{l}\text { Submit final } \\
\text { manuscript to } \\
\text { committee chair } \\
\text { for review. } \\
\text { Request date for } \\
\text { final defense. }\end{array}$ & $\begin{array}{l}\text { Prepare } \\
\text { presentation for } \\
\text { final defense. }\end{array}$ & $\begin{array}{l}\text { Prepare } \\
\text { presentation for } \\
\text { final defense. }\end{array}$ & Final defense. \\
\hline May & $\begin{array}{l}\text { Completion of } \\
\text { program. }\end{array}$ & & & \\
\hline
\end{tabular}




\section{CHAPTER FOUR: ANALYSIS OF RESULTS}

This chapter presents the analysis of the data collected in an attempt to answer the question: Is there a statistically significant difference in the perceptions of two groups of principals regarding their schools' progress toward high-performing status as measured by an instrument aligned with the domains of the West Virginia Framework for High-Performing Schools? The first section contains the descriptive and statistical analysis of survey responses by domain of both the comparison group (300 principals who have not attended the West Virginia Institute for $21^{\text {st }}$-Century Leadership [non-attendees]) and the treatment group (300 principals who have attended the Institute [attendees]). The second section describes the descriptive and statistical analysis of the responses by each survey question of both groups.

The final section describes the narrative responses of both groups to the following three questions: (1) Has the West Virginia Institute for $21^{\text {st }}$-Century Leadership had any influence on your school-improvement efforts? If yes, please explain. (2) What do you believe are the greatest challenges to your school in developing students who can be successful, productive citizens? (3) What kinds(s) of professional development would be most helpful to you as an education leader?

The $t$-test, which is used in this data analysis, is the statistical calculation that determines whether the means of the responses of the comparison group and the treatment group are significantly different at a probability level of .05. In determining significance, the $t$-test makes adjustments for the fact that the distribution of scores for small samples becomes increasingly different from the normal distribution as sample sizes become increasingly smaller. Even if the null hypothesis is true, it is not expected that two sample means will be identical. There will be some chance variation. The $t$-test for the two independent samples is a parametric test of 
significance that determines whether the observed difference is sufficiently larger than the difference that would be expected solely by chance (Gay, et al., 2006).

The significance of the difference between two populations is also measured with the Mann-Whitney $U$ test, the nonparametric equivalent of the parametric $t$-test, which may be considered a useful alternative to the $t$-test when the parametric assumptions cannot be met and when the observations are expressed in at least ordinal scale values (Best \& Kahn, 1998, p. 420). Suskie (1996) recommends conducting both parametric and non-parametric analyses. If the results are the same for both, the parametric results can be confidently reported. If they differ, the nonparametric reports should be reported.

Also used in this analysis is the calculation of the effect size, representing the power of the treatment. Effect size is expressed as a decimal number, and although numbers greater than 1.00 are possible, they do not occur very often. An effect size near .00 means that, on average, experimental and comparison groups performed the same; a positive effect size means that, on average, the experimental group performed better; and a negative effect size means that, on average, the comparison group did better. For positive effect sizes, the larger the number, the more effective the experimental treatment is. Although there are no hard and fast rules, it is generally agreed that an effect size in the twenties (e.g., .28) indicates a treatment that produces a relatively small effect, whereas an effect size in the eighties (e.g., 81) indicates a powerful treatment (Gay, et al., 2006).

Gay, Mills, and Airasian (2006) write that a good way to report results in a Likert-like scale is to group items into clusters that address the same issue and develop total scores across an item cluster. Analysis of the responses in this study corresponds well to this approach, because the 70 statements on the questionnaire are divided into the seven domains of the Framework for 
High-Performing Schools, (1) Culture of Common Beliefs and Values Dedicated to Learning for All; (2) Curriculum Management; (3) Instructional Practices; (4) School Effectiveness; (5) Student and Parent Support; (6) Systemic, Continuous Improvement; and (7) $21^{\text {st }}$-Century Skills.

The null and alternative hypotheses for each of the seven domains are:

$H_{0}$ : There is no statistically significant difference in Domain X scores when comparing individuals who have participated in the West Virginia Institute for $21^{\text {st }}$-Century Leadership with those who have not attended the Institute. $H_{0}: \mu_{1}=\mu_{2}$

$H_{\mathrm{a}}$ : There is a statistically significant difference in Domain X scores when comparing individuals who have participated in the West Virginia Institute for $21^{\text {st }}$-Century Leadership with those who have not attended the Institute. $H_{0}: \mu_{1} \neq \mu_{2}$

\section{Descriptive and Statistical Analysis by Domain}

Of the 600 principals asked to participate in the survey, 405 responded to the survey. Of this number, 366 completed all or most of the survey, creating a response rate of 61 percent. The comparison group respondents (Institute non-attendees) were comprised of 91 males (24.86 percent of the total number of respondents) and 84 females ( 22.95 percent). The treatment group respondents (Institute attendees) were comprised of 103 males (28.14 percent) and 88 females (24.04 percent).

Overall, 405 principals responded in part to the survey. There were 369 principals who answered the question regarding the grade levels in their schools. Of these, 200 were at the elementary-school programmatic level, 101 at the middle-school level, and 68 at the high-school level. There were considerably more respondents from the treatment group than the comparison group at the middle-school level (Grade $6=65$ treatment, 38 comparison; Grade $7=63$ 
treatment, 36 comparison; and Grade $8=65$ treatment, 37 comparison). It should also be noted that the majority of survey respondents were from the elementary programmatic level. The mean scores of both groups of the principals in all seven domains indicate that they agree (although they do not strongly agree) that their schools are high performing. There was a statistically significant difference between the comparison and treatment Groups in two domains: Instructional Practices and $21^{\text {st }}$-Century Skills (see Figure 11). An analysis of the results by domain follows.

\section{Domain 1: Culture of Common Beliefs and Values Dedicated to Learning for All}

The analysis of the respondents' scores for Domain 1 showed that there was no statistical difference between the responses of the principals who attended the West Virginia Institute for $21^{\text {st }}$-Century Leadership and those who did not attend the Institute. The explanation of this analysis follows. Domain 1 contains the cluster of the following eight questions:

1. I believe all children can achieve mastery of the essential curriculum, given appropriate time and conditions.

2. I believe that everyone involved with my school has an important role in creating the conditions necessary for all student to achieve.

3. I believe that everyone at my school sets high standards in all aspects that are essential for all students to achieve.

4. I believe it is essential that the school principal provides strong instructional leadership in order to achieve mastery for all.

5. I believe that highly qualified personnel are necessary to develop a culture that will allow all students to achieve mastery. 
Figure 11. Comparison of Group Means by Domain

\begin{tabular}{|c|c|c|c|c|c|c|c|c|c|c|c|c|c|}
\hline \multicolumn{14}{|c|}{ Comparison of Means -- Independent Samples Test - by Domain } \\
\hline \multicolumn{5}{|c|}{$\begin{array}{l}\text { (Group: } 1 \text { = Comparison, } 2=\text { Treatment) } \\
\text { (Equal variances assumed unless indicated) } \\
\text { ( } * *=\text { statistically significant) }\end{array}$} & \multicolumn{2}{|c|}{$\begin{array}{l}\text { Levene's Test } \\
\text { for Equality of } \\
\text { Variances }\end{array}$} & \multicolumn{7}{|c|}{$t$ - Test for Equality of Means } \\
\hline \multirow[b]{2}{*}{ Group } & \multirow[b]{2}{*}{$\mathrm{N}$} & \multirow[b]{2}{*}{ Mean } & \multirow{2}{*}{$\begin{array}{l}\text { Std. } \\
\text { Dev. }\end{array}$} & \multirow{2}{*}{$\begin{array}{l}\text { Std. } \\
\text { Error } \\
\text { Mean }\end{array}$} & \multirow[b]{2}{*}{$\mathrm{F}$} & \multirow[b]{2}{*}{ Sig. } & \multirow[b]{2}{*}{$t$} & \multirow[b]{2}{*}{$\mathrm{df}$} & \multirow{2}{*}{$\begin{array}{l}\text { Sig. } \\
2- \\
\text { tailed }\end{array}$} & \multirow{2}{*}{$\begin{array}{c}\text { Mean } \\
\text { Diff. }\end{array}$} & \multirow{2}{*}{$\begin{array}{l}\text { Std. } \\
\text { Error } \\
\text { Diff. }\end{array}$} & \multicolumn{2}{|c|}{$\begin{array}{l}\text { 95\% Confidence } \\
\text { Interval of the } \\
\text { Difference }\end{array}$} \\
\hline & & & & & & & & & & & & Lower & Upper \\
\hline \multicolumn{14}{|c|}{ DOMAIN 1: Culture of Common Beliefs and Values Dedicated to Learning for All } \\
\hline 1 & 195 & 33.60 & 3.6004 & .25783 & & & & & & & & & \\
\hline 2 & 207 & 33.95 & 3.0113 & .20930 & 8.168 & .004 & -1.059 & 378.9 & .290 & -.35169 & .33209 & -1.005 & .30128 \\
\hline \multicolumn{14}{|c|}{ Equal variances not assumed; calculations adjusted. } \\
\hline \multicolumn{14}{|c|}{ DOMAIN 2: Curriculum Management } \\
\hline 1 & 185 & 33.60 & 4.6154 & .33933 & \multirow[b]{2}{*}{1.223} & \multirow[b]{2}{*}{.269} & \multirow[b]{2}{*}{.600} & \multirow[b]{2}{*}{387} & \multirow[b]{2}{*}{.549} & \multirow[b]{2}{*}{.27107} & \multirow[b]{2}{*}{.45198} & \multirow[b]{2}{*}{-.6176} & \multirow[b]{2}{*}{1.15972} \\
\hline 2 & 204 & 33.32 & 4.2934 & .30095 & & & & & & & & & \\
\hline DOMA & 3: Inst & uctional & ractices & & & & & & & & & & \\
\hline 1 & 184 & 45.05 & 6.1542 & .45369 & & & & & & & & & \\
\hline 2 & 199 & 43.49 & 6.5452 & .46398 & .052 & .820 & 2.409 & 381 & $.016 *$ & 1.56691 & .65050 & .2879 & 2.84593 \\
\hline DOMA & 4: Sch & ol Effect & veness & & & & & & & & & & \\
\hline 1 & 183 & 61.29 & 8.2869 & .61259 & & & & & & & & & \\
\hline 2 & 195 & 59.99 & 8.3326 & .59671 & .413 & .521 & 1.517 & 376 & .130 & 1.29714 & .85533 & -.2847 & 2.97897 \\
\hline DOMA & 5: Stu & ent and & arent Su & port & & & & & & & & & \\
\hline 1 & 178 & 40.11 & 5.5230 & .41397 & & & & & & & & & \\
\hline 2 & 195 & 39.34 & 5.8986 & .42241 & .388 & .534 & 1.149 & 371 & .251 & .68169 & .59322 & -.4848 & 1.84818 \\
\hline DOMA & 6: Sys & emic, Co & tinuous I & proveme & & & & & & & & & \\
\hline 1 & 177 & 24.72 & 2.9766 & .22373 & & & & & & & & & \\
\hline 2 & 194 & 24.61 & 3.0493 & .21893 & .003 & .958 & .357 & 369 & .721 & .11184 & .31338 & -.5044 & .72807 \\
\hline DOMA & $7: 21^{\mathrm{s}}$ & Century & kills & & & & & & & & & & \\
\hline 1 & 178 & 54.05 & 5.3949 & .40437 & & & & & & & & & \\
\hline 2 & 194 & 55.30 & 4.8717 & .34977 & 6.244 & .013 & -2.350 & 357.4 & $.019 * *$ & -1.25660 & .53465 & -2.308 & -.20515 \\
\hline
\end{tabular}


6. I believe it IS NOT essential to treat parents as valued partners in order for all students to achieve mastery.

7. I believe the primary measure of school success is the number of students who achieve mastery of the essential curriculum.

8. I believe there must be a school-wide, continuous-improvement process in place in order for all students to achieve.

Domain 1 contained 8 questions. A respondent who perceived that his school was at the highest at the highest level of performance would have shown a score of 40 in this domain. The number $(N)$ of comparison group respondents was 195 with a mean score of 33.60 and a standard standard deviation of 3.6004. The treatment group $\mathrm{N}$ was 207 with a mean score of 33.95 and a standard deviation of 3.0113. Levene's Test for Equality of Variances was significant at .004; indicating; that equal variances were not assumed, and the calculation was adjusted accordingly. The $t$-Test for Equality of Means showed a two-tailed significance level of .290, which is greater than the .05 alpha level; therefore, the null hypothesis is not rejected. There is no significant difference in the scores of the comparison and treatment groups in Domain 1. The MannWhitney $U$ test, the nonparametric equivalent of the parametric $t$-test, verifies the lack of a statistically significant difference with a significance level of .507 , which is greater than the alpha .05 level.

\section{Domain 2: Curriculum Management}

The analysis of the respondents' scores for Domain 2 showed that there was no statistical difference between the responses of the principals who attended the West Virginia Institute for 
$21^{\text {st }}$-Century Leadership and those who did not attend the Institute. The explanation of this analysis follows. Domain 2 contains the cluster of the following eight questions:

9. I have provided the means for my teachers to develop a rigorous curriculum aligned with the West Virginia Content Standards and Objectives.

10. I have provided the means for my teachers to prioritize and map curriculum objectives.

11. All the teachers in my school use performance benchmarks to measure student achievement.

12. All the teachers in my school use formative assessments that align with county performance benchmarks.

13. My school IS NOT using a standards-based program to assure all students are proficient in reading.

14. My school is using a standards-based program to assure all students are proficient in math.

15. I have implemented a teacher support system for enhancing curriculum quality, such as peer-unit development, technology supports, and contentspecific professional development.

16. I have a process in place to monitor the curriculum in order to gather information for improvement.

Domain 2 contained 8 questions. A respondent who perceived that his school was at the highest level of performance would have shown a score of 40 in this domain. The 
comparison group $\mathrm{N}$ was 185 with a mean score of 33.60 and a standard deviation of 4.6154 .

The treatment group $\mathrm{N}$ was 204 with a mean score of 33.32 and a standard deviation of 4.2934. Levene's Test for Equality of Variances was not significant at .269; indicating that equal variances were assumed. The $t$-Test for Equality of Means showed a two-tailed significance level of .549 which is greater than the .05 alpha level; therefore, the null hypothesis is not rejected. There is no significant difference in the scores of the comparison and treatment groups in Domain 2. The Mann Whitney $U$ test, the nonparametric equivalent of the parametric $t$-test, verifies this with a significance level of .398 , which is greater than the alpha .05 level.

\section{Domain 3: Instructional Practices}

The analysis of the respondents' scores for Domain 3 showed that there was a statistical difference between the responses of the principals who attended the West Virginia Institute for $21^{\text {st }}$-Century Leadership and those who did not attend the Institute. The scores of the principals in the comparison group (those who had not attended the Institute) perceived their schools to be higher performing in the domain of Instructional Practices than the principals who had attended the Institute. The explanation of this analysis follows. Domain 3 contains the cluster of the following 11 questions:

17. The teachers in my school show respect for all students regardless of individual differences.

18. The classrooms in my school ARE NOT focused, productive, and well organized.

19. The students in my school are being developed into self-directed learners who are responsible for improving their own work.

20. The teachers in my school use differentiated instruction to meet the varied needs of learners. 
21. The teachers in my school use research-based, high-yield instructional strategies in all classrooms.

22. The teachers in my school use performance assessments to determine the level of student mastery.

23. The teachers in my school adjust instructional time by grade, class, and subject to meet the various learning needs of students.

24. Writing-to-inform strategies are used in all classrooms in my school in all content areas.

25. Comprehension development strategies are used in all classrooms in my school in all content areas.

26. The teachers in my school use such practices as scaffolding and previewing to help accelerate student achievement.

27. There is a teacher instructional support system that provides time and assistance to teachers for such things as data analysis, cooperative planning, observation and feedback, reflective practice, and professional growth.

Domain 3 contained 11 questions. A respondent who perceived that his school was at the highest level of performance would have shown a score of 55 in this domain. The comparison group $\mathrm{N}$ was 184 with a mean score of 45.06 and a standard deviation of 6.1542. Levene's Test for Equality of Variances was not significant at .820; indicating that equal variances were assumed. The $t$-Test for Equality of Means showed a two-tailed significance level of .016 which is less than the .05 alpha level; therefore, the null hypothesis is rejected. There is a significant difference in the scores of the comparison and treatment groups in Domain 3. The effect size, $d$ calculation, is .25 indicating a small effect of the difference made by the treatment. 
The Mann-Whitney $U$ test, the nonparametric equivalent of the parametric $t$-test, verifies the statistically significant difference in the two groups with a significance level of .009 , which is less than the alpha .05 level.

\section{Domain 4: School Effectiveness}

The analysis of the respondents' scores for Domain 4 showed that there was no statistical difference between the responses of the principals who attended the West Virginia Institute for $21^{\text {st }}$-Century Leadership and those who did not attend the Institute. The explanation of this analysis follows. Domain 4 contains the cluster of the following 15 questions:

28. We have a culture of support, trust, and collaboration between our school and the county office focused on creating conditions for all students' success.

29. Our school has developed a clear mission that provides focus to school improvement efforts.

30. Our school has a set of core beliefs to provide focus to school-improvement efforts.

31. Our school HAS NOT set performance goals to provide focus to school improvement.

32. Our school has a strategic plan to provide focus to school improvement efforts.

33. Our school-improvement team members have had professional development training on strategic planning.

34. Our school-improvement team members have had professional development training on continuous improvement.

35. Our school-improvement team members have had professional development training on the correlates of effective schools. 
36. Our school-improvement team members have time to collaborate, develop, and annually revise the five-year strategic plan.

37. Our school has a data management system to analyze data trends and establish priorities.

38. Our school has a learning community focused on strategies to achieve school performance goals.

39. Teachers in our school are provided professional development training aligned with the school's improvement plan.

40. Our county has a monitoring system that requires continuous progress and accountability for results as outlined in the school and district plan.

41. Our teachers are provided time prior to and during the instructional term for meaningful staff planning, collaboration, and problem solving related to the school's performance goals.

42. Our county office has a school monitoring system to gather information on quality of overall school operations and the presence of the correlates of effective schools.

Domain 4 contained 15 questions. A respondent who perceived that his school was at the highest level of performance would have shown a score of 75 in this domain. The comparison group $\mathrm{N}$ was 183 with a mean score of 61.29 and a standard deviation of 8.2869 . The treatment group $\mathrm{N}$ was 195 with a mean score of 59.99 and a standard deviation of 8.3326. Levene's Test for Equality of Variances was not significant at .521; indicating that equal variances were assumed. The $t$-Test for Equality of Means showed a two-tailed significance level of .130 which is greater than the .05 alpha level; therefore, the null hypothesis is not rejected. There is no significant difference in the scores of the comparison and treatment groups in Domain 4. The 
Mann-Whitney $U$ test, the nonparametric equivalent of the parametric $t$-test, verifies this with a significance level of .078, which is greater than the alpha .05 level.

\section{Domain 5: Student and Parent Support}

The analysis of the respondents' scores for Domain 5 showed that there was no statistical difference between the responses of the principals who attended the West Virginia Institute for $21^{\text {st }}$-Century Leadership and those who did not attend the Institute. The explanation of this analysis follows. Domain 5 contains the cluster of the following ten questions:

43. Our school uses research-based, innovative approaches to meet the specific academic and social/emotional needs of all learners.

44. Our school has a developmental guidance program that includes a strong character education focus.

45. Our school has a developmental guidance program that includes a career development focus.

46. Our school has an effective process for successfully transitioning students from one school to the next.

47. Our school DOES NOT have a coordinated and proactive plan to enhance parent involvement.

48. Our school has a coordinated and proactive plan to improve parent communication.

49. Our school has a coordinated and proactive plan to support parent education.

50. Our school has a coordinated and proactive plan to build a partnership with parents of low-performing students. 
51. Our school has a process for connecting students and families to community agencies, health services, counseling, and other services that promote student success.

52. Our school has a data analysis process on such things as student attendance, discipline trends, grade distribution, and participation in extra-curricular activities for monitoring student success and targeting specific interventions.

Domain 5 contained 10 questions. A respondent who perceived that his school was at the highest level of performance would have shown a score of 50 in this domain. The comparison group $\mathrm{N}$ was 178 with a mean score of 40.11 and a standard deviation of 5.5230. The treatment group $\mathrm{N}$ was 195 with a mean score of 39.34 and a standard deviation of 5.8986. Levene's Test for Equality of Variances was not significant at .534; indicating that equal variances were assumed. The $t$-Test for Equality of Means showed a two-tailed significance level of .251 which is greater than the .05 alpha level; therefore, the null hypothesis is not rejected. There is no significant difference in the scores of the comparison and treatment groups in Domain 5. The Mann Whitney $U$ test, the nonparametric equivalent of the parametric $t$-test, verifies this with a significance level of .312, which is greater than the alpha .05 level.

\section{Domain 6: Systemic, Continuous Improvement}

The analysis of the respondents' scores for Domain 5 showed that there was no statistical difference between the responses of the principals who attended the West Virginia Institute for $21^{\text {st }}$-Century Leadership and those who did not attend the Institute. The explanation of this analysis follows. Domain 6 contains the cluster of the following six questions:

53. I use a transformational leadership approach to create a learning-centered school.

54. There is an expectation in my school that change will be an ongoing, continuous process. 
55. In my school, there IS NOT a broad understanding and commitment to the need for change.

56. There is a focus on the whole school in the design and implementation of our school's programs.

57. In our school, personnel understand that change involves system activities and resources that are connected.

58. Before we implement a program in our school, we first plan it, then implement it, then evaluate its effects, and act on our evaluation.

Domain 6 contained six questions. A respondent who perceived that his school was at the highest level of performance would have shown a score of 30 in this domain. The comparison group $\mathrm{N}$ was 177 with a mean score of 24.72 and a standard deviation of 2.9766 . The treatment group $\mathrm{N}$ was 194 with a mean score of 24.61 and a standard deviation of 3.0493. Levene's Test for Equality of Variances was not significant at .958; indicating that equal variances were assumed. The $t$-Test for Equality of Means showed a two-tailed significance level of .721 which is greater than the .05 alpha level; therefore, the null hypothesis is not rejected. There is no significant difference in the scores of the comparison and treatment groups in Domain 6. The Mann Whitney $U$ test, the nonparametric equivalent of the parametric $t$-test, verifies this with a significance level of .987 , which is greater than the alpha .05 level.

\section{Domain 7: $21^{\text {st }}$-Century Skills}

The analysis of the respondents' scores for Domain 7 showed that there was a statistical difference between the responses of the principals who attended the West Virginia Institute for $21^{\text {st }}$-Century Leadership and those who did not attend the Institute. The scores of the principals in the treatment group (those who had attended the Institute) perceived their schools to be higher 
performing in the domain of instructional practices than the principals who had not attended the Institute. The explanation of this analysis follows. Domain 7 contains the cluster of the following 12 questions:

59. I DO NOT believe students need core subjects (English, reading, math, science, and social studies) in order to be successful.

60. Awareness of happenings around the world is important for students' future success.

61. Understanding business and finance is important for students' future success.

62. Knowledge of government is important for students' future success.

63. Health and wellness awareness is important for students' future success.

64. Information and communication skills are important for students' future success

65. Thinking and problem-solving skills are important for students' future success.

66. Interpersonal and self-directional skills are important for students' future success.

67. Twenty-first-century tools (computers and other technology) should be used with learning skills in order for students to be successful.

68. Ethics, including personal responsibility, are important for students' success.

69. Self-direction and social responsibility are important for students' success.

70. Student assessments should measure thinking skills in addition to knowledge of core subjects.

Domain 7 contained 12 questions. A respondent who perceived that his school was at the highest level of performance would have shown a score of 60 in this domain. The comparison group $\mathrm{N}$ was 178 with a mean score of 54.05 and a standard deviation of 5.3949. The treatment group $\mathrm{N}$ was 194 with a mean score of 55.30 and a standard deviation of 4.8717. Levene's Test 
for Equality of Variances was significant at .013; indicating that equal variances were not assumed, and the calculation was adjusted accordingly. The $t$-Test for Equality of Means showed a two-tailed significance level of .019 which is less than the .05 alpha level; therefore, the null hypothesis is rejected. There is a significant difference in the scores of the comparison and treatment groups in Domain 7. The effect size, Cohen's $d$ calculation, is .24 indicating a small effect size of the difference made by the treatment. The Mann-Whitney $U$ test, the nonparametric equivalent of the parametric $t$-test, verifies the statistically significant difference in the two groups with a significance level of .020 , which is less than the alpha .05 level.

\section{Descriptive and Statistical Analysis by Question}

Of the 70 survey statements to which principals responded, there were statistically significant differences in 16 of them (see Appendix B). The principals in the comparison group (Institute non-attendees) had a higher mean score, thus perceiving their schools were higher performing than the treatment group (Institute attendees) in regard to eight of the statements. Likewise, principals in the treatment group perceived their schools to be higher performing in regard to eight statements.

Mean scores of principals in the Comparison Group were higher on statements relating to instructional practices. Mean scores of principals in the treatment group were higher on statements relating to $21^{\text {st }}$-century skills. An explanation of the statistical analysis of responses to each survey item follows.

\section{Survey Item 1}

Item 1 was the statement: I believe all children can achieve mastery of the essential curriculum, given appropriate time and conditions. The analysis of the respondents' scores for survey Item 1 showed that there was a statistical difference between the responses of the 
principals who attended the West Virginia Institute for $21^{\text {st }}$-Century Leadership and those who did not attend the Institute. The scores of the principals in the treatment group (those who had attended the Institute) perceived their schools to be higher performing than the principals who had not attended the Institute. The explanation of this analysis follows.

The comparison group $\mathrm{N}$ was 192 with a mean score of 3.505 and a standard deviation of 1.1889. The treatment group $\mathrm{N}$ was 203 with a mean score of 3.754 and a standard deviation of 1.3383. Levene's Test for Equality of Variances was significant at .044; indicating that equal variances were not assumed, and the calculation was adjusted accordingly. The $t$-Test for Equality of Means showed a two-tailed significance level of .034, which is less than the .05 alpha level; therefore, the null hypothesis is rejected. There is a significant difference in the scores of the comparison and treatment groups in Item 1. The effect size, $d$ calculation, is -.20, indicating a small effect of the difference made by the treatment. The negative $d$ indicates that the comparison group scores were larger than the treatment group. The Mann-Whitney $U$ test, the nonparametric equivalent of the parametric $t$-test, verifies the statistically significant difference in the two groups with a significance level of .043, which is less than the alpha .05 level (see Figure 12).

Survey Item 2

Item 2 was the statement: I believe that everyone involved with my school has an important role in creating the conditions necessary for all students to achieve. The analysis of the analysis of the respondents' scores for survey Item 2 showed that there was no statistical difference between the responses of the principals who attended the West Virginia Institute for $21^{\text {st }}$-Century Leadership and those who did not attend the Institute. The explanation of this analysis follows. 
Figure 12. Statement 1: I believe all children can achieve mastery of the essential curriculum, given appropriate time and conditions.

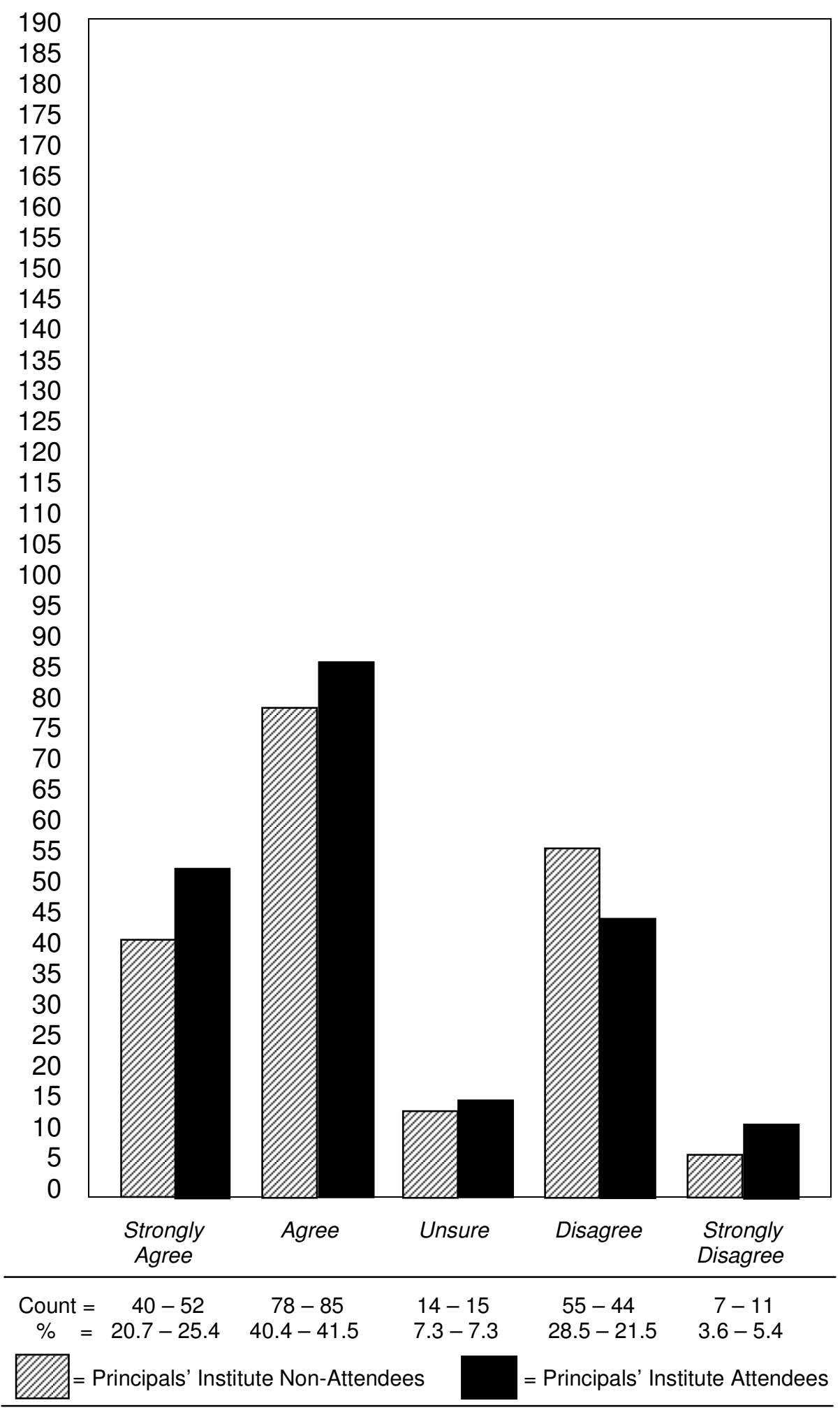

Non-Attendees: 193 answered; 3 skipped question. Attendees: 205 answered; 4 skipped question. 
The comparison group $\mathrm{N}$ was 192 with a mean score of 4.828 and a standard deviation of .45088. The treatment group $\mathrm{N}$ was 207 with a mean score of 4.826 and a standard deviation of .40470. Levene's Test for Equality of Variances was not significant at .983; indicating that equal variances were assumed. The $t$-Test for Equality of Means showed a two-tailed significance level of .093, which is greater than the .05 alpha level; therefore, the null hypothesis is not rejected. There is not a significant difference in the scores of the comparison and treatment groups in Item 2. The Mann-Whitney $U$ test, the nonparametric equivalent of the parametric $t$-test, verifies the lack of a statistically significant difference in the two groups with a significance level of .883, which is greater than the alpha .05 level.

Survey Item 3

Item 3 was the statement: I believe that everyone at my school sets high standards in all aspects that are essential for all students to achieve. The analysis of the respondents' scores for survey Item 2 showed that there was no statistical difference between the responses of the principals who attended the West Virginia Institute for $21^{\text {st }}$-Century Leadership and those who did not attend the Institute. The explanation of this analysis follows.

The comparison group $\mathrm{N}$ was 195 with a mean score of 4.164 and a standard deviation of .85780 . The treatment group $\mathrm{N}$ was 207 with a mean score of 4.135 and a standard deviation of .81316. Levene's Test for Equality of Variances was not significant at .312; indicating that equal variances were assumed. The $t$-Test for Equality of Means showed a two-tailed significance level of .730, which is greater than the .05 alpha level; therefore, the null hypothesis is not rejected. There is not a significant difference in the scores of the comparison and treatment groups in Item 3. The Mann-Whitney $U$ test, the nonparametric equivalent of the parametric $t$-test, verifies the 
lack of a statistically significant difference in the two groups with a significance level of .586, which is greater than the alpha .05 level.

\section{Survey Item 4}

Item 4 was the statement: I believe it is essential that the school principal provides strong instructional leadership in order to achieve mastery for all. The analysis of the respondents' scores for survey Item 4 showed that there was no statistical difference between the responses of the principals who attended the West Virginia Institute for $21^{\text {st }}$-Century Leadership and those who did not attend the Institute. The explanation of this analysis follows.

The comparison group $\mathrm{N}$ was 193 with a mean score of 4.782 and a standard deviation of .50446. The treatment group $\mathrm{N}$ was 206 with a mean score of 4.806 and a standard deviation of .39653. Levene's Test for Equality of Variances was not significant at .178; indicating that equal variances were assumed. The $t$-Test for Equality of Means showed a two-tailed significance level of .605, which is greater than the .05 alpha level; therefore, the null hypothesis is not rejected. There is not a significant difference in the scores of the comparison and treatment groups in Item 4. The Mann-Whitney $U$ test, the nonparametric equivalent of the parametric $t$-test, verifies the lack of a statistically significant difference in the two groups with a significance level of .096, which is greater than the alpha .05 level.

\section{Survey Item 5}

Item 5 was the statement: I believe that highly qualified personnel are necessary to develop a culture that will allow all students to achieve mastery. The analysis of the respondents' scores for survey Item 5 showed that there was no statistical difference between the responses of the principals who attended the West Virginia Institute for $21^{\text {st }}$-Century Leadership and those who did not attend the Institute. The explanation of this analysis follows. 
The comparison group $\mathrm{N}$ was 194 with a mean score of 4.438 and a standard deviation of .78112. The treatment group $\mathrm{N}$ was 207 with a mean score of 4.488 and a standard deviation of .69576. Levene's Test for Equality of Variances was not significant at .182; indicating that equal variances were assumed. The $t$-Test for Equality of Means showed a two-tailed significant difference in the scores of the comparison and treatment groups in Item 5. The Mann-Whitney $U$ test, the nonparametric equivalent of the parametric $t$-test, verifies the lack of a significance level of .500 , which is greater than the .05 alpha level; therefore, the null hypothesis is not rejected. There is not a statistically significant difference in the two groups with a significance level of .825 , which is greater than the alpha .05 level.

\section{Survey Item 6}

Item 6 was the statement: I believe it IS NOT essential to treat parents as valued partners as valued partners in order for all students to achieve mastery. The analysis of the respondents' scores for survey Item 6 showed that there was no statistical difference between the responses of the principals who attended the West Virginia Institute for $21^{\text {st }}$-Century Leadership and those who did not attend the Institute. The explanation of this analysis follows.

The comparison group $\mathrm{N}$ was 193 with a mean score of 4.580 and a standard deviation of .66538. The treatment group $\mathrm{N}$ was 205 with a mean score of 4.571 and a standard deviation of .63487. Levene's Test for Equality of Variances was not significant at .739; indicating that equal variances were assumed. The $t$-Test for Equality of Means showed a two-tailed significance level of .883 , which is greater than the .05 alpha level; therefore, the null hypothesis is not rejected. There is not a significant difference in the scores of the comparison and treatment groups in Item 6. The Mann-Whitney $U$ test, the nonparametric equivalent of the parametric $t$-test, verifies the 
lack of a statistically significant difference in the two groups with a significance level of .717, which is greater than the alpha .05 level.

\section{Survey Item 7}

Item 7 was the statement: I believe the primary measure of school success is the number of students who achieve mastery of the essential curriculum. The analysis of the respondents' scores for survey Item 7 showed that there was no statistical difference between the responses of the principals who attended the West Virginia Institute for $21^{\text {st }}$-Century Leadership and those who did not attend the Institute. The explanation of this analysis follows.

The comparison group $\mathrm{N}$ was 192 with a mean score of 3.234 and a standard deviation of .1.2118. The treatment group $\mathrm{N}$ was 207 with a mean score of 3.092 and a standard deviation of .1.1549. Levene's Test for Equality of Variances was not significant at .084; indicating that equal variances were assumed. The $t$-Test for Equality of Means showed a two-tailed significance level of .230 , which is greater than the .05 alpha level; therefore, the null hypothesis is not rejected. There is not a significant difference in the scores of the comparison and treatment groups in Item 7. The Mann-Whitney $U$ test, the nonparametric equivalent of the parametric $t-$ test, verifies the lack of a statistically significant difference in the two groups with a significance level of .289 , which is greater than the alpha .05 level.

\section{Survey Item 8}

Item 8 was the statement: I believe there must be a school-wide, continuous-improvement process in place in order for all students to achieve. The analysis of the respondents' scores for survey Item 8 showed that there was no statistical difference between the responses of the principals who attended the West Virginia Institute for $21^{\text {st }}$-Century Leadership and those who did not attend the Institute. The explanation of this analysis follows. The comparison group $\mathrm{N}$ 
was 192 with a mean score of 4.432 and a standard deviation of .62922. The treatment group $\mathrm{N}$ was 206 with a mean score of 4.442 and a standard deviation of .58768 . Levene's Test for Equality of Variances was not significant at .317; indicating that equal variances were assumed. The $t$-Test for Equality of Means showed a two-tailed significance level of .877 , which is greater than the .05 alpha level; therefore, the null hypothesis is not rejected. There is not a significant difference in the scores of the comparison and treatment groups in Item 8. The Mann-Whitney $U$ test, the nonparametric equivalent of the parametric $t$-test, verifies the lack of a statistically significant difference in the two groups with a significance level of .992, which is greater than the alpha .05 level.

\section{Survey Item 9}

Item 9 was the statement: I have provided the means for my teachers to develop a rigorous curriculum aligned with the West Virginia Content Standards and Objectives. The analysis of the respondents' scores for survey Item 9 showed that there was no statistical difference between the responses of the principals who attended the West Virginia Institute for $21^{\text {st }}$-Century Leadership and those who did not attend the Institute. The explanation of this analysis follows.

The comparison group $\mathrm{N}$ was 192 with a mean score of 4.432 and a standard deviation of .62922. The treatment group $\mathrm{N}$ was 206 with a mean score of 4.442 and a standard deviation of .58768. Levene's Test for Equality of Variances was not significant at .317; indicating that equal variances were assumed. The $t$-Test for Equality of Means showed a two-tailed significance level of .877 , which is greater than the .05 alpha level; therefore, the null hypothesis is not rejected. There is not a significant difference in the scores of the comparison and treatment groups in Item 8. The Mann-Whitney $U$ test, the nonparametric equivalent of the parametric $t$-test, verifies the 
lack of a statistically significant difference in the two groups with a significance level of .992, which is greater than the alpha .05 level.

Survey Item 10

Item 10 was the statement: I have provided the means for my teachers to prioritize and map curriculum objectives. The analysis of the respondents' scores for survey Item 10 showed that there was no statistical difference between the responses of the principals who attended the West Virginia Institute for $21^{\text {st }}$-Century Leadership and those who did not attend the Institute. The explanation of this analysis follows.

The comparison group $\mathrm{N}$ was 183 with a mean score of 4.290 and a standard deviation of .75466. The treatment group $\mathrm{N}$ was 203 with a mean score of 4.337 and a standard deviation of .69345. Levene's Test for Equality of Variances was not significant at .400; indicating that equal variances were assumed. The $t$-Test for Equality of Means showed a two-tailed significance level of .517 , which is greater than the .05 alpha level; therefore, the null hypothesis is not rejected. There is not a significant difference in the scores of the comparison and treatment groups in Item 10. The Mann-Whitney $U$ test, the nonparametric equivalent of the parametric $t$-test, verifies the lack of a statistically significant difference in the two groups with a significance level of .693, which is greater than the alpha .05 level.

\section{Survey Item 11}

Item 11 was the statement: All the teachers in my school use performance benchmarks to measure student achievement. The analysis of the respondents' scores for survey Item 11 showed that there was a statistical difference between the responses of the principals who attended the West Virginia Institute for $21^{\text {st }}$-Century Leadership and those who did not attend the Institute. The scores of the principals in the treatment group (those who had attended the Institute) 
perceived their schools to be higher performing than the principals who had not attended the Institute. The explanation of this analysis follows.

The comparison group $\mathrm{N}$ was 182 with a mean score of 4.198 and a standard deviation of .94862. The treatment group $\mathrm{N}$ was 203 with a mean score of 3.995 and a standard deviation of .96214. Levene's Test for Equality of Variances was not significant at .273; indicating that equal variances were assumed. The $t$-Test for Equality of Means showed a two-tailed significance level of .038 , which is less than the .05 alpha level; therefore, the null hypothesis is rejected. There is a significant difference in the scores of the comparison and treatment groups in Item 11. The effect size, $d$ calculation, is .21 , indicating a small effect of the difference made by the treatment. The treatment group scores were larger than the comparison group. The Mann-Whitney $U$ test, the nonparametric equivalent of the parametric $t$-test, verifies the statistically significant difference in the two groups with a significance level of .019 , which is less than the alpha .05 level (see Figure 13).

\section{Survey Item 12}

Item 12 was the statement: All the teachers in my school use formative assessments that align with county performance benchmarks. The analysis of the respondents' scores for survey Item 12 showed that there was a statistical difference between the responses of the principals who attended the West Virginia Institute for $21^{\text {st }}$-Century Leadership and those who did not attend the Institute. The scores of the principals in the treatment group (those who had attended the Institute) perceived their schools to be higher performing than the principals who had not attended the Institute. The explanation of this analysis follows. 
Figure 13. Statement 11: All the teachers in my school use performance benchmarks to measure student achievement.

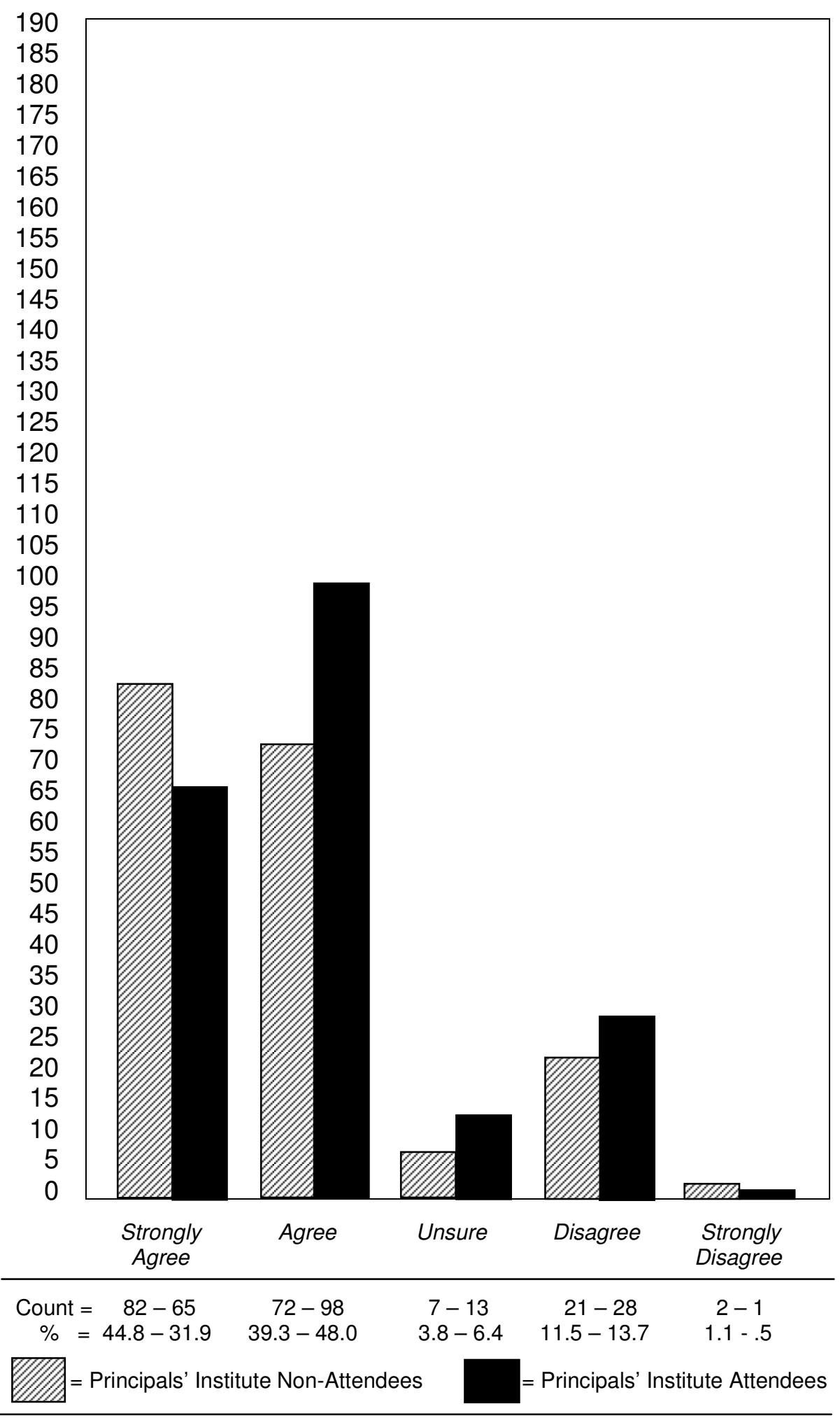

Non-Attendees: 183 answered; 13 skipped question. Attendees: 204 answered; 5 skipped question. 
The comparison group $\mathrm{N}$ was 185 with a mean score of 4.173 and a standard deviation of .97931. The treatment group $\mathrm{N}$ was 202 with a mean score of 3.921 and a standard deviation of .75852. Levene's Test for Equality of Variances was not significant at .158; indicating that equal variances were assumed. The $t$-Test for Equality of Means showed a two-tailed significance level of .010 , which is less than the .05 alpha level; therefore, the null hypothesis is rejected. There is a significant difference in the scores of the comparison and treatment groups in Item 12 . The effect size, $d$ calculation, is .26 , indicating a small effect of the difference made by the treatment. The treatment group scores were larger than the comparison group. The Mann-Whitney $U$ test, the nonparametric equivalent of the parametric $t$-test, verifies the statistically significant difference in the two groups with a significance level of .002 , which is less than the alpha .05 level (see Figure 14).

\section{Survey Item 13}

Item 13 was the statement: My school IS NOT using a standards-based program to assure all students are proficient in reading. The analysis of the respondents' scores for survey Item 13 showed that there was no statistical difference between the responses of the principals who attended the West Virginia Institute for $21^{\text {st }}$-Century Leadership and those who did not attend the Institute. The explanation of this analysis follows.

The comparison group $\mathrm{N}$ was 180 with a mean score of 4.311 and a standard deviation of .75466. The treatment group $\mathrm{N}$ was 203 with a mean score of 4.337 and a standard deviation of .82752. Levene's Test for Equality of Variances was not significant at .410; indicating that equal variances were assumed. The $t$-Test for Equality of Means showed a two-tailed significance level of .641, which is greater than the .05 alpha level; therefore, the null hypothesis is not rejected. 
Figure 14. Statement 12: All the teachers in my school use formative assessments that align with county performance benchmarks.

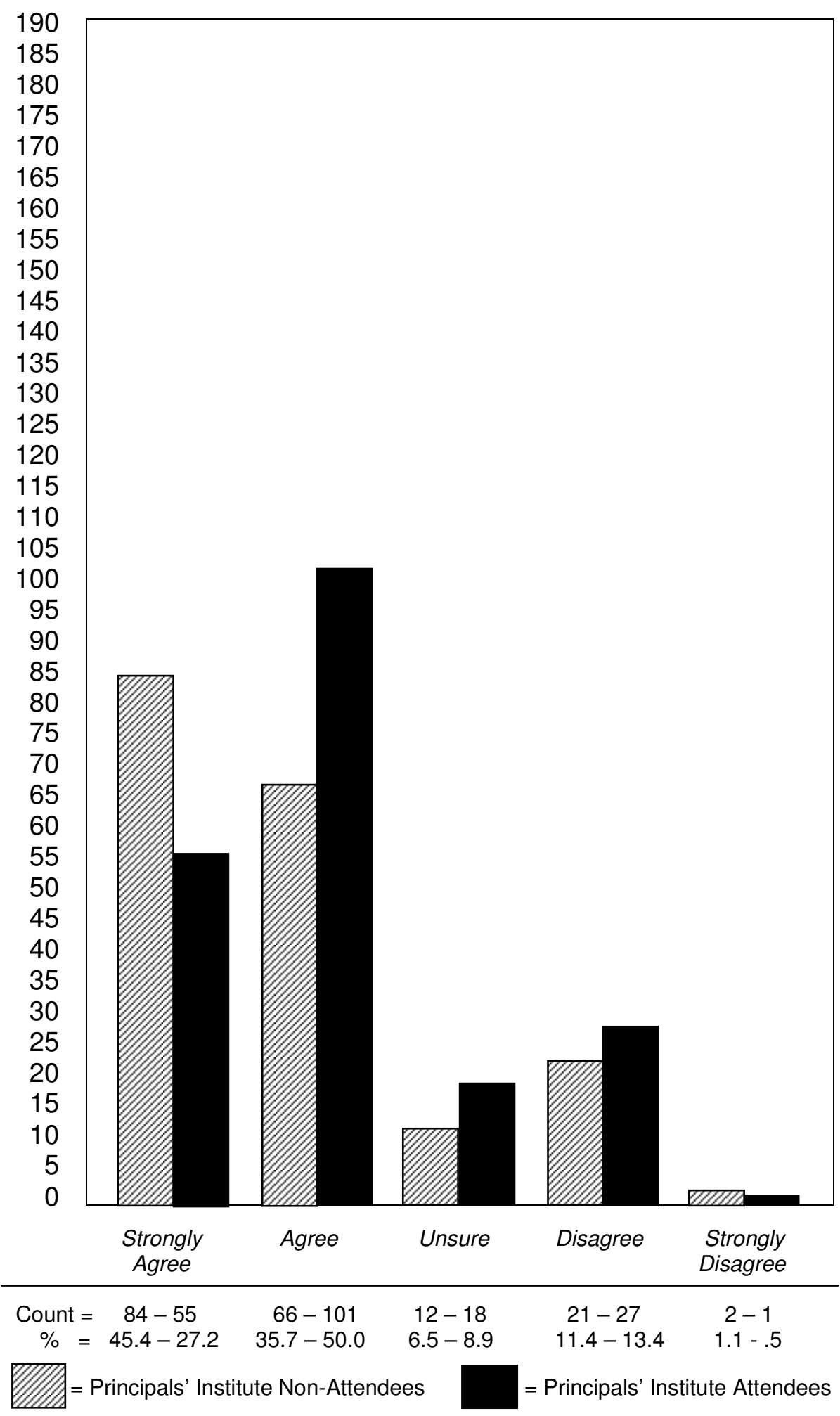

Non-Attendees: 185 answered; 11 skipped question. Attendees: 202 answered; 7 skipped question. 
There is not a significant difference in the scores of the comparison and treatment groups in Item 13. The Mann-Whitney $U$ test, the nonparametric equivalent of the parametric $t$-test, verifies the lack of a statistically significant difference in the two groups with a significance level of .874, which is greater than the alpha .05 level.

\section{Survey Item 14}

Item 14 was the statement: My school is using a standards-based program to assure all students are proficient in math. The analysis of the respondents' scores for survey Item 14 showed that there was no statistical difference between the responses of the principals who attended the West Virginia Institute for $21^{\text {st }}$-Century Leadership and those who did not attend the Institute. The explanation of this analysis follows. The comparison group $\mathrm{N}$ was 183 with a mean score of 4.281 and a standard deviation of .77657. The treatment group $\mathrm{N}$ was 201 with a mean score of 4.266 and a standard deviation of .76815. Levene's Test for Equality of Variances

was not significant at .904 ; indicating that equal variances were assumed. The $t$-Test for Equality of Means showed a two-tailed significance level of .847 , which is greater than the .05 alpha level; therefore, the null hypothesis is not rejected. There is not a significant difference in the scores of the comparison and treatment groups in Item 14. The Mann-Whitney $U$ test, the nonparametric equivalent of the parametric $t$-test, verifies the lack of a statistically significant difference in the two groups with a significance level of .803 , which is greater than the alpha .05 level.

Survey Item 15

Item 15 was the statement: I have implemented a teacher support system for enhancing curriculum quality, such as peer-unit development, technology supports, and content-specific 
professional development. The analysis of the respondents' scores for survey Item 15 showed that there was no statistical difference between the responses of the principals who attended the West Virginia Institute for $21^{\text {st }}$-Century Leadership and those who did not attend the Institute. The explanation of this analysis follows.

The comparison group $\mathrm{N}$ was 183 with a mean score of 4.104 and a standard deviation of .70527. The treatment group $\mathrm{N}$ was 201 with a mean score of 4.110 and a standard deviation of .76679. Levene's Test for Equality of Variances was not significant at .265; indicating that equal variances were assumed. The $t$-Test for Equality of Means showed a two-tailed significance level of .941, which is greater than the .05 alpha level; therefore, the null hypothesis is not rejected. There is not a significant difference in the scores of the comparison and treatment groups in Item 15. The Mann-Whitney $U$ test, the nonparametric equivalent of the parametric $t$-test, verifies the lack of a statistically significant difference in the two groups with a significance level of .729, which is greater than the alpha .05 level.

\section{Survey Item 16}

Item 16 was the statement: I have a process in place to monitor the curriculum in order to gather information for improvement. The analysis of the respondents' scores for survey Item 16 showed that there was no statistical difference between the responses of the principals who attended the West Virginia Institute for $21^{\text {st }}$-Century Leadership and those who did not attend the Institute. The explanation of this analysis follows.

The comparison group $\mathrm{N}$ was 180 with a mean score of 4.244 and a standard deviation of .52451 . The treatment group $\mathrm{N}$ was 202 with a mean score of 4.186 and a standard deviation of .67392. Levene's Test for Equality of Variances was not significant at .072; indicating that equal variances were assumed. The $t$-Test for Equality of Means showed a two-tailed significance level 
of .346, which is greater than the .05 alpha level; therefore, the null hypothesis is not rejected. There is not a significant difference in the scores of the comparison and treatment groups in Item 16. The Mann-Whitney $U$ test, the nonparametric equivalent of the parametric $t$-test, verifies the lack of a statistically significant difference in the two groups with a significance level of .721, which is greater than the alpha .05 level.

\section{Survey Item 17}

Item 17 was the statement: The teachers in my school show respect for all students regardless of individual differences. The analysis of the respondents' scores for survey Item 17 showed that there was a statistical difference between the responses of the principals who attended the West Virginia Institute for $21^{\text {st }}$-Century Leadership and those who did not attend the Institute. The scores of the principals in the treatment group (those who had attended the Institute) perceived their schools to be higher performing than the principals who had not attended the Institute. The explanation of this analysis follows.

The comparison group $\mathrm{N}$ was 184 with a mean score of 4.326 and a standard deviation of .82460 . The treatment group $\mathrm{N}$ was 198 with a mean score of 4.167 and a standard deviation of .82320. Levene's Test for Equality of Variances was not significant at .258; indicating that equal variances were assumed. The $t$-Test for Equality of Means showed a two-tailed significance level of .060 , which is greater than the .05 alpha level. The Mann-Whitney $U$ test, the nonparametric equivalent of the parametric $t$-test, however, shows a statistically significant difference in the two groups with a significance level of .030 , which is less than the alpha .05 level. When there is a difference between the parametric and non-parametric measures, the non-parametric is to be used. The null hypothesis, therefore, is rejected. There is a significant difference in the scores of the comparison and treatment groups in Item 17. The effect size, $d$ calculation, is .030, indicating 
a small effect of the difference made by the treatment. The treatment group scores were larger than the comparison group (see Figure 15).

Survey Item 18

Item 18 was the statement: The classrooms in my school ARE NOT focused, productive, and well organized. The analysis of the respondents' scores for survey Item 18 showed that there was no statistical difference between the responses of the principals who attended the West Virginia Institute for $21^{\text {st }}$-Century Leadership and those who did not attend the Institute. The explanation of this analysis follows.

The comparison group $\mathrm{N}$ was 183 with a mean score of 4.590 and a standard deviation of .60339. The treatment group $\mathrm{N}$ was 197 with a mean score of 4.462 and a standard deviation of .67372. Levene's Test for Equality of Variances was not significant at .111; indicating that equal variances were assumed. The $t$-Test for Equality of Means showed a two-tailed significance level of .052 , which is slightly greater than the .05 alpha level; therefore, the null hypothesis is not rejected. There is not a significant difference in the scores of the comparison and treatment groups in Item 16. The Mann-Whitney $U$ test, the nonparametric equivalent of the parametric $t-$ test, verifies the lack of a statistically significant difference in the two groups with a significance level of .080 , which is greater than the alpha .05 level.

Survey Item 19

Item 19 was the statement: The students in my school are being developed into selfdirected learners who are responsible for improving their own work. The analysis of the respondents' scores for survey Item 19 showed that there was a statistical difference between the responses of the principals who attended the West Virginia Institute for $21^{\text {st }}$-Century Leadership 
Figure 15. Statement 17: The teachers in my school show respect for all students regardless of individual differences.

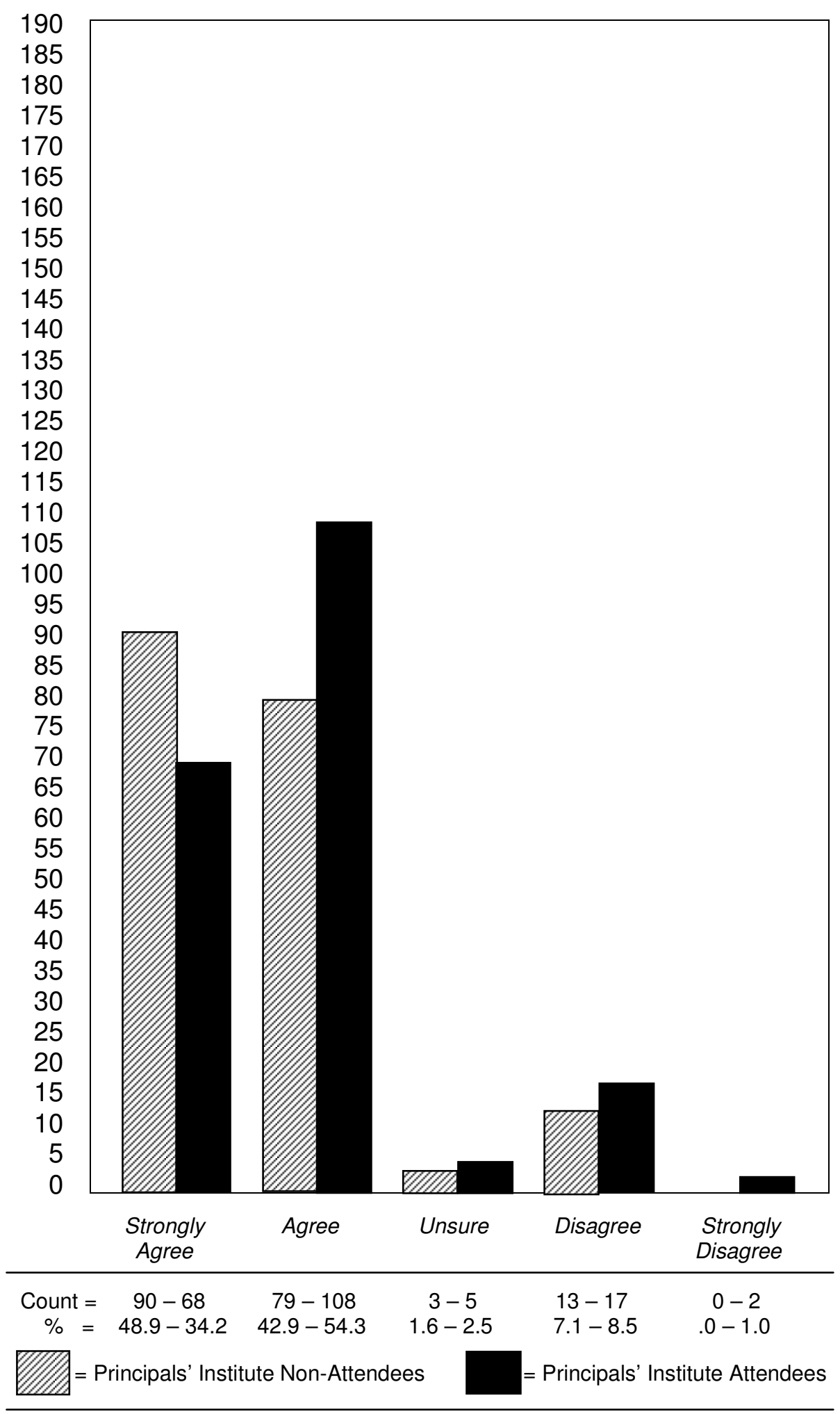

Non-Attendees: 193 answered; 3 skipped question. Attendees: 205 answered; 4 skipped question. 
and those who did not attend the Institute. The scores of the principals in the treatment group (those who had attended the Institute) perceived their schools to be higher performing than the principals who had not attended the Institute. The explanation of this analysis follows.

The comparison group $\mathrm{N}$ was 183 with a mean score of 4.077 and a standard deviation of .67502. The treatment group $\mathrm{N}$ was 196 with a mean score of 3.883 and a standard deviation of .73135. Levene's Test for Equality of Variances was not significant at .348; indicating that equal variances were assumed. The $t$-Test for Equality of Means showed a two-tailed significance level of .008 , which is less than the .05 alpha level; therefore, the null hypothesis is rejected. There is a significant difference in the scores of the comparison and treatment groups in Item 19. The effect size, $d$ calculation, is .28 , indicating a small effect of the difference made by the treatment. The treatment group scores were larger than the comparison group. The Mann-Whitney $U$ test, the nonparametric equivalent of the parametric $t$-test, verifies the statistically significant difference in the two groups with a significance level of .023 , which is less than the alpha .05 level (see Figure 16).

Survey Item 20

Item 20 was the statement: The teachers in my school use differentiated instruction to meet the varied needs of learners. The analysis of the respondents' scores for survey Item 20 showed that there was a statistical difference between the responses of the principals who attended the West Virginia Institute for $21^{\text {st }}$-Century Leadership and those who did not attend the Institute. The scores of the principals in the treatment group (those who had attended the Institute) perceived their schools to be higher performing than the principals who had not attended the Institute. The explanation of this analysis follows. 
Figure 16. Statement 19: The students in my school are being developed into self-directed learners who are responsible for improving their own work.

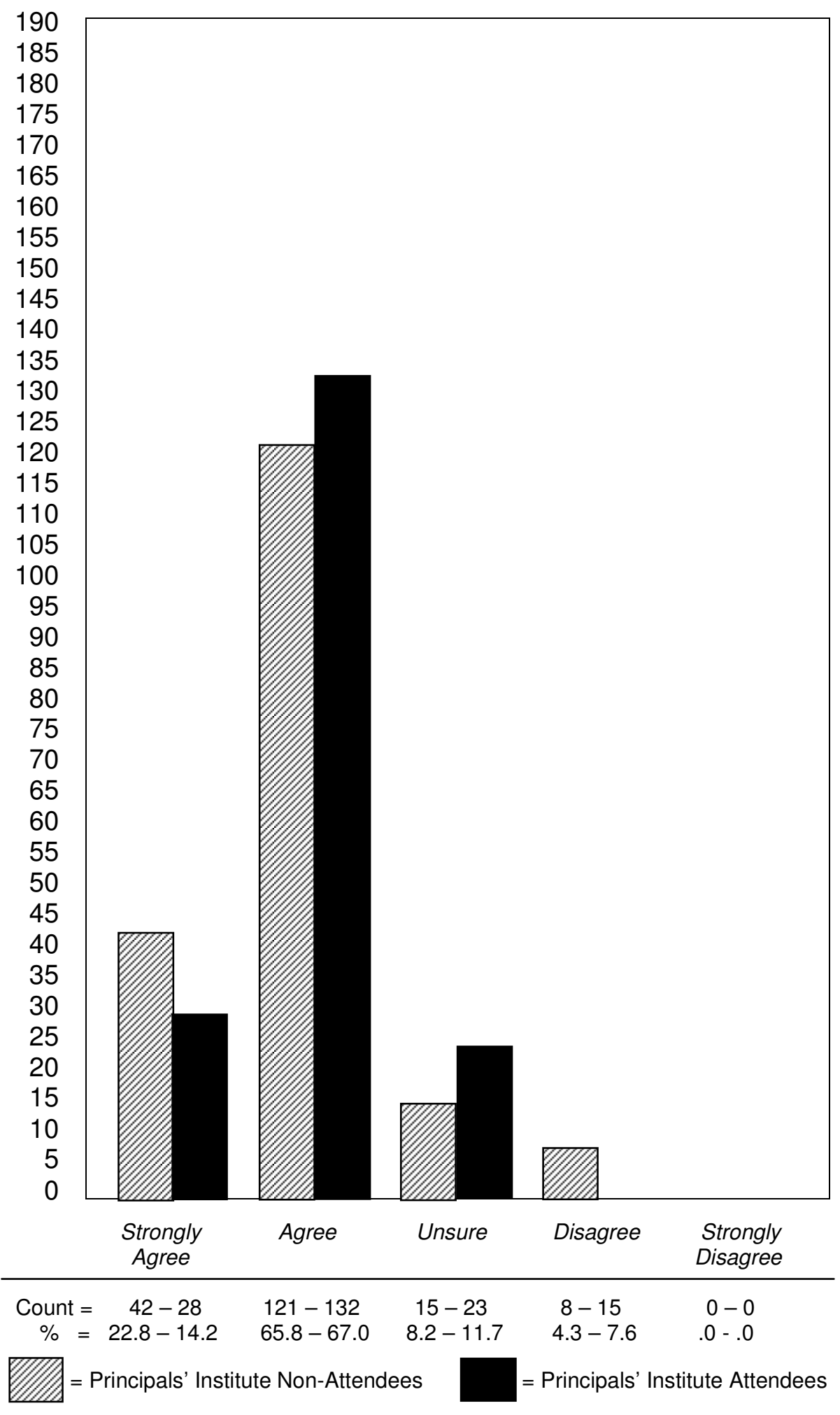

Non-Attendees: 184 answered; 12 skipped question. Attendees: 197 answered; 12 skipped question. 
The comparison group $\mathrm{N}$ was 183 with a mean score of 4.303 and a standard deviation of .70093. The treatment group $\mathrm{N}$ was 194 with a mean score of 4.108 and a standard deviation of .72956. Levene's Test for Equality of Variances was not significant at .091; indicating that equal variances were assumed. The $t$-Test for Equality of Means showed a two-tailed significance level of .009, which is less than the .05 alpha level; therefore, the null hypothesis is rejected. There is a significant difference in the scores of the comparison and treatment groups in Item 20 . The effect size, $d$ calculation, is .19 , indicating a small effect of the difference made by the treatment. The treatment group scores were larger than the comparison group. The Mann-Whitney $U$ test, the nonparametric equivalent of the parametric $t$-test, verifies the statistically significant difference in the two groups with a significance level of .011, which is less than the alpha .05 level (see Figure 17).

Survey Item 21

Item 21 was the statement: The teachers in my school use research-based, high-yield instructional strategies in all classrooms. The analysis of the respondents' scores for survey Item 21 showed that there was no statistical difference between the responses of the principals who attended the West Virginia Institute for $21^{\text {st }}$-Century Leadership and those who did not attend the Institute. The explanation of this analysis follows.

The comparison group $\mathrm{N}$ was 181 with a mean score of 4.227 and a standard deviation of .82230 . The treatment group $\mathrm{N}$ was 197 with a mean score of 4.124 and a standard deviation of .73956. Levene's Test for Equality of Variances was not significant at .012; indicating that equal variances were not assumed, and the calculation was adjusted accordingly. The $t$-Test for Equality of Means showed a two-tailed significance level of .206, which is greater than the .05 alpha level; therefore, the null hypothesis is not rejected. There is not a significant difference in 
Figure 17. Statement 20: The teachers in my school use differentiated instruction to meet the varied needs of learners.

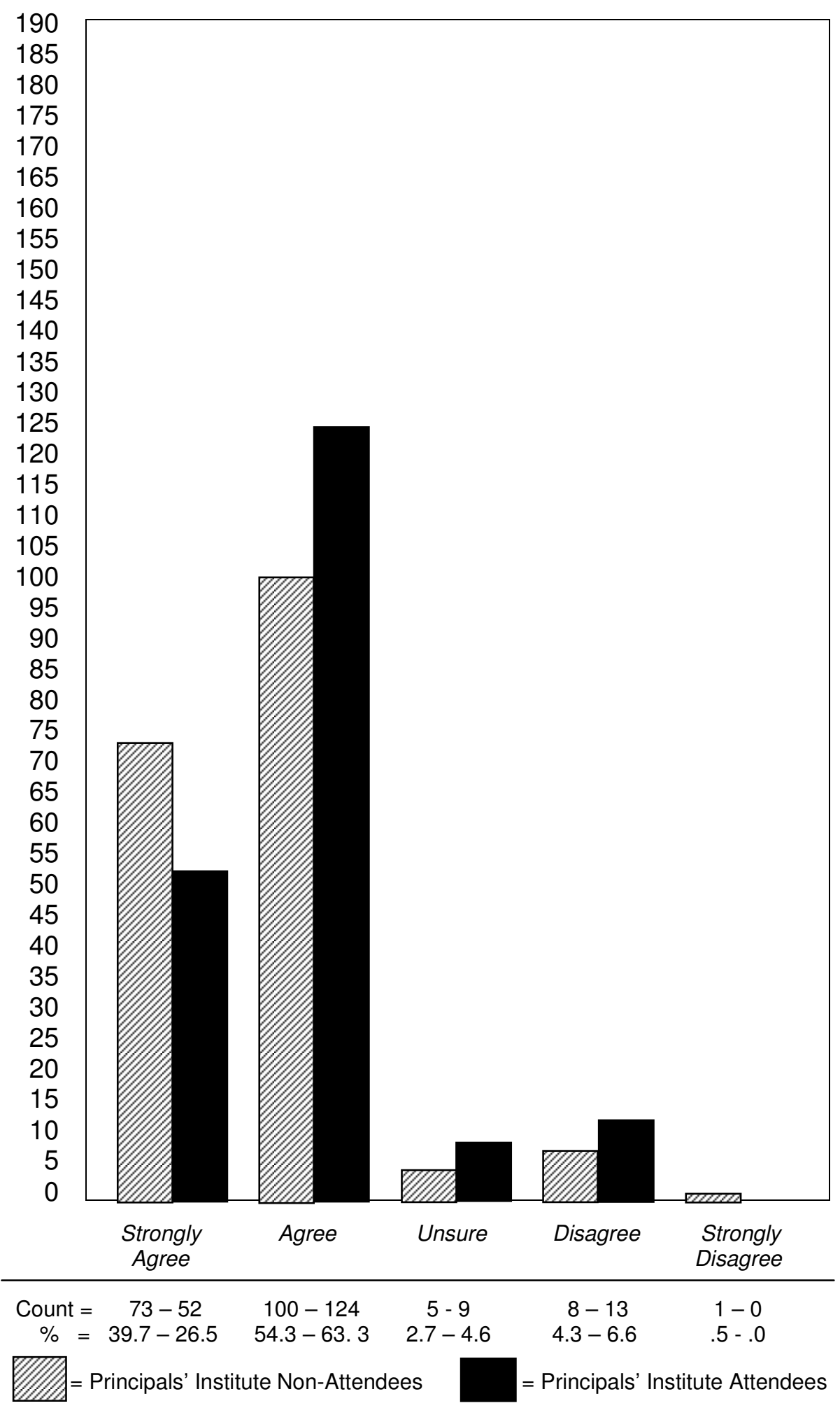

Non-Attendees: 184 answered; 12 skipped question. Attendees: 196 answered; 13 skipped question. 
the scores of the comparison and treatment groups in Item 16. The Mann-Whitney $U$ test, the nonparametric equivalent of the parametric $t$-test, verifies the lack of a statistically significant difference in the two groups with a significance level of .087 , which is greater than the alpha .05 level.

Survey Item 22

Item 22 was the statement: The teachers in my school use performance assessments to determine the level of student mastery. The analysis of the respondents' scores for survey Item 22 showed that there was a statistical difference between the responses of the principals who attended the West Virginia Institute for $21^{\text {st }}$-Century Leadership and those who did not attend the Institute. The scores of the principals in the treatment group (those who had attended the Institute) perceived their schools to be higher performing than the principals who had not attended the Institute. The explanation of this analysis follows.

The comparison group $\mathrm{N}$ was 180 with a mean score of 4.283 and a standard deviation of .67910. The treatment group $\mathrm{N}$ was 196 with a mean score of 4.128 and a standard deviation of .67865. Levene's Test for Equality of Variances was significant at .029, indicating that equal variances were not assumed, and calculations were adjusted accordingly. The $t$-Test for Equality of Means showed a two-tailed significance level of .027, which is less than the .05 alpha level; therefore, the null hypothesis is rejected. There is a significant difference in the scores of the comparison and treatment groups in Item 22 . The effect size, $d$ calculation, is .23, indicating a small effect of the difference made by the treatment. The treatment group scores were larger than the comparison group. The Mann-Whitney $U$ test, the nonparametric equivalent of the parametric $t$-test, verifies the statistically significant difference in the two groups with a significance level of .034, which is less than the alpha .05 level (see Figure 18). 
Figure 18. Statement 22: The teachers in my school use performance assessments to determine the level of student mastery.

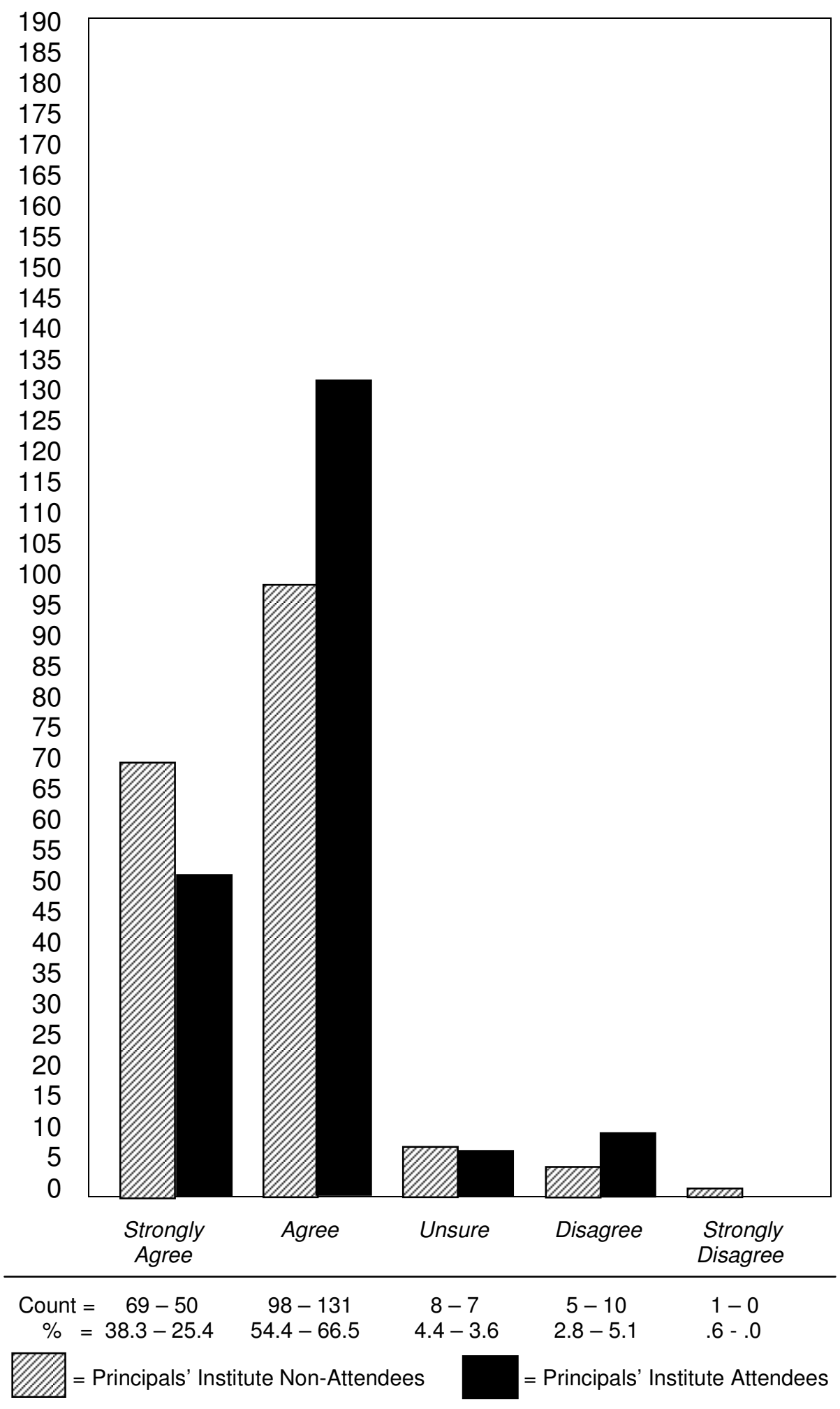

Non-Attendees: 180 answered; 16 skipped question. Attendees: 197 answered; 12 skipped question. 


\section{Survey Item 23}

Item 23 was the statement: The teachers in my school adjust instructional time by grade, class, and subject to meet the various learning needs of students. The analysis of the respondents' scores for survey Item 23 showed that there was no statistical difference between the responses of the principals who attended the West Virginia Institute for $21^{\text {st }}$-Century Leadership and those who did not attend the Institute. The explanation of this analysis follows.

The comparison group $\mathrm{N}$ was 180 with a mean score of 4.280 and a standard deviation of .67910. The treatment group $\mathrm{N}$ was 196 with a mean score of 4.128 and a standard deviation of .67865. Levene's Test for Equality of Variances was not significant at .029; indicating that equal variances were not assumed, and the calculation was adjusted accordingly. The $t$-Test for Equality of Means showed a two-tailed significance level of .317, which is greater than the .05 alpha level; therefore, the null hypothesis is not rejected. There is not a significant difference in the two groups with a significance level of .410 , which is greater than the alpha .05 level.

\section{Survey Item 24}

Item 24 was the statement: Writing-to-inform strategies are used in all classrooms in my school in all content areas. The analysis of the respondents' scores for survey Item 24 showed that there was no statistical difference between the responses of the principals who attended the West Virginia Institute for $21^{\text {st }}$-Century Leadership and those who did not attend the Institute. The explanation of this analysis follows.

The comparison group $\mathrm{N}$ was 179 with a mean score of 3.693 and a standard deviation of .84168. The treatment group $\mathrm{N}$ was 196 with a mean score of 3.523 and a standard deviation of .96781. Levene's Test for Equality of Variances was not significant at .001; indicating that equal variances were not assumed, and the calculation was adjusted accordingly. The $t$-Test for 
Equality of Means showed a two-tailed significance level of .070, which is greater than the .05 alpha level; therefore, the null hypothesis is not rejected. There is not a significant difference in the scores of the comparison and treatment groups in Item 24. The Mann-Whitney $U$ test, the nonparametric equivalent of the parametric $t$-test, verifies the lack of a statistically significant difference in the two groups with a significance level of .120, which is greater than the alpha .05 level.

Survey Item 25

Item 25 was the statement: Comprehension development strategies are used in all classrooms in my school in all content areas. The analysis of the respondents' scores for survey Item 25 showed that there was a statistical difference between the responses of the principals who attended the West Virginia Institute for $21^{\text {st }}$-Century Leadership and those who did not attend the Institute. The scores of the principals in the treatment group (those who had attended the Institute) perceived their schools to be higher performing than the principals who had not attended the Institute. The explanation of this analysis follows.

The comparison group $\mathrm{N}$ was 181 with a mean score of 4.000 and a standard deviation of .81650 . The treatment group $\mathrm{N}$ was 194 with a mean score of 3.804 and a standard deviation of .86545. Levene's Test for Equality of Variances was significant at .037, indicating that equal variances were not assumed, and calculations were adjusted accordingly. The $t$-Test for Equality of Means showed a two-tailed significance level of .025 , which is less than the .05 alpha level; therefore, the null hypothesis is rejected. There is a significant difference in the scores of the comparison and treatment groups in Item 25 . The effect size, $d$ calculation, is .23 , indicating a small effect of the difference made by the treatment. The treatment group scores were larger than the comparison group. The Mann-Whitney $U$ test, the nonparametric equivalent of the 
parametric $t$-test, verifies the statistically significant difference in the two groups with a significance level of .040, which is less than the alpha .05 level (see Figure 19).

Survey Item 26

Item 26 was the statement: The teachers in my school use such practices as scaffolding and previewing to help accelerate student achievement. The analysis of the respondents' scores for survey Item 26 showed that there was no statistical difference between the responses of the principals who attended the West Virginia Institute for $21^{\text {st }}$-Century Leadership and those who did not attend the Institute. The explanation of this analysis follows.

The comparison group $\mathrm{N}$ was 181 with a mean score of 3.981 and a standard deviation of 3.8889. The treatment group $\mathrm{N}$ was 198 with a mean score of 3.889 and a standard deviation of .77248. Levene's Test for Equality of Variances was not indicating that equal variances were assumed. The $t$-Test for Equality of Means showed a two-tailed significance level of .265, which is greater than the .05 alpha level; therefore, the null hypothesis is not rejected. There is not a significant difference in the scores of the comparison and treatment groups in Item 26 . The Mann-Whitney $U$ test, the nonparametric equivalent of the parametric $t$-test, verifies the lack of a statistically significant difference in the two groups with a significance level of .186, which is greater than the alpha .05 level.

Survey Item 27

Item 27 was the statement: There is a teacher instructional support system that provides time and assistance to teachers for such things as data analysis, cooperative planning, observation and feedback, reflective practice, and professional growth. The analysis of the respondents' scores for survey Item 27 showed that there was no statistical difference between 
Figure 19. Statement 25: Comprehension development strategies are used in all classrooms in my school in all content areas.

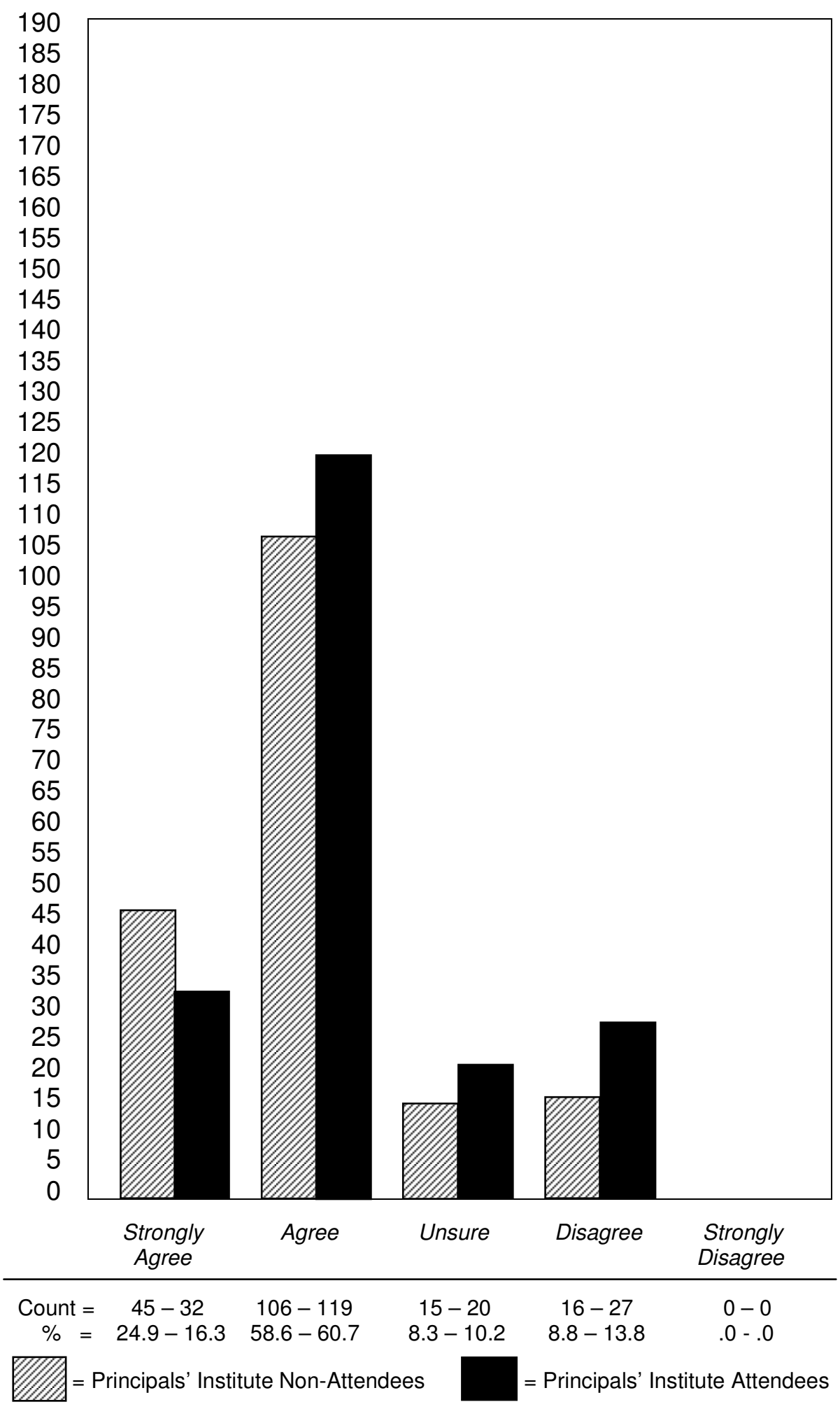

Non-Attendees: 181 answered; 15 skipped question. Attendees: 196 answered; 13 skipped question. 
the responses of the principals who attended the West Virginia Institute for $21^{\text {st }}$-Century Leadership and those who did not attend the Institute. The explanation of this analysis follows.

The comparison group $\mathrm{N}$ was 182 with a mean score of 4.050 and a standard deviation of .88122. The treatment group $\mathrm{N}$ was 196 with a mean score of 4.015 and a standard deviation of 90286. Levene's Test for Equality of Variances was not significant at .899, indicating that equal variances were assumed. The $t$-Test for Equality of Means showed a two-tailed significance level of .710, which is greater than the .05 alpha level; therefore, the null hypothesis is not rejected. There is not a significant difference in the scores of the comparison and treatment groups in Item 26. The Mann-Whitney $U$ test, the nonparametric equivalent of the parametric $t$-test, verifies the lack of a statistically significant difference in the two groups with a significance level of .786, which is greater than the alpha .05 level.

Survey Item 28

Item 28 was the statement: We have a culture of support, trust, and collaboration between our school and the county office focused on creating conditions for all students' success. The analysis of the respondents' scores for survey Item 28 showed that there was no statistical difference between the responses of the principals who attended the West Virginia Institute for $21^{\text {st }}$-Century Leadership and those who did not attend the Institute. The explanation of this analysis follows.

The comparison group $\mathrm{N}$ was 181 with a mean score of 4.061 and a standard deviation of .83110. The treatment group $\mathrm{N}$ was 195 with a mean score of 3.877 and a standard deviation of 1.0078. Levene's Test for Equality of Variances was not significant at .005 , indicating that equal variances were not assumed, and calculations were adjusted accordingly. The $t$-Test for Equality of Means showed a two-tailed significance level of .054 , which is slightly greater than the .05 
alpha level; therefore, the null hypothesis is not rejected. There is not a significant difference in the scores of the comparison and treatment groups in Item 26. The Mann-Whitney $U$ test, the nonparametric equivalent of the parametric $t$-test, verifies the lack of a statistically significant difference in the two groups with a significance level of .170, which is greater than the alpha .05 level.

Survey Item 29

Item 29 was the statement: Our school has developed a clear mission that provides focus to school improvement efforts. The analysis of the respondents' scores for survey Item 29 showed that there was no statistical difference between the responses of the principals who attended the West Virginia Institute for $21^{\text {st }}$-Century Leadership and those who did not attend the Institute. The explanation of this analysis follows.

The comparison group $\mathrm{N}$ was 183 with a mean score of 4.530 and a standard deviation of .55264. The treatment group $\mathrm{N}$ was 193 with a mean score of 4.422 and a standard deviation of .54407 . Levene's Test for Equality of Variances was not significant at .867, indicating that equal variances were assumed. The $t$-Test for Equality of Means showed a two-tailed significance level of .058, which is slightly greater than the .05 alpha level; therefore, the null hypothesis is not rejected. There is not a significant difference in the scores of the comparison and treatment groups in Item 29. The Mann-Whitney $U$ test, the nonparametric equivalent of the parametric $t-$ test, verifies the lack of a statistically significant difference in the two groups with a significance level of .072 , which is greater than the alpha .05 level.

Survey Item 30

Item 30 was the statement: Our school has a set of core beliefs to provide focus to school improvement efforts. The analysis of the respondents' scores for survey Item 30 showed that 
there was no statistical difference between the responses of the principals who attended the West Virginia Institute for $21^{\text {st }}$-Century Leadership and those who did not attend the Institute. The explanation of this analysis follows.

The comparison group $\mathrm{N}$ was 180 with a mean score of 4.533 and a standard deviation of .56331 . The treatment group $\mathrm{N}$ was 193 with a mean score of 4.453 and a standard deviation of .53803. Levene's Test for Equality of Variances was not significant at .673, indicating that equal variances were assumed. The $t$-Test for Equality of Means showed a two-tailed significance level of .162, which is greater than the .05 alpha level; therefore, the null hypothesis is not rejected. There is not a significant difference in the scores of the comparison and treatment groups in Item 30. The Mann-Whitney $U$ test, the nonparametric equivalent of the parametric $t$-test, verifies the lack of a statistically significant difference in the two groups with a significance level of .157, which is greater than the alpha .05 level

Survey Item 31

Item 31 was the statement: Our school HAS NOT set performance goals to provide focus to school improvement. The analysis of the respondents' scores for survey Item 31 showed that there was no statistical difference between the responses of the principals who attended the West Virginia Institute for $21^{\text {st }}$-Century Leadership and those who did not attend the Institute. The explanation of this analysis follows.

The comparison group $\mathrm{N}$ was 181 with a mean score of 4.541 and a standard deviation of .53197. The treatment group $\mathrm{N}$ was 190 with a mean score of 4.497 and a standard deviation of .63931. Levene's Test for Equality of Variances was not significant at .061, indicating that equal variances were assumed. The $t$-Test for Equality of Means showed a two-tailed significance level of .472 , which is greater than the .05 alpha level; therefore, the null hypothesis is not rejected. 
There is not a significant difference in the scores of the comparison and treatment groups in Item 31. The Mann-Whitney $U$ test, the nonparametric equivalent of the parametric $t$-test, verifies the lack of a statistically significant difference in the two groups with a significance level of .850, which is greater than the alpha .05 level.

Survey Item 32

Item 32 was the statement: Our school has a strategic plan to provide focus to schoolimprovement efforts. The analysis of the respondents' scores for survey Item 32 showed that there was no statistical difference between the responses of the principals who attended the West Virginia Institute for $21^{\text {st }}$-Century Leadership and those who did not attend the Institute. The explanation of this analysis follows.

The comparison group $\mathrm{N}$ was 181 with a mean score of 4.591 and a standard deviation of .50413 . The treatment group $\mathrm{N}$ was 193 with a mean score of 4.554 and a standard deviation of .51881 . Levene's Test for Equality of Variances was not significant at .219, indicating that equal variances were assumed. The $t$-Test for Equality of Means showed a two-tailed significance level of .488 , which is greater than the .05 alpha level; therefore, the null hypothesis is not rejected. There is not a significant difference in the scores of the comparison and treatment groups in Item 32. The Mann-Whitney $U$ test, the nonparametric equivalent of the parametric $t$-test, verifies the lack of a statistically significant difference in the two groups with a significance level of .572 , which is greater than the alpha .05 level.

Survey Item 33

Item 33 was the statement: Our school-improvement team members have had professional development training on strategic planning. The analysis of the respondents' scores for survey Item 33 showed that there was no statistical difference between the responses of the 
principals who attended the West Virginia Institute for $21^{\text {st }}$-Century Leadership and those who did not attend the Institute. The explanation of this analysis follows.

The comparison group $\mathrm{N}$ was 179 with a mean score of 3.743 and a standard deviation of 1.0605. The treatment group $\mathrm{N}$ was 192 with a mean score of 3.664 and a standard deviation of 1.1613. Levene's Test for Equality of Variances was not significant at .024, indicating that equal variances were not assumed, and calculations were adjusted accordingly. The $t$-Test for Equality of Means showed a two-tailed significance level of .494 , which is greater than the .05 alpha level; therefore, the null hypothesis is not rejected. There is not a significant difference in the scores of the comparison and treatment groups in Item 33. The Mann-Whitney $U$ test, the nonparametric equivalent of the parametric $t$-test, verifies the lack of a statistically significant difference in the two groups with a significance level of .736, which is greater than the alpha .05 level.

Survey Item 34

Item 34 was the statement: Our school-improvement team members have had professional development training on continuous improvement. The analysis of the respondents' scores for survey Item 34 showed that there was no statistical difference between the responses of the principals who attended the West Virginia Institute for $21^{\text {st }}$-Century Leadership and those who did not attend the Institute. The explanation of this analysis follows.

The comparison group $\mathrm{N}$ was 180 with a mean score of 3.772 and a standard deviation of .99063. The treatment group $\mathrm{N}$ was 194 with a mean score of 3.691 and a standard deviation of 1.0951. Levene's Test for Equality of Variances was not significant at .025, indicating that equal variances were not assumed, and calculations were adjusted accordingly. The $t$-Test for Equality of Means showed a two-tailed significance level of .450 , which is greater than the .05 alpha 
level; therefore, the null hypothesis is not rejected. There is not a significant difference in the scores of the comparison and treatment groups in Item 34. The Mann-Whitney $U$ test, the nonparametric equivalent of the parametric $t$-test, verifies the lack of a statistically significant difference in the two groups with a significance level of .678 , which is greater than the alpha .05 level.

Survey Item 35

Item 35 was the statement: Our school-improvement team members have had professional development training on the correlates of effective schools. The analysis of the respondents' scores for survey Item 35 showed that there was no statistical difference between the responses of the principals who attended the West Virginia Institute for $21^{\text {st }}$-Century Leadership and those who did not attend the Institute. The explanation of this analysis follows.

The comparison group $\mathrm{N}$ was 181 with a mean score of 3.762 and a standard deviation of .99103. The treatment group $\mathrm{N}$ was 193 with a mean score of 3.705 and a standard deviation of 1.0512. Levene's Test for Equality of Variances was not significant at .268, indicating that equal variances were assumed. The $t$-Test for Equality of Means showed a two-tailed significance level of .268, which is greater than the .05 alpha level; therefore, the null hypothesis is not rejected. There is not a significant difference in the scores of the comparison and treatment groups in Item 35. The Mann-Whitney $U$ test, the nonparametric equivalent of the parametric $t$-test, verifies the lack of a statistically significant difference in the two groups with a significance level of .735, which is greater than the alpha .05 level.

\section{Survey Item 36}

Item 36 was the statement: Our school-improvement team members have time to collaborate, develop, and annually revise the five-year strategic plan.. The analysis of the 
respondents' scores for survey Item 36 showed that there was no statistical difference between the responses of the principals who attended the West Virginia Institute for $21^{\text {st }}$-Century Leadership and those who did not attend the Institute. The explanation of this analysis follows.

The comparison group $\mathrm{N}$ was 180 with a mean score of 3.950 and a standard deviation of .97037. The treatment group $\mathrm{N}$ was 191 with a mean score of 3.890 and a standard deviation of 99655. Levene's Test for Equality of Variances was not significant at .412, indicating that equal variances were assumed. The $t$-Test for Equality of Means showed a two-tailed significance level of .558 , which is greater than the .05 alpha level; therefore, the null hypothesis is not rejected. There is not a significant difference in the scores of the comparison and treatment groups in Item 36. The Mann-Whitney $U$ test, the nonparametric equivalent of the parametric $t$-test, verifies the lack of a statistically significant difference in the two groups with a significance level of .572 , which is greater than the alpha .05 level.

\section{Survey Item 37}

Item 37 was the statement: Our school has a data management system to analyze data trends and establish priorities. The analysis of the respondents' scores for survey Item 37 showed that there was a statistical difference between the responses of the principals who attended the West Virginia Institute for $21^{\text {st }}$-Century Leadership and those who did not attend the Institute. The scores of the principals in the treatment group (those who had attended the Institute) perceived their schools to be higher performing than the principals who had not attended the Institute. The explanation of this analysis follows.

The comparison group $\mathrm{N}$ was 177 with a mean score of 4.186 and a standard deviation of .78642. The treatment group $\mathrm{N}$ was 187 with a mean score of 3.973 and a standard deviation of .85781. Levene's Test for Equality of Variances was significant at .404, indicating that equal 
variances were assumed. The $t$-Test for Equality of Means showed a two-tailed significance level of .014, which is less than the .05 alpha level; therefore, the null hypothesis is rejected. There is a significant difference in the scores of the comparison and treatment groups in Item 37 . The effect size, $d$ calculation, is .26 , indicating a small effect of the difference made by the treatment. The treatment group scores were larger than the comparison group. The Mann-Whitney $U$ test, the nonparametric equivalent of the parametric $t$-test, verifies the statistically significant difference in the two groups with a significance level of .018 , which is less than the alpha .05 level (see Figure 20).

Survey Item 38

Item 38 was the statement: Our school has a learning community focused on strategies to achieve school performance goals. The analysis of the respondents' scores for survey Item 38 showed that there was no statistical difference between the responses of the principals who attended the West Virginia Institute for $21^{\text {st }}$-Century Leadership and those who did not attend the Institute. The explanation of this analysis follows.

The comparison group $\mathrm{N}$ was 180 with a mean score of 4.156 and a standard deviation of .69171. The treatment group $\mathrm{N}$ was 194 with a mean score of 4.072 and a standard deviation of .74455. Levene's Test for Equality of Variances was not significant at .870, indicating that equal variances were assumed. The $t$-Test for Equality of Means showed a two-tailed significance level of .264, which is greater than the .05 alpha level; therefore, the null hypothesis is not rejected. There is not a significant difference in the scores of the comparison and treatment groups in Item 38. The Mann-Whitney $U$ test, the nonparametric equivalent of the parametric $t$-test, verifies the lack of a statistically significant difference in the two groups with a significance level of .336, which is greater than the alpha .05 level. 
Figure 20. Statement 37: Our school has a data management system to analyze data trends and establish priorities.

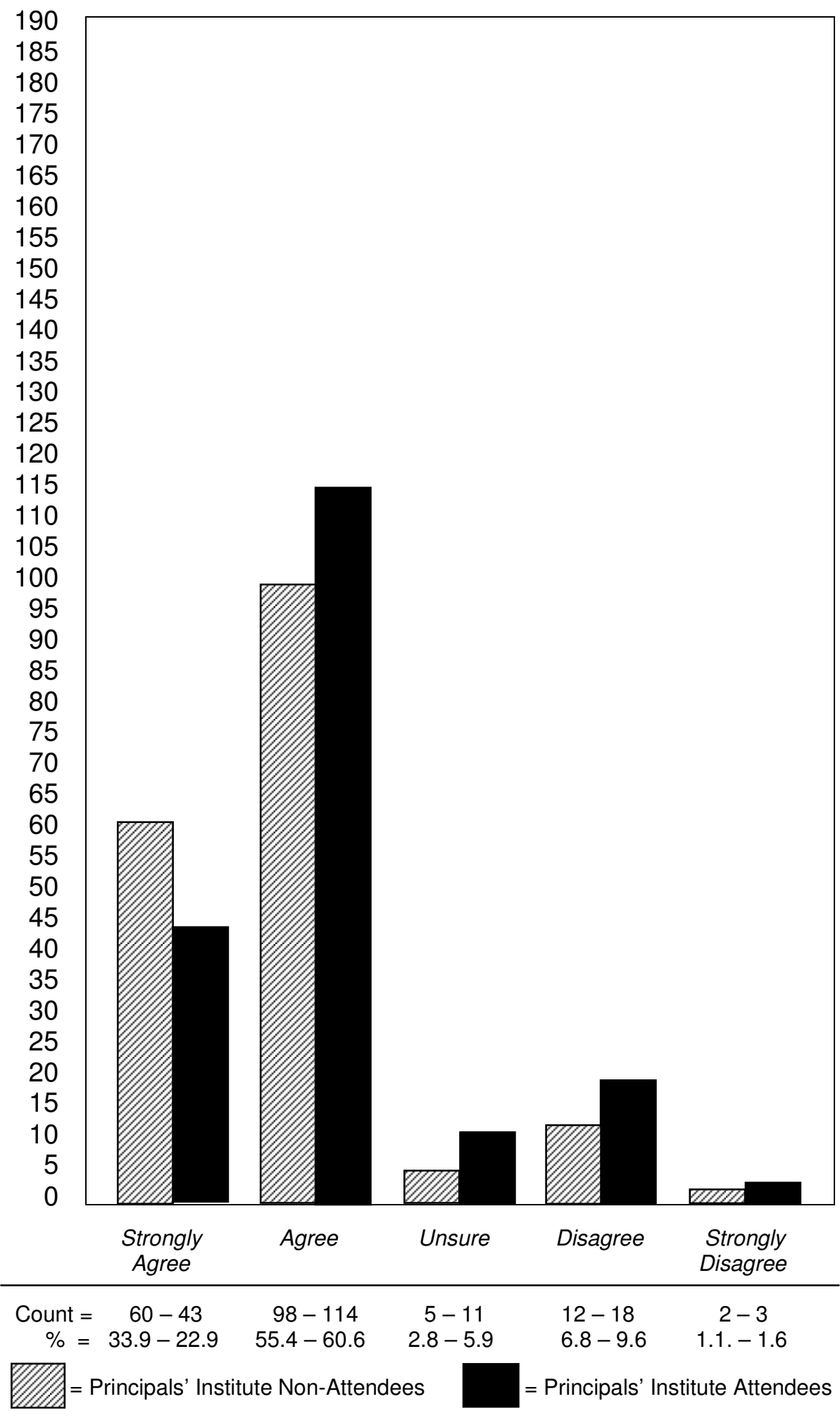

Non-Attendees: 193 answered; 3 skipped question. Attendees: 205 answered; 4 skipped question. 
Survey Item 39

Item 39 was the statement: Teachers in our school are provided professional development training aligned with the school's improvement plan. The analysis of the respondents' scores for survey Item 39 showed that there was no statistical difference between the responses of the principals who attended the West Virginia Institute for $21^{\text {st }}$-Century Leadership and those who did not attend the Institute. The explanation of this analysis follows.

The comparison group $\mathrm{N}$ was 179 with a mean score of 4.372 and a standard deviation of .55861. The treatment group $\mathrm{N}$ was 192 with a mean score of 4.245 and a standard deviation of .67682. Levene's Test for Equality of Variances was not significant at .576, indicating that equal variances were assumed. The $t$-Test for Equality of Means showed a two-tailed significance level of .051 , which is slightly greater than the .05 alpha level; therefore, the null hypothesis is not rejected. There is not a significant difference in the scores of the comparison and treatment groups in Item 38. The Mann-Whitney $U$ test, the nonparametric equivalent of the parametric $t-$ test, verifies the lack of a statistically significant difference in the two groups with a significance level of .167, which is greater than the alpha .05 level.

Survey Item 40

Item 40 was the statement: Our county has a monitoring system that requires continuous progress and accountability for results as outlined in the school and district plan. The analysis of the respondents' scores for survey Item 40 showed that there was no statistical difference between the responses of the principals who attended the West Virginia Institute for $21^{\text {st }}$-Century Leadership and those who did not attend the Institute. The explanation of this analysis follows.

The comparison group $\mathrm{N}$ was 177 with a mean score of 4.212 and a standard deviation of .68799. The treatment group $\mathrm{N}$ was 193 with a mean score of 4.075 and a standard deviation of 
.75747. Levene's Test for Equality of Variances was not significant at .736, indicating that equal variances were assumed. The $t$-Test for Equality of Means showed a two-tailed significance level of .071 , which is greater than the .05 alpha level; therefore, the null hypothesis is not rejected. There is not a significant difference in the scores of the comparison and treatment groups in Item 38. The Mann-Whitney $U$ test, the nonparametric equivalent of the parametric $t$-test, verifies the lack of a statistically significant difference in the two groups with a significance level of .118, which is greater than the alpha .05 level.

\section{Survey Item 41}

Item 41 was the statement: Our teachers are provided time prior to and during the instructional term for meaningful staff planning, collaboration, and problem solving related to the school's performance goals. The analysis of the respondents' scores for survey Item 41 showed that there was no statistical difference between the responses of the principals who attended the West Virginia for $21^{\text {st }}$-Century Leadership and those who did not attend the Institute. The explanation of this analysis follows.

The comparison group $\mathrm{N}$ was 181 with a mean score of 3.939 and a standard deviation of 1.0120. The treatment group $\mathrm{N}$ was 193 with a mean score of 3.886 and a standard deviation of .99868. Levene's Test for Equality of Variances was not significant at .840, indicating that equal variances were assumed. The $t$-Test for Equality of Means showed a two-tailed significance level of .609, which is greater than the .05 alpha level; therefore, the null hypothesis is not rejected. There is not a significant difference in the scores of the comparison and treatment groups in Item 41. The Mann-Whitney $U$ test, the nonparametric equivalent of the parametric $t$-test, verifies the 
lack of a statistically significant difference in the two groups with a significance level of .542, which is greater than the alpha .05 level.

Survey Item 42

Item 42 was the statement: Our county office has a school monitoring system to gather information on quality of overall school operations and the presence of the correlates of effective schools. The analysis of the respondents' scores for survey Item 42 showed that there was no statistical difference between the responses of the principals who attended the West Virginia Institute for $21^{\text {st }}$-Century Leadership and those who did not attend the Institute. The explanation of this analysis follows.

The comparison group $\mathrm{N}$ was 178 with a mean score of 3.997 and a standard deviation of 83784. The treatment group $\mathrm{N}$ was 190 with a mean score of 3.861 and a standard deviation of .87152. Levene's Test for Equality of Variances was not significant at .132, indicating that equal variances were assumed. The $t$-Test for Equality of Means showed a two-tailed significance level of .126, which is greater than the .05 alpha level; therefore, the null hypothesis is not rejected. There is not a significant difference in the scores of the comparison and treatment groups in Item 42. The Mann-Whitney $U$ test, the nonparametric equivalent of the parametric $t$-test, verifies the lack of a statistically significant difference in the two groups with a significance level of .155, which is greater than the alpha .05 level.

\section{Survey Item 43}

Item 43 was the statement: Our school uses research-based, innovative approaches to meet the specific academic and social/emotional needs of all learners. The analysis of the respondents' scores for survey Item 43 showed that there was no statistical difference between 
the responses of the principals who attended the West Virginia Institute for $21^{\text {st }}$-Century Leadership and those who did not attend the Institute. The explanation of this analysis follows.

The comparison group $\mathrm{N}$ was 178 with a mean score of 4.258 and a standard deviation .69750. The treatment group $\mathrm{N}$ was 193 with a mean score of 4.194 and a standard deviation of .61646. Levene's Test for Equality of Variances was not significant at .068, indicating that equal variances were assumed. The $t$-Test for Equality of Means showed a two-tailed significance level of .348, which is greater than the .05 alpha level; therefore, the null hypothesis is not rejected. There is not a significant difference in the scores of the comparison and treatment groups in Item 43. The Mann-Whitney $U$ test, the nonparametric equivalent of the parametric $t$-test, verifies the lack of a statistically significant difference in the two groups with a significance level of .193, which is greater than the alpha .05 level.

\section{Survey Item 44}

Item 44 was the statement: Our school has a developmental guidance program that includes a strong character education focus. The analysis of the respondents' scores for survey Item 44 showed that there was no statistical difference between the responses of the principals who attended the West Virginia Institute for $21^{\text {st }}$-Century Leadership and those who did not attend the Institute. The explanation of this analysis follows.

The comparison group $\mathrm{N}$ was 177 with a mean score of 4.164 and a standard deviation of .89267. The treatment group $\mathrm{N}$ was 193 with a mean score of 4.119 and a standard deviation of .80448. Levene's Test for Equality of Variances was not significant at .138, indicating that equal variances were assumed. The $t$-Test for Equality of Means showed a two-tailed significance level of .613, which is greater than the .05 alpha level; therefore, the null hypothesis is not rejected. There is not a significant difference in the scores of the comparison and treatment groups in Item 
44. The Mann-Whitney $U$ test, the nonparametric equivalent of the parametric $t$-test, verifies the lack of a statistically significant difference in the two groups with a significance level of .312, which is greater than the alpha .05 level.

Survey Item 45

Item 45 was the statement: Our school has a developmental guidance program that includes a career development focus. The analysis of the respondents' scores for survey Item 45 showed that there was no statistical difference between the responses of the principals who attended the West Virginia Institute for $21^{\text {st }}$-Century Leadership and those who did not attend the Institute. The explanation of this analysis follows.

The comparison group $\mathrm{N}$ was 174 with a mean score of 3.902 and a standard deviation of .94758. The treatment group $\mathrm{N}$ was 191 with a mean score of 3.942 and a standard deviation of .89550. Levene's Test for Equality of Variances was not significant at .311, indicating that equal variances were assumed. The $t$-Test for Equality of Means showed a two-tailed significance level of .678, which is greater than the .05 alpha level; therefore, the null hypothesis is not rejected. There is not a significant difference in the scores of the comparison and treatment groups in Item 45. The Mann-Whitney $U$ test, the nonparametric equivalent of the parametric $t$-test, verifies the lack of a statistically significant difference in the two groups with a significance level of .770, which is greater than the alpha .05 level.

\section{Survey Item 46}

Item 46 was the statement: Our school has an effective process for successfully transitioning students from one school to the next. The analysis of the respondents' scores for survey Item 46 showed that there was no statistical difference between the responses of the 
principals who attended the West Virginia Institute for $21^{\text {st }}$-Century Leadership and those who did not attend the Institute. The explanation of this analysis follows.

The comparison group $\mathrm{N}$ was 176 with a mean score of 4.034 and a standard deviation of .80639. The treatment group $\mathrm{N}$ was 192 with a mean score of 3.969 and a standard deviation of .77868. Levene's Test for Equality of Variances was not significant at .582, indicating that equal variances were assumed. The $t$-Test for Equality of Means showed a two-tailed significance level of .430 , which is greater than the .05 alpha level; therefore, the null hypothesis is not rejected. There is not a significant difference in the scores of the comparison and treatment groups in Item 46. The Mann-Whitney $U$ test, the nonparametric equivalent of the parametric $t$-test, verifies the lack of a statistically significant difference in the two groups with a significance level of .368, which is greater than the alpha .05 level.

\section{Survey Item 47}

Item 47 was the statement: Our school DOES NOT have a coordinated and proactive plan to enhance parent involvement. The analysis of the respondents' scores for survey Item 44 showed that there was no statistical difference between the responses of the principals who attended the West Virginia Institute for $21^{\text {st }}$-Century Leadership and those who did not attend the Institute. The explanation of this analysis follows.

The comparison group $\mathrm{N}$ was 178 with a mean score of 4.281 and a standard deviation of .79531. The treatment group $\mathrm{N}$ was 194 with a mean score of 4.150 and a standard deviation of .82909. Levene's Test for Equality of Variances was not significant at .756, indicating that equal variances were assumed. The $t$-Test for Equality of Means showed a two-tailed significance level of .120, which is greater than the .05 alpha level; therefore, the null hypothesis is not rejected. There is not a significant difference in the scores of the comparison and treatment groups in Item 
47. The Mann-Whitney $U$ test, the nonparametric equivalent of the parametric $t$-test, verifies the lack of a statistically significant difference in the two groups with a significance level of .118, which is greater than the alpha .05 level.

Survey Item 48

Item 48 was the statement: Our school has a coordinated and proactive plan to improve parent communication. The analysis of the respondents' scores for survey Item 48 showed that there was no statistical difference between the responses of the principals who attended the West Virginia Institute for $21^{\text {st }}$-Century Leadership and those who did not attend the Institute. The explanation of this analysis follows.

The comparison group $\mathrm{N}$ was 176 with a mean score of 4.182 and a standard deviation of .73361 . The treatment group $\mathrm{N}$ was 190 with a mean score of 4.100 and a standard deviation of .76842. Levene's Test for Equality of Variances was not significant at .803, indicating that equal variances were assumed. The $t$-Test for Equality of Means showed a two-tailed significance level of .299, which is greater than the .05 alpha level; therefore, the null hypothesis is not rejected. There is not a significant difference in the scores of the comparison and treatment groups in Item 48. The Mann-Whitney $U$ test, the nonparametric equivalent of the parametric $t$-test, verifies the lack of a statistically significant difference in the two groups with a significance level of .350, which is greater than the alpha .05 level.

Survey Item 49

Item 49 was the statement: Our school has a coordinated and proactive plan to support parent education. The analysis of the respondents' scores for survey Item 49 showed that there was no statistical difference between the responses of the principals who attended the West 
Virginia Institute for $21^{\text {st }}$-Century Leadership and those who did not attend the Institute. The explanation of this analysis follows.

The comparison group $\mathrm{N}$ was 176 with a mean score of 3.645 and a standard deviation of 1.0120. The treatment group $\mathrm{N}$ was 193 with a mean score of 3.521 and a standard deviation of .98138. Levene's Test for Equality of Variances was not significant at .998, indicating that equal variances were assumed. The $t$-Test for Equality of Means showed a two-tailed significance level of .234, which is greater than the .05 alpha level; therefore, the null hypothesis is not rejected. There is not a significant difference in the scores of the comparison and treatment groups in Item 49. The Mann-Whitney $U$ test, the nonparametric equivalent of the parametric $t$-test, verifies the lack of a statistically significant difference in the two groups with a significance level of .193, which is greater than the alpha .05 level.

Survey Item 50

Item 50 was the statement: Our school has a coordinated and proactive plan to build a partnership with parents of low-performing students. The analysis of the respondents' scores for survey Item 50 showed that there was no statistical difference between the responses of the principals who attended the West Virginia Institute for $21^{\text {st }}$-Century Leadership and those who did not attend the Institute. The explanation of this analysis follows.

The comparison group $\mathrm{N}$ was 176 with a mean score of 3.784 and a standard deviation of .88736. The treatment group $\mathrm{N}$ was 195 with a mean score of 3.703 and a standard deviation of .97057. Levene's Test for Equality of Variances was significant at .048, indicating that equal variances were not assumed, and the calculations were adjusted accordingly. The $t$-Test for Equality of Means showed a two-tailed significance level of .399, which is greater than the .05 
alpha level; therefore, the null hypothesis is not rejected. There is not a significant difference in the scores of the comparison and treatment groups in Item 50. The Mann-Whitney $U$ test, the nonparametric equivalent of the parametric $t$-test, verifies the lack of a statistically significant difference in the two groups with a significance level of .525 , which is greater than the alpha .05 level.

\section{Survey Item 51}

Item 51 was the statement: Our school has a process for connecting students and families to community agencies, health services, counseling, and other services that promote student success. The analysis of the respondents' scores for survey Item 51 showed that there was no statistical difference between the responses of the principals who attended the West Virginia Institute for $21^{\text {st }}$-Century Leadership and those who did not attend the Institute. The explanation of this analysis follows.

The comparison group $\mathrm{N}$ was 176 with a mean score of 4.017 and a standard deviation of .78903. The treatment group $\mathrm{N}$ was 191 with a mean score of 4.084 and a standard deviation of .63519. Levene's Test for Equality of Variances was not significant at .298, indicating that equal variances were assumed. The $t$-Test for Equality of Means showed a two-tailed significance level of .371 , which is greater than the .05 alpha level; therefore, the null hypothesis is not rejected. There is not a significant difference in the scores of the comparison and treatment groups in Item 51. The Mann-Whitney $U$ test, the nonparametric equivalent of the parametric $t$-test, verifies the lack of a statistically significant difference in the two groups with a significance level of .804, which is greater than the alpha .05 level. 
Survey Item 52

Item 52 was the statement: Our school has a data analysis process on such things as student attendance, discipline trends, grade distribution, and participation in extra-curricular activities to monitor student progress. The analysis of the respondents' scores for survey Item 52 showed that there was no statistical difference between the responses of the principals who attended the West Virginia Institute for $21^{\text {st }}$-Century Leadership and those who did not attend the Institute. The explanation of this analysis follows.

The comparison group $\mathrm{N}$ was 175 with a mean score of 4.160 and a standard deviation of .76384. The treatment group $\mathrm{N}$ was 189 with a mean score of 4.164 and a standard deviation of .72902. Levene's Test for Equality of Variances was not significant at .567, indicating that equal variances were assumed. The $t$-Test for Equality of Means showed a two-tailed significance level of .959, which is greater than the .05 alpha level; therefore, the null hypothesis is not rejected. There is not a significant difference in the scores of the comparison and treatment groups in Item 52. The Mann-Whitney $U$ test, the nonparametric equivalent of the parametric $t$-test, verifies the lack of a statistically significant difference in the two groups with a significance level of .926, which is greater than the alpha .05 level.

\section{Survey Item 53}

Item 53 was the statement: I use a transformational leadership approach to create a learning-centered school. The analysis of the respondents' scores for survey Item 53 showed that there was a statistical difference between the responses of the principals who attended the West Virginia Institute for $21^{\text {st }}$-Century Leadership and those who did not attend the Institute. The scores of the principals in the treatment group (those who had attended the Institute) perceived 
their schools to be higher performing than the principals who had not attended the Institute. The explanation of this analysis follows.

The comparison group $\mathrm{N}$ was 171 with a mean score of 3.866 and a standard deviation of .71087. The treatment group $\mathrm{N}$ was 190 with a mean score of 4.040 and a standard deviation of .65850. Levene's Test for Equality of Variances was significant at .024, indicating that equal variances were not assumed, and calculations were adjusted accordingly. The $t$-Test for Equality of Means showed a two-tailed significance level of .017, which is less than the .05 alpha level; therefore, the null hypothesis is rejected. There is a significant difference in the scores of the comparison and treatment groups in Item 53. The effect size, $d$ calculation, is .25, indicating a small effect of the difference made by the treatment. The treatment group scores were larger than the comparison group. The Mann-Whitney $U$ test, the nonparametric equivalent of the parametric $t$-test, verifies the statistically significant difference in the two groups with a significance level of .026, which is less than the alpha .05 level (see Figure 21). Survey Item 54

Item 54 was the statement: There is an expectation in my school that change will be an ongoing, continuous process. The analysis of the respondents' scores for survey Item 54 showed that there was no statistical difference between the responses of the principals who attended the West Virginia Institute for $21^{\text {st }}$-Century Leadership and those who did not attend the Institute. The explanation of this analysis follows.

The comparison group $\mathrm{N}$ was 177 with a mean score of 4.384 and a standard deviation of .53234 . The treatment group $\mathrm{N}$ was 193 with a mean score of 4.365 and a standard deviation of .56595 . Levene's Test for Equality of Variances was not significant at .810, indicating that equal variances were assumed. The $t$-Test for Equality of Means showed a two-tailed significance level 
Figure 21. Statement 53: I use a transformational leadership approach to create a learning-centered school.

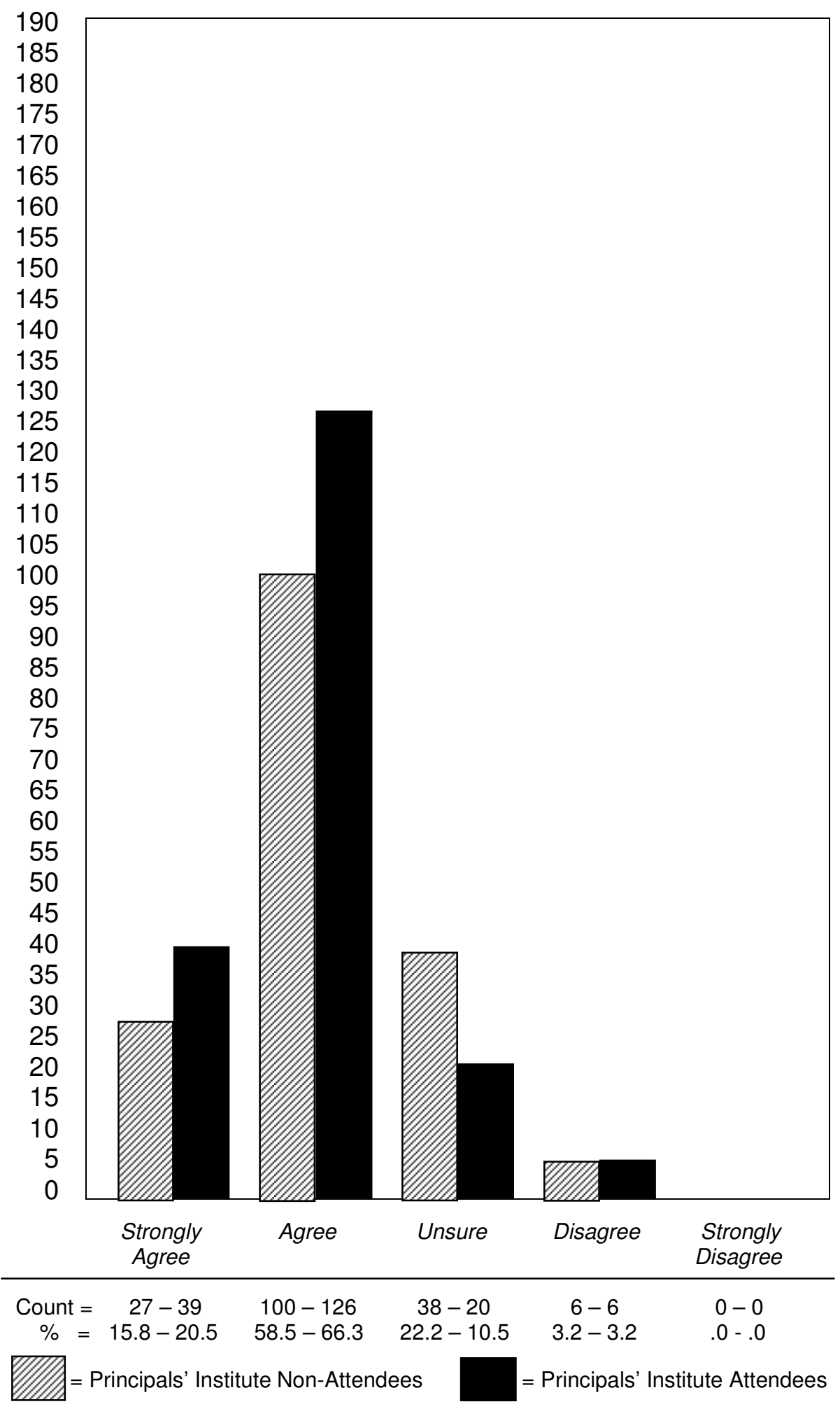

Non-Attendees: 171 answered; 25 skipped question. Attendees: 190 answered; 19 skipped question. 
of .742, which is greater than the .05 alpha level; therefore, the null hypothesis is not rejected. There is not a significant difference in the scores of the comparison and treatment groups in Item 54. The Mann-Whitney $U$ test, the nonparametric equivalent of the parametric $t$-test, verifies the lack of a statistically significant difference in the two groups with a significance level of .874 , which is greater than the alpha .05 level.

Survey Item 55

Item 55 was the statement: In my school, there IS NOT a broad understanding and commitment to the need for change. The analysis of the respondents' scores for survey Item 55 showed that there was no statistical difference between the responses of the principals who attended the West Virginia Institute for $21^{\text {st }}$-Century Leadership and those who did not attend the Institute. The explanation of this analysis follows.

The comparison group $\mathrm{N}$ was 176 with a mean score of 4.298 and a standard deviation of .69934. The treatment group $\mathrm{N}$ was 192 with a mean score of 4.193 and a standard deviation of .70847. Levene's Test for Equality of Variances was not significant at .435, indicating that equal variances were assumed. The $t$-Test for Equality of Means showed a two-tailed significance level of .152, which is greater than the .05 alpha level; therefore, the null hypothesis is not rejected. There is not a significant difference in the scores of the comparison and treatment groups in Item 55. The Mann-Whitney $U$ test, the nonparametric equivalent of the parametric $t$-test, verifies the lack of a statistically significant difference in the two groups with a significance level of .156, which is greater than the alpha .05 level. 
Survey Item 56

Item 56 was the statement: There is a focus on the whole school in the design and implementation of our school's programs. The analysis of the respondents' scores for survey Item 56 showed that there was no statistical difference between the responses of the principals who attended the West Virginia Institute for $21^{\text {st }}$-Century Leadership and those who did not attend the Institute. The explanation of this analysis follows.

The comparison group $\mathrm{N}$ was 175 with a mean score of 4.320 and a standard deviation of .57775. The treatment group $\mathrm{N}$ was 192 with a mean score of 4.216 and a standard deviation of .56643. Levene's Test for Equality of Variances was not significant at .063, indicating that equal variances were assumed. The $t$-Test for Equality of Means showed a two-tailed significance level of .083, which is greater than the .05 alpha level; therefore, the null hypothesis is not rejected. There is not a significant difference in the scores of the comparison and treatment groups in Item 56. The Mann-Whitney $U$ test, the nonparametric equivalent of the parametric $t$-test, verifies the lack of a statistically significant difference in the two groups with a significance level of .116, which is greater than the alpha .05 level.

Survey Item 57

Item 57 was the statement: In our school, personnel understand that change involves system activities and resources that are connected. The analysis of the respondents' scores for survey Item 57 showed that there was no statistical difference between the responses of the principals who attended the West Virginia Institute for $21^{\text {st }}$-Century Leadership and those who did not attend the Institute. The explanation of this analysis follows. 
The comparison group $\mathrm{N}$ was 177 with a mean score of 4.130 and a standard deviation of .67425. The treatment group $\mathrm{N}$ was 192 with a mean score of 4.122 and a standard deviation of .61130. Levene's Test for Equality of Variances was not significant at .409, indicating that equal variances were assumed. The $t$-Test for Equality of Means showed a two-tailed significance level of .910, which is greater than the .05 alpha level; therefore, the null hypothesis is not rejected. There is not a significant difference in the scores of the comparison and treatment groups in Item 57. The Mann-Whitney $U$ test, the nonparametric equivalent of the parametric $t$-test, verifies the lack of a statistically significant difference in the two groups with a significance level of .694, which is greater than the alpha .05 level.

Survey Item 58

Item 58 was the statement: Before we implement a program in our school, we first plan it, then implement it, then evaluate its effects, and act on our evaluation. The analysis of the respondents' scores for survey Item 58 showed that there was no statistical difference between the responses of the principals who attended the West Virginia Institute for $21^{\text {st }}$-Century Leadership and those who did not attend the Institute. The explanation of this analysis follows.

The comparison group $\mathrm{N}$ was 174 with a mean score of 3.991 and a standard deviation of .76874. The treatment group $\mathrm{N}$ was 192 with a mean score of 3.945 and a standard deviation of .80142. Levene's Test for Equality of Variances was not significant at .608, indicating that equal variances were assumed. The $t$-Test for Equality of Means showed a two-tailed significance level of .576 , which is greater than the .05 alpha level; therefore, the null hypothesis is not rejected. There is not a significant difference in the scores of the comparison and treatment groups in Item 58. The Mann-Whitney $U$ test, the nonparametric equivalent of the parametric $t$-test, verifies the 
lack of a statistically significant difference in the two groups with a significance level of .777, which is greater than the alpha .05 level.

Survey Item 59

Item 59 was the statement: I DO NOT believe students need core subjects (English, reading, math, science, and social studies) in order to be successful. The analysis of the respondents' scores for survey Item 59 showed that there was no statistical difference between the responses of the principals who attended the West Virginia Institute for $21^{\text {st }}$-Century Leadership and those who did not attend the Institute. The explanation of this analysis follows.

The comparison group $\mathrm{N}$ was 178 with a mean score of 4.775 and a standard deviation of .48135 . The treatment group $\mathrm{N}$ was 193 with a mean score of 4.790 and a standard deviation of .41927. Levene's Test for Equality of Variances was not significant at .388, indicating that equal variances were assumed. The $t$-Test for Equality of Means showed a two-tailed significance level of .751, which is greater than the .05 alpha level; therefore, the null hypothesis is not rejected. There is not a significant difference in the scores of the comparison and treatment groups in Item 59. The Mann-Whitney $U$ test, the nonparametric equivalent of the parametric $t$-test, verifies the lack of a statistically significant difference in the two groups with a significance level of .979, which is greater than the alpha .05 level.

\section{Survey Item 60}

Item 60 was the statement: Awareness of happenings around the world is important for students' future success. The analysis of the respondents' scores for survey Item 60 showed that there was a statistical difference between the responses of the principals who attended the West Virginia Institute for $21^{\text {st }}$-Century Leadership and those who did not attend the Institute. The 
scores of the principals in the treatment group (those who had attended the Institute) perceived their schools to be higher performing than the principals who had not attended the Institute. The explanation of this analysis follows.

The comparison group $\mathrm{N}$ was 178 with a mean score of 4.416 and a standard deviation of .62543. The treatment group $\mathrm{N}$ was 191 with a mean score of 4.560 and a standard deviation of .53831. Levene's Test for Equality of Variances was not significant at .297, indicating that equal variances were assumed. The $t$-Test for Equality of Means showed a two-tailed significance level of .018, which is less than the .05 alpha level; therefore, the null hypothesis is rejected. There is a significant difference in the scores of the comparison and treatment groups in Item 60 . The effect size, $d$ calculation, is .25 , indicating a small effect of the difference made by the treatment. The treatment group scores were larger than the comparison group. The Mann-Whitney $U$ test, the nonparametric equivalent of the parametric $t$-test, verifies the statistically significant difference in the two groups with a significance level of .046, which is less than the alpha .05 level (see Figure 22).

\section{Survey Item 61}

Item 61 was the statement: Understanding business and finance is important for students' future success. The analysis of the respondents' scores for survey Item 61 showed that there was no statistical difference between the responses of the principals who attended the West Virginia Institute for $21^{\text {st }}$-Century Leadership and those who did not attend the Institute. The explanation of this analysis follows. 
Figure 22. Statement 60: Awareness of happenings around the world is important for students' future success.

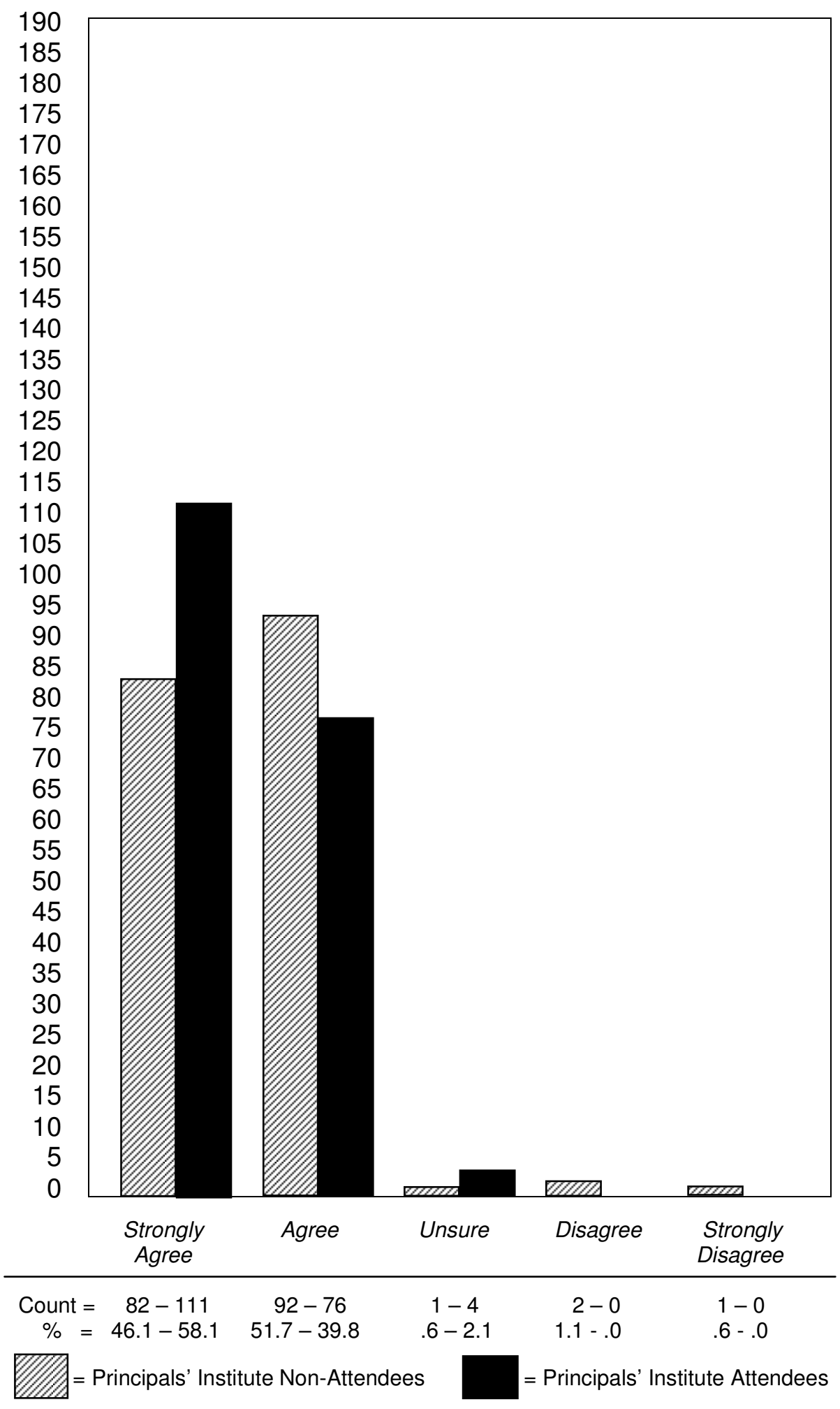

Non-Attendees: 178 answered; 18 skipped question. Attendees: 191 answered; 18 skipped question. 
The comparison group $\mathrm{N}$ was 176 with a mean score of 4.301 and a standard deviation of .68885. The treatment group $\mathrm{N}$ was 192 with a mean score of 4.432 and a standard deviation of .58390 . Levene's Test for Equality of Variances was significant at .598, indicating that equal variances were assumed. The $t$-Test for Equality of Means showed a two-tailed significance level of .049, which is slightly less than the .05 alpha level. Based on this alone, the null hypothesis is rejected. The Mann-Whitney $U$ test, the nonparametric equivalent of the parametric $t$-test, however, shows a significance level of .156 , which is greater than the alpha .05 level. When the parametric and non-parametric measures differ, the non-parametric measure prevails; therefore, there is not a significant difference in the scores of the comparison and treatment groups in Item 61.

Survey Item 62

Item 62 was the statement: Knowledge of government is important for students' future success. The analysis of the respondents' scores for survey Item 62 showed that there was no statistical difference between the responses of the principals who attended the West Virginia Institute for $21^{\text {st }}$-Century Leadership and those who did not attend the Institute. The explanation of this analysis follows.

The comparison group $\mathrm{N}$ was 175 with a mean score of 4.326 and a standard deviation of .61790. The treatment group $\mathrm{N}$ was 192 with a mean score of 4.412 and a standard deviation of .58109 . Levene's Test for Equality of Variances was not significant at .417 , indicating that equal variances were assumed. The $t$-Test for Equality of Means showed a two-tailed significance level of .172, which is greater than the .05 alpha level; therefore, the null hypothesis is not rejected. There is not a significant difference in the scores of the comparison and treatment groups in Item 
62. The Mann-Whitney $U$ test, the nonparametric equivalent of the parametric $t$-test, verifies the lack of a statistically significant difference in the two groups with a significance level of .248, which is greater than the alpha .05 level.

Survey Item 63

Item 63 was the statement: Health and wellness awareness is important for students' future success. The analysis of the respondents' scores for survey Item 63 showed that there was no statistical difference between the responses of the principals who attended the West Virginia Institute for $21^{\text {st }}$-Century Leadership and those who did not attend the Institute. The explanation of this analysis follows.

The comparison group $\mathrm{N}$ was 176 with a mean score of 4.477 and a standard deviation of .60431. The treatment group $\mathrm{N}$ was 192 with a mean score of 4.537 and a standard deviation of .57770 . Levene's Test for Equality of Variances was not significant at .757, indicating that equal variances were assumed. The $t$-Test for Equality of Means showed a two-tailed significance level of .338 , which is greater than the .05 alpha level; therefore, the null hypothesis is not rejected. There is not a significant difference in the scores of the comparison and treatment groups in Item 63. The Mann-Whitney $U$ test, the nonparametric equivalent of the parametric $t$-test, verifies the lack of a statistically significant difference in the two groups with a significance level of .371, which is greater than the alpha .05 level.

Survey Item 64

Item 64 was the statement: Information and communication skills are important for students' future success. The analysis of the respondents' scores for survey Item 64 showed that there was a statistical difference between the responses of the principals who attended the West 
Virginia Institute for $21^{\text {st }}$-Century Leadership and those who did not attend the Institute. The scores of the principals in the treatment group (those who had attended the Institute) perceived their schools to be higher performing than the principals who had not attended the Institute. The explanation of this analysis follows.

The comparison group $\mathrm{N}$ was 176 with a mean score of 4.619 and a standard deviation of .48694 . The treatment group $\mathrm{N}$ was 191 with a mean score of 4.759 and a standard deviation of .42872. Levene's Test for Equality of Variances was significant at .000, indicating that equal variances were not assumed, and calculations were adjusted accordingly. The $t$-Test for Equality of Means showed a two-tailed significance level of .004, which is less than the .05 alpha level; therefore, the null hypothesis is rejected. There is a significant difference in the scores of the comparison and treatment groups in Item 64 . The effect size, $d$ calculation, is .31 , indicating a small effect of the difference made by the treatment. The treatment group scores were larger than the comparison group. The Mann-Whitney $U$ test, the nonparametric equivalent of the parametric $t$-test, verifies the statistically significant difference in the two groups with a significance level of .020, which is less than the alpha .05 level (see Figure 23).

\section{Survey Item 65}

Item 65 was the statement: Thinking and problem-solving are important for students' future success. The analysis of the respondents' scores for survey Item 65 showed that there was showed that there was no statistical difference between the responses of the principals who attended the West Virginia Institute for $21^{\text {st }}$-Century Leadership and those who did not attend the Institute. The explanation of this analysis follows. 
Figure 23. Statement 64: Information and communication skills are important for students' future success.

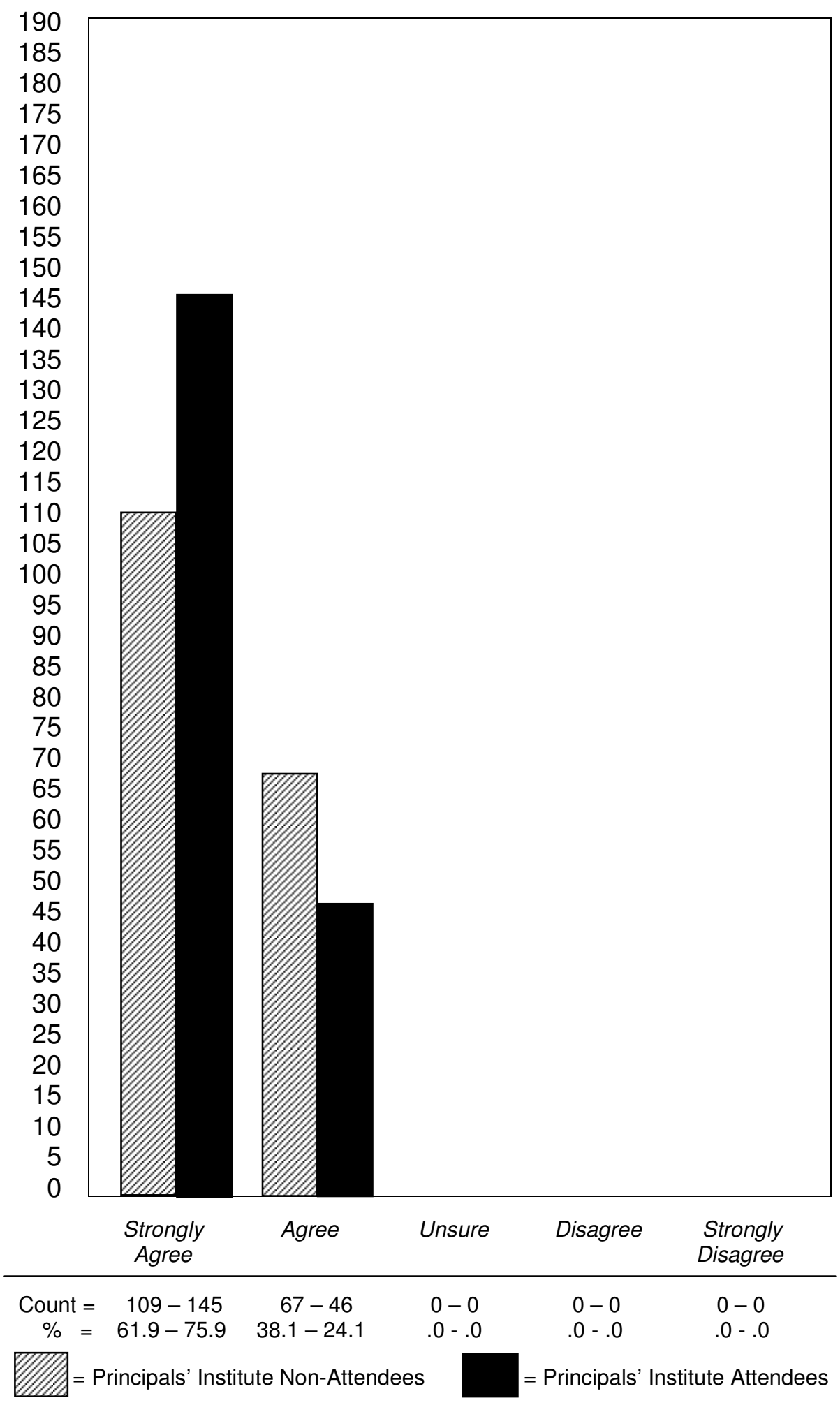

Non-Attendees: 176 answered; 20 skipped question. Attendees: 191 answered; 18 skipped question. 
The comparison group $\mathrm{N}$ was 177 with a mean score of 4.706 and a standard deviation of .45679. The treatment group $\mathrm{N}$ was 191 with a mean score of 4.812 and a standard deviation of .39212. Levene's Test for Equality of Variances was significant at .000, indicating that equal variances were not assumed, and calculations were adjusted accordingly. The $t$-Test for Equality of Means showed a two-tailed significance level of .019, which is less than the .05 alpha level. Based on this alone, the null hypothesis could be rejected; however, the Mann-Whitney $U$ test, the nonparametric equivalent of the parametric $t$-test shows a significance level of .079 , which is greater than the alpha .05 level. When the parametric and non-parametric measures differ, the non-parametric measure prevails; therefore, there is not a significant difference in the scores of the comparison and treatment groups in Item 65.

\section{Survey Item 66}

Item 66 was the statement: Interpersonal and self-directional skills are important for students' future success. The analysis of the respondents' scores for survey Item 66 showed that there was a statistical difference between the responses of the principals who attended the West Virginia Institute for $21^{\text {st }}$-Century Leadership and those who did not attend the Institute. The scores of the principals in the treatment group (those who had attended the Institute) perceived their schools to be higher performing than the principals who had not attended the Institute. The explanation of this analysis follows.

The comparison group $\mathrm{N}$ was 177 with a mean score of 4.582 and a standard deviation of .50600 . The treatment group $\mathrm{N}$ was 193 with a mean score of 4.757 and a standard deviation of .43032. Levene's Test for Equality of Variances was significant at .000, indicating that equal variances were not assumed, and calculations were adjusted accordingly. The $t$-Test for Equality of Means showed a two-tailed significance level of .000 , which is less than the .05 alpha level; 
therefore, the null hypothesis is rejected. There is a significant difference in the scores of the comparison and treatment groups in Item 66 . The effect size, $d$ calculation, is .37, indicating a small effect of the difference made by the treatment. The treatment group scores were larger than the comparison group. The Mann-Whitney $U$ test, the nonparametric equivalent of the parametric $t$-test, verifies the statistically significant difference in the two groups with a significance level of .004, which is less than the alpha .05 level (see Figure 24).

\section{Survey Item 67}

Item 67 was the statement: Twenty-first-century tools (computers and other technology) should be used with learning skills in order for students to be successful. The analysis of the respondents' scores for survey Item 67 showed that there was a statistical difference between the responses of the principals who attended the West Virginia Institute for $21^{\text {st }}$-Century Leadership and those who did not attend the Institute. The scores of the principals in the treatment group (those who had attended the Institute) perceived their schools to be higher performing than the principals who had not attended the Institute. The explanation of this analysis follows.

The comparison group $\mathrm{N}$ was 176 with a mean score of 4.580 and a standard deviation of .50645. The treatment group $\mathrm{N}$ was 192 with a mean score of 4.771 and a standard deviation of .43364. Levene's Test for Equality of Variances was significant at .000, indicating that equal variances were not assumed, and calculations were adjusted accordingly. The $t$-Test for Equality of Means showed a two-tailed significance level of .000 , which is less than the .05 alpha level; therefore, the null hypothesis is rejected. There is a significant difference in the scores of the comparison and treatment groups in Item 67 . The effect size, $d$ calculation, is .41 , indicating a small effect of the difference made by the treatment. The treatment group scores were larger than the comparison group. The Mann-Whitney $U$ test, the nonparametric equivalent of the 
Figure 24. Statement 66: Interpersonal and self-directional skills are important for students' future success.

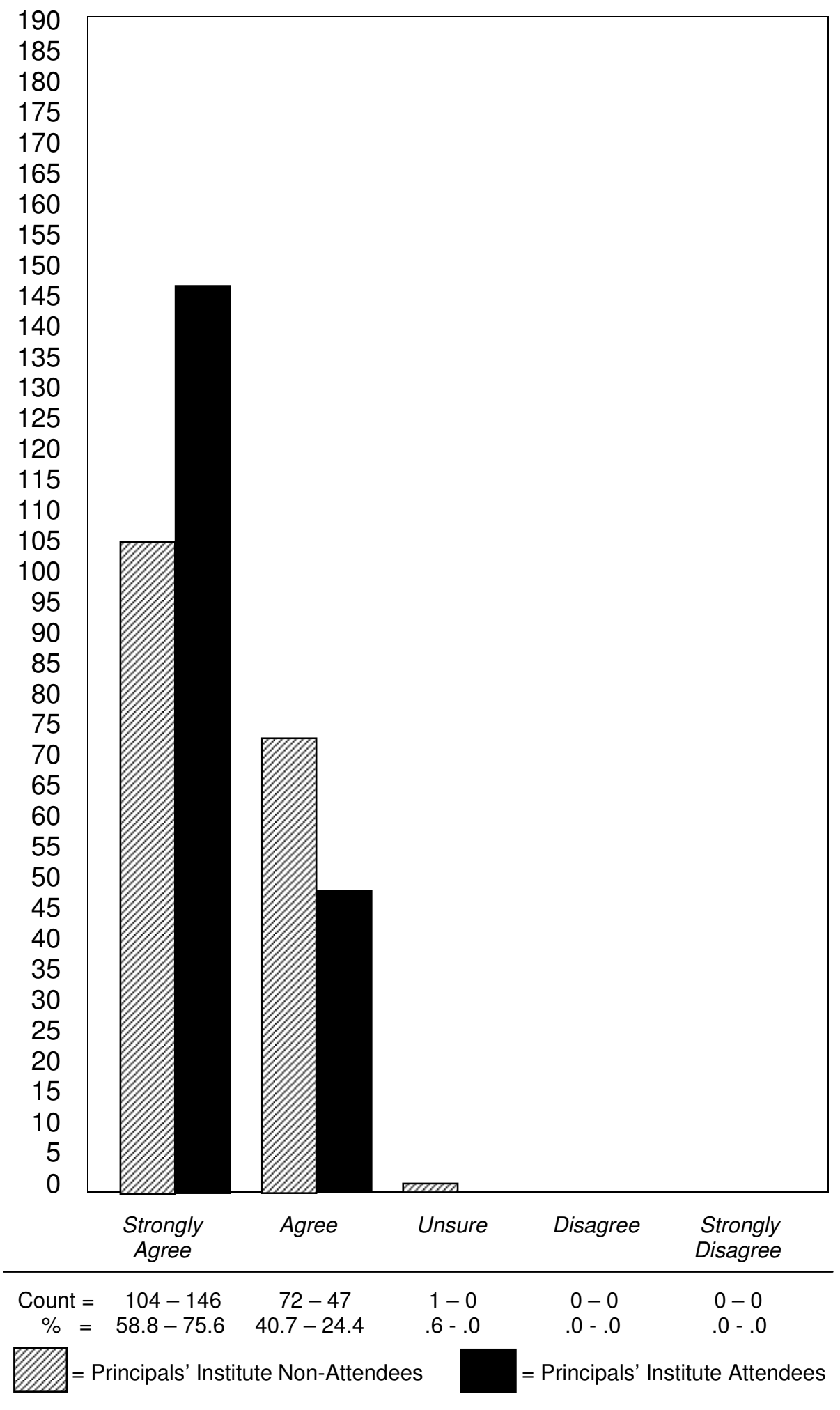

Non-Attendees: 177 answered; 19 skipped question. Attendees: 193 answered; 16 skipped question. 
parametric $t$-test, verifies the statistically significant difference in the two groups with a significance level of .002, which is less than the alpha .05 level (see Figure 25).

\section{Survey Item 68}

Item 68 was the statement: Ethics, including personal responsibility, are important for students' success. The analysis of the respondents' scores for survey Item 68 showed that there was a statistical difference between the responses of the principals who attended the West Virginia Institute for $21^{\text {st }}$-Century Leadership and those who did not attend the Institute. The scores of the principals in the treatment group (those who had attended the Institute) perceived their schools to be higher performing than the principals who had not attended the Institute. The explanation of this analysis follows.

The comparison group $\mathrm{N}$ was 175 with a mean score of 4.629 and a standard deviation of .48457. The treatment group $\mathrm{N}$ was 194 with a mean score of 4.778 and a standard deviation of .42869. Levene's Test for Equality of Variances was significant at .000, indicating that equal variances were not assumed, and calculations were adjusted accordingly. The $t$-Test for Equality of Means showed a two-tailed significance level of .002, which is less than the .05 alpha level; therefore, the null hypothesis is rejected.

There is a significant difference in the scores of the comparison and treatment groups in Item 66. The effect size, $d$ calculation, is .33 , indicating a small effect of the difference made by the treatment. The treatment group scores were larger than the comparison group. The MannWhitney $U$ test, the nonparametric equivalent of the parametric $t$-test, verifies the statistically significant difference in the two groups with a significance level of .010, which is less than the alpha .05 level (see Figure 26). 
Figure 25. Statement 67: Twenty-first-century tools (computers and other technology) should be used with learning skills in order for students to be successful.

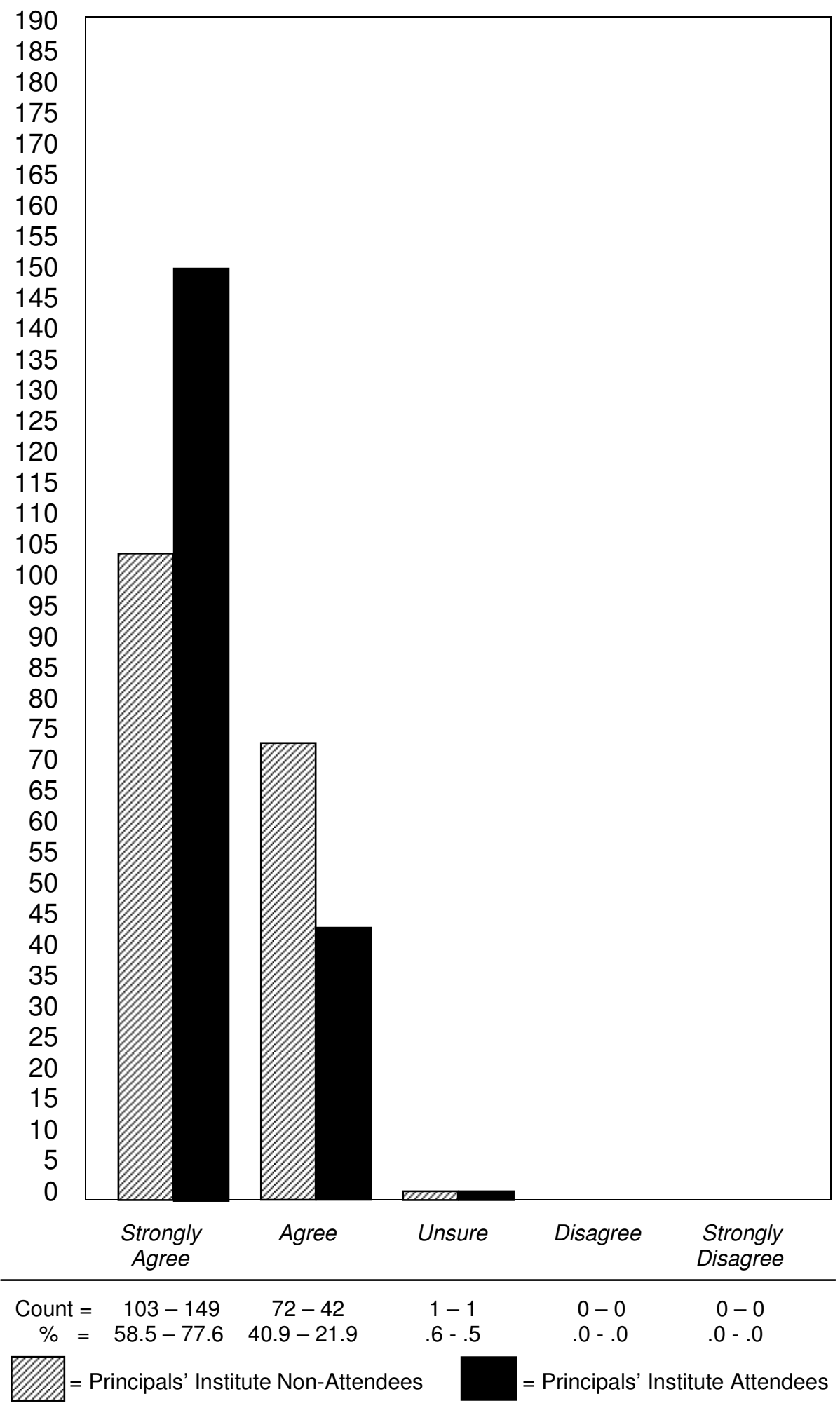

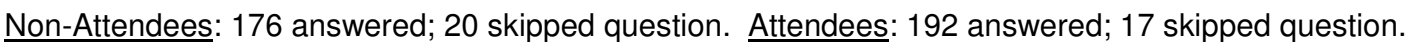


Figure 26. Statement 68: Ethics, including personal responsibility, are important for students' success.

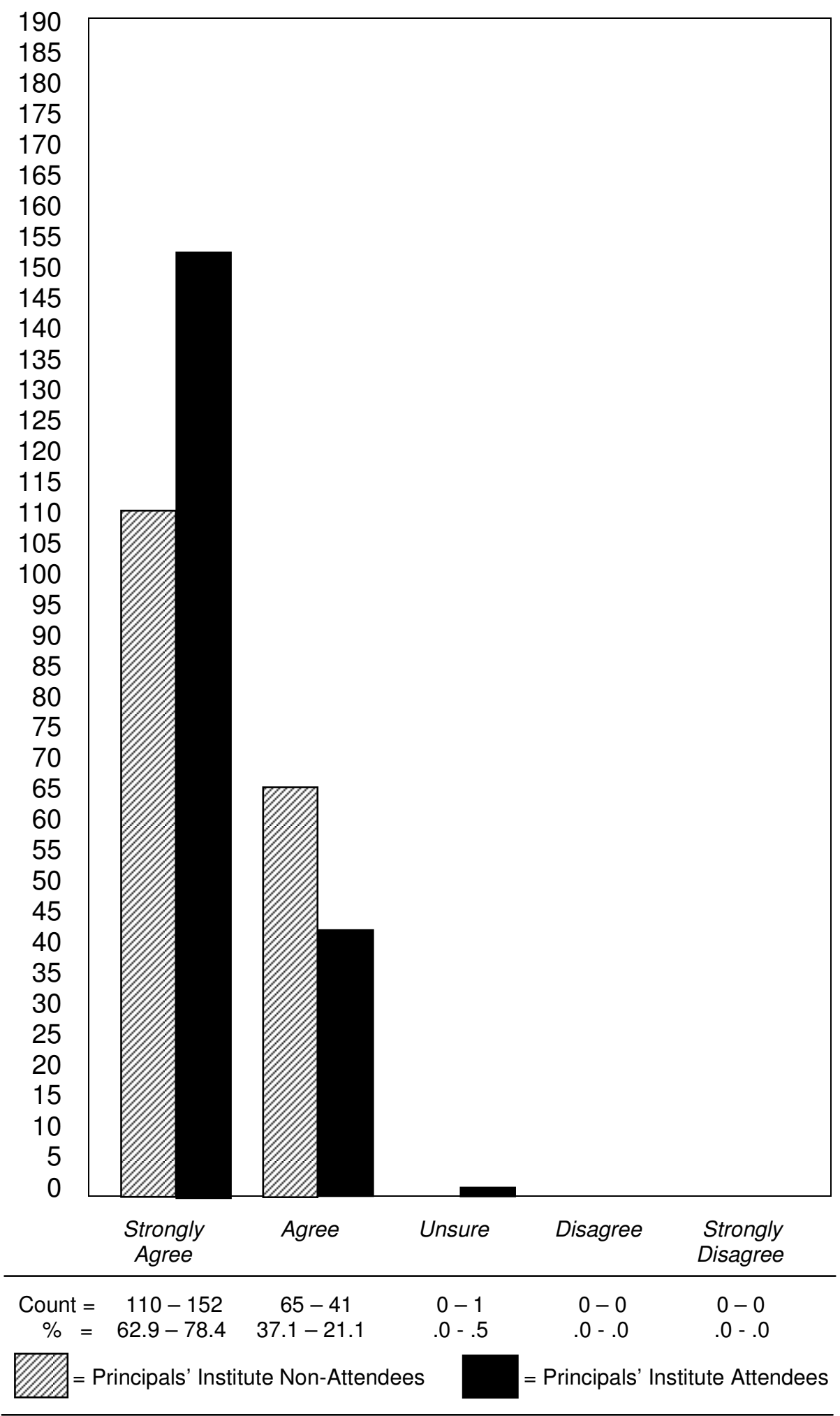

Non-Attendees: 175 answered; 21 skipped question. Attendees: 194 answered; 15 skipped question. 
Survey Item 69

Item 69 was the statement: Self-direction and social responsibility are important for students' success. The analysis of the respondents' scores for survey Item 69 showed that there was a statistical difference between the responses of the principals who attended the West Virginia Institute for $21^{\text {st }}$-Century Leadership and those who did not attend the Institute. The scores of the principals in the treatment group (those who had attended the Institute) perceived their schools to be higher performing than the principals who had not attended the Institute. The explanation of this analysis follows.

The comparison group $\mathrm{N}$ was 177 with a mean score of 4.605 and a standard deviation of .52395. The treatment group $\mathrm{N}$ was 190 with a mean score of 4.7732 and a standard deviation of .45606. Levene's Test for Equality of Variances was significant at, .000 indicating that equal variances were not assumed, and calculations were adjusted accordingly. The $t$-Test for Equality of Means showed a two-tailed significance level of .014, which is less than the .05 alpha level; therefore, the null hypothesis is rejected. There is a significant difference in the scores of the comparison and treatment groups in Item 69 . The effect size, $d$ calculation, is .26, indicating a small effect of the difference made by the treatment. The treatment group scores were larger than the comparison group. The Mann-Whitney $U$ test, the nonparametric equivalent of the parametric $t$-test, verifies the statistically significant difference in the two groups with a significance level of .045, is less than the alpha .05 level (see Figure 27).

\section{Survey Item 70}

Item 70 was the statement: Student assessments should measure thinking skills in addition to knowledge of core subjects. The analysis of the respondents' scores for survey Item 70 showed that there was no statistical difference between the responses of the principals who 
Figure 27. Statement 69: Self-direction and social responsibility are important for students' success.

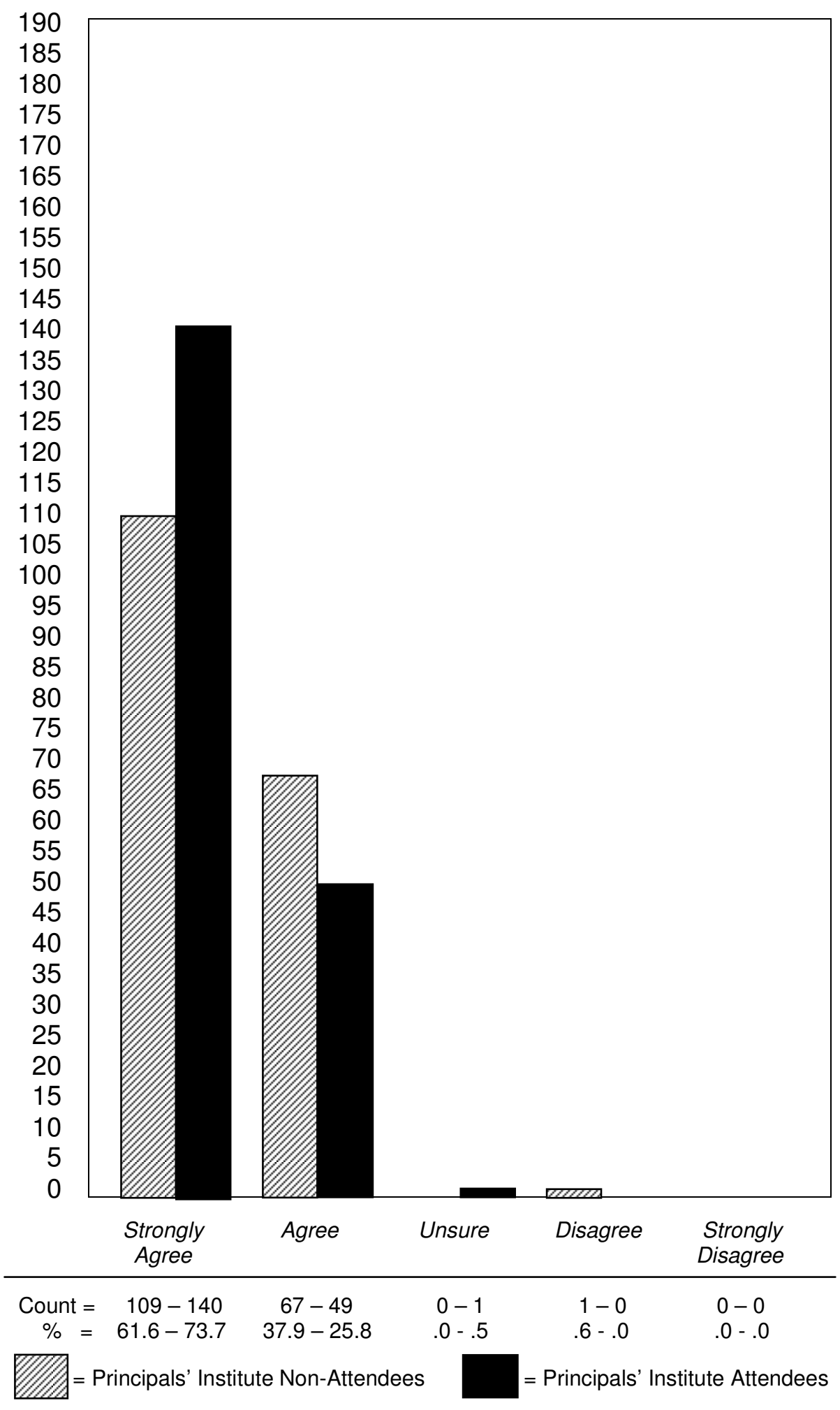

Non-Attendees: 177 answered; 19 skipped question. Attendees: 190 answered; 19 skipped question. 
attended the West Virginia Institute for $21^{\text {st }}$-Century Leadership and those who did not attend the Institute. The explanation of this analysis follows.

The comparison group $\mathrm{N}$ was 177 with a mean score of 4.486 and a standard deviation of .55501 . The treatment group $\mathrm{N}$ was 191 with a mean score of 4.586 and a standard deviation of .56347. Levene's Test for Equality of Variances was not significant at .476, indicating that equal variances were assumed. The $t$-Test for Equality of Means showed a two-tailed significance level of .086, which is greater than the .05 alpha level; therefore, the null hypothesis is not rejected. There is not a significant difference in the scores of the comparison and treatment groups in Item 70. The Mann-Whitney $U$ test, the nonparametric equivalent of the parametric $t$-test, verifies the lack of a statistically significant difference in the two groups with a significance level of .86, which is greater than the alpha .05 level.

\section{Analysis of Narrative Responses}

Question 1: Has the West Virginia Institute for $21^{\text {st }}$-Century Leadership any influence on your school-improvement efforts? If so, please explain.

The responses to this question can be divided into 14 categories: (1) $21^{\text {st }}$-century skills, (2) Change, (3) Concerns, (4) Culture and Climate, (5) Curriculum and Instruction, (6) General Comments, (7) Leadership, (8) Networking, (9) No Influence, (10) Professional Development, (11) Research-Based Strategies, (12) School Improvement, (13) Strategic Planning, (14) Technology, and (15) Yes, with no explanation. A complete listing of all responses from the comparison group made to Question 1 may be seen in Appendix C. A complete listing of all responses from the treatment group made to Question 1 may be seen in Appendix D. See Figure 28 for the number of comments made relating to each category. 
Figure 28. Question 1: Narrative Responses by Category

Question 1 - Has the West Virginia Institute for $21^{\text {st }}$-Century Leadership had any influence on your school-improvement efforts? If yes, please explain.

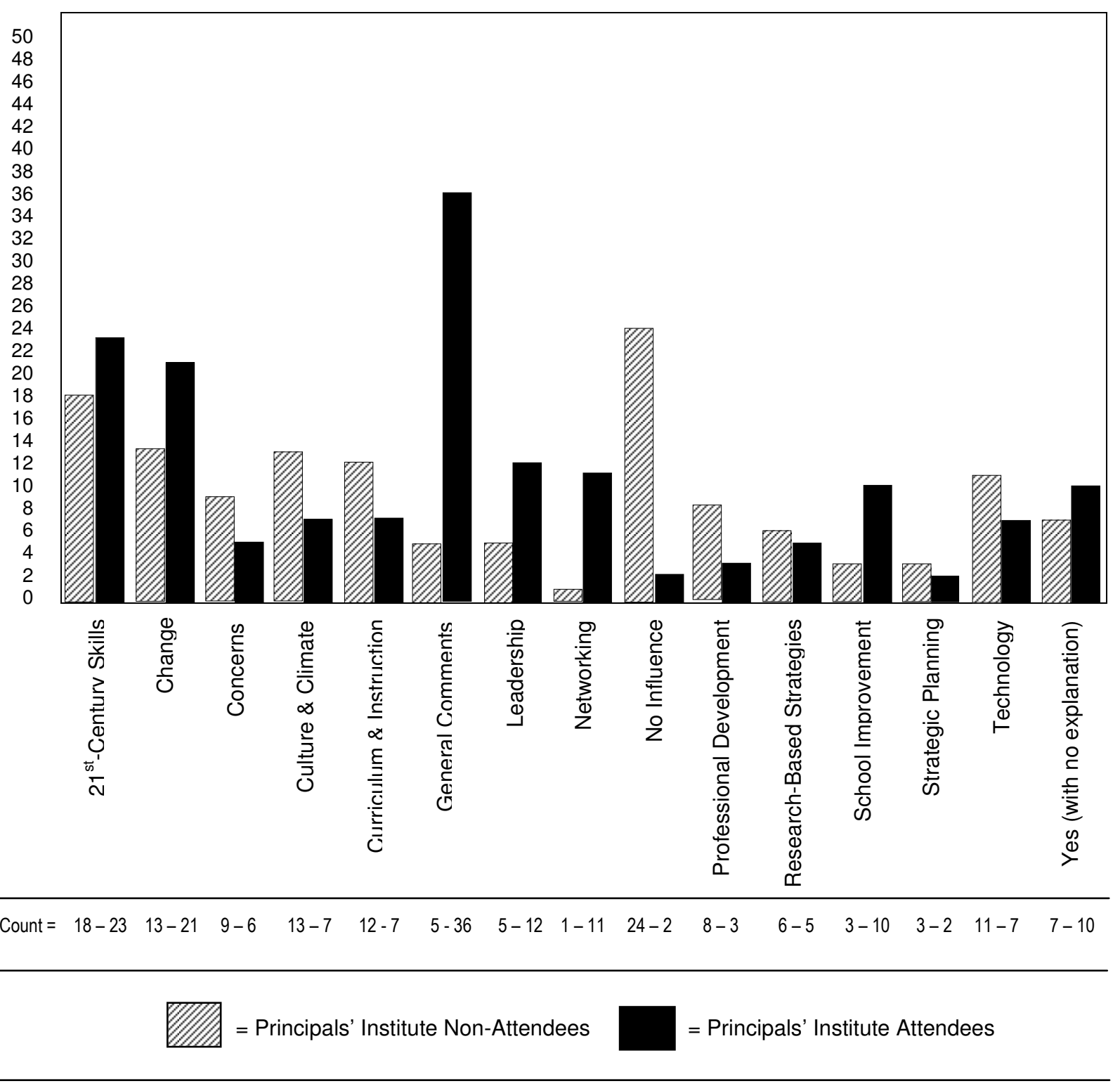


The largest number of comments to this question was in the category of No Influence. In the comparison group, which consisted of principals who had not attended the Institute, 24 respondents commented that the Institute had no influence on their school-improvement efforts. Two respondents in the treatment group responded with No Influence.

Another major disparity between the two groups was in the General category. The five responses from the Comparison group were short and non-specific. It is not clear whether they were referring to the Principals' Leadership Institute or the Teachers' Institute. There were 36 responses in the General category from the treatment group. These were all positive and expressed a great deal of support for the Principals' Institute.

The third largest disparity in the responses of the two groups dealt with the category of Networking. Only one member of the comparison group cited networking as having an impact on school-improvement efforts, whereas 11 in the treatment group cited it. There were a substantial number of responses from both groups in the categories of $21^{\text {st }}$-Century Skills and Change.

\section{Comparison Group}

In reviewing comments by respondents to this question, it should be kept in mind that many in this group appeared to be referring to the West Virginia Teacher Leadership Institute. The West Virginia Institute for $21^{\text {st }}$-Century Leadership, which is for principals, is the one to which is referred in this survey. This is a weakness in the survey and the two Institutes should have been clearly distinguished.

The overwhelming majority of those providing written responses, approximately 80 percent, stated that the Institute has affected their school-improvement efforts in positive ways. Twenty-four respondents indicated that the Institute had no influence on their school- 
improvement efforts; however, as members of the comparison group, they had not attended the Institute. Nine respondents listed concerns generally unrelated to the Institute.

Of those who provided positive responses, the most comments (19) were related to $21^{\text {st }}$ century skills. Comments in this category covered topics ranging from making educators more aware of $21^{\text {st }}$-century skills to providing guidance on how to provide those skills to students.

Some responses focused on responses for students. Examples of this include "What students must know in a global marketplace" and "social, political and environmental issues." Other responses discussed instructional strategies related to $21^{\text {st }}$-century skills. Examples of this include, "Geared much of strategic plan to development of $21^{\text {st }}$-century skills," and "Our county and school goals are all based on instruction and assessment of $21^{\text {st }}$-century skills."

Three other categories of responses from those who believed the Institute had an influence on their school-improvement efforts provided similar numbers of responses. They were (1) School Culture and Climate with 13 responses; (2) Change with 13 responses; (3) Curriculum and Instruction with 12 responses; and (4) Use of Technology with 11 responses.

A common thread among those whose comments dealt with school culture and climate was that all indicated, either directly, indirectly, or by implication, that the Institute (which may have been interpreted as the Teachers' Institute) had been beneficial. Direct indicators were provided by comments such as, "energized staff," and "taught and motivated others." Implications that the Institute had been beneficial were provided by comments indicating that Institute participants had brought back ideas to the school and that participants had shared "many aspects" of the training.

In regard to change, several respondents commented that the Institute had affected their outlook on it in general, and concerning education specifically. Three stated directly that the 
Institute had given them perspective on how change affects their leadership. Three others stated the Institute had provided professional development for leaders in education change. Several for respondents indicated the Institute gave them new perspectives on change, particularly in communicating the urgency for change.

Comments regarding technology indicated that respondents were interested primarily in more training in technology and more use of it. Three of the 11 comments referred to obtaining more equipment at their schools, and one commented that technologically advanced equipment should be purchased and used more. One respondent suggested more access to computer labs would be beneficial, and another referred to laptop computers and specific high-technology programs. Several respondents indicated that more use of advanced technology is being made in their schools. A typical comment in that regard discussed "more teaching using technology and students using computers to learn."

Issues regarding the Institute's effects on curriculum and instruction reflected awareness of $21^{\text {st }}$-century school components and a need to use them in schools. Some respondents indicated the Institute was of direct help in that regard, with one respondent indicating that it provided "a blueprint for what to teach." Others cited specific components of $21^{\text {st }}$-century schools. One respondent noted that the Institute "communicated what we need to allow students to investigate, teach; that we need to use the tolls students are familiar with in educating them."

Eight comments concerning professional development were provided by respondents (in addition to those made under the "change" category). One noted that the Institute "has become a major portion and direction of our continuing education programming." Others suggested that it is important for more educators to be exposed to the Institute. 
The Institute's direct benefits for leaders were discussed by six respondents. Three of the six specifically indicated the Institute's connection to " $21^{\text {st }}$-century leadership" or " $21^{\text {st }}$-century learning."

Six respondents wrote about the research-based strategies provided by the Institute. Three indicated they had "learned new ones," and three wrote that the Institute gave them new insight or reinforced prior training. One respondent appeared to be requesting "more emphasis on Bloom's Taxonomy" from the Institute.

Three respondents tied their comments to strategic planning. Two specifically acknowledged their schools' five-year strategic plans. Three others pointed out school improvement in relation to the Institute. One respondent noted that the Institute had provided "updates and specific information," and another stated that the Institute "helped our school become more aware of the direction we need to go to become a better school."

Five general comments were received. They ranged from one that called the Institute a "wonderful experience" to others who cited information provided on resources, career information, improvement in the "scope of learning," and another that the Institute was "used to make improvements at the school level." Seven respondents stated that the Institute had been influential without explanation with the exception of one who held that it had influenced the school "only marginally."

Of the nine respondents stating concerns, the great majority were not directly related to the Institute itself. Examples of concerns cited ranged from not being able to attend the Institute to "funding not provided for things the Institute presents" and "new and improved technology equipment needed." One respondent wrote that, "We are getting a general understanding of the outline; however, not all the staff is on board." Another suggested that the "WVDE and 
Legislature must provide additional funding for the desperately needed administrative support staff." Another concern noted was that "Monitoring and testing have become overwhelming on all staff."

\section{Treatment Group}

Approximately 90 percent of respondents indicated that the Institute has had an influence on their school-improvement efforts. Of that number, seven responses related to technology. The remaining respondents focused on other influences, such as those involving teaching, leadership techniques, and knowledge of what $21^{\text {st }}$-century learning means to students.

The most responses in any category were listed under the General heading. Examples of general responses in reference to the Institute are, "Fantastic!" and "Very informative." Other examples include, "It has provided me with a shared vision," "The strategies learned have been quite beneficial," and "It has truly changed the way I view education in the $21^{\text {st }}$ century." Also in the general category were statements such as, "It has made me much more aware of the importance of developing those skills in order for students to be successful, responsible adults" and "I have made an effort to implement many of the ideas that I learned at the Instituteimproving culture, climate, involving parents, etc."

Twenty-first-Century Skills, with 23 responses, warranted the second highest number among categories. Examples include, "Yes, it has brought both an awareness and a motivation of the needs to move into the $21^{\text {st }}$ century" and "It has focused us on what we need to do to get ready for the $21^{\text {st }}$ century." A substantial number of responses related to $21^{\text {st }}$-century skills and $21^{\text {st }}$-century learning. Some of these noted that the Institute had made them more aware of precisely what the term " $21^{\text {st }}$-century learning" means. Examples include, "It was a great help in understanding how the $21^{\text {st }}$-century student learns" and "It made me aware of the need to teach 
$21^{\text {st }}$-century skills and provide my staff with the tools necessary to do so." One respondent stated that the Institute had provided "a greater realization of the urgency for us to address the unique needs of $21^{\text {st }}$-century learners."

Close behind the category of $21^{\text {st }}$-Century Skills in number of responses was the "Change" category with 21 responses. Some, such as "It was a great help in dealing with change," and "It has had a huge impact on the need for change," were general in nature. Most responses in this category appeared to reflect respondents' personal attitudes. Examples include, "motivation for change," "made me aware (of) the need for change," and "The urgency for change was brought to my attention." Some respondents cited the help they received at the Institute, as in "The skills I learned there were helpful in managing the change movement in my building," and "It has given me the tools to use to explain the need for change to my teachers."

Respondents appeared to indicate that the Institute made important differences for those attending. For example, in the category of Leadership, the following statements were made: "It has helped me develop my transformational leadership qualities"; "enabled me to provide a more focused approach"; and "helped me to understand effective leadership practices. Very beneficial!" One respondent stated, "It has made ALL the difference! I approach my leadership role differently because of the Institute. Every principal should attend!"

Respondents stated two major benefits under the category of Networking: (1) obtaining information from contacts made through the Institute, and (2) receiving positive reinforcement from these contacts. Examples of such responses include, "Great to have the support of other principals" and "It has given me the opportunity to meet and discuss new ideas with other innovative thinkers." Of the 11 responses in this category, only three discussed networking as it 
pertains to staff in their own schools. An example of this is, "We use professional learning communities."

Ten respondents entered the word, "Yes," without explanation in answer to the question about whether the Institute had any influence on their school-improvement efforts. The seven respondents in the Technology category, however, all discussed the use of equipment. Examples of comments in this category are, "We purchased whiteboards last summer ..." and "We have a greater use of technology in our classroom instruction.” Two explained further with such responses as "It is so important to teach our students the way they learn outside our doors" and "Learning isn't just about reading a book and answering questions anymore."

The Curriculum and Instruction category drew seven responses. Half of them were stated in general terms, such as, "The Institute has provided valuable information, tools, and support to help move us to becoming a school to meet the instructional needs of $21^{\text {st }}$-century learners." Others expressed that, as a result of attending the Institute, their schools were now moving toward a "problem-based curriculum" and "project-based learning.

The School Culture and Climate also provided seven responses. They included statements such as, "It has resulted in higher teacher and student expectations"; "I have attempted to change a large amount of things in our school-like the environment and safety conditions"; and “Technology, building positive relationships with students, building a positive culture.” Some responses generally indicated that the Institute had helped improve their schools' cultures.

Five responses were received under the Research-Based Strategies category. Each of these made a specific point. They included comments on "use of Acuity," "formative assessment," change as a global phenomenon, change in the needs of students, and putting 
strategies in motion "to realize 'whole school' improvement instead of just 'pockets' of improvement."

The three responses under the Professional Development category were all general in nature. "It has given me a wealth of information ..." is an example. Two respondents made comments under the Strategic Planning category. One cited "directed plans," and the other one wrote that the Institute had provided "the Framework for the development of this year's five-year strategic plan and ongoing goal revision."

It should be noted that there were no responses in the No Influence category. Every respondent indicated that there had been some degree of influence on school improvement efforts as a result of the Institute.

Question 2: What do you believe are the greatest challenges to your school in developing students who can be successful, productive citizens?

The responses to this question can be divided into 11 categories: (1) Stress, (2) Socioeconomic Concerns, (3) Needs, (4) $21^{\text {st }}$-Century Learning, (5) Special Education, (6) Student Issues, (7) Curriculum and Instruction, (8) Faculty Attitudes, (9) Accountability, (10) Parent Issues, and (11) Societal Issues. A complete listing of all responses from the comparison group made to Question 2 may be seen in Appendix E. A complete listing of all responses from the treatment group made to Question w may be seen in Appendix F. Figure 29 shows the number of comments made relating to each category.

The largest number of comments to this question by respondents in both groups was in the category of Needs, with 45 comments from the comparison group and 50 from the treatment group. Other categories with large numbers of responses from both groups were Student Issues, Faculty Attitudes, and Parent Issues. 
Figure 29. Question 2: Narrative Responses by Category

Question 2 - What do you believe are the greatest challenges to your school in developing students who can be successful, productive citizens?

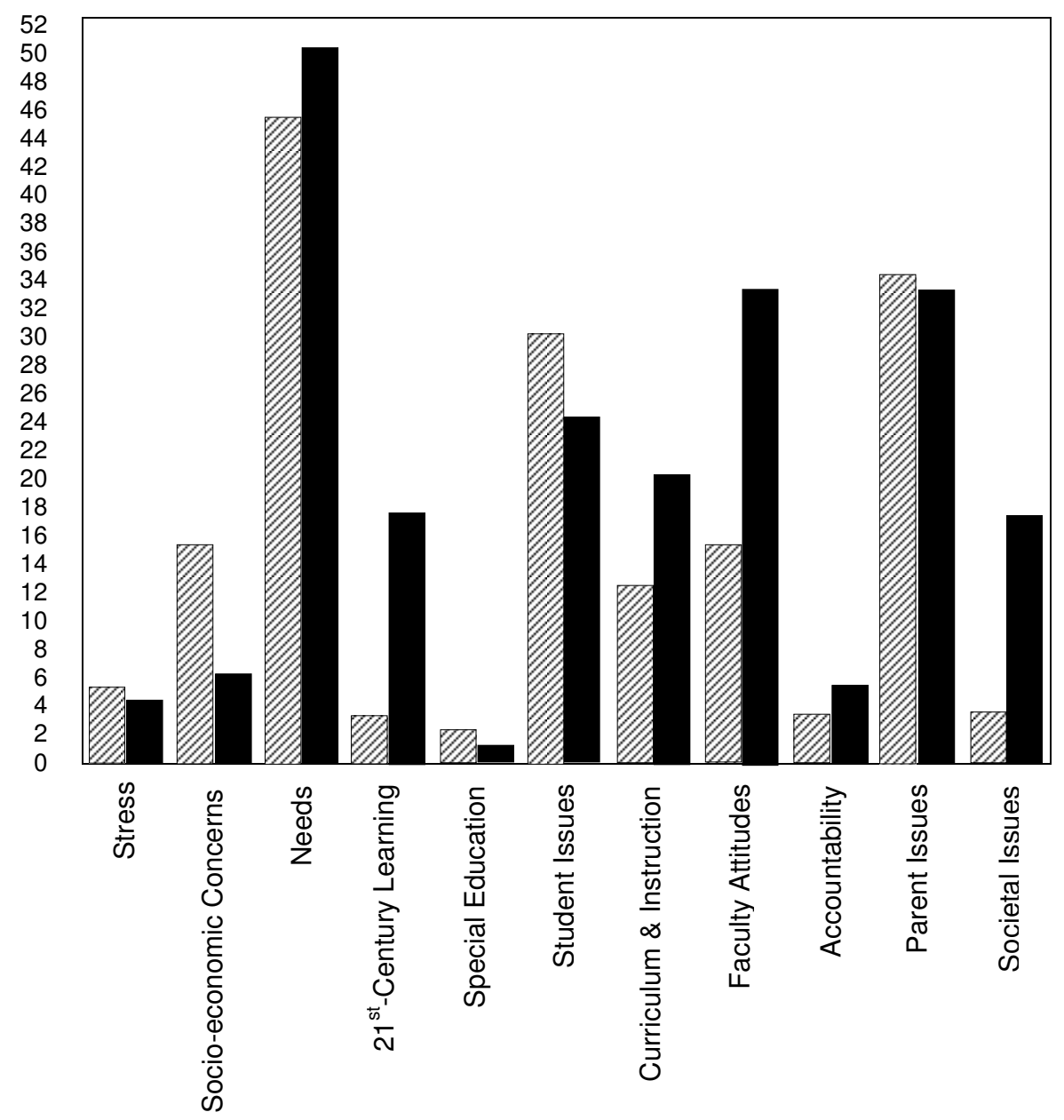

Count $=5-4 \quad 15-6 \quad 45-50 \quad 3-17 \quad 2-1 \quad 30-24 \quad 12-20 \quad 15-33 \quad 3-5 \quad 34-33 \quad 3-17$ 
The greatest disparity between the comparison and treatment groups came in the categories of $21^{\text {st }}$-Century Learning and Societal Issues. In terms of $21^{\text {st }}$-Century Learning, only three members of the comparison Group indicated it was the greatest challenge to developing students who can be successful, productive citizens; whereas, 17 in the treatment group indicated it was a challenge. Exactly the same number of respondents in both groups indicated that Societal Issues were the greatest challenge.

\section{Comparison Group}

A wide variety of issues were cited by respondents to this question. By far, the largest category of responses (45) came under the category of Needs. Close behind, with 34 responses, was Parent Issues. The concept of $21^{\text {st }}$-Century Learning was cited by only three respondents.

The majority of respondents under the Needs category cited a lack of resources, with the word, "time," occurring frequently. Most of the respondents in this category expressed concern that they and others in their schools do not have enough time to do their jobs adequately. Some of these comments were, “Time!" "Time, money, and additional staff”; "Time factors"; “Time and resources to meet the needs of slower learners"; "Time--having enough resources to group children for interventions." Other needs mentioned by respondents included "physical plant," "district funding," "more technology," and "attracting and retaining qualified staff for schools."

Under this category, five of the respondents cited $21^{\text {st }}$-century schools, learning, or skills. Two of those cited needs for more equipment, whereas three others were concerned about staff training and time. Other comments related to needs for better equipment and staff trained in how to use it.

Under the category of Parent Issues, some respondents wrote that parents are not involved in their children's education. Using the words "support" or "involved," 25 respondents 
expressed the need for parents to provide more help with their children's education. More specific concerns were cited by some. Among their responses were: "Changing the culture with parents and students to make education a high priority"; We must make the parents aware of the educational challenge of the future and seek their assistance in its implementation"; "I believe that all stakeholders must be involved in this process. In saying this, the culture of the community can be a challenge before the core beliefs are identified. When the core beliefs are uncovered, then a new direction or focus can be developed while lowering the cultural barriers." A few respondents in this category suggested that basic attitudes need to be changed, with the comment, "Better parenting and less drug abuse."

Another category drawing a large number of comments (30) was Student Issues. Under that category motivation was cited frequently. Ten respondents cited motivation as a problem. Other student issues named included: attendance, discipline, problems at home, and emotional challenges. "Lack of social skills"; “children's home situations"; "our school population is very transient"; "lack of basic education"; "loss of respect"; and "worry about food, shelter, parent safety" were among other responses in this category.

Socio-economic concerns were expressed by 15 respondents, with some of their comments also applicable under Student Issues. Low socio-economic status of students was cited as a challenge by most of those who responded under this category. "We combat the influences of home daily," one respondent wrote. Another cited "lack of coordinated services to meet children's needs from outside the school system." One respondent noted that students with lower socio-economic backgrounds "have no access to technology outside the school environment."

A number of responses equal to that relating to the category of Socio-economic Concerns were received under the category of Faculty Attitudes. A large number of respondents expressed 
concern about their colleagues' attitudes about education. Persuading teachers that change is needed and that progress can be made was brought up by several respondents. Their comments included: "Getting faculty and staff buy-in to changes that are needed for student success"; "improving teachers who don't want to be improved"; and "teachers who are reluctant to change." One respondent noted that "80 percent of our faculty are within five years of retirement; thus, the inclination to change or to do more is not there."

Twelve responses were received under the Curriculum and Instruction category. They were varied and included concerns about "teaching in the way today's students learn"; "teaching reading, relevance of curriculum, curriculum appropriate to students"; "getting the proper attention and focus"; "meeting government mandates."

Five respondents stated that "stress" was their biggest challenge. One used just one word, "bureaucracy," to sum up the stress problem. One referred to the challenge of motivating teachers, whereas, two wrote that "making learning fun" was a challenge. One respondent stated in reference to completing the survey, "I won't be a part of providing more data to justify more and more interventions and put more demands on teachers. All these programs/interventions, in and of themselves, are fine; but when we keep adding without subtracting, the whole kitchen can become messy. Shop, prioritize, then adopt!"

Three respondents contributed to the Societal Issues category. These respondents expressed concerns about students "who feel and whose families feel disenfranchised by our society," with "better student character and morality," and "preparing children adequately before kindergarten. 
Special education was considered a challenge by two respondents. One stated that special-needs children are "neglected and deprived by being held in regular classrooms too much.” Another wanted "a higher level of rigor" for special students.

Just three respondents in this group referred to $21^{\text {st }}$-century learning as a challenge. Their comments were: "To be able to keep up with the pace with how fast society is changing"; "relating an education to the real world of work and how they are interconnected"; and "connectivity to the real world."

\section{Question 3: What kind(s) of professional development would}

be most helpful to you as an education leader?

The responses to this question can be divided into professional development on the following 37 categories: (1) Assessment, (2) At-Risk Students, (3) Change, (4) Classroom Management, (5) Curriculum, (6) Data Analysis, (7) Research, (8) General, (9) Instructional Strategies, (10) Leadership (11) Motivation, (12) Networking, (13) Parent Involvement, (14) Problem Solving, (15) Professional Learning Communities, (16) Project-Based Learning, (17) Response-to-Intervention, (18) Resources, (19) Scheduling, (20) School Culture, (21) Poverty or Socio-Economic Status, (22) Strategic Planning, (23) Standards-Based Learning, (24) Stress Management, (25) Technology, (26) Time Management, (27) Too Much Already, (28) $21^{\text {st }}$ Century Leadership Institute, (29) $21^{\text {st }}$-Century Learning, (30) West Virginia Education Information System [WVEIS], (31) Finances, (32) Teacher Evaluation, (33) People Skills (34) Diverse Learners, (35) Grant Writing, (36) Higher-Order Thinking, and (37) School Law. A complete listing of all responses from the comparison group made to Question 3 may be seen in Appendix G. A complete listing of all responses from the treatment group made to Question 3 
Figure 30. Question 3: Narrative Responses by Category

Question 3 - What kind(s) of professional development would be most helpful to you as an education leader?

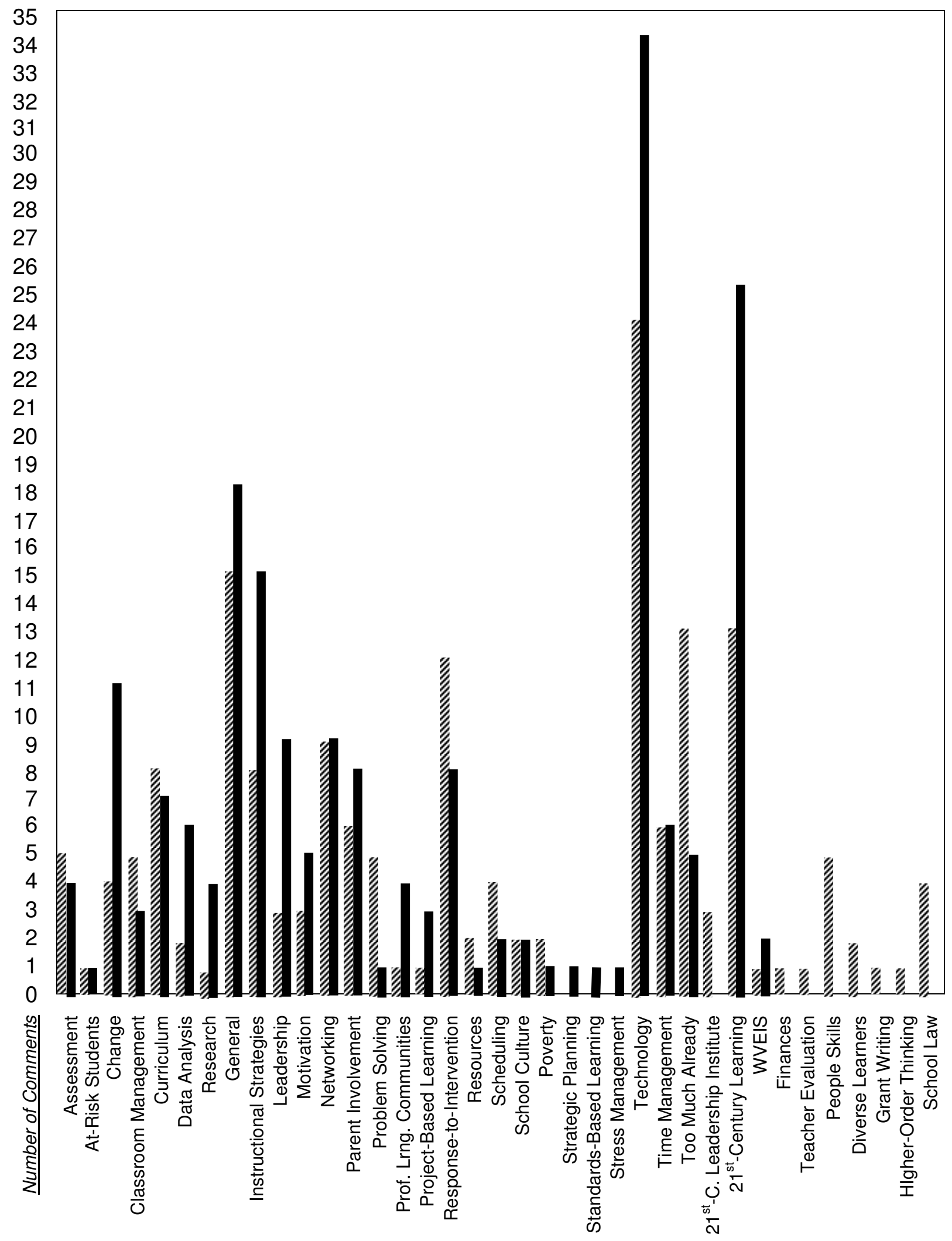


may be seen in Appendix H. Figure 30 shows the number of comments made relating to each category.

More responses to this question were received from the treatment group than from the comparison group in the categories of Change, Classroom Management, Data Analysis, Research, General, Instructional Strategies, Leadership, Motivation, Parent Involvement, Professional Learning Communities, Project-Based Learning, Technology, $21^{\text {st }}$-Century Learning, and the West Virginia Education Information System (WVEIS). More responses to this question were received from the comparison group in the categories of Assessment, At-Risk Students, Curriculum, Networking, Problem Solving, Response-to-Intervention, Resources, Scheduling, School Culture, Poverty or Socio-Economic Status, Time Management, and Too Much Already.

By far, the largest number of requests for professional development was made in the category of Technology. Also noteworthy is the number of respondents in the treatment group who requested professional development in $21^{\text {st }}$-Century Learning.

\section{Comparison Group}

The largest category of responses to this question was Technology, although nine respondents did not provide specific information about their answers. Principals' responses in the Technology category indicate that they believe they are not adequately trained in how to use technology effectively. Typical responses included: "Technology (keeping up with the changes)" and "I am feeling very technologically challenged right now." Only one respondent cited a specific need, which was for "hands-on Podcasting, Excel, [and] Photoshop."

Under the General category, a variety of ideas were suggested. About one-fifth of the responses involved training for, and sometimes by, teachers. One respondent, without offering 
specific recommendations, sought professional development "that addresses real issues/problems and assists in developing real solutions/insights/visions." Another respondent stated, "Currently, Title I provides the type of professional development needed at our school to keep us at Exemplary status." Other comments came from respondents seeking professional development in "the strategic plan," "getting back to basics," "prescription drug abuse," and "the types of staff development you have offered in the past." One respondent noted, "I would value more support from our central office." Another sought development in "how to put together meaningful professional development to meet my staff's needs." One respondent appeared to be indicating he or she wants no professional development activities with the comment, "I will be retiring at the end of this year. I am having major trouble keeping up with the amount of work involved in the administrative position as it is now."

Of the 13 respondents who chose the $21^{\text {st }}$-Century Learning category, six did not add explanatory comments. Responses in this category could be divided into several sub-categories. Two responses were brief, calling for " $21^{\text {st }}$-century tools," and "continue $21^{\text {st }}$-century training." Two responses dealt with seeking professional development that would help educators "aid students in being successful learners" or "competitive in today's world." One sought information on trends for the future, "so we will know a year or two ahead and can make smooth transitions and plans for success." Another wanted professional development on "how to get veteran teachers to change the method in which they teach."

Most of the 13 respondents whose comments fit into the category of Too Much Already wrote that they believe they already have adequate or, in some cases, too many opportunities for professional development. Comments in that regard ranged from, "Give us time to master what we are doing" to "None at this point-I am ready to retire." Other respondents appeared to be 
expressing complaints, such as "We tend to have training on something and then move on to something else" and "We are too quick to jump to the next great idea and never work a particular strategy long enough to test results or evaluate effectiveness."

Twelve responses were received under the category of Response-to-Intervention, although ten of them did not add explanations. One respondent wrote, "Teachers are wanting and needing more tricks up their sleeves for student receiving RTI."

The categories of Networking, Curriculum, and Instructional Strategies drew approximately the same numbers of responses. Under the category of Networking, several respondents made it clear that their priority in this regard is not merely attending meetings with their peers, but "observing other administrators on the job." An equal number of respondents, however, wrote something to the effect of "some reflection time and collaboration with peers can be useful."

Respondents whose comments fell under the category of Curriculum made several detailed points, with three of them focusing on professional development about "standardsbased" curriculum. One respondent specified a need for work on standards-based curriculum in mathematics, whereas another emphasized "in areas other than math." Another respondent cited a need, not for professional development, but for "curriculum personnel."

Instructional Strategies drew eight responses on varied topics. Two sought "the latest teaching techniques." One wanted professional development on "learning the processes that students use in playing electronic games for insight into instructional approaches." Professional development requests were also made in specific topics, such as collaborative teaching, researchbased strategies, and skill-group development. One respondent wanted the "latest data-driven teaching techniques rather than politically driven ones." 
Similar numbers of responses were received expressing needs for professional development under the categories of Time Management, Parent Involvement, Relationships, Classroom Management, and Problem Solving. Four comments under the Time Management category simply cited it as a concern. One respondent wrote, "Time is needed and not there for ANYTHING.” Respondents under the Parent Involvement category had a common theme, summed up by one who stated, "Need ways to get more parent involvement in the school system."

Four different concerns were included in responses under the People Skills category: "handling difficult people," "positive relationships with people in authority," "how to deal with teachers in my building," and "book study on effective emotional understanding" were the responses. Under the category of Classroom Management, two respondents explained their choices. One focused on "more discipline techniques," while the other wanted help in providing “different classroom management techniques" for teachers.

Four of the five respondents under the category of Problem Solving is summarized in the comment of one respondent: "Hands-on professional development instead of lecture is preferred." One respondent stated that professional development should "be done as much as possible in the school itself, dealing with the school's initiatives, not the county's or state's."

Under the remaining 22 categories, four or fewer respondents selected each category. Categories each receiving four responses were Scheduling, Assessment, and School Law. Those receiving three responses each were $21^{\text {st }}$-Century Leadership Institute, Leadership, and Motivation. Those categories receiving two responses each were Community Resources, Diverse Learners, Poverty, Data Analysis, and School Culture. The categories receiving one response each were Finance, Professional Learning Communities, Teacher Evaluation, Benchmark 
Assessments, WVEIS Documentation, Grant Writing, Research-Based Strategies, Project-Based Learning, Higher Order Thinking, and At-Risk Students.

\section{Treatment Group}

Requests for professional development involving $21^{\text {st }}$-century learning strategies and advanced technology were cited by approximately half of the respondents in the treatment group. Some responses in the categories of Instructional Strategies and Change made similar points.

Twelve respondents who indicated a need for professional development under the Technology category did not elaborate. Nearly twice as many, however, did include comments. Some were specific in the types of professional development they considered would be helpful. "Assessment technology," "use and need for technology in core classes" and "technology use; new, developing technology; and how to incorporate use of that technology into the classroom for student learning opportunities" were among such responses. One response was quite specific, citing "professional development that is associated with the new technology innovations, such as student responders, Thinkfinity, blogging for teacher staff development, and any other activities that would enhance the way technology is used to enhance student achievement."

A few responses were wide ranging. Examples include: "Technology training and best practices," "any type of technology training" and "I need as much technology training as I can get." One respondent wanted to "keep up with the latest gadgets." Two respondents requested, not professional development, but to the need for "Technology Integration Specialists in all schools" and "more technology and equipment to back it up."

Of the 25 responses under the category of $21^{\text {st }}$-Century Learning, all respondents appeared to be expressing a need for more information for themselves. Responses such as "Professional development on $21^{\text {st }}$-century learning" and "anything on $21^{\text {st }}$-century instruction" 
are examples. Several respondents cited a need to ensure that "teachers, not just administrators, benefit." Responses such as "All staff would benefit from $21^{\text {st }}$-century learning skills" and "more $21^{\text {st }}$-century skills for teachers" and " $21^{\text {st }}$-century skills in the classroom" are examples. Some noted specific requests for training with such responses as "How to evaluate quality $21^{\text {st }}$-century instructional practices" and " $21^{\text {st }}$-century skills in the classroom" are examples. Some cited specific requests for training, such as "How to evaluate quality, $21^{\text {st }}$-century instructional practices" and " $21^{\text {st }}$-century skills that include strategies and methods supported by technology." A few respondents emphasized what they see as a need for ongoing professional development in this area with such comments, such as "Continued work in $21^{\text {st }}$-century learning skills" and "the ongoing change to $21^{\text {st }}$-century skills."

The third highest number of responses came under the General category. Some respondents suggested specific types of professional development they deemed would be helpful with comments such as "Covey training for the entire staff on the Seven Habits of Highly Effective People," "Progress Monitoring," "Delegation of tasks," "Crisis management techniques," "School law refresher," and "Glasser, Total Behavior Sax, Gurian, Kindlon \& Thompson, Gender Jensen, Brain Research" (punctuation shown here as written in response). Some made suggestions for the format of professional development sessions. Examples of this include "National Conferences" and "I would like for ALL professional development sessions to be held in the summer when I do not have to be out of my building during the school day." One respondent wrote a comment specific to his or her own county: "The most helpful professional development for this county would be for the school board, so they would not look at the 'number' of complaints, but base their judgments on 'principles' and on 'what is best for kids,' not what is best for their teacher friends who can bend their ears." 
Fifteen responses, the fourth highest number, were received under the Instructional Strategies category. Four respondents requested professional development in differentiated instruction. Three respondents cited problem-based learning, whereas, two used the term "research-based" strategies in their responses. Among other responses were those citing “intervention strategies for academic areas and behavioral issues of students," "student engagement," and "higher-level thinking skills."

The Change category drew 11 responses, with seven of them focusing on professional development that would, in the words of two respondents, help to create "positive change in 'not-so-positive' teachers" and "how to inspire and motivate staff to want to continue to change." One respondent suggested professional development to deal with the stresses of change "on faculty and the community."

The Leadership and Networking categories drew the same numbers of responses at nine for each category. Examples of responses under Leadership include "Leaders of leaders," “continued professional development on leadership," "Leaders need to be trained on so many aspects of the school and leadership," and "instructional leadership." Under the Networking category, respondents expressed a variety of thoughts on how professional development could benefit them. Among their ideas are "How others handle everyday situations," "visiting schools to see how organized they are and how successful schools are implementing the needed changes," "bringing leaders together to talk to one another to share best practices," and "group discussions with peers."

Of those whose responses fell under the Parent Involvement category, some expressed concern about convincing parents to become involved in their children's education. Examples are "Parents also need to be held more accountable for student attendance and behavior" and 
"Exposure to new ideas relating to finding ways to get parents and the community involved in the education of our children." A few others responded that professional development is needed on specific ways to help parents become involved in their children's education. For example, this comment was written: "How to train parents in working with their children to develop the responsibility aspect of becoming productive."

Seven responses were received in each of the categories of Curriculum and Response-toIntervention. Under the Curriculum category, responses indicated desire for professional development in a variety of areas; including reading, mathematics, leadership; and content standards and objectives (CSOs). One respondent, addressing the issue of content standards and objectives, requested professional development “. . . specifically for elementary CSOs. It is very hard to separate when instruction should be textbook driven or CSO driven. They want us to have fidelity to the core, and it confuses these lower-grade teachers. It confuses me."

Three of the comments under the category of Response-to-Intervention cited no specifics. Of the four respondents who did elaborate, one wanted "more intervention ideas" and "another wanted "tiered instruction." A third respondent was interested in Response-to-Intervention at the middle-school level, and the fourth respondent commented simply, "With RTI, scheduling is now a nightmare!!! HELP!!!”

Six responses each were received under the categories of Data Analysis, Time Management, and $21^{\text {st }}$-Century Leadership Institute. Of the Data Analysis responses, four were not specific. One sought "more comprehensive training," whereas, the other wanted a "hands-on data analysis workshop where we bring our school's data and analyze it under the direction of an expert." 
Under the Time Management category, responses reflected more concern about handling tasks in the amount of time available rather than about professional development. One respondent stated that "I feel I have been provided with adequate training. I wish I had more time with the staff to work through issues ...." Other similar responses included such comments as "time to be in my school to actually carry out al of the professional development that we have already received" and "more time to work with staff on issues that will improve student achievement."

Responses under the category of $21^{\text {st }}$-Century Leadership Institute were all complimentary. One respondent encapsulated comments in this category by writing, "Nothing could beat the $21^{\text {st }}$-Century Leadership Institute." A few respondents wanted more of the same, with one suggesting, "extended work from the Principals' Institute."

Five responses were received under the Motivation category. Comments were divided among those who wanted professional development ideas and strategies to which they already have been exposed. One expressed frustration with the response, "I am not sure. I have been through so much, and we have provided so much to the faculty, and we still meet with frustration. I don't know what will help; however, we are continuing to move forward." Remaining categories received four or fewer responses. They included Assessment, Effective-Schools Research, and Professional Learning Communities, with four comments each. Classroom Management and Project-Based Learning received three comments each. Receiving two responses each were At-Risk Students, Problem Solving, Resources, Socio-Economic Status, Strategic Planning, Standards-Based Learning, and Stress Management. 


\section{Chapter Summary}

This chapter presents the analysis of the data collected from 405 school

principals in West Virginia in an attempt to answer the question: Is there a statistically significant difference in the perceptions of two groups of principals regarding their schools' progress toward high-performing status as measured by an instrument aligned with the domains of the West Virginia Framework for High-Performing Schools?

The first section is a statistical analysis of survey responses by domain of the Framework. The null hypothesis for each of the seven domains is: There is no statistically significant difference in Domain X scores when comparing individuals who have participated in the West Virginia Institute for $21^{\text {st }}$-Century Leadership with those who have not attended the Institute, that is $H_{0}: \mu_{1}=\mu_{2 . .}$ The alternative hypothesis for each of the seven domains is: There is a statistically significant difference in Domain X scores when comparing individuals who have participated in the West Virginia Institute for $21^{\text {st }}$-Century Leadership with those who have not attended the Institute, that is $H_{0}: \mu_{1} \neq \mu_{2}$.

The second section of this chapter is a statistical analysis of survey responses by individual question. This is an attempt to delve into the specifics of the responses within each domain.

The third section of this chapter provides a description of the narrative responses of both the comparison and treatment groups to the three open-ended questions: (1) Has the West Virginia Institute for $21^{\text {st }}$-Century Leadership had any influence on your school-improvement efforts? If yes, please explain. (2) What do you believe are the greatest challenges to your school in developing students who can be successful, productive citizens? (3) What kinds of professional development would be most helpful to you as an education leader? 
The $t$-test for the two independent sample groups is the parametric test of significance used in this study to determine whether the observed difference in the scores of the two groups is sufficiently larger than the difference that would be expected solely by chance. The MannWhitney $U$ test, the nonparametric equivalent of the $t$-test was also used on the same comparisons to verify the results. For the cases in which the results of both parametric and nonparametric showed agreement on the significance level, the results were reported with reasonable confidence. When the results differed, the non-parametric results were reported (Suskie, 1996). Also used in this analysis is the Cohen $d$ calculation of the effect size, representing the power of the treatment.

This study yielded a response rate of 67 percent, although not all respondents answered all questions. Far more elementary-school principals in both the comparison and treatment groups responded to the survey than principals at any other programmatic level. The secondhighest number of respondents came from the middle-school level principals in the treatment group, but their numbers were only about half of those in the elementary-school principal group. The results, then, must be weighed primarily, although not entirely, from the perspective of principals in West Virginia's elementary schools. The numbers of male and female respondents in both groups were similar, thereby dismissing gender as a primary factor.

At first glance, it would appear that the perceptions of the 405 West Virginia principals who responded to the survey were similar in all seven domains of the Framework for HighPerforming Schools. In all domains in both groups, the mean score showed principals' perceptions close to the category of "Agree" (as opposed to "Strongly Agree") that their schools were high performing. 
In all cases of statistically significant differences in both domains and statements, the effect sizes of the differences were small. Statistically significant differences, however, were found in two domains of the Framework. In the domain of Instructional Practices, principals who had not attended the Institute for $21^{\text {st }}$-Century Leadership perceived that their schools were higher performing than those principals who had attended the Institute. In the domain of $21^{\text {st }}$ Century Skills, principals who had attended the Institute perceived their schools to be higher performing than principals who had not attended.

Of the 70 statements in the survey, a statistically significant difference was found between the treatment and comparison groups in 16 statements. Those who had not attended the Institute had statistically higher perception ratings for the following eight statements:

11. All the teachers in my school use performance benchmarks to measure student achievement.

12. All the teachers in my school use formative assessments that align with county performance benchmarks.

17. The teachers in my school show respect for all students regardless of individual differences.

19. The students in my school are being developed into self-directed learners who are responsible for improving their own work.

20. The teachers in my school use differentiated instruction to meet the varied needs of learners.

22. The teachers in my school use performance assessments to determine the level of student mastery. 
25. Comprehension development strategies are used in all classrooms in my school in all content areas.

37. Our school has a data management system to analyze data trends and establish priorities.

Those who had attended the Institute had statistically higher perception ratings for the following eight statements:

1. I believe all children can achieve mastery of the essential curriculum, given appropriate time and conditions.

53. I use a transformational leadership approach to create a learning-centered school.

60. Awareness of happenings around the world is important for students' future success.

64. Information and communication skills are important for students' future success.

66. Interpersonal and self-directional skills are important for students' future success.

67. Twenty-first-century tools (computers and technology) should be used with learning skills in order for students to be successful.

68. Ethics, including personal responsibility, are important for students' success.

69. Self-direction and social responsibility are important for students' success.

Six of the eight statements for which the Institute attendees' perceptions were higher than the non-attendees fell under the domain of $21^{\text {st }}$-Century Skills. Five of the eight statements for 
which the non-attendees' perceptions were higher than the attendees fell under the domain of Instructional Practices.

An explanation logically follows the description of the data analysis. Explanation, by helping us understand situations well enough to predict what will happen, allows us to take steps to change projected outcomes (Krathwohl, 1998). The following chapter presents the major conclusions drawn from the analysis of the data generated by this research . 


\section{CHAPTER FIVE: RESULTS}

This study provides a picture of school performance in West Virginia as seen through the lens of its school principals. The convincing picture painted by the perceptions of 67 percent of the state's principals is that the Institution for $21^{\text {st }}$-Century Leadership has had a positive influence on school improvement in West Virginia.

This claim is substantiated by a careful and thorough analysis of the data collected in this research. The null hypothesis was rejected in two of the seven domains of the Framework for High-Performing Schools: Instructional Strategies and $21^{\text {st }}$-Century Skills. Conclusions warranted by the analysis of these data, as well as an explanation of how the conclusions were substantiated, will be cited in this chapter after a synopsis of the study. The chapter will conclude with recommendations for further study.

\section{Synopsis of the Study}

The perceptions of principals were gleaned from their responses to a 70-item survey questionnaire based on the West Virginia Framework for High-Performing Schools. This research-based framework contained the following six domains: (1) Culture of Common Beliefs and Values Dedicated to Learning for All: (2) Curriculum Management; (3) Instructional Practices; (4) School Effectiveness; (5) Student and Parent Support; (6) Systemic, Continuous Improvement. In addition, it contained an implied $7^{\text {th }}$ domain of $21^{\text {st }}$-Century Skills. To promote school improvement efforts in the domains of the Framework, the West Virginia Department of Education implemented the Institute for $21^{\text {st }}$-Century Leadership (Institute) for school principals.

The research question that logically followed was whether the Institute has had an influence on school improvement in the state. To validate the research hypothesis that the Institute has had an influence, 70 statements were gleaned from the Framework for High- 
Performing Schools, embedded into an electronic survey, and sent to 600 principals in West Virginia. Of these 600 principals, 300 of them had attended the Institute and, therefore, served as the treatment group. The comparison group consisted of 300 principals whose names were quasirandomly generated from a list of the remaining principals in the state who had not attended the Institute.

The 600 principals were asked to indicate their level of agreement on a Likert-type scale about each of the survey items in relation to their own schools. In addition, the principals were asked to respond to the following three questions: (1) Has the West Virginia Institute for $21^{\text {st }}$ Century Leadership had any influence on your school-improvement efforts? If yes, please explain. (2) What do you believe are the greatest challenges to your school in developing students who can be successful, productive citizens? (3) What kinds of professional development would be most helpful to you as an education leader?

Of the 600 principals receiving the survey, 405 responded, in whole or in part, providing a response rate of 67 percent. The number of principals who responded to all or the majority of survey items was 366 , providing a 61.5 percent response rate. The responses of these principals on the Likert-type scale were analyzed, using both parametric and non-parametric calculations, to determine if there was a statistically significant difference between the perceptions of the comparison group and the treatment group. The responses to the three open-ended questions were analyzed qualitatively and coded by category. The results of the data analysis lead convincingly to the conclusions that follow.

\section{Conclusions}

The West Virginia Institute for $21^{\text {st }}$-Century Leadership has been a significant factor in the paradigm shift needed for school improvement in West Virginia, given the data collected in 
this study. The Institute principals, when compared to non-Institute principals, seem to have a significantly heightened awareness of the research-based elements needed to improve their schools and increase student achievement.

Institute principals perceive a greater sense of urgency for change in their schools in order to provide their students with a foundation for success. They are faced with resistance to this change on many fronts, and they express concern about having the skills and resources to deal with the resistance. They value the networking aspect among Institute principals, indicating that it has become a viable professional learning community.

Those who have attended the Institute appear to be more open to new ideas and are more willing to implement them. They indicate they are searching for a greater depth of knowledge about leadership skills, $21^{\text {st }}$-century teaching and learning, and continued professional development on ways to improve their schools. Although they view the role of principal as a stressful one, Institute principals appear to be placing their focus beyond the stress toward strategies, programs, and initiatives that will make their schools higher performing.

Both groups of principals agree (although not strongly) that their schools are high performing. Institute principals believe they are making progress toward high performance in the domain of $21^{\text {st }}$-Century Skills, whereas the non-Institute principals believe their schools to be higher performing in the domain of Instructional Practices.

What the survey did not provide was a look at the results of those instructional practices in terms of student achievement and other measures of school effectiveness. The non-Institute principals, not having been exposed to the concepts of $21^{\text {st }}$-century teaching and learning, would not have knowledge of another set of instructional practices with which to compare the ones they are now using. Although there is no statistical difference in the responses between male and 
female principals (see Appendix C), a closer look at responses to specific items will reveal other significant differences between the two groups.

Many more Institute principals than the non-Institute ones believe all children can master the essential curriculum, given appropriate time and conditions. This is a key finding in light of the research on the effects of educators' expectations on student achievement.

Non-Institute principals believe their schools are higher performing in some of the instructional strategies teachers use. Examples are such things as using performance benchmarks, formative assessment, differentiated instruction, comprehension development strategies, performance assessments, and data management to analyze student achievement trends. They believe their staff members show respect for all students, regardless of individual differences, and that they are developing their students into self-directed learners who are responsible for improving their own work.

Institute principals, however, are focusing on concepts that many current researchers proclaim have broader and more profound effects on student success. Some examples are: (1) They use a transformational leadership approach to create a learning-centered school; (2) They believe that students need to be aware of happenings around the world in order to be successful; (3) They believe that students need information and communication skills; (4) They deem interpersonal and self-directional skills as important for students' future success; (5) They understand that $21^{\text {st }}$-century tools should be used along with learning skills in order for students to be successful; (6) They consider it important for students to understand the concepts of ethics and personal responsibility; and (7) They support the idea of the importance of self-direction and social responsibility to students' success. 
Institute principals responded in overwhelmingly positive ways to the open-ended question regarding whether it has had any influence on their school-improvement efforts. They cite positive effects in such key areas as $21^{\text {st }}$-century skills, change, leadership, networking, school improvement, and in other positive general areas.

Responses to the study's three narrative questions strongly indicated that the West Virginia Institute for $21^{\text {st }}$-Century Leadership has had a positive influence on its participants and on school improvement. Approximately 90 percent of the Institute principals replied in the affirmative when asked whether the Institute had been a positive influence on their school improvement efforts.

Institute principals, for instance, submitted substantially more responses than nonInstitute principals in the Questions 2 and 3 categories of Leadership, Technology, Change, School Improvement, and $21^{\text {st }}$-Century Skills. These questions had to do with challenges principals face and the kinds of professional development they need. This shows a focus on research-based, critical areas for school improvement by Institute principals. Also, Institute principals provided 17 responses, compared to only three from the non-Institute principals, under the category of $21^{\text {st }}$-Century Learning. Institute principals appear to have more progressive attitudes toward improving their schools than non-Institute principals and more progressive attitudes than veteran teachers in their schools. For example, under the category of Faculty Attitudes, 33 Institute principals expressed concerns compared to 15 from the comparison group.

Some non-Institute principals' responses indicated that the Institute had affected their school-improvement efforts in positive ways_-even though they had not attended the Institute. Their perception, although incorrect, was that they had been exposed to $21^{\text {st }}$-century leadership training. This implies that at least some of them are concerned with $21^{\text {st }}$-century leadership, yet 
the number of responses actually indicating familiarity with $21^{\text {st }}$-century leadership concepts was substantially lower from the non-Institute principals compared to the Institute principals.

Far higher levels of what appeared to be frustration, stress, and feelings of already having too many initiatives to implement came from the non-Institute principals than from the Institute principals. This may be a good indication that principals who have attended the Institute have been provided the leadership tools to deal with such challenges.

The responses of Institute principals were significantly higher than those of non-Institute principals in regard to eight survey statements, which also revealed the positive impact of the Institute. The importance of their responses is especially apparent, because these areas have been cited as vitally important in $21^{\text {st }}$-century school-improvement efforts. These statements related to the following key areas:

1. Whether all children can achieve mastery of the essential curriculum, given appropriate time and conditions.

2. Whether transformational leadership to create a learning-centered school.

3. Whether awareness of events around the world is important for students' future success.

4. Whether information and communication skills are important for students' future success.

5. Whether interpersonal and self-directional skills are important for students' future success.

6. Whether $21^{\text {st }}$-century tools, such as computers and other technology, should be used with all learning skills in order for students to be successful.

7. Whether ethics, including personal responsibility, are important for students' success. 
8. Whether self-direction and social responsibility are important for students' success.

Other inferences worthy of note were drawn from the data analysis. This information should be taken into consideration in future state-wide, school-improvement efforts. These items follow:

1. The majority of school principals in West Virginia perceive their schools to be relatively high performing as defined by the state's Framework for HighPerforming Schools. The interpretation of the definition of a high-performing school may need to be explored.

2. There is ambivalence among West Virginia principals about whether all children can achieve mastery of the essential curriculum, given appropriate time and conditions. Research on expectations bears out the importance of expectations to student achievement. Given the fact that most people's behavior reflects their beliefs, this is an issue that may need to be addressed.

3. There are inconsistent interpretations among West Virginia principals about such as concepts as "performance benchmarks," "formative assessment," "comprehension development strategies," "transformational leadership," and “ $21^{\text {st }}$-century learning." Further clarification may be needed.

4. All principals in the survey indicated that they perceive their jobs to be overwhelming and stressful, specifically citing a lack of time and resources to do the job well. This is important information for state-level decision makers.

5. Principals in most schools are dealing with resistance to change by elements of the faculty. 
6. West Virginia principals have a need for assistance in dealing with such societal issues as parent attitudes about education and at-risk students.

7. The majority of principals indicate that they and their staffs need additional training in the use of technology to improve both instruction and school management.

8. Most West Virginia principals believe they would benefit from sustained, highquality, authentic professional development in all areas of school improvement, along with time provided to implement, monitor, and evaluate their school-improvement initiatives.

9. Most West Virginia principals sense an urgency to change their schools and their own skills, but they are dealing with significant challenges.

\section{Recommendations for Further Study}

There are several potential research offshoots from this work. For instance, the survey instrument used in this study could be tested for reliability and validity, and each survey item could be reviewed for clarity and elimination of multiple points. The curriculum and structure of the Institute could be studied to determine components deemed most valuable. A longitudinal study could be done on the student achievement of Institute attendees versus non-attendees. Qualitative research could be done in the schools implementing initiatives presented at the Institute.

The West Virginia Framework for High-Performing Schools, which spans 2004 to 2014, could be revisited and verified or revised in terms of the most updated research. Also, a study could be conducted to explore ways of providing school principals more time and assistance for implementing $21^{\text {st }}$-century learning initiatives. The role of the school principal could be studied for potential re-structuring of responsibilities. 
In terms of instructional practices, an investigation could be conducted of effective ways to provide a more in-depth understanding of $21^{\text {st }}$-century learning. A study could be conducted of how technology is currently being used in West Virginia schools. A final suggestion is to investigate ways to increase parental involvement in their children's schools.

Education has always been in a state of reform. The direction the body of education research takes will drive the direction of the reform. It is, therefore, critical to the well-being of students that quality research is conducted on as many aspects of education as possible. It is also important to understand the nexus between societal issues and the education system.

Conclusions about education topics reached through quantitative means should be verified through qualitative approaches. "When examined closely, [some] quantitative data turn out to be composites of qualitative interpretations" (House, 1994, p. 17). A call for more and different methods focusing on education issues is in order:

Our individual methods may be flawed, but fortunately the flaws are not identical. A diversity of imperfection allows us to combine methods, not only to gain their individual strengths, but also to compensate for their particular faults and limitations" (Brewer and House, 1989, p. 16).

The direction the body of education research takes will drive the direction of education reform. Research is, therefore, critical to the well-being of students. Systemic, continuous improvement is dependent on continuous learning opportunities such as those provided by the West Virginia Institute for $21^{\text {st }}$-Century Leadership. 


\section{References}

Adelman, H. \& Taylor, L. (2003). On sustainability of project innovations as systemic change. Journal of Educational and Psychological Consultation, 14. 1-26.

Alliance for Excellent Education. (October, 2007). Potential economic impacts of improved education on West Virginia. State information. Washington, DC: www.all4ed.org.

Barth, R. (2002). Learning by Heart. San Francisco: Jossey-Bass.

Best, J. \& Kahn, J. (1998). Research in Education (8 ${ }^{\text {th }}$ Ed.) Needham Heights, MA: Allyn \& Bacon.

Bolman, L. \& Deal, T. (2006). The wizard and the warrior: Leading with passion and power. San Francisco, CA: Jossey-Bass.

Brewer, J. \& Hunter, A. (1989). Multimethod research: A synthesis of styles. Newbury Park, CA: Sage.

Cash, J. (2007). The "S" word: Ten years later [Association of California School Administrators, issue on standards in education]. Leadership, September/October, $8-12$.

Coleman, J. (1966). Equality of educational opportunity. Inter-university Consortium for Political and Social Research Study (6389). Washington, D.C.: United States Department of Education.

Dewey, J. (1916). Essays in experimental logic. Chicago, IL: University of Chicago Press.

Dewey, J. (1937). My pedagogic creed. Retrieved August 1, 2008, from Education Research of Wikisource Organization: http://en.wikisource.org/wiki/My_Pedagogic_Creed. 
Ford, M., \& Friederici, P. (2007). An inconvenient curriculum. The Educational Forum, 71(4).

Fullan, M. (2002). The change leader. Educational Leadership, (May), 16-20.

Fullan, M. (2003). The moral imperative of school leadership. Thousand Oaks, CA: Corwin Press, xiv.

Gay, L., Mills, G., \& Airasian, P. (2006). Educational research: Competencies for analysis and applications, (8th Ed.). Upper Saddle River, NJ: Pearson Prentice Hall.

Guskey, T. (2000). Evaluating professional development. Thousand Oaks, CA: Corwin Press, xi. Hallinger, P. (2000). A review of two decades of research on the principalship using the “Principal Instructional Management Rating Scale”. Paper presented at the annual meeting of the American Educational Research Association, Seattle, WA.

Henderson, A., \& Berla, N. (2004). Research findings on parent/family involvement. National standards for parent/family involvement programs. Chicago: National Parent-Teacher Association, 8.

Henderson, A., \& Mapp, K. (2002). A new wave of evidence: The impact of school, family, and community connections on student achievement. National center for family and community connections with schools: Annual Synthesis. Austin, TX: Southwest Educational Development Laboratory, 7.

House, E.R. (1994). Integrating the quantitative and qualitative. In C.S. Reichardt \& S.F. Rallis (Eds.), The qualitative-quantitative debate: New perspectives (pp.13-22). New Directions for Program Evaluation, No. 61. San Francisco: Jossey-Bass. 
Hoyle, J., English, F., \& Steffy, B. (1998). Skills for successful $21^{\text {st }}$-century school leaders: Standards for peak performers. Arlington, VA: American Association of School Administrators.

Katz, D. \& Kahn, R. (1966). The Social Psychology of Organizations. New York: John Wiley \& Sons.

Krathwohl, D. (1998). Methods of educational and social science research. Long Grove, IL: Waveland Press, Inc.

Leithwood, K., Seashore Louis, K., Anderson, S., \& Wahlstrom, K. (2004). How leadership influences student learning. Learning from leadership project (p. 4-7). Ontario Institute for Studies in Education, University of Toronto, Canada, Center for Applied Research and Educational Improvement: Wallace Foundation.

Lezotte, L. (1991). Correlates of effective schools: The first and second generation. Okemos, MI: Effective Schools Products, Ltd.

Lezotte, L. (2001). Revolutionary and evolutionary: The effective schools movement. Okemos, MI: Effective Schools Products, Ltd.

McLaughlin, M. (1995). Improving education through standards-based reform. Stanford, CA: National Academy of Education.

Murphy, J. (1994). Reshaping the principalship: Insights from transformational reform efforts. Thousand Oaks, CA: Corwin Press, 8.

O’Day, J. \& Smith, M. (1993). Systemic reform and educational opportunity. In S.H. Furman (Ed.), Designing coherent education policy: Improving the system. San Francisco, CA: Jossey-Bass, 250-312. 
Partnership for $21^{\text {st }}$ Century Skills. (2007). Intellectual and policy foundations of the $21^{\text {st }}$ century skills framework (pp. 1-7). Tucson, AZ.

Peterson, K. (February, 2001). The Professional Development of Principals: Innovations and Opportunities. Educational Administration Quarterly. Retrieved March 9, 2008, from http://intl-eaq.sagepub.com/.

Reeves, D. (2007). Leading to change: How do you change school culture? Education Leadership. 64, 92-94.

Schein, E. (1992). Organizational culture and leadership ( $2^{\text {nd }}$ ed.). San Francisco: Jossey-Bass.

Scott Foresman Advanced Dictionary. (1983). Glenview, IL: Scott, Foresman, and Company.

Southern Regional Education Board. (2007). Challenge to lead. Atlanta, GA: www.sreb.org, 1.

Sparks, D., \& Hirsch, S. (2002). Learning to lead, leading to learn. National Staff Development Council, 5-6. Retrieved February 24, 2008, from www.nsdc.org/library/leaders/leader_report.cfm.

Spence, D. (2007). A leadership imperative: A special message to policy-makers from the president of SREB. Schools need good leaders now: State progress in creating a learning-centered school leadership system (07V48). Atlanta, GA: Southern Regional Education Board, III.

Suskie, L. (1996). Questionnaire survey research: What works ( $2^{\text {nd }}$ Ed.). Tallahassee, FL: Association for Institutional Research.

Swanson, C. \& Stevenson, D. (2002). Standards-based reform in practice: Evidence on state policy and classroom instruction from the NAEP state assessments. Educational Evaluation and Policy Analysis, 24(1), 1-27. 
U.S. Department of Education. (2008). West Virginia at a glance. Mapping West Virginia's educational progress. Washington, DC: $\underline{\text { www.ed.gov. }}$

University of Colorado, Advantages and Disadvantages of the Survey Method. Writing Guides and Research. Retrieved August 22, 2008, fromhttp://writing.colostate.edu/guides/research/survey/com2d1.cfm.

Wagner, T. (1993). Systemic change: Rethinking the purpose of school [ERIC \#: EJ468683]. Educational Leadership, 51(1), 24-28.

West Virginia Department of Education. (2004). Framework for high-performing school systems. Charleston, WV: West Virginia Board of Education.

West Virginia Department of Education. (2006). Learning community digital resource. Retrieved February 23, 2008, from http://wvde.state.wv.us/.

Waters, T., Marzano, R., \& McNulty, B. (2003). Balanced leadership: What 30 years of research tells us about the effect of leadership on student achievement. (A working paper). Mid-Continent Regional Educational Lab., Aurora, CO. (ERIC Document Reproduction Service No. ED 481972. 


\section{Appendix A}

Survey Instrument Items Correlated to Domain

\begin{tabular}{|c|c|c|}
\hline Domain & $\begin{array}{l}\text { Item No. } \\
\quad \text { in } \\
\text { Survey }\end{array}$ & Item as Worded in Survey \\
\hline 1 & 1 & $\begin{array}{l}\text { I believe all children can achieve mastery of the essential curriculum, } \\
\text { given appropriate time and conditions. }\end{array}$ \\
\hline 1 & 2 & $\begin{array}{l}\text { I believe that everyone involved with my school has an important role } \\
\text { in creating the conditions necessary for all students to achieve. }\end{array}$ \\
\hline 1 & 3 & $\begin{array}{l}\text { I believe that everyone at my school sets high standards in all aspects } \\
\text { that are essential for all students to achieve. }\end{array}$ \\
\hline 1 & 4 & $\begin{array}{l}\text { I believe it is essential that the school principal provides strong } \\
\text { instructional leadership in order to achieve mastery for all. }\end{array}$ \\
\hline 1 & 5 & $\begin{array}{l}\text { I believe that highly qualified personnel are necessary to develop a } \\
\text { culture that will allow all to achieve mastery. }\end{array}$ \\
\hline 1 & 6 & $\begin{array}{l}\text { I believe it IS NOT essential to treat parents as valued partners in order } \\
\text { for all students to achieve mastery. }\end{array}$ \\
\hline 1 & 7 & $\begin{array}{l}\text { I believe the primary measure of school success is the number of } \\
\text { students who achieve mastery of the essential curriculum. }\end{array}$ \\
\hline 1 & 8 & $\begin{array}{l}\text { I believe there must be a school-wide, continuous-improvement } \\
\text { process in place in order for all students to achieve. }\end{array}$ \\
\hline 2 & 9 & $\begin{array}{l}\text { I have provided the means for my teachers to develop a rigorous } \\
\text { curriculum aligned with the West Virginia Content Standards and } \\
\text { Objectives. }\end{array}$ \\
\hline 2 & 10 & $\begin{array}{l}\text { I have provided the means for my teachers to prioritize and map } \\
\text { curriculum objectives. }\end{array}$ \\
\hline 2 & 11 & $\begin{array}{l}\text { All the teachers in my school use performance benchmarks to measure } \\
\text { student achievement. }\end{array}$ \\
\hline 2 & 12 & $\begin{array}{l}\text { All the teachers in my school use formative assessments that align with } \\
\text { county performance benchmarks. }\end{array}$ \\
\hline 2 & 13 & $\begin{array}{l}\text { My school IS NOT using a standards-based program to assure students } \\
\text { are proficient in reading. }\end{array}$ \\
\hline 2 & 14 & $\begin{array}{l}\text { My school is using a standards-based program to assure students are } \\
\text { proficient in math. }\end{array}$ \\
\hline 2 & 15 & $\begin{array}{l}\text { I have implemented a teacher support system for enhancing curriculum } \\
\text { quality, such as peer-unit development, technology supports, content- } \\
\text { specific professional development. }\end{array}$ \\
\hline 2 & 16 & $\begin{array}{l}\text { I have a process in place to monitor the curriculum in order to gather } \\
\text { information for improvement. }\end{array}$ \\
\hline 3 & 17 & $\begin{array}{l}\text { The teachers in my school show respect for all students regardless of } \\
\text { individual differences. }\end{array}$ \\
\hline 3 & 18 & $\begin{array}{l}\text { The classrooms in my school ARE NOT focused, productive, and well } \\
\text { organized. }\end{array}$ \\
\hline 3 & 19 & $\begin{array}{l}\text { The students in my school are being developed into self-directed } \\
\text { learners who are responsible for improving their own work. }\end{array}$ \\
\hline
\end{tabular}




\begin{tabular}{|c|c|c|}
\hline Domain & $\begin{array}{l}\text { Item No. } \\
\quad \text { in } \\
\text { Survey }\end{array}$ & Item as Worded in Survey \\
\hline 3 & 20 & $\begin{array}{l}\text { The teachers in my school use differentiated instruction to meet the } \\
\text { needs of varied learners. }\end{array}$ \\
\hline 3 & 21 & $\begin{array}{l}\text { The teachers in my school use research-based, high-yield instructional } \\
\text { strategies in all classrooms. }\end{array}$ \\
\hline 3 & 22 & $\begin{array}{l}\text { The teachers in my school use performance assessments to determine } \\
\text { level of student mastery. }\end{array}$ \\
\hline 3 & 23 & $\begin{array}{l}\text { The teachers in my school adjust instructional time by grade, class, and } \\
\text { subject to meet the various learning needs of students. }\end{array}$ \\
\hline 3 & 24 & $\begin{array}{l}\text { Writing-to-inform strategies are used in all classrooms in my school in } \\
\text { all content areas. }\end{array}$ \\
\hline 3 & 25 & $\begin{array}{l}\text { Comprehension development strategies are used in all classrooms in } \\
\text { my school in all content areas. }\end{array}$ \\
\hline 3 & 26 & $\begin{array}{l}\text { The teachers in my school use such practices as scaffolding and } \\
\text { previewing to help accelerate student achievement. }\end{array}$ \\
\hline 3 & 27 & $\begin{array}{l}\text { In my school, there is a teacher instructional support system that } \\
\text { provides time and assistance to teachers for data analysis, cooperative } \\
\text { planning, observation and feedback, reflective practice, and } \\
\text { professional growth. }\end{array}$ \\
\hline 4 & 28 & $\begin{array}{l}\text { We have a culture of support, trust, and collaboration between our } \\
\text { school and the county office focused on creating conditions for all } \\
\text { students' success. }\end{array}$ \\
\hline 4 & 29 & $\begin{array}{l}\text { Our school has developed a clear mission to provide focus to school } \\
\text { improvement efforts. }\end{array}$ \\
\hline 4 & 30 & $\begin{array}{l}\text { Our school has a set of core beliefs to provide focus to school } \\
\text { improvement efforts. }\end{array}$ \\
\hline 4 & 31 & $\begin{array}{l}\text { Our school HAS NOT set performance goals to provide focus to school } \\
\text { improvement. }\end{array}$ \\
\hline 4 & 32 & $\begin{array}{l}\text { Our school has a strategic plan to provide focus to school improvement } \\
\text { efforts. }\end{array}$ \\
\hline 4 & 33 & $\begin{array}{l}\text { Our school-improvement team members have had professional } \\
\text { development training on strategic planning. }\end{array}$ \\
\hline 4 & 34 & $\begin{array}{l}\text { Our school-improvement team members have had professional } \\
\text { development training on continuous improvement. }\end{array}$ \\
\hline 4 & 35 & $\begin{array}{l}\text { Our school-improvement team members have had professional } \\
\text { development training on the correlates of effective schools. }\end{array}$ \\
\hline 4 & 36 & $\begin{array}{l}\text { Our school improvement team members have time to collaborate, } \\
\text { develop, and annually revise the five-year strategic plan. }\end{array}$ \\
\hline 4 & 37 & $\begin{array}{l}\text { Our school has a data management system to analyze data trends and } \\
\text { establish priorities. }\end{array}$ \\
\hline 4 & 38 & $\begin{array}{l}\text { Our school has a learning community focused on strategies to achieve } \\
\text { school performance goals. }\end{array}$ \\
\hline
\end{tabular}




\begin{tabular}{|c|c|c|}
\hline Domain & $\begin{array}{l}\text { Item No. } \\
\text { in } \\
\text { Survey }\end{array}$ & Item as Worded in Survey \\
\hline 4 & 39 & $\begin{array}{l}\text { Teachers in our school are provided professional development training } \\
\text { aligned with the school's improvement plan. }\end{array}$ \\
\hline 4 & 40 & $\begin{array}{l}\text { Our county has a monitoring system that requires continuous progress } \\
\text { and accountability for results as outlined in the school and district plan. }\end{array}$ \\
\hline 4 & 41 & $\begin{array}{l}\text { Our teachers are provided time prior to and during the instructional } \\
\text { term for meaningful staff planning, collaboration, and problem solving } \\
\text { related to the school's performance goals. }\end{array}$ \\
\hline 4 & 42 & $\begin{array}{l}\text { Our county office has a school monitoring system to gather information } \\
\text { on quality of overall school operations and the presence of the } \\
\text { correlates of effective schools. }\end{array}$ \\
\hline 5 & 43 & $\begin{array}{l}\text { Our school uses research-based, innovative approaches to meeting the } \\
\text { specific academic and social/emotional needs of all learners. }\end{array}$ \\
\hline 5 & 44 & $\begin{array}{l}\text { Our school has a developmental guidance program that includes a } \\
\text { strong character education focus. }\end{array}$ \\
\hline 5 & 45 & $\begin{array}{l}\text { Our school has a developmental guidance program that includes a } \\
\text { career development focus. }\end{array}$ \\
\hline 5 & 46 & $\begin{array}{l}\text { Our school has an effective process for successfully transitioning } \\
\text { students from one school to the next. }\end{array}$ \\
\hline 5 & 47 & $\begin{array}{l}\text { Our school DOES NOT have a coordinated and proactive plan to } \\
\text { enhance parent involvement. }\end{array}$ \\
\hline 5 & 48 & $\begin{array}{l}\text { Our school has a coordinated and proactive plan to improve parent } \\
\text { communication. }\end{array}$ \\
\hline 5 & 49 & $\begin{array}{l}\text { Our school has a coordinated and proactive plan to support parent } \\
\text { education. }\end{array}$ \\
\hline 5 & 50 & $\begin{array}{l}\text { Our school has a coordinated and proactive plan to build a partnership } \\
\text { with parents of low-performing students. }\end{array}$ \\
\hline 5 & 51 & $\begin{array}{l}\text { Our school has a process for connecting students and families to } \\
\text { community agencies, health services, counseling, and other services, } \\
\text { that promote student success. }\end{array}$ \\
\hline 5 & 52 & $\begin{array}{l}\text { Our school has a data analysis process on student attendance, discipline } \\
\text { trends, grade distribution, participation in extra-curricular activities, } \\
\text { etc., for monitoring student success and targeting specific } \\
\text { interventions. }\end{array}$ \\
\hline 6 & 53 & $\begin{array}{l}\text { I use a transformational leadership approach to create a learning- } \\
\text { centered school. }\end{array}$ \\
\hline 6 & 54 & $\begin{array}{l}\text { There is an expectation in my school that change will be an ongoing, } \\
\text { continuous process. }\end{array}$ \\
\hline 6 & 55 & $\begin{array}{l}\text { In my school, there IS NOT a broad understanding and commitment to } \\
\text { the need for change. }\end{array}$ \\
\hline 6 & 56 & $\begin{array}{l}\text { There is a focus on the whole school in the design and implementation } \\
\text { of our school's programs. }\end{array}$ \\
\hline 6 & 57 & $\begin{array}{l}\text { In our school, personnel understand that change involves system } \\
\text { activities and resources that are connected. }\end{array}$ \\
\hline
\end{tabular}




\begin{tabular}{|c|c|c|}
\hline Domain & $\begin{array}{c}\text { Item No. } \\
\text { in } \\
\text { Survey }\end{array}$ & Item as Worded in Survey \\
\hline 6 & 58 & $\begin{array}{l}\text { Before we implement a program in our school, we first plan it, then } \\
\text { implement it, study it to evaluate its effects, and act on our evaluation. }\end{array}$ \\
\hline 7 & 59 & $\begin{array}{l}\text { I DO NOT believe students need core subjects, such as English, } \\
\text { reading, math, science, and social studies, in order to be successful. }\end{array}$ \\
\hline 7 & 60 & $\begin{array}{l}\text { Awareness of happenings around the world is important for students' } \\
\text { future success. }\end{array}$ \\
\hline 7 & 61 & $\begin{array}{l}\text { Understanding business and finances is important for students' future } \\
\text { success. }\end{array}$ \\
\hline 7 & 62 & Knowledge of government is important for students' future success. \\
\hline 7 & 63 & $\begin{array}{l}\text { Health and wellness awareness is important for students' future } \\
\text { success. }\end{array}$ \\
\hline 7 & 64 & $\begin{array}{l}\text { Information and communication skills are important for students' } \\
\text { future success. }\end{array}$ \\
\hline 7 & 65 & $\begin{array}{l}\text { Thinking and problem-solving skills are important for students' future } \\
\text { success. }\end{array}$ \\
\hline 7 & 66 & $\begin{array}{l}\text { Interpersonal and self-directional skills are important for students' } \\
\text { future success. }\end{array}$ \\
\hline 7 & 67 & $\begin{array}{l}21^{\text {st }} \text {-century tools should be used with learning skills in order for } \\
\text { students to be successful }\end{array}$ \\
\hline 7 & 68 & $\begin{array}{l}\text { Ethics, including personal responsibility, is important for students' } \\
\text { future success. }\end{array}$ \\
\hline 7 & 69 & $\begin{array}{l}\text { Self-direction and social responsibility are important for students' } \\
\text { success. }\end{array}$ \\
\hline 7 & 70 & $\begin{array}{l}\text { Student assessments should measure thinking skills in addition to } \\
\text { knowledge of cores subjects. }\end{array}$ \\
\hline \multicolumn{3}{|c|}{ Demographic Items: } \\
\hline 1 & \multicolumn{2}{|l|}{ Gender } \\
\hline 2 & \multicolumn{2}{|c|}{ The grade levels at my school } \\
\hline 3 & \multicolumn{2}{|c|}{ The number of years, including this year, that you have been an administrator } \\
\hline \multicolumn{3}{|c|}{ Open-Ended Questions } \\
\hline 1 & \multicolumn{2}{|c|}{$\begin{array}{l}\text { How has the West Virginia Institute for } 21^{\text {st }} \text {-Century Leadership affected your } \\
\text { school? }\end{array}$} \\
\hline 2 & \multicolumn{2}{|c|}{$\begin{array}{l}\text { What do you believe are the greatest challenges to your school in developing } \\
\text { students who can be successful, productive citizens? }\end{array}$} \\
\hline 3 & \multicolumn{2}{|c|}{$\begin{array}{l}\text { What kinds of professional development would be most helpful to you as an } \\
\text { education leader? }\end{array}$} \\
\hline
\end{tabular}




\section{Appendix B}

\section{Survey Statistics Summary by Survey Item}

\begin{tabular}{|c|c|c|c|c|c|c|c|c|c|c|c|c|c|}
\hline \multicolumn{14}{|c|}{ Comparison of Means -- Independent Samples Test - by Question } \\
\hline \multicolumn{5}{|c|}{$\begin{array}{l}\text { (Group: } 1=\text { Comparison, } 2=\text { Treatment }) \\
\text { (Equal variances assumed unless indicated) } \\
(* *=\text { statistically significant) } \\
(*=\text { close to statistically significant) }\end{array}$} & \multicolumn{2}{|c|}{$\begin{array}{l}\text { Levene's Test } \\
\text { for Equality of } \\
\text { Variances }\end{array}$} & \multicolumn{7}{|c|}{$t-$ Tes $t$ for Equality of Means } \\
\hline \multirow[b]{2}{*}{$\begin{array}{c}\text { Grou } \\
\mathrm{p}\end{array}$} & \multirow[b]{2}{*}{$\mathrm{N}$} & \multirow[b]{2}{*}{ Mean } & \multirow{2}{*}{$\begin{array}{l}\text { Std. } \\
\text { Dev. }\end{array}$} & \multirow{2}{*}{$\begin{array}{l}\text { Std. } \\
\text { Error } \\
\text { Mean }\end{array}$} & \multirow[b]{2}{*}{$\mathrm{F}$} & \multirow[b]{2}{*}{ Sig. } & \multirow[b]{2}{*}{$t$} & \multirow[b]{2}{*}{ df } & \multirow{2}{*}{$\begin{array}{l}\text { Sig. } \\
2- \\
\text { tailed }\end{array}$} & \multirow{2}{*}{$\begin{array}{c}\text { Mean } \\
\text { Diff. }\end{array}$} & \multirow{2}{*}{$\begin{array}{l}\text { Std. } \\
\text { Error } \\
\text { Diff. }\end{array}$} & \multicolumn{2}{|c|}{$\begin{array}{l}\text { 95\% Confidence } \\
\text { Interval of the } \\
\text { Difference }\end{array}$} \\
\hline & & & & & & & & & & & & Lower & Upper \\
\hline \multicolumn{14}{|c|}{ 1. I believe all children can achieve mastery of the essential curriculum, given appropriate time and conditions. } \\
\hline 1 & 192 & 3.505 & 1.1889 & .0858 & \multirow[b]{2}{*}{4.080} & \multirow[b]{2}{*}{.044} & \multirow[b]{2}{*}{-2.123} & & & & & & \\
\hline 2 & 203 & 3.754 & 1.3383 & .0796 & & & & 388.9 & $034 * *$ & -.2485 & .1170 & -.4786 & -.01840 \\
\hline & Equ & varianc & s not assu & ned; calcu & ations ad & sted. & & & & NULL H & YPOTHESI & SCAN BE & REJECTED. \\
\hline $\begin{array}{l}\text { 2. I be } \\
\text { ach }\end{array}$ & $\begin{array}{l}\text { ve th } \\
\text { ge. }\end{array}$ & everyor & e involvec & with my sc & nool has & impo & ant rol & crea & 5 the con & tions nece & sary for & II student & \\
\hline 1 & 192 & 4.828 & .45088 & .03254 & & & & & & & & & \\
\hline 2 & 207 & 4.826 & .40470 & .02813 & .000 & .983 & .048 & 397 & .962 & .00204 & .04284 & -.0822 & .08626 \\
\hline 3. I be & ve th & everyon & e at my sc & ool sets hi & gh standa & ds in al & aspects $t$ & nat are $e$ & ential fo & all studen & s to achie & ve. & \\
\hline 1 & 195 & 4.164 & .85780 & .06143 & & & & & & & & & \\
\hline 2 & 207 & 4.135 & .81316 & .05652 & 1.024 & .312 & .346 & 400 & .730 & .02884 & .08334 & -.1350 & .19268 \\
\hline 4. I be & ve it & essentia & that the & hool princ & pal provi & s strol & $\mathrm{g}$ instruc & nal le & ership in & rder to acl & ieve mas & ery for al & \\
\hline 1 & 193 & 4.782 & .50446 & .03631 & & & & & & & & & \\
\hline 2 & 206 & 4.806 & .39653 & .02763 & 1.820 & .178 & -.518 & 397 & .605 & -.0234 & .04528 & -.1125 & .06557 \\
\hline 5. I be & ve th & highly q & ualified $\mathrm{pe}$ & sonnel are & necessar & to dev & lop a cul & ure that & ill allow & I students & to achiev & mastery & \\
\hline 1 & 194 & 4.438 & .78112 & .05608 & & & & & & & & & \\
\hline 2 & 207 & 4.488 & .69576 & .04836 & 1.790 & .182 & -.675 & 399 & .500 & -.0498 & .07377 & -.1948 & .09526 \\
\hline 6. I be & ve it & NOT ess & ential to $t$ & at parents & s valuec & oartne & in order & for all st & ents to & hieve ma & tery. & & \\
\hline 1 & 193 & 4.580 & .66538 & .04790 & & & & & & & & & \\
\hline 2 & 205 & 4.571 & .63487 & .04434 & .111 & .739 & .147 & 396 & .883 & .00958 & .06518 & -.1186 & .13772 \\
\hline 7. I be & ve th & primary & neasure o & school suc & cess is th & numbe & of stude & s who & hieve $\mathrm{m}$ & tery of th & essentia & curricule & \\
\hline 1 & 192 & 3.234 & 1.2118 & .08745 & & & & & & & & & \\
\hline 2 & 207 & 3.092 & 1.1549 & .08027 & 3.004 & .084 & 1.203 & 397 & .230 & .14259 & .11849 & -.0904 & .37553 \\
\hline 8. I be & ve th & e must b & e a schoo & wide, cont & nuous-im & rovem & nt proce & s in plac & in order & $r$ all stude & nts to ach & ieve. & \\
\hline 1 & 192 & 4.432 & .62922 & .04541 & & & & & & & & & \\
\hline 2 & 206 & 4.442 & .58768 & .04095 & 1.004 & .317 & -.155 & 396 & .877 & -.0095 & .06100 & -.1294 & .11046 \\
\hline $\begin{array}{l}\text { 9. I ha } \\
\text { and }\end{array}$ & $\begin{array}{l}\text { prov } \\
\text { bjecti }\end{array}$ & $\begin{array}{l}\text { ed the } m \\
\text { s. }\end{array}$ & eans for $n$ & $y$ teachers & to develo & a rigor & us curr & llum a & d with & e West Vi & ginia Con & tent Stan & ards \\
\hline 1 & 183 & 4.478 & .60860 & .04499 & & & & & & & & & \\
\hline 2 & 203 & 4.468 & .54746 & .03842 & .281 & .596 & .173 & 384 & .863 & .01016 & .05884 & -.1055 & .12585 \\
\hline 10. I h & e pro & ded the & neans for & yy teacher & to priori & ze an & ap cur & lum & ctives. & & & & \\
\hline 1 & 183 & 4.290 & .75466 & .05579 & & & & & & & & & \\
\hline 2 & 203 & 4.337 & .69345 & .04867 & .708 & .400 & -.649 & 384 & .517 & -.0478 & .07371 & -.1927 & .0971 \\
\hline 11. All & e tea & ners in $\mathrm{m}$ & yschool u & e perform & ce benc & marks & measu & studer & chieve & & & & \\
\hline 1 & 182 & 4.198 & .94862 & .07032 & & & & & & & & & \\
\hline 2 & 203 & 3.995 & .96214 & .06753 & 1.208 & .273 & 2.078 & 383 & $8 * *$ & .20273 & .09757 & .01089 & .39456 \\
\hline & & & & & & & & & & NULL H & IPOTHESI & S CAN BE & REJECTED. \\
\hline 2. All & ted & ers in $m$ & y school u & formativ & 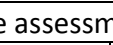 & nts th & 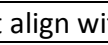 & u & rforn & benchn & arks. & & \\
\hline 1 & 185 & 4.173 & .97931 & .07200 & & & & & & & & & \\
\hline 2 & 202 & 3.921 & .94824 & .06672 & 2.000 & .158 & 2.573 & 385 & $010 * *$ & .25218 & .09802 & .05946 & .4449 \\
\hline & & & & & & & & & & NULL H & YPOTHESI & $S$ CAN BE & REJECTED. \\
\hline
\end{tabular}




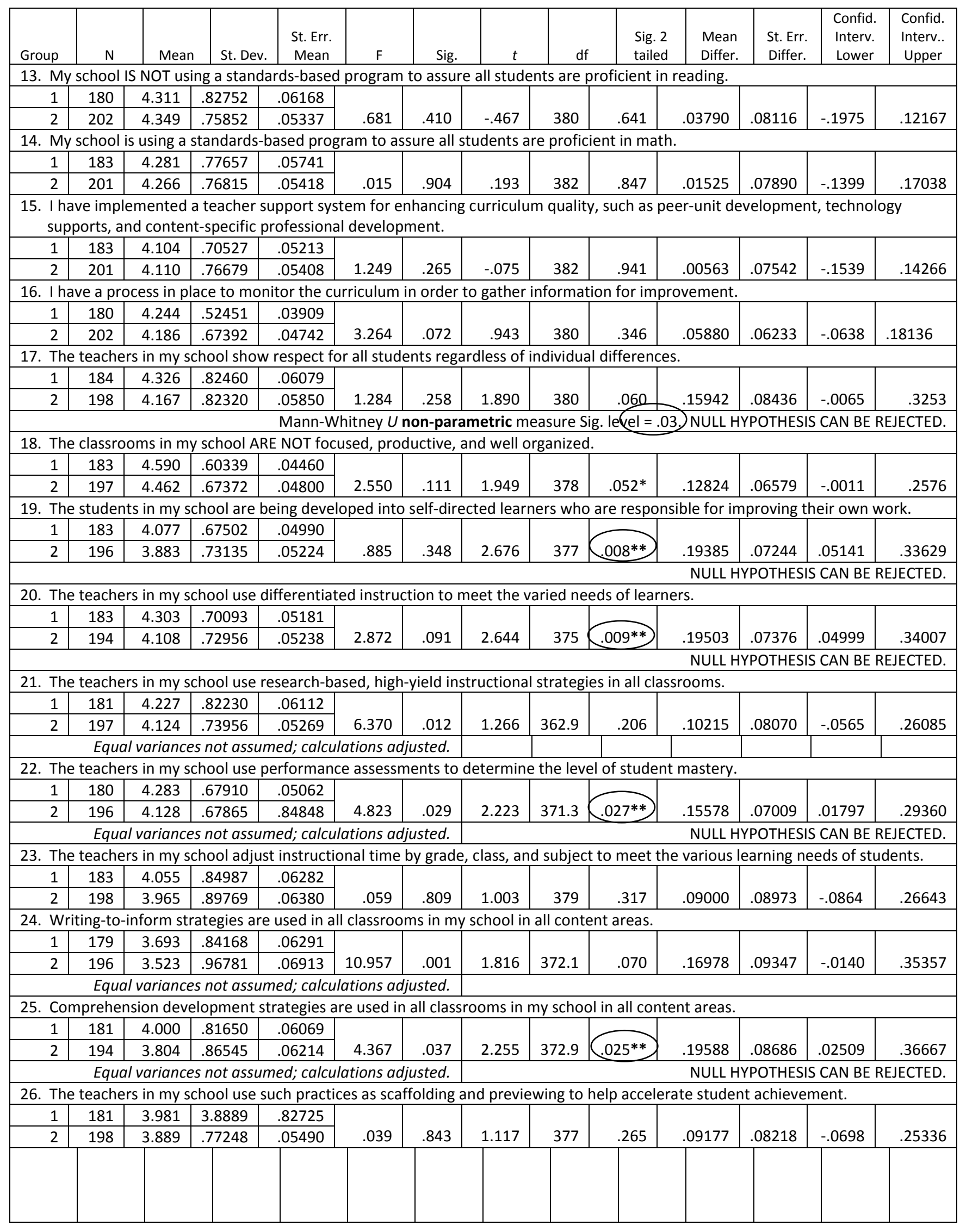




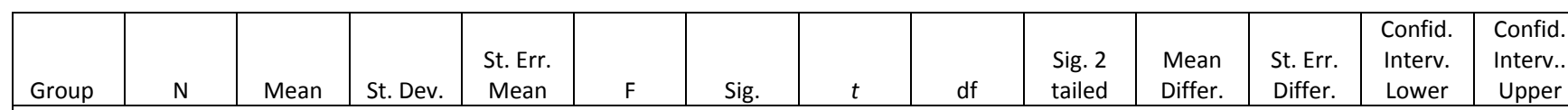

27. There is a teacher instructional support system that provides time and assistance to teachers for such things as data analysis, cooperative planning, observation and feedback, reflective practice, and professional growth.

\begin{tabular}{|l|l|l|l|l|l|l|l|l|l|l|l|r|r|r|r|r|r|}
\hline 1 & 182 & 4.050 & .88122 & .06532 & & & & & & & & & \\
\hline 2 & 196 & 4.015 & .90286 & .06449 & .016 & .899 & .372 & 376 & .710 & .03414 & .09187 & -.1465 & .21480 \\
\hline
\end{tabular}

28. We have a culture of support, trust, and collaboration between our school and the county office focused on creating conditions for all students' success.

\begin{tabular}{|c|c|c|c|c|c|c|c|c|c|c|c|c|c|}
\hline 1 & 181 & 4.061 & .83110 & .06178 & & & & & & & & & \\
\hline 2 & 195 & 3.877 & 1.0078 & .07217 & 7.879 & .005 & 1.935 & 368.9 & $.054^{*}$ & .18385 & .09500 & -.0030 & .37066 \\
\hline \multicolumn{14}{|c|}{ Equal variances not assumed; calculations adjusted. } \\
\hline \multicolumn{14}{|c|}{ 29. Our school has developed a clear mission that provides focus to school improvement efforts. } \\
\hline 1 & 183 & 4.530 & .55264 & .04085 & & & & & & & & & \\
\hline 2 & 193 & 4.422 & .54407 & .03916 & .028 & .867 & 1.905 & 374 & $.058^{*}$ & 10777 & .05657 & -.0035 & .21901 \\
\hline
\end{tabular}

30. Our school has a set of core beliefs to provide focus to school improvement efforts. \begin{tabular}{l|l|l|l|l|}
1 & 180 & 4.533 & .56331 & .04199 \\
\hline 2 & 193 & 4.453 & .53803 & .03873 \\
\hline
\end{tabular} \begin{tabular}{l|l}
.178 & .673
\end{tabular}
1.402
\begin{tabular}{l|l|}
371 & .162 \\
\hline
\end{tabular}
\begin{tabular}{|l|l|l|}
\hline .07997 & .05703 & -.0322 \\
\hline
\end{tabular}
.19211

31. Our school HAS NOT set performance goals to provide focus to school improvement.

\begin{tabular}{|c|c|c|c|c|c|c|c|c|c|c|c|c|c|}
\hline 1 & 181 & 4.541 & .53197 & .03954 & \multirow[b]{2}{*}{3.540} & \multirow[b]{2}{*}{.061} & \multirow[b]{2}{*}{.720} & \multirow[b]{2}{*}{369} & \multirow[b]{2}{*}{.472} & \multirow[b]{2}{*}{.04407} & \multirow[b]{2}{*}{.06122} & \multirow[b]{2}{*}{-.0763} & \multirow[b]{2}{*}{.16445} \\
\hline 2 & 190 & 4.497 & .63931 & .04638 & & & & & & & & & \\
\hline \multicolumn{14}{|c|}{ 32. Our school has a strategic plan to provide focus to school improvement efforts. } \\
\hline 1 & 181 & 4.591 & .50413 & .03747 & \multirow[b]{2}{*}{1.517} & \multirow[b]{2}{*}{.219} & \multirow[b]{2}{*}{.694} & \multirow[b]{2}{*}{372} & \multirow[b]{2}{*}{.488} & \multirow[b]{2}{*}{.03676} & \multirow[b]{2}{*}{.05295} & \multirow[b]{2}{*}{-.0674} & \multirow[b]{2}{*}{.14088} \\
\hline 2 & 193 & 4.554 & .51881 & .03734 & & & & & & & & & \\
\hline
\end{tabular}

\begin{tabular}{|c|c|c|c|c|c|c|c|c|c|c|c|c|c|}
\hline 1 & 179 & 3.743 & 1.0605 & .07926 & & & & & & & & & \\
\hline 2 & 192 & 3.664 & 1.1613 & .08381 & 5.145 & .024 & .684 & 368.8 & .494 & .07895 & .11535 & -.1479 & .30579 \\
\hline
\end{tabular}

34. Our school-improvement team members have had professional development training on continuous improvement.

\begin{tabular}{|c|c|c|c|c|c|c|c|c|c|c|c|c|c|}
\hline 1 & 180 & 3.772 & .99063 & .07384 & \multirow[b]{2}{*}{5.065} & \multirow[b]{2}{*}{.025} & \multirow[b]{2}{*}{.756} & \multirow[b]{2}{*}{371.8} & \multirow[b]{2}{*}{.450} & \multirow[b]{2}{*}{.08150} & \multirow[b]{2}{*}{.10786} & \multirow[b]{2}{*}{-1306 } & \multirow[b]{2}{*}{29359} \\
\hline 2 & 194 & 3.691 & 1.0951 & .07862 & & & & & & & & & \\
\hline \multicolumn{14}{|c|}{ Equal variances not assumed; calculations adjusted. } \\
\hline \multicolumn{14}{|c|}{ 55. Our school-improvement team members have had professio } \\
\hline 1 & 181 & 3.762 & .99103 & .07366 & \multirow[b]{2}{*}{1.229} & \multirow[b]{2}{*}{.268} & \multirow[b]{2}{*}{.546} & \multirow[b]{2}{*}{372} & \multirow[b]{2}{*}{.585} & \multirow[b]{2}{*}{.05777} & \multirow[b]{2}{*}{10580} & \multirow[b]{2}{*}{-.1503} & \multirow[b]{2}{*}{.26581} \\
\hline 2 & 193 & 3.705 & 1.0512 & .07567 & & & & & & & & & \\
\hline
\end{tabular}

36. Our school-improvement team members have time to collaborate, develop, and annually revise the five-year strategic plan.

\begin{tabular}{|c|c|c|c|c|c|c|c|c|c|c|c|c|c|}
\hline 1 & 180 & 3.950 & .97037 & .07233 & & & & & & & & & \\
\hline 2 & 191 & 3.890 & .99655 & .07211 & .675 & .412 & .587 & 369 & .558 & .05995 & .10221 & -.1410 & .26094 \\
\hline
\end{tabular}

37. Our school has a data management system to analyze data trends and establish priorities.

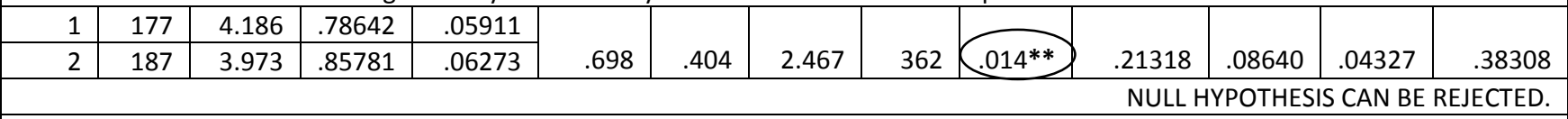

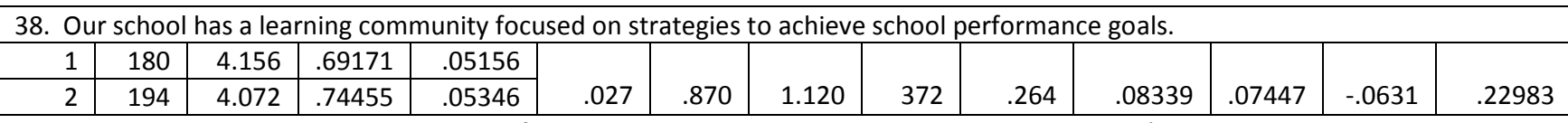

39. Teachers in our school are provided professional development training aligned with the school's improvement plan.

\begin{tabular}{|c|c|c|c|c|c|c|c|c|c|c|c|c|c|}
\hline 1 & 179 & 4.372 & .55861 & .04175 & \multirow[b]{2}{*}{.314} & \multirow[b]{2}{*}{.576} & \multirow[b]{2}{*}{1.959} & \multirow[b]{2}{*}{369} & \multirow[b]{2}{*}{$.051^{*}$} & \multirow[b]{2}{*}{.12672} & \multirow[b]{2}{*}{.06469} & \multirow[b]{2}{*}{-.0005} & \multirow[b]{2}{*}{.25392} \\
\hline 2 & 192 & 4.245 & .67682 & .04885 & & & & & & & & & \\
\hline \multicolumn{14}{|c|}{$\begin{array}{l}\text { 40. Our county has a monitoring system that requires continuous progress and accountability for results as outlined in the school } \\
\text { and district plan. }\end{array}$} \\
\hline 1 & 177 & 4.212 & .68799 & .05171 & \multirow{2}{*}{.114} & \multirow[b]{2}{*}{.736} & \multirow[b]{2}{*}{1.812} & \multirow[b]{2}{*}{368} & \multirow[b]{2}{*}{.071} & \multirow[b]{2}{*}{.13673} & \multirow[b]{2}{*}{.07546} & \multirow[b]{2}{*}{-.0117} & \multirow[b]{2}{*}{.28512} \\
\hline 2 & 193 & 4.075 & .75747 & .05452 & & & & & & & & & \\
\hline & & & & & & & & & & & & & \\
\hline & & & & & & & & & & & & & \\
\hline
\end{tabular}




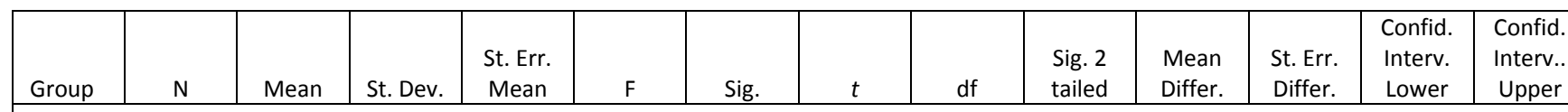

41. Our teachers are provided time prior to and during the instructional term for meaningful staff planning, collaboration, and problem solving related to the school's performance goals.

\begin{tabular}{|l|l|l|l|l|l|l|l|l|l|l|l|l|}
\hline 1 & 181 & 3.939 & 1.0120 & .07522 & & & & & & & & \\
\hline 2 & 193 & 3.886 & .99868 & .07189 & .041 & .840 & .512 & 372 & .609 & .05322 & .10400 & -.1513 \\
\hline
\end{tabular}

42. Our county office has a school monitoring system to gather information on quality of overall school operations and the presence of the correlates of effective schools.

\begin{tabular}{l|l|l|l|l|l|l|l|l|l|l|l|l|}
\hline 1 & 178 & 3.997 & .83784 & .06280 & & & & & & & & \\
\hline 2 & 190 & 3.861 & .87152 & .06323 & 2.268 & .133 & 1.532 & 366 & .126 & .13666 & .08923 & -.0388 \\
\hline
\end{tabular}

43. Our school uses research-based, innovative approaches to meet the specific academic and social/emotional needs of all learners.

\begin{tabular}{|l|l|l|l|l|l|l|l|l|l|l|l|l|}
\hline 1 & 178 & 4.258 & .69750 & .05228 & & & & & & & & \\
\hline 2 & 193 & 4.194 & .61646 & .04437 & 3.352 & .068 & .940 & 369 & .348 & .06413 & .06823 & -.0701 \\
\hline
\end{tabular}

44. Our school has a developmental guidance program that includes a strong character education focus.
\begin{tabular}{l|l|l|l|l|}
1 & 177 & 4.164 & .89267 & .06710 \\
\hline
\end{tabular}
\begin{tabular}{l|l|l|l|l|l|}
2 & 193 & 4.119 & .80448 & .05791 \\
\hline
\end{tabular}
$2.204 \quad .138$
$.506 \quad 368$
.613
.04467
\begin{tabular}{l|l}
.08823 & -.1288 \\
\hline
\end{tabular}
.21817

45. Our school has a developmental guidance program that includes a career development focus.

\begin{tabular}{|c|c|c|c|c|c|c|c|c|c|c|c|c|c|}
\hline 1 & 174 & 3.902 & .94758 & .07184 & & & & & & & & & \\
\hline 2 & 191 & 3.942 & .89550 & .06480 & 1.028 & .311 & -.416 & 363 & .678 & -.0401 & 09649 & -.2299 & 14963 \\
\hline
\end{tabular}

46. Our school has an effective process for successfully transitioning students from one school to the next.

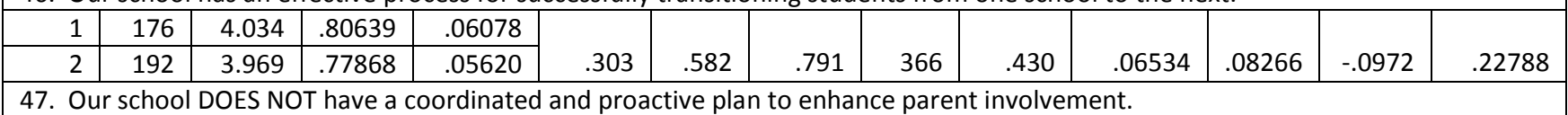

47. Our school DOES NOT have a coordinated and proactive plan to enhance parent involvement.

\begin{tabular}{|c|c|c|c|c|c|c|c|c|c|c|c|c|c|}
\hline 1 & 178 & 4.281 & .79531 & .05961 & & & & & & & & & \\
\hline 2 & 194 & 4.150 & .82909 & .05952 & .096 & .756 & 1.557 & 370 & .120 & .13141 & .08439 & -.0345 & .29736 \\
\hline
\end{tabular}

48. Our school has a coordinated and proactive plan to improve parent communication.

\begin{tabular}{|c|c|c|c|c|c|c|c|c|c|c|c|c|c|}
\hline 1 & 176 & 4.182 & .73361 & .05530 & & & & & & & & & \\
\hline 2 & 190 & 4.100 & .76842 & .05575 & .063 & .803 & 1.040 & 364 & .299 & .08182 & .07866 & -.0729 & 23651 \\
\hline
\end{tabular}

49. Our school has a coordinated and proactive plan to support parent education.

\begin{tabular}{|c|c|c|c|c|c|c|c|c|c|c|c|c|c|}
\hline 1 & 176 & 3.645 & 1.0120 & .07688 & & & & & & & & & \\
\hline 2 & 193 & 3.521 & .98138 & .07064 & .000 & .998 & 1.191 & 367 & .234 & .12416 & .10422 & -.0808 & .32911 \\
\hline
\end{tabular}

50. Our school has a coordinated and proactive plan to build a partnership with parents of low-performing students.

\begin{tabular}{|c|c|c|c|c|c|c|c|c|c|c|c|c|c|}
\hline 1 & 176 & 3.784 & .88736 & .06689 & & & & & & & & & \\
\hline 2 & 195 & 3.703 & .97057 & .06950 & 3.924 & .048 & .845 & 368.9 & .399 & .08153 & .09646 & -.1082 & .27121 \\
\hline
\end{tabular}

51. Our school has a process for connecting students and families to community agencies, health services, counseling, and other services that promote student success.

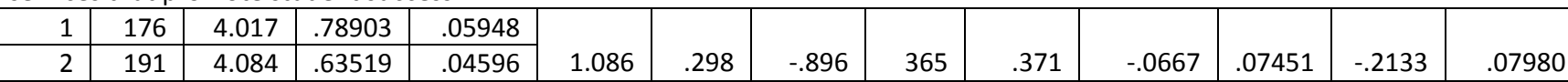

52. Our school has a data analysis process on such things as student attendance, discipline trends, grade distribution, participation in extra-curricular activities to monitor student progress.

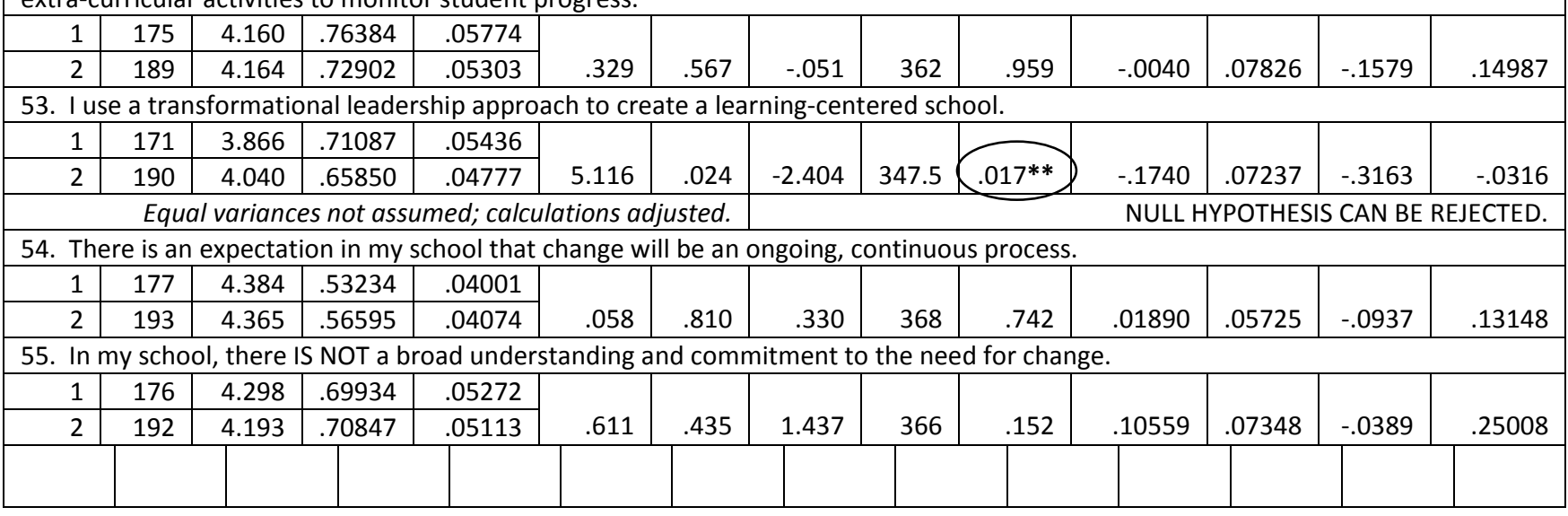




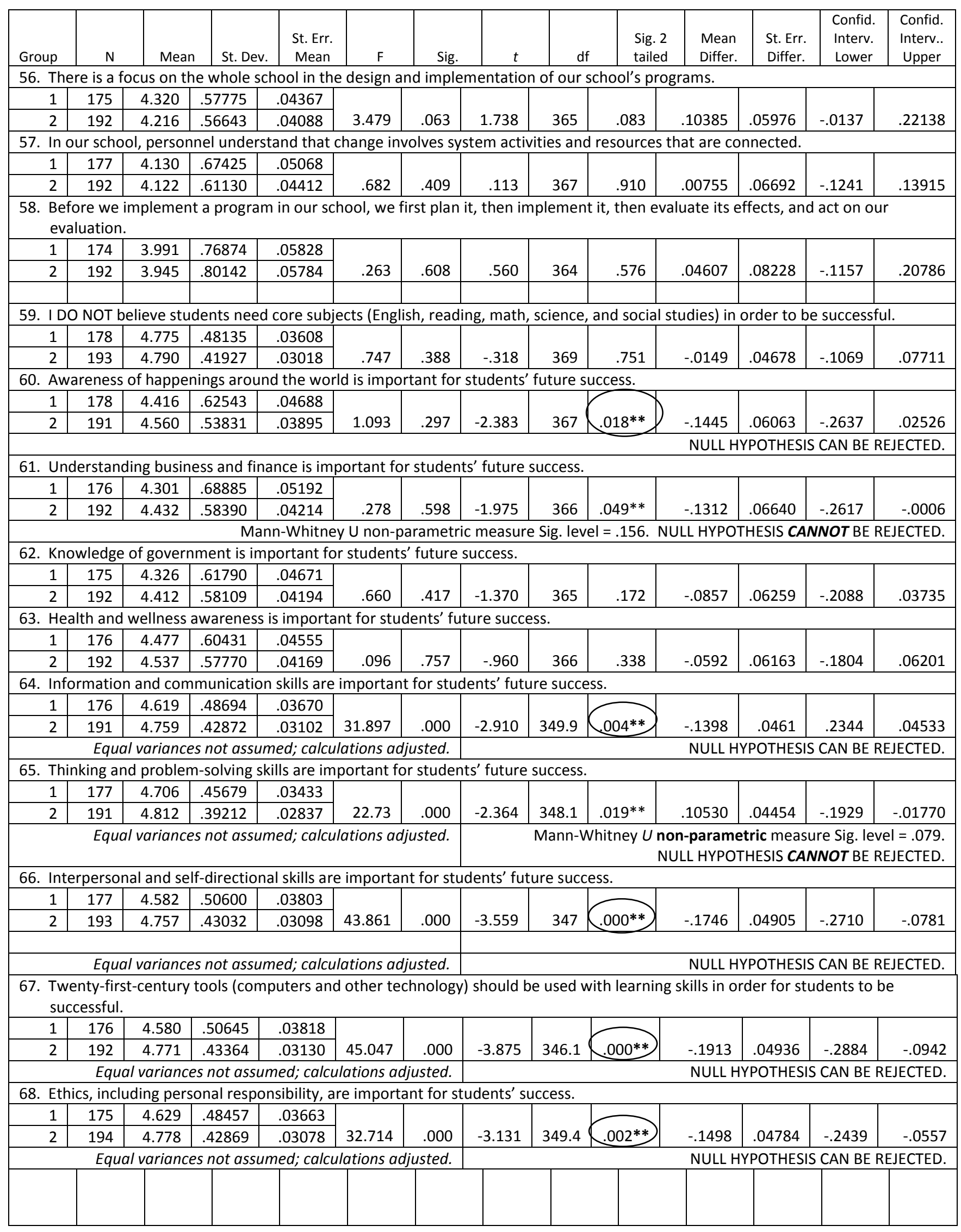




\begin{tabular}{|c|c|c|c|c|c|c|c|c|c|c|c|c|c|}
\hline Group & $\mathrm{N}$ & Mean & St. Dev. & $\begin{array}{l}\text { St. Err. } \\
\text { Mean }\end{array}$ & $\mathrm{F}$ & Sig. & $t$ & df & $\begin{array}{l}\text { Sig. } 2 \\
\text { tailed }\end{array}$ & $\begin{array}{l}\text { Mean } \\
\text { Differ. }\end{array}$ & $\begin{array}{l}\text { St. Err. } \\
\text { Differ. }\end{array}$ & $\begin{array}{l}\text { Confid. } \\
\text { Interv. } \\
\text { Lower }\end{array}$ & $\begin{array}{l}\text { Confid. } \\
\text { Interv.. } \\
\text { Upper }\end{array}$ \\
\hline \multicolumn{14}{|c|}{ 69. Self-direction and social responsibility are important for students' success. } \\
\hline 1 & 177 & 4.605 & .52395 & .03938 & \multirow[b]{2}{*}{17.617} & \multirow[b]{2}{*}{.000} & \multirow[b]{2}{*}{-2.470} & \multirow[b]{2}{*}{349.8} & & \multirow[b]{2}{*}{-.1271} & \multirow[b]{2}{*}{.05144} & \multirow[b]{2}{*}{-.2282} & \multirow[b]{2}{*}{-.0259} \\
\hline 2 & 190 & 4.732 & .45606 & .03309 & & & & & $14 * *$ & & & & \\
\hline \multicolumn{7}{|c|}{ Equal variances not assumed; calculations adjusted. } & \multicolumn{7}{|c|}{ NULL HYPOTHESIS CAN BE REJECTED. } \\
\hline \multicolumn{14}{|c|}{ 70. Student assessments should measure thinking skills in addition to knowledge of core subjects. } \\
\hline 1 & 177 & 4.486 & .55501 & .04172 & \multirow[b]{2}{*}{.510} & \multirow[b]{2}{*}{.476} & \multirow[b]{2}{*}{-1.722} & \multirow[b]{2}{*}{366} & \multirow[b]{2}{*}{.086} & \multirow[b]{2}{*}{-.1005} & \multirow[b]{2}{*}{.05837} & \multirow[b]{2}{*}{-.2153} & \multirow[b]{2}{*}{.0143} \\
\hline 2 & 191 & 4.586 & .56347 & .04077 & & & & & & & & & \\
\hline
\end{tabular}




\section{Appendix C. Domain Responses by Gender}

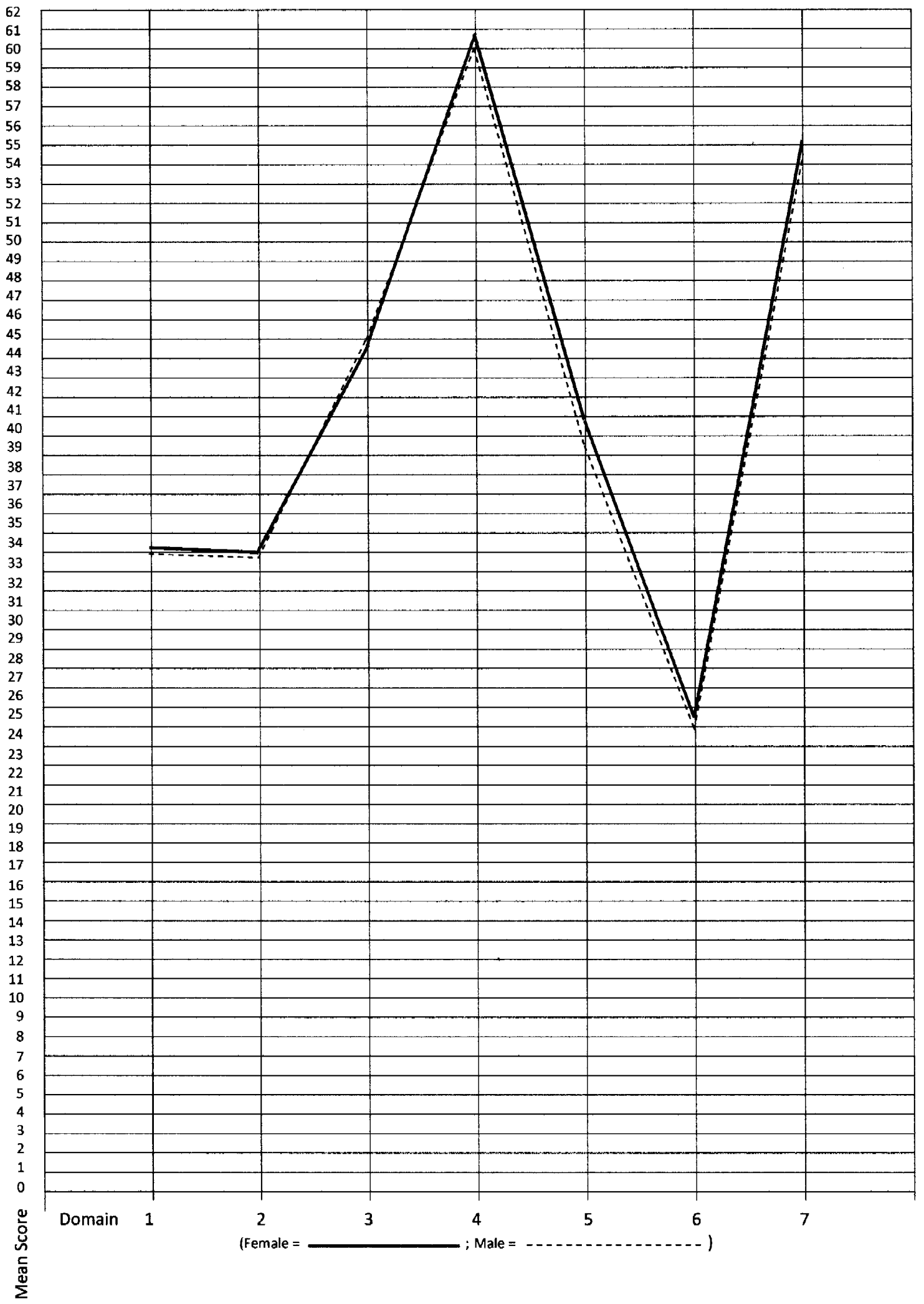




\section{Appendix D}

\section{Question 1: Narrative Responses by Category - Comparison Group}

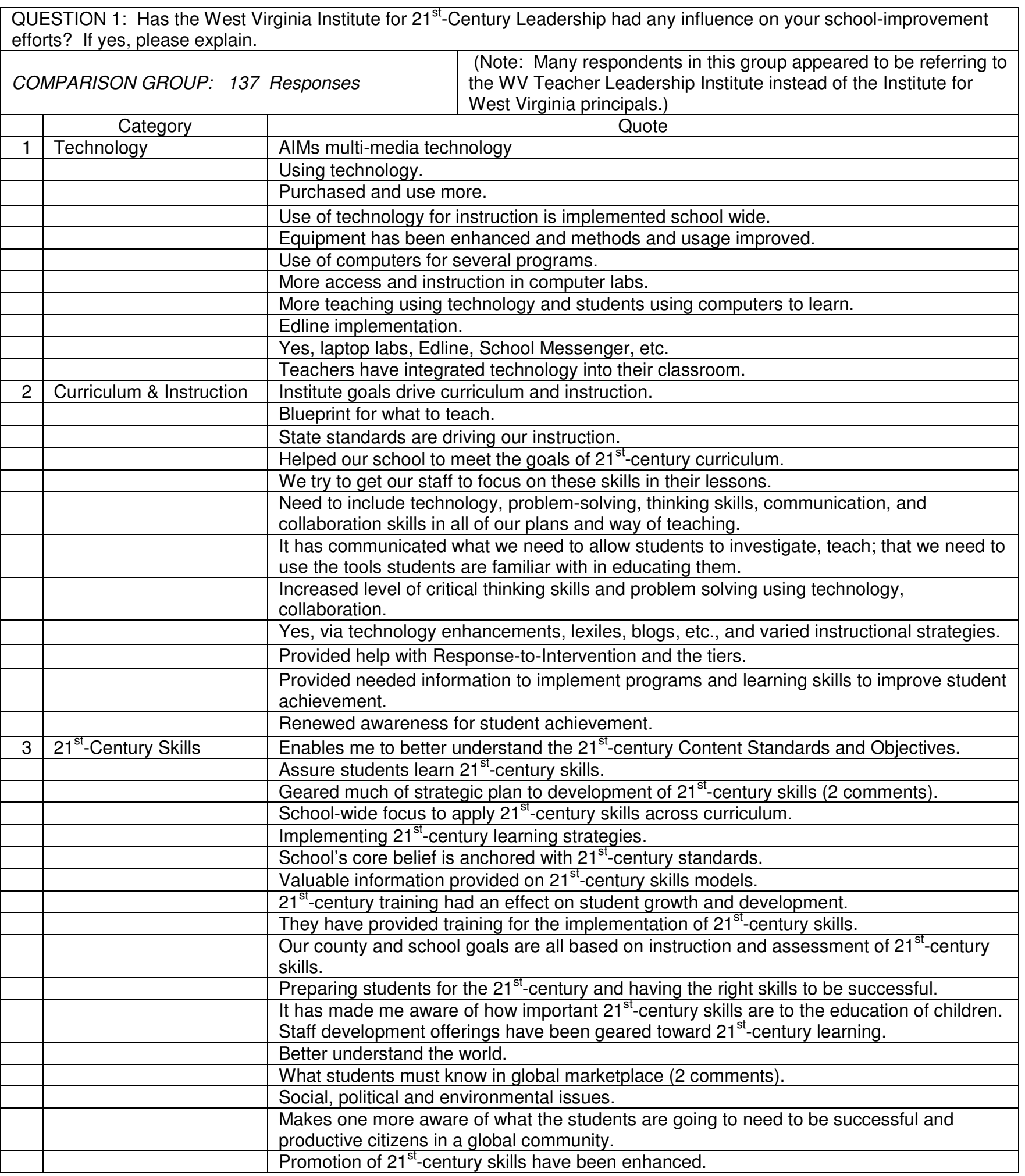




\begin{tabular}{|c|c|c|}
\hline & Category & Quote \\
\hline \multirow[t]{5}{*}{4} & $\begin{array}{l}\text { Research-Based } \\
\text { Strategies }\end{array}$ & Learned new ones ( 2 comments). \\
\hline & & Reinforced prior training on effective-schools research. \\
\hline & & More emphasis on Bloom's Taxonomy. \\
\hline & & Insight on the most current trends and approach to delivering and receiving knowledge. \\
\hline & & Valuable information provided on assessment. \\
\hline \multirow[t]{4}{*}{5} & No Influence & 16 responses of No without explanations. \\
\hline & & I do not know what the West Virginia Institute for $21^{\text {st }}$-Century Leadership is. \\
\hline & & Have not attended yet (6 comments). \\
\hline & & No, I am supposed to go this summer. \\
\hline \multirow[t]{2}{*}{6} & Yes & 6 responses without explanation. \\
\hline & & Only marginally. \\
\hline \multirow[t]{9}{*}{7} & Change & How it is incorporated in the world and in education. \\
\hline & & School-wide implementation. \\
\hline & & $\begin{array}{l}\text { Provides professional development on current trends and practices of individuals leading } \\
\text { education change throughout nation ( } 3 \text { comments). }\end{array}$ \\
\hline & & Beginning to implement. Need to educate students for the future. \\
\hline & & Living in an ever-changing world and students need to learn to survive in it. \\
\hline & & Valuable information provided on change models. \\
\hline & & It has communicated that there is urgency in the needed changes. \\
\hline & & $\begin{array}{l}\text { I have not had an opportunity to participate yet, but what my colleagues have presented } \\
\text { has helped me to understand the direction we are headed. }\end{array}$ \\
\hline & & $\begin{array}{l}\text { Being made aware and understanding the needs for change and how to change has } \\
\text { certainly affected my leadership ( } 3 \text { comments). }\end{array}$ \\
\hline \multirow[t]{9}{*}{8} & Concerns & Only a few go at a time. \\
\hline & & Funding not provided for things the Institute presents. \\
\hline & & $\begin{array}{l}\text { Required to implement the Tech Steps program, Writing Assessment, etc. With limited } \\
\text { infrastructure, VERY DIFFICULT. Students need more access to technology. }\end{array}$ \\
\hline & & New and improved technology equipment needed. \\
\hline & & $\begin{array}{l}\text { WVDE and Legislature must provide additional funding for desperately needed } \\
\text { administrative SUPPORT STAFF. }\end{array}$ \\
\hline & & $\begin{array}{l}\text { We are getting a general understanding of the outline; however, not all the staff is on } \\
\text { board. }\end{array}$ \\
\hline & & $\begin{array}{l}\text { Did not get to attend due to a personal conflict. Trying to keep pace with the change, but it } \\
\text { is a major challenge. }\end{array}$ \\
\hline & & We need to be careful to balance out the training with the time out of school. \\
\hline & & Monitoring and testing have become overwhelming on all staff. \\
\hline \multirow[t]{8}{*}{9} & $\begin{array}{l}\text { Professional } \\
\text { Development }\end{array}$ & Administrator and teacher training. \\
\hline & & Want training for ALL teachers mandated. \\
\hline & & Provides more current training and knowledge. \\
\hline & & $\begin{array}{l}\text { Professional development is more focused on providing tools for students to be successful } \\
\text { citizens and basics to build the foundation. }\end{array}$ \\
\hline & & Staff development has been beneficial. \\
\hline & & Has become a major portion and direction of our continuing education programming. \\
\hline & & $\begin{array}{l}\text { Yes, it has been the best professional development that I have ever attended. It is so well } \\
\text { thought out and applicable. }\end{array}$ \\
\hline & & Changes in professional development opportunities. \\
\hline \multirow[t]{4}{*}{10} & Leadership & Sessions and modules on $21^{\text {st }}$-century leadership ( 2 comments). \\
\hline & & Reaffirmed the importance of being the instructional leader of my school. \\
\hline & & 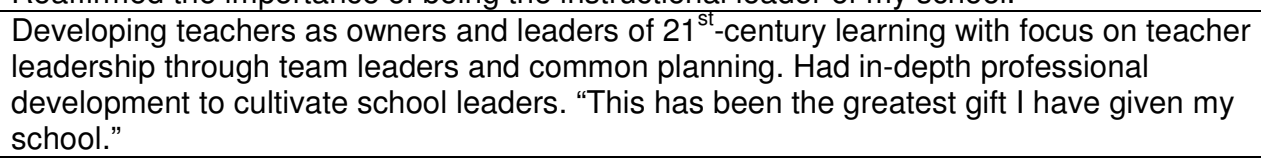 \\
\hline & & Established a viable school leadership team. \\
\hline \multirow[t]{2}{*}{11} & $\begin{array}{l}\text { School Culture and } \\
\text { Climate }\end{array}$ & Energized staff. \\
\hline & & and motivated others. \\
\hline
\end{tabular}




\begin{tabular}{|c|c|c|}
\hline & Category & Quote \\
\hline & & $\begin{array}{l}\text { One teacher at a time has an enormous return in the changing of a school culture to } \\
\text { student centered, not teacher centered. }\end{array}$ \\
\hline & & $\begin{array}{l}\text { Made me aware of the importance of the climate. Helped me better understand } \\
\text { Professional Learning Communities. }\end{array}$ \\
\hline & & Incorporating new ideas and information into the school. \\
\hline & & Helped in implementation of new ideas. \\
\hline & & Teacher Leadership Institute participants have shared many aspects (3 comments). \\
\hline & & $\begin{array}{l}\text { Teachers share a list of activities that apply to implementation of } 21^{\text {st }} \text { century in the } \\
\text { classroom. }\end{array}$ \\
\hline & & $\begin{array}{l}\text { School representatives have attended the training, then brought back information for the } \\
\text { rest to see. }\end{array}$ \\
\hline & & $\begin{array}{l}\text { Currently have two teachers working with this program and providing information to the } \\
\text { remainder of the staff. }\end{array}$ \\
\hline & & Yes, $21^{\text {st }}$-century teaching and learning brought back to the entire staff by participants. \\
\hline 12 & Strategic Planning & Geared much of strategic plan for the development of $21^{\text {st }}$-century skills. \\
\hline & & $\begin{array}{l}\text { Closing the Achievement Gap initiatives have been very informative and instrumental in } \\
\text { planning for the Five-Year Strategic Plan goals and strategies. }\end{array}$ \\
\hline & & Changes to the Five-Year Strategic Plan. \\
\hline 13 & School Improvement & It has helped set the standard for school improvement. \\
\hline & & $\begin{array}{l}\text { Helped our school become more aware of the direction we need to go to become a better } \\
\text { school. }\end{array}$ \\
\hline & & $\begin{array}{l}\text { Yes, it is always good to have updates and specific information on how to help improve the } \\
\text { school. }\end{array}$ \\
\hline 14 & General & Wonderful experience. \\
\hline & & Used to make improvements at the school level. \\
\hline & & Scope of learning has improved. \\
\hline & & Provided career information. \\
\hline & & Information on resources. \\
\hline 15 & Networking & None. \\
\hline
\end{tabular}




\section{Appendix E}

\section{Question 1: Narrative Responses by Category - Treatment Group}

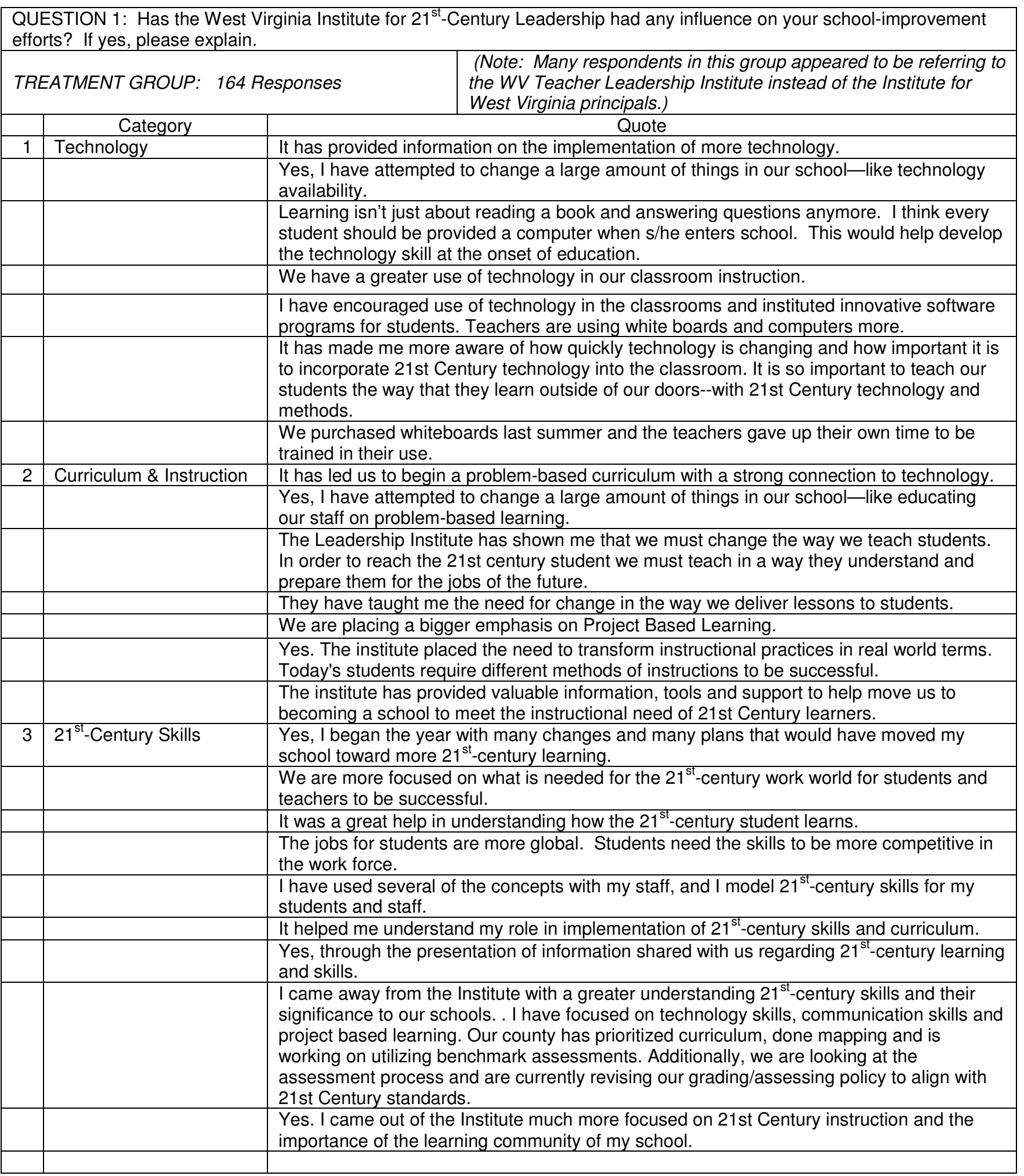




\begin{tabular}{|c|c|c|}
\hline & Category & Quote \\
\hline & & $\begin{array}{l}\text { Yes Our school is using the skills and content of } 21 \text { st century learning as the basis of } \\
\text { change agent reforms. }\end{array}$ \\
\hline & & $\begin{array}{l}\text { The institute has had a dramatic influence on the school's efforts. Due to the institute, I } \\
\text { have a better understanding of the } 21 \text { st Century Skills and have been able to implement in } \\
\text { the school. }\end{array}$ \\
\hline & & $\begin{array}{l}\text { Made me aware of the need to teach } 21 \text { st century skills and provide my staff with the tools } \\
\text { necessary to do so. }\end{array}$ \\
\hline & & $\begin{array}{l}\text { Yes, it has brought both an awareness and a motivation of the needs to move into the } 21 \mathrm{st} \\
\text { century. }\end{array}$ \\
\hline & & $\begin{array}{l}\text { YES, it has provided me with guidance on implementation of 21st century skills. The pillars } \\
\text { provide direction of essential components. }\end{array}$ \\
\hline & & $\begin{array}{l}\text { Yes, I attended the Principal's Leadership Academy and we have worked hard on } \\
\text { implementation of the } 21 \text { st Century learning skills. }\end{array}$ \\
\hline & & $\begin{array}{l}\text { Yes, I have learned the value technology and having to get on board with the 21st Century } \\
\text { Learning and embrace and place in the school. }\end{array}$ \\
\hline & & $\begin{array}{l}\text { Yes, it has had a great influence on } 21 \text { st Century Learning. We need to change the way } \\
\text { we are doing things. We need to think outside the box. There is a need for a paradigm } \\
\text { shift for students to compete globally. We need to prepare them for careers there are not } \\
\text { yet in place. }\end{array}$ \\
\hline & & $\begin{array}{l}\text { Yes, has provided an overview of what is needed in developing a 21st Century learning } \\
\text { environment for students and teachers. }\end{array}$ \\
\hline & & Yes, it has focused us on what we need o do to get ready for the 21st century. \\
\hline & & $\begin{array}{l}\text { A greater realization of the urgency for us to address the unique needs of } 21 \text { st Century } \\
\text { learners. }\end{array}$ \\
\hline & & Yes, The understanding that we are changing not just in our school but globally. \\
\hline & & $\begin{array}{l}\text { Yes. Taking part in the institute has helped me realize the need for } 21 \mathrm{st} \text { century skills in } \\
\text { our globally competitive society. It has also helped me understand these digital natives } \\
\text { learn differently and teachers and administrators must adapt their methods in order to } \\
\text { reach these students. I see the need for self-directed learning and the importance of } \\
\text { helping students develop skills in areas such as communication, teamwork, and civic } \\
\text { responsibility. }\end{array}$ \\
\hline & & $\begin{array}{l}\text { Yes, I think I am much more aware of attending to student success as measured in the } 10 \\
\text { to } 15 \text { years from now perspective. }\end{array}$ \\
\hline \multirow[t]{5}{*}{4} & $\begin{array}{l}\text { Research-Based } \\
\text { Strategies }\end{array}$ & Use of acuity. \\
\hline & & We are working on formative assessment. \\
\hline & & $\begin{array}{l}\text { It Yes, The understanding that we are changing not just in our school but globally. has } \\
\text { provided knowledge of more research. }\end{array}$ \\
\hline & & Helped to support beliefs that students' needs are different in today's society. \\
\hline & & $\begin{array}{l}\text { Yes, the Institute brought a perspective to the vast body of research-based knowledge. } \\
\text { The various speakers and facilitators gave me the information I needed to put strategies } \\
\text { and plans into motion to realize "whole school" improvement instead of just "pockets" of } \\
\text { improvement. Each and every principal should take part in this very worthwhile program. }\end{array}$ \\
\hline 5 & No Influence & None. \\
\hline \multirow[t]{2}{*}{6} & Yes (no explanation) & 9 responses. \\
\hline & & Yes, I am currently attending. \\
\hline 7 & No (no explanation) & 1 response. \\
\hline \multirow[t]{10}{*}{8} & Change & It has caused me to reflect on the changes that need to take place in my school. \\
\hline & & Learning about the various types of changes. \\
\hline & & I am learning how to implement change in an effective manner. \\
\hline & & It was a great help in dealing with change. \\
\hline & & It has helped me bring the change process and the urgency for change to my school. \\
\hline & & Yes, it helped me to see the large picture of where we want West Virginia to go. \\
\hline & & It has had a huge impact on the need for change. \\
\hline & & Motivation for change. \\
\hline & & $\begin{array}{l}\text { Helped me become a more focused administrator. I have gotten more of my staff involved } \\
\text { in seeing the need for an actually making change. }\end{array}$ \\
\hline & & Helped me look at change for what students need for the future. \\
\hline
\end{tabular}




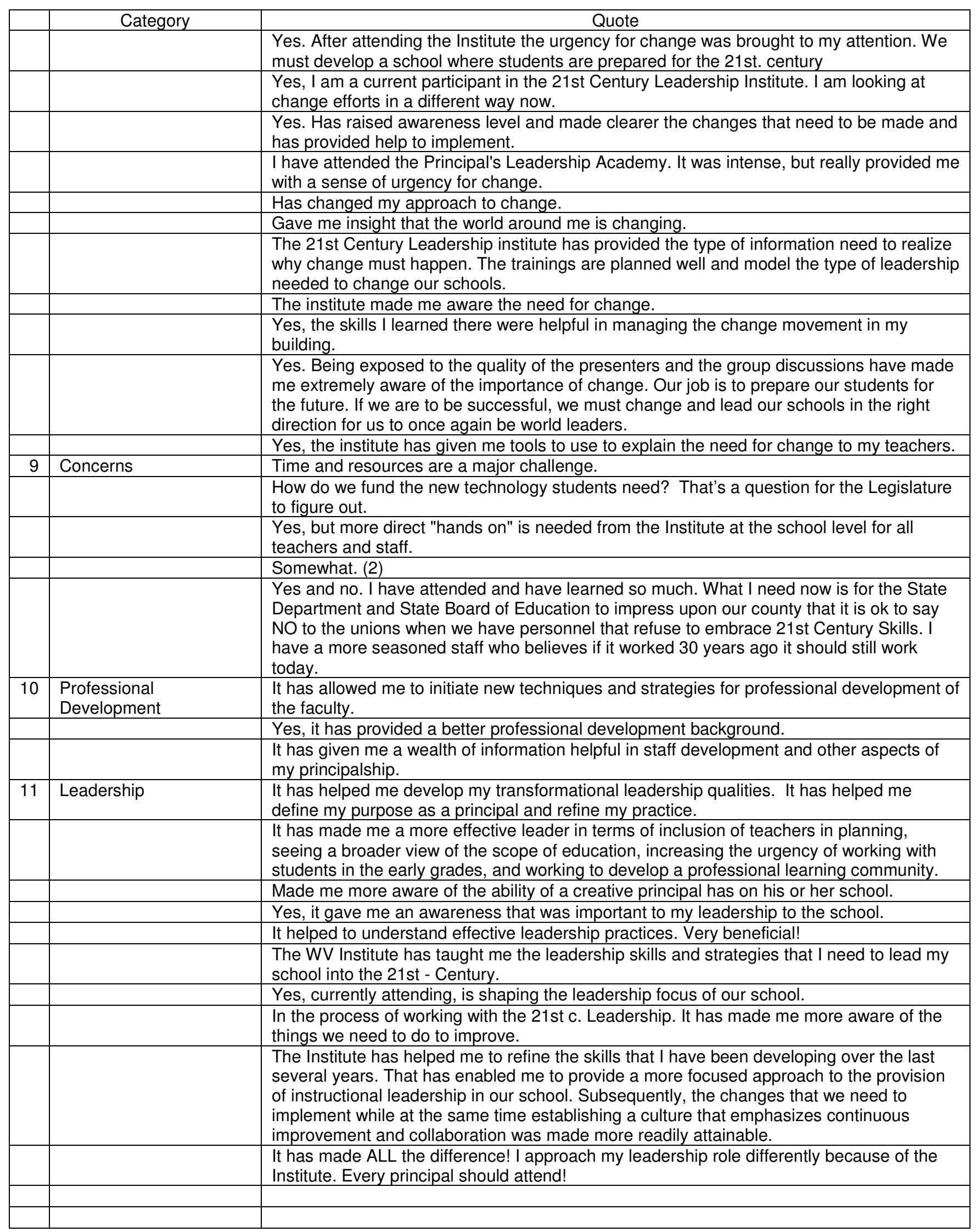




\begin{tabular}{|c|c|c|}
\hline & Category & Quote \\
\hline & & $\begin{array}{l}\text { The Leadership has helped bring in alignment all of the areas for school improvement. It is } \\
\text { researched based and assists leaders with showing teachers how the effects have been } \\
\text { studied and shown to improve student performance and understanding. }\end{array}$ \\
\hline & & Yes it has helped me become a transformational leader \\
\hline \multirow[t]{7}{*}{12} & $\begin{array}{l}\text { School Culture and } \\
\text { Climate }\end{array}$ & Improving school culture. \\
\hline & & $\begin{array}{l}\text { I attended the first year. Our staff has now had training on culture and effective-school } \\
\text { correlates. }\end{array}$ \\
\hline & & It has resulted in higher teacher and student expectations. \\
\hline & & It was a great help in the development of the school culture. \\
\hline & & $\begin{array}{l}\text { Yes, I have attempted to change a large amount of things in our school-like the } \\
\text { environment and safety conditions. }\end{array}$ \\
\hline & & Helped change the school culture. \\
\hline & & Technology, building positive relationships with students, building a positive culture. \\
\hline \multirow[t]{2}{*}{13} & Strategic Planning & $\begin{array}{l}\text { Very strong influence. We utilized the Framework for the development of this year's five- } \\
\text { year strategic plan and for ongoing goal revision. }\end{array}$ \\
\hline & & Yes, directed plans. \\
\hline \multirow[t]{10}{*}{14} & School Improvement & $\begin{array}{l}\text { I used the knowledge gained at the Leadership conference to enhance my school- } \\
\text { improvement efforts. }\end{array}$ \\
\hline & & I have implemented many of the areas that were discussed at the Leadership Academy. \\
\hline & & It is influencing my efforts for school improvement. \\
\hline & & $\begin{array}{l}\text { Training has improved my understanding of the vital components that need to be in place } \\
\text { for a school to be truly successful for its students and community. }\end{array}$ \\
\hline & & $\begin{array}{l}\text { WV Institute has provided valuable information and training on issues important to our } \\
\text { school improvement process. }\end{array}$ \\
\hline & & $\begin{array}{l}\text { My school-improvement efforts are more inclusive of the staff and parents than it was } \\
\text { before the institute. I seek more input from others on needs and implementation. }\end{array}$ \\
\hline & & $\begin{array}{l}\text { The 21st Century Leadership Institute has provided me with important data, techniques, } \\
\text { information and tools that have enabled me to move our school improvement toward } \\
\text { meeting the } 21 \text { st Century expectations. What I have learned has provided me with a much } \\
\text { better understanding and focus for my school. }\end{array}$ \\
\hline & & $\begin{array}{l}\text { Yes, I believe as a school we are looking for ways to make our school a better learning } \\
\text { center. }\end{array}$ \\
\hline & & $\begin{array}{l}\text { Yes, it has allowed me to focus my direction on the most important issues and provided } \\
\text { me with the processes that are needed to achieve improvement. }\end{array}$ \\
\hline & & $\begin{array}{l}\text { I attended the Principal's Institute in the Summer of } 2007 \text { and came away with a renewed } \\
\text { understanding of school improvement. When I first became principal, my school had very } \\
\text { low test scores and I went through much professional development in school } \\
\text { improvement. I believe a refresher is needed on a regular basis and a plan to rejuvenate } \\
\text { and energize principals is needed statewide! }\end{array}$ \\
\hline \multirow[t]{14}{*}{15} & General & Resources and trainings have provided a vast amount of knowledge. \\
\hline & & The information and language has an impact. \\
\hline & & The wide variety of issues discussed alone will open up a new world to you. \\
\hline & & Very informative. \\
\hline & & $\begin{array}{l}\text { The influence has been one in which ideas and top-notch programs have been shared, } \\
\text { which are helping me to turn around a school that has steadily been going downhill for the } \\
\text { last several years. }\end{array}$ \\
\hline & & Bringing awareness to the table. \\
\hline & & Fantastic! \\
\hline & & Yes, attending the PLI was a life changing experience for me. \\
\hline & & Just started in school - starting from scratch. \\
\hline & & Somewhat. I have learned many different ideas that can be utilized in my school. \\
\hline & & $\begin{array}{l}\text { Yes! It has provided the direction, resources, and communication needed for me to be } \\
\text { successful in the implementation of all the new standards. }\end{array}$ \\
\hline & & $\begin{array}{l}\text { Being a member of the 21st Century Principals' Leadership Academy has been one of the } \\
\text { greatest experiences in my career as a principal. }\end{array}$ \\
\hline & & More focused on what is important \\
\hline & & Yes, it has given me the opportunity to look closer at my school and our needs. \\
\hline
\end{tabular}




\begin{tabular}{|c|c|c|}
\hline & Category & $\begin{array}{l}\text { Quote } \\
\end{array}$ \\
\hline & & $\begin{array}{l}\text { Yes, I have participated in the Leadership Institute and am now a facilitator. It has been } \\
\text { the best experience of my educational career. }\end{array}$ \\
\hline & & Good stuff. \\
\hline & & $\begin{array}{l}\text { Yes. It has made me much more aware of the importance of developing those skills in } \\
\text { order for students to be successful, responsible adults. }\end{array}$ \\
\hline & & $\begin{array}{l}\text { I was a member of the } 1 \text { st institute. We are using the correlates in all of our decision } \\
\text { making. I understand the sense of urgency that we have in developing rigor and relevance } \\
\text { for our students. }\end{array}$ \\
\hline & & $\begin{array}{l}\text { Yes. Greatly increased my awareness and focused me on the issues needed to help } \\
\text { students meet the demands of the } 21 \text { st Century post-secondary environment. }\end{array}$ \\
\hline & & Yes, it has helped me understand the direction my school needs to be moving in. \\
\hline & & Supports what I'm already trying to do. \\
\hline & & Yes, I am currently a member of the Principals' Academy. \\
\hline & & $\begin{array}{l}\text { I have attended the WV Principals } 21 \text { st Century Leadership Academy and I have had staff } \\
\text { members attend several } 21 \text { st century leadership conferences. We are learning from these } \\
\text { sessions and implementing these learning strategies and concepts into the school wide } \\
\text { strategic plan and daily instruction. }\end{array}$ \\
\hline & & $\begin{array}{l}\text { YES. I was a participant and graduate of the first WV Institute for } 21 \text { st Century Leadership } \\
\text { and have implemented many of the concepts that I learned into the operation and } \\
\text { administration of my school. }\end{array}$ \\
\hline & & $\begin{array}{l}\text { Yes, I have made an effort to implement many of the ideas that I learned at the institute- } \\
\text { improving culture, climate, involving parents, etc. }\end{array}$ \\
\hline & & As a Principal, I have found the trainings very useful. \\
\hline & & $\begin{array}{l}\text { The diversity of the Institute has given me a national and international overview of public } \\
\text { school education. }\end{array}$ \\
\hline & & Yes, It has provided me with a shared vision. \\
\hline & & Yes, several of my teachers have attended. \\
\hline & & It has provided me with guidance. \\
\hline & & $\begin{array}{l}\text { Yes, I'm attending the } 21 \text { st Century Institute this year and I am implementing things I have } \\
\text { learned into our system. }\end{array}$ \\
\hline & & Yes, the strategies learned have been very beneficial. \\
\hline & & Myself and 5 teachers have participated in the institute. \\
\hline & & Certainly has provided me with a big-picture and an agenda. \\
\hline & & $\begin{array}{l}\text { Yes, transformational leadership, school culture, correlates of effective schools as } \\
\text { pathways to improvement, collaboration, and a broadening of my view of schooling } \\
\text { considering global factors and changes in students. }\end{array}$ \\
\hline & & It has truly changed the way I view education in the 21 st Century. \\
\hline 16 & Networking & $\begin{array}{l}\text { The networking with other educators is a resource that is beyond compare. It has helped } \\
\text { in all aspects of moving our school into the } 21^{\mathrm{st}} \text { century. }\end{array}$ \\
\hline & & $\begin{array}{l}\text { It has given me the opportunity to meet and discuss new ideas with other innovative } \\
\text { thinkers. }\end{array}$ \\
\hline & & We use professional learning communities. \\
\hline & & $\begin{array}{l}\text { It developed my confidence in making decisions and provided me with a networking } \\
\text { system. }\end{array}$ \\
\hline & & $\begin{array}{l}\text { I gained many ideas, valuable networking contacts, and motivation for change through the } \\
\text { Leadership Institute. }\end{array}$ \\
\hline & & Yes, it was very productive to share and learn with those who participated. \\
\hline & & $\begin{array}{l}\text { I find myself more focused on what needs to happen in order to be successful and passing } \\
\text { that along to the rest of the school community. }\end{array}$ \\
\hline & & Provided a support system among principals so that we can network. \\
\hline & & Yes, with the leadership team learning and bringing that training back to the staff. \\
\hline & & Yes, the institute gives many opportunities to collaborate with others in the field. \\
\hline & & $\begin{array}{l}\text { I believe that it gave me the confidence to keep moving many of the programs that I had } \\
\text { begun. It also gave me new ideas to use. It is also great to have the support of other } \\
\text { principals. }\end{array}$ \\
\hline
\end{tabular}




\section{Appendix F}

\section{Question 2: Narrative Responses by Category - Comparison Group}

\begin{tabular}{|c|c|c|}
\hline \multicolumn{3}{|c|}{ COMPARISON GROUP: 145 Responses } \\
\hline & Category & Quote \\
\hline \multirow[t]{5}{*}{1.} & Stress & $\begin{array}{l}\text { How to motivate teachers who feel overwhelmed with RTI, assessment, and the feeling } \\
\text { that they don't have time to teach. }\end{array}$ \\
\hline & & There is very little opportunity for learning to be fun and exciting. \\
\hline & & $\begin{array}{l}\text { It is a sad day when teachers have to ask if they can do a special "fun" lesson, or when } \\
\text { superb teachers say publicly they are tired of teaching and are thinking of changing } \\
\text { grades because of all the stresses on them to meet the requirements. I worry about the } \\
\text { future of these children and their teachers! }\end{array}$ \\
\hline & & $\begin{array}{l}\text { I won't be a part of providing more data to justify more and more interventions and put } \\
\text { more demands on teachers. All these programs/interventions, in and of themselves, are } \\
\text { fine; but when we keep adding without subtracting, the whole kitchen can become messy. } \\
\text { Shop, prioritize, then adopt! }\end{array}$ \\
\hline & & Bureaucracy. \\
\hline \multirow[t]{15}{*}{2.} & $\begin{array}{l}\text { Socio-economic } \\
\text { Concerns }\end{array}$ & Economy, family status, values. \\
\hline & & Many students are from low-income families. \\
\hline & & The biggest challenge for our students is low income and one-parent families. \\
\hline & & Poverty, broken homes, two parents working. \\
\hline & & Cyclical poverty-level conditions. \\
\hline & & Helping low-income families-teaching parents. \\
\hline & & Extensive poverty. \\
\hline & & $\begin{array}{l}\text { The high number of low socio-economic status students who have no access to } \\
\text { technology outside the school environment. }\end{array}$ \\
\hline & & $\begin{array}{l}\text { The income level of my students is a challenge to overcome in dealing with building } \\
\text { productive citizens. We combat the influences of home daily. }\end{array}$ \\
\hline & & Overcoming generational poverty that filters to the students' thinking about their futures. \\
\hline & & $\begin{array}{l}\text { Socio-economic issues. As the local economy fails, our brightest and best are moving } \\
\text { away, and not all the remaining students have the same abilities or the same work ethic. } \\
\text { It is sometimes difficult to achieve and/or maintain parent involvement. }\end{array}$ \\
\hline & & We need to raise expectations and do a better job of instruction for our low SES students. \\
\hline & & $\begin{array}{l}\text { Low socio-economic status and parent involvement. They do not see education as a } \\
\text { priority. }\end{array}$ \\
\hline & & $\begin{array}{l}\text { Low socio-economic clientele and a lack of coordinated services to meet children's needs } \\
\text { from outside the school system. }\end{array}$ \\
\hline & & Overcoming high poverty area roles and expectations. \\
\hline \multirow[t]{13}{*}{3.} & Needs & Physical plant. \\
\hline & & District funding. \\
\hline & & $\begin{array}{l}\text { Technological assistance is needed to provide the students with the avenue to be } \\
\text { successful learners. }\end{array}$ \\
\hline & & Time and money are always the greatest challenges. \\
\hline & & Time to organize and develop implementations. \\
\hline & & More technology. \\
\hline & & Reaching the needs of all students with a lack of staff and funding. \\
\hline & & Time factors. \\
\hline & & $\begin{array}{l}\text { Teachers need to be provided more time and resources to provide students with the } \\
\text { knowledge base to be productive citizens. }\end{array}$ \\
\hline & & Time, money, and additional staff. \\
\hline & & Time! \\
\hline & & Limited staff. \\
\hline & & Time and resources to meet the needs of slower learners. \\
\hline
\end{tabular}




\begin{tabular}{|c|c|c|}
\hline & Category & Quote \\
\hline & & 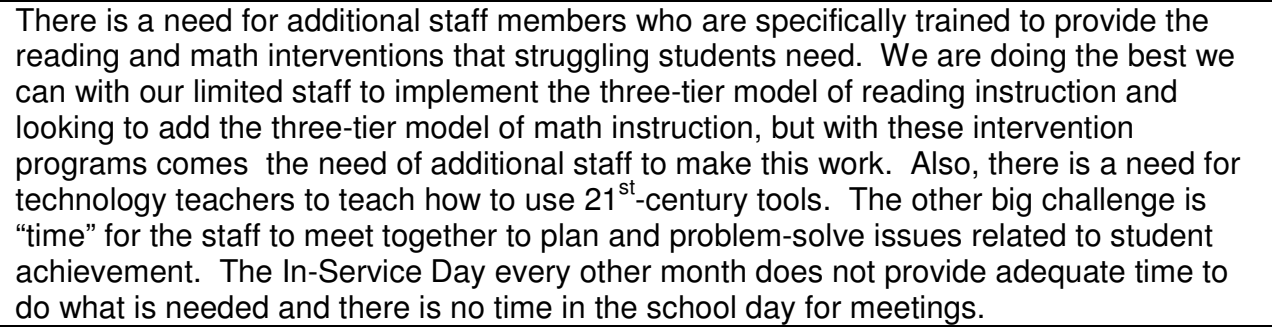 \\
\hline & & $\begin{array}{l}\text { Having time for collaboration among teachers (grade level, regular educators, and special } \\
\text { educators. }\end{array}$ \\
\hline & & Keeping a highly qualified teaching staff in this part of the state. \\
\hline & & $\begin{array}{l}\text { Good personnel are needed to provide the students with the avenue to be successful } \\
\text { learners. }\end{array}$ \\
\hline & & $\begin{array}{l}\text { Personnel assistance is needed to provide the students with the avenue to be successful } \\
\text { learners. }\end{array}$ \\
\hline & & Need professional development time for teachers. \\
\hline & & $\begin{array}{l}\text { The greatest challenge for a seasoned staff is to have the knowledge of the } 21^{\text {st }} \text { century } \\
\text { technology to integrate into the curriculum. }\end{array}$ \\
\hline & & Staying current on $21^{\text {st }}$-century technology skills. \\
\hline & & $\begin{array}{l}\text { Maintaining the staff to continue programs and adequate technology resources and } \\
\text { equipment. }\end{array}$ \\
\hline & & Teacher training. \\
\hline & & Time to improve skills on slow learners providing different tiers of learning. \\
\hline & & Fully implementing $21^{\text {st }}$-century skills without a computer lab. \\
\hline & & Time-having enough resources to group children for interventions. \\
\hline & & Training for staff and more resources. \\
\hline & & Having the necessary time (minutes, hours) to get all the remediation accomplished. \\
\hline & & $\begin{array}{l}\text { Time for professional development and planning for staff to fully internalize the importance } \\
\text { of } 21^{\text {st }} \text {-century skills in their lives, as well as in the lives of their students. }\end{array}$ \\
\hline & & Time. \\
\hline & & Having adequate facilities and an experienced staff. \\
\hline & & Equal access to technology and other offerings. \\
\hline & & Getting technology that will meet the needs of all students. \\
\hline & & $\begin{array}{l}\text { Financial and staffing constraints. If the state is going to mandate a program, such as the } \\
\text { three-tier reading plan, they need to provide the funds needed to implement it } \\
\text { successfully. }\end{array}$ \\
\hline & & Limited authority at the school level with discipline. \\
\hline & & Difficulty of getting rid of bad employees. \\
\hline & & Time!! We would always like to have more time. \\
\hline & & Financial funding for staffing needs, technology updates and facilities. \\
\hline & & $\begin{array}{l}\text { Not enough time to work with staff (and for staff to work together) to be an effective } \\
\text { Professional Learning Community. }\end{array}$ \\
\hline & & Limited funds. \\
\hline & & $\begin{array}{l}\text { Money to purchase the needed } 21^{\text {st }} \text {-century equipment. Money and time to pay } \\
\text { professionals for additional training. }\end{array}$ \\
\hline & & Not enough collaboration time. Need a full-time counselor. \\
\hline & & Ongoing, quality staff development. \\
\hline & & Adequate personnel and finances to develop and incorporate programs needed. \\
\hline & & Time and resources. \\
\hline 4. & $21^{\text {st }}$-Century Learning & To be able to keep up with the pace with how fast society is changing. \\
\hline & & Relating an education to the real world of work and how they are interconnected. \\
\hline & & Connectivity to the real world. \\
\hline & & \\
\hline & & \\
\hline & & \\
\hline & & \\
\hline
\end{tabular}




\begin{tabular}{|c|c|c|}
\hline & Category & Quote \\
\hline \multirow[t]{2}{*}{6.} & Special Education & $\begin{array}{l}\text { When students have to stay in the regular classroom and are not allowed to be pulled to a } \\
\text { special-education classroom. Our special education students are being neglected and } \\
\text { deprived of an appropriate education on their level. }\end{array}$ \\
\hline & & $\begin{array}{l}\text { Adaptation and instruction of Special Education students is needed at the higher level of } \\
\text { rigor required. }\end{array}$ \\
\hline \multirow[t]{30}{*}{7.} & Student Issues & Lack of social skills. \\
\hline & & Lack of motivation to excel. \\
\hline & & $\begin{array}{l}\text { Students DO NOT see the need for what we are teaching (or trying to teach) them. They } \\
\text { are not motivated at all (as a whole). }\end{array}$ \\
\hline & & Students that are discipline problems and have severe academic issues. \\
\hline & & Discipline in the classroom in a factor \\
\hline & & Discipline in the classroom is another factor that causes much concern. \\
\hline & & $\begin{array}{l}\text { Students are not engaged. They do not enjoy the structured routines and lessons from } \\
\text { DIBELS and } 95 \% \text { group. }\end{array}$ \\
\hline & & Children's home situations. \\
\hline & & Effective transitions back to the students' home school. \\
\hline & & Lack of social experiences. \\
\hline & & $\begin{array}{l}\text { Taking care of students' basic needs. Most come from single parents with little or no } \\
\text { attention given to the child for his or her basic needs-food, clothes, love, etc. }\end{array}$ \\
\hline & & Attendance. \\
\hline & & Student interest. \\
\hline & & To develop an effective work ethic and caring for your fellow man. \\
\hline & & $\begin{array}{l}\text { Teaching kids how to be independent learners while dealing with current social problems: } \\
\text { i.e., drugs, divorces, teen pregnancy, responsible use of technology, avoiding Internet } \\
\text { mistakes in chat rooms, too much information, or cyber bullies. While social issues have } \\
\text { not changed greatly, the speed and intensity of their effect on our students have because } \\
\text { of the use of communications technology. We need to develop a well-grounded individual } \\
\text { to give them the skills to learn and cope with an ever rapidly changing social and work } \\
\text { environment. }\end{array}$ \\
\hline & & $\begin{array}{l}\text { Our school population is very transient. This impedes our ability to make a long-term } \\
\text { impact on their learning. }\end{array}$ \\
\hline & & $\begin{array}{l}\text { I feel the greatest challenge we face is helping our students realize that they are the ones } \\
\text { who hold their futures in their hands and that, regardless of their present situations, they } \\
\text { can accomplish great things. I feel that our students do not really have the confidence in } \\
\text { themselves to achieve to their potential. }\end{array}$ \\
\hline & & Attendance and lack of basic education, such as reading and math. \\
\hline & & $\begin{array}{l}\text { The biggest challenge is for them to remain successful and productive when they leave } \\
\text { our school. }\end{array}$ \\
\hline & & Development of a desire or interest in learning. \\
\hline & & Severe behavior and interruptions. \\
\hline & & Lack of motivation and desire to be successful. \\
\hline & & Student attitudes are a challenge. \\
\hline & & $\begin{array}{l}\text { Enable students to take responsibility for their own learning by engaging in self- } \\
\text { assessment and goal setting. }\end{array}$ \\
\hline & & Lack of responsibility of one's own actions. \\
\hline & & Loss of respect. \\
\hline & & The varied abilities of students when they first arrive in pre-school or kindergarten. \\
\hline & & Attendance, home environment. \\
\hline & & Increasing their realization that their effort is the key to success. \\
\hline & & $\begin{array}{l}\text { Overcoming the emotional issues they come to school with-worry about food, shelter, } \\
\text { parent safety, etc. }\end{array}$ \\
\hline \multirow[t]{6}{*}{8.} & $\begin{array}{l}\text { Curriculum and } \\
\text { Instruction }\end{array}$ & Teaching in the way today's students learn. \\
\hline & & Teaching reading is the very most important variable in determining success. \\
\hline & & The concept of social promotion (chronological age vs. intellectual reasoning age. \\
\hline & & Making the learning relevant to all students, not just those we know will attend college. \\
\hline & & \\
\hline & & \\
\hline
\end{tabular}




\begin{tabular}{|c|c|c|}
\hline & Category & Quote \\
\hline & & $\begin{array}{l}\text { Many of the graduation requirements are not relevant to students who will never pass high } \\
\text { school or go to college. Providing a technical school component, back to the basics of } \\
\text { Shop, Home. Ec. at the middle level is the key to keeping students in school and focused } \\
\text { on a relevant education. Some of the arts and music classes do little to maintain the } \\
\text { interest of students who are not able to see a connection to these classes and their lives. }\end{array}$ \\
\hline & & $\begin{array}{l}\text { We are jamming too much into the primary curriculum. It needs to be reading, writing, } \\
\text { math, and technology at this level. }\end{array}$ \\
\hline & & $\begin{array}{l}\text { Teaching curriculum that is developmentally appropriate to the students. The curriculum } \\
\text { is great; however, it is not developmentally correct. }\end{array}$ \\
\hline & & $\begin{array}{l}\text { The greatest challenge is to provide real, problem/project-based, technology-rich } \\
\text { experiences for students to "think outside the box." }\end{array}$ \\
\hline & & $\begin{array}{l}\text { Gaining the proper attention and focus. Helping my teachers, parents, students broaden } \\
\text { their vision. }\end{array}$ \\
\hline & & $\begin{array}{l}\text { We need more flexibility to teach students real-life skills to prepare them for what is to } \\
\text { come. We are tied too tightly to WESTEST and other assessment tools to teach what is } \\
\text { needed. }\end{array}$ \\
\hline & & $\begin{array}{l}\text { Mastering the basic but being able to go beyond and use problem solving skills, higher } \\
\text { level thinking skills, think on their own, have good social skills, and a good solid } \\
\text { background in Science and Social Studies. }\end{array}$ \\
\hline & & $\begin{array}{l}\text { Meeting the many mandates handed down sometimes gets in the way of what is really } \\
\text { important. Too much emphasis on test scores. }\end{array}$ \\
\hline 9. & Faculty Attitudes & Have $100 \%$ of the teachers actively involved. \\
\hline & & Getting faculty and staff buy-in to changes that are needed for student success. \\
\hline & & Teachers who do not believe it is possible. \\
\hline & & Strengthening the belief of "yes, we can." \\
\hline & & Enhancing a culture of excellence. \\
\hline & & Persuading every teacher that this is an achievable goal. \\
\hline & & $\begin{array}{l}\text { Getting the teachers of non-core classes to work to support efforts of core teachers to } \\
\text { improve identified weaknesses (particularly reading comprehension and writing). }\end{array}$ \\
\hline & & Getting teachers to improve their instructional strategies. \\
\hline & & Teacher attitudes toward their responsibilities and expectation for change. \\
\hline & & $\begin{array}{l}80 \% \text { of our faculty are within five years of retirement; thus, the inclination to change or to } \\
\text { do more is not there. }\end{array}$ \\
\hline & & $\begin{array}{l}\text { Most teachers are changing instruction as needed, but one or two are having problems } \\
\text { doing this. }\end{array}$ \\
\hline & & Getting teachers to buy into the change process. \\
\hline & & Improving teachers who don't want to be improved. \\
\hline & & $\begin{array}{l}\text { Having the best teachers available with positive attitudes. Educators who will continue to } \\
\text { learn and use their knowledge to help all students to be successful. }\end{array}$ \\
\hline & & Teachers who are reluctant to change. \\
\hline 10. & Accountability & The greatest challenge is to have all children achieve mastery. \\
\hline & & Federal intervention, No Child Left Behind. \\
\hline & & $\begin{array}{l}\text { Our being successful in all aspects of the educational process, not the judgment of just } \\
\text { the No Child Left Behind standards. }\end{array}$ \\
\hline 11. & Parents & Lack of parental support. \\
\hline & & Teaching parents to be parents, not their child's friends. \\
\hline & & Changing the culture with parents and students to make education a high priority. \\
\hline & & Parent attitudes. \\
\hline & & Sorry-parents! \\
\hline & & Having $100 \%$ of the students and parents actively involved. \\
\hline & & $\begin{array}{l}\text { Involving parents in the team effort of jointly correcting and training the students to be } \\
\text { respectful of each other and that rules are to be followed by all. }\end{array}$ \\
\hline & & $\begin{array}{l}\text { We must make the parents aware of the educational challenge of the future and seek their } \\
\text { assistance in its implementation. }\end{array}$ \\
\hline & & Dysfunctional homes, transient population. \\
\hline & & Better parenting and less drug abuse. \\
\hline & & Reaching parents! \\
\hline & & $\begin{array}{l}\text { There appears to be an increased number of students who lack a home support system } \\
\text { that enables them to achieve their potential. }\end{array}$ \\
\hline
\end{tabular}




\begin{tabular}{|c|c|c|}
\hline & Category & Quote \\
\hline & & Parents need to make the time to support all school activities. \\
\hline & & $\begin{array}{l}\text { Parental involvement. Getting parents to understand that if the child is educated and } \\
\text { wants to do better than the parent, it is OKAY to leave the "nest." }\end{array}$ \\
\hline & & Parental support. \\
\hline & & Educating parents. \\
\hline & & Getting and keeping parents involved and caring about their children's education. \\
\hline & & $\begin{array}{l}\text { I believe that all stakeholders must be involved in this process. In saying this, the culture } \\
\text { of the community can be a challenge before the core beliefs are identified. When the core } \\
\text { beliefs are uncovered then a new direction or focus can be developed while lowering the } \\
\text { cultural barriers. }\end{array}$ \\
\hline & & $\begin{array}{l}\text { Buy-in by parents who have dropped out and do not have the savvy in making school } \\
\text { important for their children. }\end{array}$ \\
\hline & & Continuing to promote parents to actively help in the learning process. \\
\hline & & $\begin{array}{l}\text { Another challenge is the quality of parenting. Most of our students are from single- or } \\
\text { blended-family situations and believe that because of the circumstances that they do not } \\
\text { need to be responsible. }\end{array}$ \\
\hline & & $\begin{array}{l}\text { Their home life-parents in jail, drug and alcohol abuse, not seeing education as a } \\
\text { priority. }\end{array}$ \\
\hline & & $\begin{array}{l}\text { Increasing parent involvement to insure student success and increase school-home } \\
\text { communication. }\end{array}$ \\
\hline & & $\begin{array}{l}\text { Total involvement of home and family to be supportive and provide help to the students. } \\
\text { Parents are too busy and don't always share the values of the school system. }\end{array}$ \\
\hline & & $\begin{array}{l}\text { Parents: We have good parent support, but I wonder what goes on at a student's home to } \\
\text { see how the parents are working with us to improve their child's education. }\end{array}$ \\
\hline & & Lack of parent involvement. \\
\hline & & Parent involvement. \\
\hline & & Lack of parental support for struggling students. \\
\hline & & Motivation of students who come from homes where education is not valued. \\
\hline & & $\begin{array}{l}\text { The greatest challenges are educating parents to understand their dynamic role in their } \\
\text { child's education. Their role sets the attitude that most children have toward learning. }\end{array}$ \\
\hline & & $\begin{array}{l}\text { Once parents understand their need to help, support, and work closely with the school, we } \\
\text { are well on the way to help the child become a productive citizen. }\end{array}$ \\
\hline & & Overcoming deficits from the home. \\
\hline & & Home life. \\
\hline & & Parent involvement and support. \\
\hline 12. & Societal Issues & $\begin{array}{l}\text { The challenge will be in preparing students who feel and whose families feel } \\
\text { disenfranchised by our society. To give them the tools to be productive, successful } \\
\text { citizens will be challenging because they fell little hope for success. }\end{array}$ \\
\hline & & $\begin{array}{l}\text { Achieving better attendance, better work ethic, better student character and morality. } \\
\text { Better parenting, and less drug abuse with students and parents. }\end{array}$ \\
\hline & & $\begin{array}{l}\text { Dealing with today's society in not preparing the children with prerequisite skills before } \\
\text { entering Kindergarten. Unusual level of skill deficiencies in our special needs students } \\
\text { (academically, emotionally, and behaviorally. }\end{array}$ \\
\hline
\end{tabular}




\section{Appendix G}

\section{Question 2: Narrative Responses by Category - Treatment Group}

\begin{tabular}{|c|c|c|}
\hline \multicolumn{3}{|c|}{ TREATMENT GROUP: 167 Responses } \\
\hline & Category & Quote \\
\hline \multirow[t]{4}{*}{1.} & Stress & Getting TIME to work with teachers when they aren't overwhelmed with teaching duties. \\
\hline & & Teacher burn-out. \\
\hline & & Staff reductions. \\
\hline & & $\begin{array}{l}\text { More control over our daily schedules (too many mandates to leave room for new needs). } \\
\text { Too many new things piled upon us without time to learn it well and implement it the right } \\
\text { way. Never enough funding to do what's truly needed. Social problems are increasing, } \\
\text { making children's lives unstable and leaving them unable to focus at school. }\end{array}$ \\
\hline \multirow[t]{6}{*}{2.} & $\begin{array}{l}\text { Socio-economic } \\
\text { Concerns }\end{array}$ & Overcoming generational poverty. \\
\hline & & The greatest challenges for our students include isolation and generational poverty. \\
\hline & & Economically disadvantaged children. \\
\hline & & Fighting poverty. \\
\hline & & The rural area and having family support to strive beyond. \\
\hline & & Poverty. \\
\hline \multirow[t]{21}{*}{3.} & Needs & $\begin{array}{l}\text { TIME: For staff development, teacher collaboration, for real embedded learning for staff } \\
\text { and for them to be able to do the work necessary to assess for learning and differentiate. }\end{array}$ \\
\hline & & Money for 21st century tools \\
\hline & & Caring Adults. Time Management. Technology. \\
\hline & & More computers student/computer ratio \\
\hline & & The time and manpower to establish and maintain all the programs we initiate. \\
\hline & & Time is not available to implement all programs. \\
\hline & & time and resources \\
\hline & & Time and tools to accomplish 21st century learning. \\
\hline & & $\begin{array}{l}\text { Addressing the needs of our at-risk students without adequate support staff and budget; } \\
\text { time for our teachers to network, collaborate etc. }\end{array}$ \\
\hline & & $\begin{array}{l}\text { Having tools that are easy and effective to assess students' ability levels and then using } \\
\text { the data to effectively implement instruction to meet the needs of students. }\end{array}$ \\
\hline & & Lack of onsite technology support and trouble shooting structural issues. \\
\hline & & $\begin{array}{l}\text { Providing the training for teachers to become effective with designing lessons utilizing } \\
\text { technology. Modeling technology skills that enhance the development of our students to } \\
\text { utilize research and to participate in research in the classroom. }\end{array}$ \\
\hline & & Need more equipment, such laptops, whiteboards, etc. \\
\hline & & $\begin{array}{l}\text { My school is a small PK-8 grade school with a declining enrollment. We have lost } \\
\text { positions and staff for the past two years. One challenge is the facility itself-a multi- } \\
\text { purpose room that serves as the gym and cafeteria. It makes it difficult to meet the state } \\
\text { PE requirements for my lower school. Also, my primary and middle school PE teachers, } \\
\text { one each, teach other classes. However, even if I had more PE Staff, they would not have } \\
\text { a room in which to teach. }\end{array}$ \\
\hline & & $\begin{array}{l}\text { Another great challenge is the time to provide on-going professional development to my } \\
\text { staff combined with the time for them to plan for implementation. }\end{array}$ \\
\hline & & $\begin{array}{l}\text { The greatest challenges I believe is time. Teachers need time to change their teaching in } \\
\text { order to develop students (more than academically) }\end{array}$ \\
\hline & & Lack of money and resources. \\
\hline & & Technology needs. \\
\hline & & Providing teachers with appropriate training to assist them in the teaching of our students. \\
\hline & & \\
\hline & & \\
\hline
\end{tabular}




\begin{tabular}{|c|c|c|}
\hline & Category & Quote \\
\hline & & $\begin{array}{l}\text { Time. Time to plan as a school team. Our school currently has approx } 25 \text { minutes per day } \\
\text { that } 30 \% \text { of the staff can meet as a unit. The majority of this time is spent in the SAT and } \\
\text { IEP process. The time to work as a staff on curriculum and other programs is vital (and } \\
\text { currently missing from the school calendar.) }\end{array}$ \\
\hline & & $\begin{array}{l}\text { Time for meaningful professional development activities. In order for teachers and school } \\
\text { leaders to understand what is necessary to move toward truly effective } 21 \text { st Century } \\
\text { learning, time for quality professional development activities is necessary. }\end{array}$ \\
\hline & & Finding and retaining HQT (highly qualified teachers). \\
\hline & & Facility and technology upgrades. \\
\hline & & $\begin{array}{l}\text { Finding time for the teachers to simply teach students and not be constantly be bogged } \\
\text { down by new initiatives that replace initiatives that we have not even mastered yet. Over } \\
\text { testing is also an obstacle. }\end{array}$ \\
\hline & & Ongoing professional development for teachers. \\
\hline & & Time. Getting everything in within the school day. \\
\hline & & Finances. \\
\hline & & $\begin{array}{l}\text { We need time for teachers to be able to work and collaborate to plan for programs and } \\
\text { instruction that will benefit and effect student success. We have too many new programs } \\
\text { without enough time to plan in professional learning communities to make the transition } \\
\text { into the new program seamless and comfortable for teachers and students. }\end{array}$ \\
\hline & & $\begin{array}{l}\text { Keeping up with technology and keeping all of it working. In a school that doesn't have } \\
\text { walls and doors it is hard to have the focus that many students need. }\end{array}$ \\
\hline & & Time. \\
\hline & & Time. \\
\hline & & Staff awareness. \\
\hline & & $\begin{array}{l}\text { All schools need more technology (hardware); this should be a priority for WV. Teachers } \\
\text { cannot effectively utilize technology if they don't have access to it. }\end{array}$ \\
\hline & & Financial support for teacher training and sustained professional development. \\
\hline & & $\begin{array}{l}\text { Developing the } 6 \text { pillars of character counts so that students become aware of the } \\
\text { importance of these to be successful in school and in life. }\end{array}$ \\
\hline & & Time is the greatest challenge to producing successful-productive students. \\
\hline & & Money-Investing in Technology. \\
\hline & & Money to fund the technology needed to integrate/support project-based learning. \\
\hline & & $\begin{array}{l}\text { The time for meaningful staff development. All must attend and not be able to use } \\
\text { personal or sick leave instead of attending. }\end{array}$ \\
\hline & & Time. \\
\hline & & $\begin{array}{l}\text { It is difficult for elementary to get any time with only } 30 \text { minutes of planning and students } \\
\text { arriving so early and leaving close to the end of the teachers' time. }\end{array}$ \\
\hline & & $\begin{array}{l}\text { Being a technical school there are challenges with scheduling and placement. Many } \\
\text { counselors have no idea of the requirements of specific curriculums and students are not } \\
\text { always properly placed. There is a need for a state-mandated attendance policy } \\
\text { (something with some teeth). There is also a need for increased technology and while my } \\
\text { school is better than most, there are still issues with technology and technology access } \\
\text { that hinder our educational goals for our students. }\end{array}$ \\
\hline & & $\begin{array}{l}\text { I realize that } 21 \text { st Century skills do not only focus on computers and technology } \\
\text { equipment but you really need them to fully prepare the students. More money needs to } \\
\text { be available to equip classroom, computer labs, provide learning field trips, etc. }\end{array}$ \\
\hline & & $\begin{array}{l}\text { I believe it to be the facilities that were designed for traditional teaching. Modifying existing } \\
\text { structures to meet the needs of effective learning centers (including technology) will be a } \\
\text { major challenge. }\end{array}$ \\
\hline & & Resources such as more teachers and more technology are a challenge. \\
\hline & & Lack of technology resources. Lack of space. Lack of time. \\
\hline & & Time for professional development. \\
\hline & & $\begin{array}{l}\text { Providing adequate technology experiences to give students an adequate learning/data } \\
\text { base. }\end{array}$ \\
\hline & & Providing adequate technology hardware for student learning. \\
\hline & & Training and supplying teachers with up to date technology uses and hardware. \\
\hline \multirow[t]{3}{*}{4.} & $21^{\text {st }}$-Century Learning & Keeping up with change and technology. \\
\hline & & The transition from 20th Century practices to 21 st Century concepts is a challenge. \\
\hline & & Using more 21st Century skills. \\
\hline
\end{tabular}




\begin{tabular}{|c|c|c|}
\hline & Category & Quote \\
\hline & & The ability to have students connect to the real world. \\
\hline & & The introduction of "globalism" and how they are a part of a larger world \\
\hline & & Keeping up with the new technology that is being developed everyday. \\
\hline & & Preparing students for jobs that don't even exist yet. \\
\hline & & $\begin{array}{l}\text { Mastering all of the } 21 \text { st Century Skills before leaving 5th grade and having the time and } \\
\text { technology to do so. }\end{array}$ \\
\hline & & Teaching children to learn to reason and problem solve on their own. \\
\hline & & $\begin{array}{l}\text { 20th century learning strategies, lack of use of formative assessments (old paradigm that } \\
\text { using formative assessments take too much time). }\end{array}$ \\
\hline & & Giving students 21 st century skills. \\
\hline & & Preparing students for a global society. \\
\hline & & $\begin{array}{l}\text { Our greatest challenge is making kids understand the need for a quality education built } \\
\text { around } 21 \text { st Century skills. }\end{array}$ \\
\hline & & $\begin{array}{l}\text { Each school needs to be empowered and supported by County and State systems to } \\
\text { make decisions about how } 21 \text { st Century learning will be addressed in their school. County } \\
\text { and State systems cannot mandate "cookie cutter" implementations of initiatives and } \\
\text { expect that to result in success of developing and implementing a curriculum that will } \\
\text { provide students with skills needed to be successful. Those kinds of mandates demoralize } \\
\text { teachers and take away the opportunity for teachers to provide their students the } \\
\text { specialized attention they need to be successful. }\end{array}$ \\
\hline & & Understanding the depth of citizenship at this age. \\
\hline & & Time for teachers to develop 21st century lesson plans. \\
\hline & & $\begin{array}{l}\text { Time for staff development in helping teachers understand } 21 \text { st century skills sets is a } \\
\text { critical issue. }\end{array}$ \\
\hline 6. & Special Education & The greatest challenge is special education. \\
\hline 7. & Student Issues & Need to be self-directed. \\
\hline & & Discipline. Teaching the kids that hate school. \\
\hline & & Student attendance. \\
\hline & & Student apathy. \\
\hline & & $\begin{array}{l}\text { The greatest challenges are maintaining student engagement in the learning process. It's } \\
\text { our jobs to help students develop a sense of self that includes learning and education as } \\
\text { highly valued. }\end{array}$ \\
\hline & & Drive....students must have the drive. \\
\hline & & Having students attend school regularly! \\
\hline & & $\begin{array}{l}\text { Regular attendance in one school. We have a 'revolving door' effect for too many } \\
\text { students. Poor performance is directly related to poor attendance and the number of } \\
\text { schools a child attends during a school year. }\end{array}$ \\
\hline & & Motivating students who do not seem to care. \\
\hline & & They want me to change but they do not give me the help to do it. \\
\hline & & $\begin{array}{l}\text { Competing with their environments for their attention so we can teach them seems to be } \\
\text { our biggest challenge. Some students are so distracted by mixed up home lives and/or } \\
\text { not having their basic needs met (food, shelter, clothing, etc.) }\end{array}$ \\
\hline & & Motivation. \\
\hline & & Student apathy. \\
\hline & & Motivating students to take responsibility for learning. \\
\hline & & Student apathy. \\
\hline & & Getting them to be able to be better thinkers and solvers of challenges. \\
\hline & & Making the children learn how to take responsibility. \\
\hline & & Motivating students to seek personal improvement. \\
\hline & & $\begin{array}{l}\text { I believe our biggest challenge is trying to teach our students to be more responsible for } \\
\text { themselves and to be responsible in their ability to be more independent thinkers. }\end{array}$ \\
\hline & & $\begin{array}{l}\text { Behavior. Teachers spend SO much time addressing inappropriate behavior that it robs } \\
\text { student learning. }\end{array}$ \\
\hline & & Social skills, developing a sense of responsibility. \\
\hline & & Ethics, responsibility, duty. \\
\hline & & Lack of motivation of students that is backed up by unmotivated, uninvolved parents. \\
\hline & & Developing appropriate social skills within the student community. \\
\hline 8. & $\begin{array}{l}\text { Curriculum and } \\
\text { Instruction }\end{array}$ & Eliminating skill gaps \\
\hline
\end{tabular}




\begin{tabular}{|c|c|c|}
\hline & Category & Quote \\
\hline & & Making learning relevant and rigorous in this fast paced "internet" society \\
\hline & & All students placed in business classes, financial classes, and computer skill classes. \\
\hline & & Graduation requirements that are unrealistic. \\
\hline & & Scheduling our interventionists. \\
\hline & & Application of data based research to actual classroom instruction \\
\hline & & Getting students early so that we can make a greater impact on their brain development. \\
\hline & & Different learning capabilities and how they learn. \\
\hline & & $\begin{array}{l}\text { Economics/Health/Active Engagement in the learning process/ Teaching to the way the } \\
\text { brain actually works. }\end{array}$ \\
\hline & & Changing the instruction procedures of my teachers. \\
\hline & & $\begin{array}{l}\text { Many students have lost the initiative to be successful beyond HS. There is also a lack of } \\
\text { a seamless curriculum coming from elementary to middle school and middle school to } \\
\text { high school. }\end{array}$ \\
\hline & & Using data analysis to inform instruction. \\
\hline & & The developing of the use of teams in all core subjects. \\
\hline & & $\begin{array}{l}\text { If schools could cut out the "cute" stuff and focus on the "important/valuable" curriculum } \\
\text { stuff, teachers could teach and students would learn. WVDE needs to stop asking for } \\
\text { "submit your students essays - art work - posters, etc" that take students away from the } \\
\text { true work - learning. }\end{array}$ \\
\hline & & $\begin{array}{l}\text { Different children need to be reached in different ways. True differentiation requires } \\
\text { training on more that just strategies in the classroom. Staff need to be knowledgeable of } \\
\text { the reasons certain strategies work on different children due to their home environment. }\end{array}$ \\
\hline & & Teaching kids to think! \\
\hline & & The challenge of changing from teacher led learning to student led learning; \\
\hline & & $\begin{array}{l}\text { Changing from instruction based to learning based. Focusing more on formative rather } \\
\text { than summative assessment. }\end{array}$ \\
\hline & & Time and too much in the curriculum. \\
\hline & & Developing adequate communication skills within the student population. \\
\hline 9. & Faculty Attitudes & Many of my staff are older and find change hard. \\
\hline & & $\begin{array}{l}\text { Change often requires a lot of work ... change in lesson plans, change in instructional } \\
\text { practices, change in curriculum. This is very hard on experienced teachers. I think they } \\
\text { become "lazy" over time. }\end{array}$ \\
\hline & & Teacher buy-in and the age-old problem of TTWWADI (This is the way we always did it.) \\
\hline & & Teachers are moving from one school to another to change jobs. \\
\hline & & Having all staff believe the same. \\
\hline & & $\begin{array}{l}\text { The greatest challenge to developing all students is to get all teachers to believe and } \\
\text { implement the mission. }\end{array}$ \\
\hline & & $\begin{array}{l}\text { Ensuring that all faculty members believe all children can achieve mastery of the } \\
\text { curriculum. }\end{array}$ \\
\hline & & $\begin{array}{l}\text { Changing attitudes of teachers about new ways to educate our students and having the } \\
\text { time to so. }\end{array}$ \\
\hline & & I need my entire staff to be emotionally involved and not just going through the routine. \\
\hline & & $\begin{array}{l}\text { Changing teaching strategies \& perspectives The acceptance of coaches as a resource. } \\
\text { Changing the focus of the teachers from, how I teach to how they learn. Using the data to } \\
\text { drive instruction. }\end{array}$ \\
\hline & & $\begin{array}{l}\text { Switching the mind set of our school community that a students' world is now global and } \\
\text { that their learning must be too. }\end{array}$ \\
\hline & & $\begin{array}{l}\text { Providing the message of urgency for change in how we do things. We have a lot of older } \\
\text { teachers that have to be pulled kicking and screaming in to the } 21 \text { st Century. }\end{array}$ \\
\hline & & $\begin{array}{l}\text { With an aging faculty, it would involve getting everyone on board and cooperating with the } \\
\text { changes. }\end{array}$ \\
\hline & & Staff members that don't want to change. \\
\hline & & I am working to make my school a Professional Learning Community. It will take time. \\
\hline & & Getting teachers on board with the changes. \\
\hline & & Overcoming past stereotypes and perceptions of what people think school should be \\
\hline & & Developing all teachers into 21st Century Teachers. \\
\hline & & Changing the way we teach. \\
\hline
\end{tabular}




\begin{tabular}{|c|c|c|}
\hline & Category & Quote \\
\hline & & Changing the school culture. \\
\hline & & Changing the style of teaching. \\
\hline & & $\begin{array}{l}\text { The staff that does not believe that ALL students can learn the same skills with the proper } \\
\text { strategies and time. }\end{array}$ \\
\hline & & $\begin{array}{l}\text { We need to educate everyone that there is a dire need for change and why we need to } \\
\text { change. Everyone must have this mindset. }\end{array}$ \\
\hline & & $\begin{array}{l}\text { Getting our experienced staff to change their way of teaching so we can better prepare } \\
\text { our kids for the future }\end{array}$ \\
\hline & & The development (acceptance) of continual change and improvement. \\
\hline & & To improve the quality of teaching. \\
\hline & & Teachers who are not life-long learners and resist change. \\
\hline & & Getting everyone to buy in! \\
\hline & & Changing the beliefs and traditions of teachers who have been teaching for many years. \\
\hline & & The greatest challenge that I face is getting all teachers on board. \\
\hline & & Teacher working conditions linked to teacher morale and acceptance of change. \\
\hline & & Changing attitudes of "experienced" teachers. \\
\hline & & Teacher unwillingness to change. \\
\hline 10. & Accountability & $\begin{array}{l}\text { The question is how to achieve mastery for ALL STUDENTS!!! I still feel there needs to be } \\
\text { a process in which we look at student progress year by year instead of one test score. } \\
\text { Especially when we look at the special needs students. Just because a student doesn't } \\
\text { score a certain score doesn't mean he/she will not be successful. Too much is put on all } \\
\text { students scoring a certain score for mastery. }\end{array}$ \\
\hline & & $\begin{array}{l}\text { The belief that ALL students can achieve mastery on standardized test. All students can } \\
\text { learn but not all will be able to achieve mastery. }\end{array}$ \\
\hline & & $\begin{array}{l}\text { Meeting the unrealistic expectation that "All" students will meet mastery level on core } \\
\text { content. Meeting the expectations of WESTEST } 2 \text {. }\end{array}$ \\
\hline & & $\begin{array}{l}\text { Currently high school students are assessed to the point that it is an impediment to the } \\
\text { education process. WESTEST, End of Course Test, NAEP, Work Keys, PLAN, ACT, } \\
\text { PSAT, benchmark tests, and classroom assessments. }\end{array}$ \\
\hline & & $\begin{array}{l}\text { Unfunded mandates that have precipitated an environment in education that places } \\
\text { achievement on high-stakes standardized tests above student mastery of content. }\end{array}$ \\
\hline 11. & Parents & Parents' involvement in child's education \\
\hline & & Parent and staff support. \\
\hline & & Motivation, lack of support from home. \\
\hline & & Get away from one assessment as being the governing factor of a schools success. \\
\hline & & Changing attitudes instilled by the student's home life. \\
\hline & & Parent understanding of our overall goals. \\
\hline & & Parent support \& involvement in their child's education. \\
\hline & & The environment from where they come impacts their success each day of their lives. \\
\hline & & Lack of parent/community support. \\
\hline & & $\begin{array}{l}\text { The greatest challenge for our school is to get the parents involved not only in sports but } \\
\text { in the academic aspects of our school. We need to and are working on ways to } \\
\text { communicate with parents (such as at Little League games, church announcements, etc.). } \\
\text { So many of our parents work and it is difficult to get them in to the school or to attend } \\
\text { meetings. }\end{array}$ \\
\hline & & Parental support. \\
\hline & & Working with the parents and trying to show them that the students can be successful. \\
\hline & & Divorce and the breakdown of family values consistent with lack of training at home. \\
\hline & & Respect for themselves and others--family values are not what they need to be. \\
\hline & & Lack of support from parents. \\
\hline & & Getting parents and students to understand the importance of 21 st century learning. \\
\hline & & The lack of parental involvement and socioeconomic status. \\
\hline & & Parental apathy. \\
\hline & & $\begin{array}{l}\text { Parent involvement and allowing parents to have the understanding of the value of } \\
\text { education. }\end{array}$ \\
\hline & & $\begin{array}{l}\text { Getting the Parents and Students to understand and buy in to the changes that need to } \\
\text { occur in order for this to happen. }\end{array}$ \\
\hline & & Parental involvement. \\
\hline & & Parent involvement. \\
\hline
\end{tabular}




\begin{tabular}{|c|c|c|}
\hline & Category & Quote \\
\hline & & Lack of parent support. \\
\hline & & $\begin{array}{l}\text { Parent involvement and their understanding of the skills their children need to possess to } \\
\text { be successful. }\end{array}$ \\
\hline & & Increasing parental involvement. \\
\hline & & Parents are the greatest obstacles. \\
\hline & & Lack of parental help at home. \\
\hline & & Getting parents to understand their importance to the success of their child. \\
\hline & & Uninformed and/or apathetic parents. \\
\hline & & Getting parents to take a more active role in their child's education growth. \\
\hline & & $\begin{array}{l}\text { Changing the mindset of parents who do not recognize the value of an education for their } \\
\text { children. }\end{array}$ \\
\hline & & $\begin{array}{l}\text { Development of parent involvement from parents that do not value education is a } \\
\text { challenge. }\end{array}$ \\
\hline & & Poor parenting. \\
\hline \multirow[t]{17}{*}{12.} & Societal Issues & $\begin{array}{l}\text { The greatest challenge is helping them overcome all the influences of current } \\
\text { environment, culture at home and the media/TV. }\end{array}$ \\
\hline & & $\begin{array}{l}\text { My community is changing quickly into a drug infested community that doesn't care about } \\
\text { it's children. }\end{array}$ \\
\hline & & $\begin{array}{l}\text { Helping children and parents understand the importance of learning and its impact on } \\
\text { their future. }\end{array}$ \\
\hline & & $\begin{array}{l}\text { There has been much progress in my } 11 / 2 \text { years as principal, but about } 15 \text { veteran } \\
\text { faculty members fight me with the school board every inch of the way. The county office, } \\
\text { newly placed also, seems to be more interested in saving their jobs than in making } \\
\text { decisions on "principles" and "students" in some cases. As an outsider coming into the } \\
\text { system, it appears that I have to prove every thought and every action I make. It amazes } \\
\text { me that adults can be so focused on their own needs rather than the kids. The greatest } \\
\text { challenge, then, is changing the culture and climate of not only the school but the county } \\
\text { office and school board to believing in the kids and making decisions on kids. Excuses are } \\
\text { common that deal with the kids' not being able to do the work, whether in the classroom } \\
\text { or in athletics. The idea that it is "I don't have the Jimmy's and Joe's" is believed rather } \\
\text { than "What can I do to make the kids better?" }\end{array}$ \\
\hline & & Overcoming life circumstances and making students see importance for education. \\
\hline & & Ethics. \\
\hline & & Lack of trust between county office and school \\
\hline & & $\begin{array}{l}\text { There is a disconnect with my school's efforts for high expectations for attendance and } \\
\text { achievement efforts and those of the central office. Also, issues with special education } \\
\text { practices. }\end{array}$ \\
\hline & & $\begin{array}{l}\text { Convincing teachers, administration and board members that we must make our schools } \\
\text { technology efficient for teaching and learning. }\end{array}$ \\
\hline & & Children and students coming from "broken home" situations. \\
\hline & & $\begin{array}{l}\text { We are held back because as the principal I do not have the support I need from the } \\
\text { Central office to follow through with enforcing teachers to perform necessary task to } \\
\text { accomplish student success. }\end{array}$ \\
\hline & & Culture, tradition, state mandates. \\
\hline & & $\begin{array}{l}\text { We have a serious problem with students moving in and out of the school district. This is } \\
\text { more than } 20 \% \text { yearly. It is hard to keep data on these children. }\end{array}$ \\
\hline & & Lack of understanding by parents and govt. of the need for a well rounded education. \\
\hline & & The diversity of the students and the cultures they come from are challenges. \\
\hline & & $\begin{array}{l}\text { The Central Office staff is the biggest barrier to providing our students with the best } \\
\text { quality education available. Their aversion to adequately staffing schools and providing } \\
\text { the correct fiscal support makes it difficult to improve with less staff and less resources. } \\
\text { They have the mindset that services or programs stay in place even though personnel } \\
\text { and fiscal support decrease. }\end{array}$ \\
\hline & & $\begin{array}{l}\text { Student discipline has deteriorated rapidly in the last decade. Teachers and the staff get } \\
\text { questioned continuously for the decisions they make regarding discipline by the public. } \\
\text { Most times when a student gets in trouble his/her parents come to the school office and } \\
\text { argue why their child should not be punished for a violation of the student code of } \\
\text { conduct. All of the parents want a safe school until their child gets in trouble and then they } \\
\text { will be overzealous in trying to get the child little or no punishment. }\end{array}$ \\
\hline
\end{tabular}




\section{Appendix $\mathrm{H}$}

\section{Question 3: Narrative Responses by Category - Comparison Group}

\begin{tabular}{|c|c|c|}
\hline \multicolumn{3}{|c|}{ COMPARISON GROUP: 121 Responses } \\
\hline & Category & Quote \\
\hline \multirow[t]{3}{*}{1} & Time management & 4 \\
\hline & & Time is needed and not there for ANYTHING. \\
\hline & & $\begin{array}{l}\text { Some days are just days of responding to various things such as IEP Meetings, parent } \\
\text { conferences, student issues, teacher issues, and discipline. There are not enough hours in } \\
\text { the day to keep pace with this job anymore. }\end{array}$ \\
\hline \multirow[t]{2}{*}{2} & Scheduling & 3 \\
\hline & & How to schedule all the co-teaching that needs to take place. \\
\hline 3 & Finances & 1 \\
\hline \multirow[t]{3}{*}{4} & Response to Intervention & 10 \\
\hline & & $\begin{array}{l}\text { Teachers are wanting and needing more tricks up their sleeve in students receiving RTI } \\
\text { and balancing that with the above average student to give more in depth meaningful } \\
\text { lessons. }\end{array}$ \\
\hline & & RTI training as I still am not sure we are absolutely headed in the right direction. \\
\hline 5 & $\begin{array}{l}\text { Professional Learning } \\
\text { Communities }\end{array}$ & 1 \\
\hline 6 & Teacher Evaluation & $\begin{array}{l}\text { Evaluation of school personnel for meaningful classroom improvement. Most } \\
\text { administrators do not want to give "bad" evaluations so they don't have to deal with the } \\
\text { teacher unions like AFT. Any meaningful and accurate assessment of a bad teacher } \\
\text { usually involves AFT. Too many evaluations in a given semester. Administrators spend all } \\
\text { their time focusing on doing formal evaluation of beginning teachers. Five formal } \\
\text { assessments for beginning teachers is way too much. I can tell a good or ineffective } \\
\text { teacher without sitting and doing numerous "formal" evaluations. }\end{array}$ \\
\hline \multirow[t]{3}{*}{7} & $\begin{array}{l}\text { 21st Century Leadership } \\
\text { Institutes. }\end{array}$ & 1 \\
\hline & & $\begin{array}{l}\text { I am currently involved in the } 21 \text { st century principal leadership academy at Glade Springs. } \\
\text { It has been WONDERFUL! It has been the most helpful learning experience I have had in } \\
\text { years! }\end{array}$ \\
\hline & & $\begin{array}{l}\text { Continue with the } 21 \text { st Century Leadership Academy - but add follow-up sessions for } \\
\text { those who have completed the year training. Perhaps a 3-day annual conference just to } \\
\text { update/refresher sessions. }\end{array}$ \\
\hline \multirow[t]{3}{*}{8} & Leadership & Leadership styles. \\
\hline & & $\begin{array}{l}\text { Leadership enhancement Tools to deal with teachers who come from a different } \\
\text { generation and who have a different work ethic and orientation to education }\end{array}$ \\
\hline & & Instructional leadership. \\
\hline \multirow[t]{8}{*}{9} & Curriculum & Help with Creative Curriculum. \\
\hline & & Curriculum development. \\
\hline & & $\begin{array}{l}\text { Prof. dev. that keeps admin. enlightened as to new data on current programs, new } \\
\text { educational programs available in curriculum development. }\end{array}$ \\
\hline & & Standards-based curriculum implementation. \\
\hline & & Standards-Based math training continued. \\
\hline & & Standards-based instruction in areas other than math. \\
\hline & & Need help with curriculum mapping. \\
\hline & & $\begin{array}{l}\text { Curriculum personnel are desperately needed because running the school does not allow } \\
\text { enough time to focus on curriculum. }\end{array}$ \\
\hline 10 & $\begin{array}{l}\text { Benchmark } \\
\text { Assessments }\end{array}$ & 1 \\
\hline 11 & WVEIS Documentation & 1 \\
\hline 12 & Parent Involvement & 1 \\
\hline
\end{tabular}




\begin{tabular}{|c|c|c|}
\hline & Category & Quote \\
\hline & & $\begin{array}{l}\text { How to explain to parents the importance of being responsible for their children until they } \\
\text { reach the age of } 18 \text {. It is not someone else's responsibility. }\end{array}$ \\
\hline & & New concepts on partnerships with parents. \\
\hline & & Need ways to get more parent involvement in the school system. \\
\hline & & How to help parents do a better job with their children. \\
\hline & & Ideas to get parents on board. \\
\hline \multirow[t]{5}{*}{13} & Relationships & 1 \\
\hline & & Handling difficult people. \\
\hline & & Positive relationships with people in authority. \\
\hline & & Book study on effective emotional understanding. \\
\hline & & How to deal with the teachers in my building. \\
\hline 14 & Grant Writing & 1 \\
\hline 15 & $\begin{array}{l}\text { Research-Based } \\
\text { Strategies }\end{array}$ & $\begin{array}{l}\text { I am always interested in efforts that show proven student success. There is no one size } \\
\text { fits all to education but much can be learned and adapted to each of our situations. }\end{array}$ \\
\hline 16 & Project-Based Instruction & 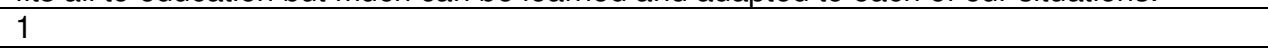 \\
\hline \multirow[t]{4}{*}{17} & Classroom Management & 2 \\
\hline & & More discipline techniques. \\
\hline & & $\begin{array}{l}\text { The ability to convince teachers that different classroom management techniques need to } \\
\text { be applied on certain students. They think one glove fits all. }\end{array}$ \\
\hline & & Tools to deal effectively with "behavior challenged" students and their parents. \\
\hline \multirow[t]{16}{*}{18} & Technology & 9 \\
\hline & & $\begin{array}{l}\text { How to use the computers more in education where students do not just guess and for } \\
\text { teachers to better understand these programs. }\end{array}$ \\
\hline & & I would like to have more technology training as that field is forever changing and updating \\
\hline & & Tech Steps Thinkfinity --training in concepts teachers are trained in \\
\hline & & $\begin{array}{l}\text { In order to help the staff understand the change in the traditional mind set I need to be } \\
\text { equipped with the technology and processes for them to use with various strategies and } \\
\text { practices to model. I believe I need to practice what I want them to do. }\end{array}$ \\
\hline & & Ways to help teachers integrate technology. \\
\hline & & Technology (keeping up with the changes). \\
\hline & & $\begin{array}{l}\text { Continual professional development of new initiatives, including use of technology to } \\
\text { enhance learning. }\end{array}$ \\
\hline & & Technology skills improved. \\
\hline & & Innovative technology. \\
\hline & & $\begin{array}{l}\text { Training in the use of technology--- more time on task- so educators feel comfortable and } \\
\text { competent and secure in the knowledge that the technology will WORK! }\end{array}$ \\
\hline & & Continued technology advances. \\
\hline & & I am feeling very technology challenged right now. \\
\hline & & $\begin{array}{l}\text { Allow staff the flexibility to receive training in } 21 \text { st. century technology during working } \\
\text { hours. We need to treat professionals as professionals! }\end{array}$ \\
\hline & & Hands-on Podcasting, Excel, Photoshop, etc. \\
\hline & & Tech-based opportunities. \\
\hline 19 & Higher Order Thinking & That which would involve teaching more problem solving and higher level thinking skills. \\
\hline \multirow[t]{5}{*}{20} & Problem Solving & Hands-on professional development instead of lecture. \\
\hline & & On-going, measured, practical learning experiences. \\
\hline & & Real, everyday, common-sense development. \\
\hline & & Hands-on, experiential. \\
\hline & & $\begin{array}{l}\text { When professional development must take place during the school day and year, it must } \\
\text { be done as much as possible in the school itself, dealing with the school's initiatives, not } \\
\text { the county's or state's. }\end{array}$ \\
\hline \multirow[t]{6}{*}{21} & Instructional Strategies & Continuing to learn about new teaching strategies. \\
\hline & & Skill group development (differentiated instruction). \\
\hline & & $\begin{array}{l}\text { Personally, I would like to receive an overview of the latest teaching techniques, so that I } \\
\text { will have a first hand knowledge of what I am asking my teachers to implement. }\end{array}$ \\
\hline & & Research based teaching strategies. \\
\hline & & Differentiated instruction, collaborative teaching. \\
\hline & & Latest data driven teaching techniques rather than politically driven. \\
\hline
\end{tabular}




\begin{tabular}{|c|c|c|}
\hline & Category & Quote \\
\hline & & $\begin{array}{l}\text { Learning the processes that students use in playing electronic games for insight into } \\
\text { instructional approaches. }\end{array}$ \\
\hline & & Better teaching strategies. \\
\hline \multirow[t]{4}{*}{22} & Assessment & $\begin{array}{l}\text { I would like to have more detailed data on norm-referenced tests; i.e., the PLAN and } \\
\text { EXPLORE tests. }\end{array}$ \\
\hline & & Using assessment to monitor achievement. \\
\hline & & $\begin{array}{l}\text { To develop a long range plan for achieving AYP in reading and mathematics as measured } \\
\text { by WESTEST II. }\end{array}$ \\
\hline & & Assessment analysis. \\
\hline \multirow[t]{3}{*}{23} & Motivation & .1 \\
\hline & & Motivating the unmotivated \\
\hline & & $\begin{array}{l}\text { Motivating the unmotivated staff member...it is no longer enough to move with those willing } \\
\text { to change. }\end{array}$ \\
\hline \multirow[t]{8}{*}{24} & $21^{\text {st }}$-Century Learning & 6 \\
\hline & & $\begin{array}{l}\text { Training how to provide the opportunities for students to be successful learners in 21st } \\
\text { century. }\end{array}$ \\
\hline & & $\begin{array}{l}\text { Future trends (so we will know a year or two ahead and can make smooth transitions and } \\
\text { plans for success) }\end{array}$ \\
\hline & & $\begin{array}{l}\text { Continual support of the } 21 \text { st century standards and how to get veteran teachers to } \\
\text { change the method in which they teach. }\end{array}$ \\
\hline & & $\begin{array}{l}\text { Specific development dealing with identification of instructional goals in } 21 \text { st century } \\
\text { learning objectives. }\end{array}$ \\
\hline & & $21^{\text {st }}$-century tools. \\
\hline & & Continue $21^{\text {st }}$-century training. \\
\hline & & $\begin{array}{l}\text { Anything that would keep me abreast of changing curriculum, strategies, theories, etc., to } \\
\text { help make our students competitive in today's world. }\end{array}$ \\
\hline \multirow[t]{2}{*}{25} & Community Resources & $\begin{array}{l}\text { I would benefit from professional development which would give me better insight to } \\
\text { community resources which would help provide the basic need of several of our students. } \\
\text { This professional development should also have outlined what schools can do legally to } \\
\text { provide for the care of our students. }\end{array}$ \\
\hline & & How to locate resources for our school. \\
\hline \multirow[t]{4}{*}{26} & Urgency for Change & $\begin{array}{l}\text { Teachers need to understand that changes need to be made to teaching methods and } \\
\text { strategies. I have veteran teachers who simply do not see the need to change how they } \\
\text { work. }\end{array}$ \\
\hline & & Leading for change. \\
\hline & & How to move personnel from point A to point B with the least amount of controversy. \\
\hline & & Hands on strategies and methods to help get the staff to buy into the change process. \\
\hline \multirow[t]{8}{*}{27} & Networking & Observing other administrators on the job. \\
\hline & & $\begin{array}{l}\text { Networking with my colleagues around the country and the world. We all face similar } \\
\text { situations. I have been blessed to be able to do this, but ALL school leaders need to do } \\
\text { this. }\end{array}$ \\
\hline & & $\begin{array}{l}\text { Too much time is spent on sending teachers and administrators away from their school to } \\
\text { one shot deals that take time and money for very little gain. An exception to this is time } \\
\text { spent in other schools actually observing others at work. Example participating on a } \\
\text { HSTW Technical Assistance Visit. }\end{array}$ \\
\hline & & $\begin{array}{l}\text { It would be nice to have some collaboration and reflection time provided with other } \\
\text { principals without the large egos ruling the atmosphere. Perhaps some virtual situations } \\
\text { that require the same analysis and problem solving that occur on a daily basis in schools } \\
\text { across the state that would require the needed collaboration and discussion to develop the } \\
\text { best case scenario for the particular situation. Therefore the situation wouldn't be owned } \\
\text { by the individuals but by the group working together. We need to know how to } \\
\text { cooperatively and collaboratively work together before we can identify it in our own } \\
\text { workplace or classroom. }\end{array}$ \\
\hline & & Collegial. \\
\hline & & Opportunities to work with colleagues to address specific topics. \\
\hline & & Programs that are successful in schools with the same demographics \\
\hline & & $\begin{array}{l}\text { Opportunities to brainstorm and talk with other leaders to see what they came up } \\
\text { with...more heads are better than one. }\end{array}$ \\
\hline
\end{tabular}




\begin{tabular}{|c|c|c|}
\hline & Category & Quote \\
\hline & & $\begin{array}{l}\text { Collaboration with principals and teachers on implementation strategies for embedding } \\
21^{\text {st }} \text { - century learning in our classrooms. }\end{array}$ \\
\hline \multirow[t]{2}{*}{28} & Data Analysis & 1 \\
\hline & & Data disaggregation and practices to support the findings \\
\hline \multirow[t]{2}{*}{20} & Diverse Learners & 1 \\
\hline & & Differentiated Instruction, layered instruction \\
\hline \multirow{2}{*}{21} & Poverty & 1 \\
\hline & & $\begin{array}{l}\text { Working with Appalachian people. What will it take to get them to understand and value } \\
\text { education? }\end{array}$ \\
\hline \multirow[t]{13}{*}{22} & Too Much Already & I'm getting plenty--too many to implement. \\
\hline & & $\begin{array}{l}\text { There is so much available- it's hard to balance the demands of the state and county with } \\
\text { the daily demands of my PreK-8th school. }\end{array}$ \\
\hline & & $\begin{array}{l}\text { Nothing new for the next couple years. Give us time to master what we are doing. } \\
\text { Reinforcement activities only. }\end{array}$ \\
\hline & & More knowledge with the programs already implemented at my school. \\
\hline & & My county has so much professional development on every program possible. \\
\hline & & None at this point-I am ready to retire. \\
\hline & & $\begin{array}{l}\text { As an educational leader the most helpful staff development for me would be teaching me } \\
\text { to deal with all the initiatives sent down from the federal, state, and local boards. It is } \\
\text { difficult to implement and deal with changes that occur so rapidly. I understand change is } \\
\text { good and I like change, but we hardly ever see results from change before we change } \\
\text { again! }\end{array}$ \\
\hline & & $\begin{array}{l}\text { I actually believe our professional development resulting from our involvement within FSU } \\
\text { \& WVU Collaboratives; a current WVCPD Grant for AP development from middle to high } \\
\text { school; our technology emphasis/use currently address today's needs for our staff. }\end{array}$ \\
\hline & & Not so much pressure for immediacy when all is not in place. \\
\hline & & Too many to list. More help maybe! \\
\hline & & $\begin{array}{l}\text { We tend to have training on something and then move on to something else. We need to } \\
\text { have a more consistent method of allowing the schools to develop the necessary skills } \\
\text { before moving on. }\end{array}$ \\
\hline & & Sustaining the professional development we currently have. \\
\hline & & $\begin{array}{l}\text { All staff development must be sustained and focused. We are too quick to jump to the next } \\
\text { great idea and never work a particular strategy long enough to test results or evaluate } \\
\text { effectiveness. We seem to have to change the vocabulary of school improvement every } \\
\text { other year. }\end{array}$ \\
\hline \multirow[t]{2}{*}{23} & School Culture & 1 \\
\hline & & How to change a community/school culture. \\
\hline \multirow[t]{3}{*}{24} & At-Risk Students & 1 \\
\hline & School Law & 3 \\
\hline & & Special education laws. \\
\hline \multirow[t]{10}{*}{25} & General & $\begin{array}{l}\text { The kind that addresses real issues/problems and assists in developing real } \\
\text { solutions/insights/visions. }\end{array}$ \\
\hline & & $\begin{array}{l}\text { The kind that can be presented by teacher trainers. We have had ongoing staff } \\
\text { development in differentiation and quality tools. }\end{array}$ \\
\hline & & Ways to make it fun again for the teachers. \\
\hline & & $\begin{array}{l}\text { Currently Title } 1 \text { provides the type of professional development needed at our school to } \\
\text { keep us at Exemplary status. }\end{array}$ \\
\hline & & $\begin{array}{l}\text { We need to make administration and teaching school a year-round job for the } \\
\text { professionals. This would give us truly enough time to plan, train, assess and implement } \\
\text { new strategies. Trying to do this at the end of the work day or three hours every other } \\
\text { month is not nearly as successful or efficient as it needs to be. }\end{array}$ \\
\hline & & Continue to offer the types of staff development you have offered in the past. \\
\hline & & $\begin{array}{l}\text { Professional development that addresses the needs of the school done in a moderate size } \\
\text { audience. }\end{array}$ \\
\hline & & No comment. \\
\hline & & How to put together meaningful professional development to meet my staffs needs. \\
\hline & & $\begin{array}{l}\text { None that I can think of, mainly because I am going to a couple in the upcoming year that I } \\
\text { feel will benefit me greatly. Ask me again next school year! }\end{array}$ \\
\hline
\end{tabular}




\begin{tabular}{|l|l|l|}
\hline & \multicolumn{1}{|c|}{ Category } & \multicolumn{1}{c|}{ Quote } \\
\hline & & $\begin{array}{l}\text { I will be retiring at the end of this year. I am having major trouble keeping up with the } \\
\text { amount of work involved in the administrative position as it is now. }\end{array}$ \\
\hline & & Prescription drug abuse information and how to stop/identify it. \\
\hline & & I would value more support from our central office. \\
\hline & & Getting back to the basics. \\
\hline & & Training in the strategic plan. \\
\hline
\end{tabular}




\section{Appendix I}

\section{Question 3: Narrative Responses by Category - Treatment Group}

\begin{tabular}{|c|c|c|}
\hline \multicolumn{3}{|c|}{ TREATMENT GROUP: 121 Responses } \\
\hline & Category & Quote \\
\hline \multirow[t]{4}{*}{1} & Assessment & $\begin{array}{l}\text { I need professional development in all the areas of assessment including DIBELS, Acuity, } \\
\text { etc. }\end{array}$ \\
\hline & & Formative assessments. \\
\hline & & Formative assessment development \\
\hline & & Assessment for learning. \\
\hline 2 & At-Risk Students & Dealing with at-risk students. \\
\hline \multirow[t]{11}{*}{3} & Change & Dealing with teachers who do not want to change. \\
\hline & & Helping senior teachers change to meet current needs of our students. \\
\hline & & Teacher motivation and change. \\
\hline & & $\begin{array}{l}\text { Motivating teachers to accept the need for using } 21 \text { st century teaching and learning } \\
\text { techniques }\end{array}$ \\
\hline & & $\begin{array}{l}\text { Mentor who visits with the school principal at least once a month to help with change } \\
\text { implementation. }\end{array}$ \\
\hline & & Change brings a variety stresses on a faculty and the community. \\
\hline & & How to inspire and motivate staff to want to continue to change. \\
\hline & & How to move my staff into changing they way they are teaching. \\
\hline & & More professional development on the change process. \\
\hline & & Keeping up with the changing world. \\
\hline & & Creating positive change in "not so positive" teachers. \\
\hline \multirow[t]{3}{*}{4} & Classroom Management & Discipline professional development. \\
\hline & & Behavior Modification techniques. \\
\hline & & Working with BD children. \\
\hline \multirow[t]{7}{*}{5} & Curriculum & 1 \\
\hline & & Unpacking the CSOs. \\
\hline & & Math - how does the Math brain work and what are the best practices to support it! \\
\hline & & Reading First support after the program ends. \\
\hline & & $\begin{array}{l}\text { Along with a solid understanding of school leadership, school leaders need to understand } \\
\text { the various curricular initiates being supported by the state. Continuous training on } \\
\text { leadership and curricular initiatives is key. }\end{array}$ \\
\hline & & $\begin{array}{l}\text { I would like some training specifically for elementary CSO's. It is very hard to separate } \\
\text { when instruction should be textbook driven or CSO driven. They want us to have fidelity to } \\
\text { the core and it confuses these lower grade teachers. It confuses me. }\end{array}$ \\
\hline & & Staff development in the areas of developing a standards-based curriculum. \\
\hline \multirow[t]{3}{*}{6} & Data Analysis & 4 \\
\hline & & More comprehensive training with data analysis. \\
\hline & & $\begin{array}{l}\text { Hands-on data analysis workshop where we bring our school's data and analyze it under } \\
\text { the direction of an expert. }\end{array}$ \\
\hline \multirow[t]{4}{*}{7} & $\begin{array}{l}\text { Effective Schools } \\
\text { Research }\end{array}$ & $\begin{array}{l}\text { Required professional development for the central office, including the superintendent, on } \\
\text { high expectations and correlates of effective schools. I "get" it, central office doesn't. }\end{array}$ \\
\hline & & Effective Classrooms, what works in schools, correlates of effective school. \\
\hline & & I would like to have more training on the Effective Schools Movement and Larry Lezotte. \\
\hline & & Dr. Larry Lezotte on effective schools. \\
\hline \multirow[t]{6}{*}{8} & General & $\begin{array}{l}\text { Training held away from school before or after the school year begins, held with other } \\
\text { professional staff from the school. }\end{array}$ \\
\hline & & Covey training for the entire staff on the Seven Habits of Highly Effective People. \\
\hline & & Progress Monitoring. \\
\hline & & National Conferences. \\
\hline & & Delegation of tasks. \\
\hline & & All. \\
\hline
\end{tabular}




\begin{tabular}{|c|c|c|}
\hline & Category & Quote \\
\hline & & $\begin{array}{l}\text { The most helpful professional development for this county would be for the school board } \\
\text { so they would not look at the "number" of complaints but base their judgments on } \\
\text { "principles" and on "what is best for kids" not what is best for their teacher friends who can } \\
\text { bend their ears. This is not said in meanness but in objective observation of what is } \\
\text { happening in this county, and I bet it is in others as well, especially when it comes to high } \\
\text { school teachers. }\end{array}$ \\
\hline & & $\begin{array}{l}\text { I would like for ALL professional development sessions to be held in the summer when I } \\
\text { do not have to be out of my building during the school day. }\end{array}$ \\
\hline & & $\begin{array}{l}\text { Developing teachers as effective teachers who recognize that they hold great } \\
\text { responsibility for relationship building with students. }\end{array}$ \\
\hline & & Give me the training to meet the needs of my teachers and students. \\
\hline & & How to remain positive when all around you are not. \\
\hline & & Crisis management techniques could be useful, usually that is OJT. \\
\hline & & Team building. \\
\hline & & Organizational skills. \\
\hline & & School law refresher. \\
\hline & & How to be more understanding. \\
\hline & & $\begin{array}{l}\text { Glasser, Total Behavior Sax, Gurian, Kindlon \& Thompson, Gender Jensen, Brain } \\
\text { Research }\end{array}$ \\
\hline & & Continuous improvement. \\
\hline 9 & Instructional Strategies & Research-based teaching strategies. \\
\hline & & Strategies for delivering content within the classroom. \\
\hline & & Teaching strategies (researched based) that have proven to be successful. \\
\hline & & Additional differentiated instruction. \\
\hline & & Intervention strategies for academic areas and behavioral issues of students. \\
\hline & & Differentiated instruction (2). \\
\hline & & Problem-based learning (3). \\
\hline & & We need more instruction on differentiated instruction. \\
\hline & & Student engagement. \\
\hline & & Anything regarding instructional strategies. \\
\hline & & Higher level thinking skills. \\
\hline & & Continue with high-yield instructional strategies. \\
\hline 10 & Leadership & A more personal approach in all areas. \\
\hline & & Leaders of leaders. \\
\hline & & $\begin{array}{l}\text { Also professional development on capacity building and developing the leaders around } \\
\text { you would also be very useful. In today's world we need to have shared leadership and } \\
\text { develop teacher leaders. }\end{array}$ \\
\hline & & Continued PD on leadership \\
\hline & & Leaders need to be trained on so many aspects of the school and leadership. \\
\hline & & Learning how to be an instructional leader. \\
\hline & & $\begin{array}{l}\text { Professional development on "creating teacher leaders" who actually accept } \\
\text { responsibilities for the many programs for which principals are responsible would be very } \\
\text { helpful. }\end{array}$ \\
\hline & & Professional development that provides strategies for making successful leaders. \\
\hline & & Instructional leadership. \\
\hline 11 & Motivation & Motivation for students, parents, and staff. \\
\hline & & Motivational Seminar. \\
\hline & & $\begin{array}{l}\text { How to engage students who just don't care. I worry about } 16 \text { year old 8th graders. We } \\
\text { need an alternative for students who don't want to come to school; so they don't. }\end{array}$ \\
\hline & & $\begin{array}{l}\text { Professional development on "keeping teachers motivated" and "over-coming teacher } \\
\text { burnout" are two important auxiliary topics that are of concern to my colleagues and me. }\end{array}$ \\
\hline & & How to motivate teachers to do whatever is needed to help students achieve success. \\
\hline 12 & Networking & How others handle everyday situations. \\
\hline & & Time with other principals to learn from their experiences. \\
\hline & & $\begin{array}{l}\text { I have learned more in situations where principals from around the state have had time to } \\
\text { talk with each other and help with everyday issues. }\end{array}$ \\
\hline & & More information on collaboration and teaming and how it works in a small school. \\
\hline & & Bringing leaders together to talk to one another, to share best practices. \\
\hline
\end{tabular}




\begin{tabular}{|c|c|c|}
\hline & Category & Quote \\
\hline & & Group discussions with peers. \\
\hline & & $\begin{array}{l}\text { More seminars/opportunities for real-world principals that have been implementing } 21 \mathrm{st} \\
\text { century skills to share their results/challenges. }\end{array}$ \\
\hline & & $\begin{array}{l}\text { Visiting schools to see how organized they are and successful schools are implementing } \\
\text { the needed changes. }\end{array}$ \\
\hline & & Shared experiences from colleagues and those who are still in the field. \\
\hline \multirow[t]{8}{*}{13} & Parent Involvement & 1 \\
\hline & & Parent involvement tips. \\
\hline & & $\begin{array}{l}\text { it would be great to be involved in professional development that would help in parent } \\
\text { involvement, communication, etc. Parents need to be aware of the changes taking place in } \\
\text { education and they need to realize the importance of their support to the school and their } \\
\text { child's education. }\end{array}$ \\
\hline & & $\begin{array}{l}\text { Exposure to new ideas relating to finding ways to get parents and the community involved } \\
\text { in the education of our children. }\end{array}$ \\
\hline & & Parents also need to be held more accountable for student attendance and behavior. \\
\hline & & How to make the parents aware of the need for change. \\
\hline & & Parental involvement programs. \\
\hline & & $\begin{array}{l}\text { How to train Parents in working with their children to develop the responsibility aspect of } \\
\text { becoming productive. }\end{array}$ \\
\hline 14 & Problem Solving & $\begin{array}{l}\text { Direct and relative "Hands On" at the school level. ie; A team would spend time with } \\
\text { faculty and staff to ensure that all have access to the professional development. }\end{array}$ \\
\hline \multirow[t]{3}{*}{15} & $\begin{array}{l}\text { Professional Learning } \\
\text { Communities }\end{array}$ & 2 \\
\hline & & $\begin{array}{l}\text { More on professional learning communities. We had the training at the conference. We } \\
\text { have been working at it for a year. We need follow up sessions to see if we are still on the } \\
\text { right track. }\end{array}$ \\
\hline & & $\begin{array}{l}\text { I'm really into defining profession learning communities. We have found out that the teams } \\
\text { who work and collaborate on a daily basis about students are showing huge results. When } \\
\text { I talk about teams, I'm looking at across grade levels, vertical and departmental teams. All } \\
\text { play an important part of our student's successes. This should be mandated across the } \\
\text { state!!! }\end{array}$ \\
\hline \multirow[t]{2}{*}{16} & Project-Based Learning & $\begin{array}{l}\text { Continued training on project based learning. It would help me to have more of the staff } \\
\text { receive training; however, I have a small staff and not many who will travel for training } \\
\text { sessions. }\end{array}$ \\
\hline & & Problem-based learning (2). \\
\hline \multirow[t]{5}{*}{17} & Response to Intervention & 3 \\
\hline & & RTI at the middle-school level. \\
\hline & & More intervention ideas. \\
\hline & & Tiered instruction \\
\hline & & With RTI scheduling is now a nightmare!!! HELP!!! \\
\hline 18 & Resources & How to find resources. \\
\hline 19 & Scheduling & 2 \\
\hline \multirow[t]{2}{*}{20} & School Culture & 1 \\
\hline & & Improving school culture. \\
\hline 21 & Socio-Economic Status & How to get progress from a low SES subgroup. \\
\hline 22 & Strategic Planning & 1 \\
\hline 23 & $\begin{array}{l}\text { Standards-Based } \\
\text { Learning }\end{array}$ & $\begin{array}{l}\text { More information on standards-based learning and how to assess /evaluate it would be } \\
\text { helpful. }\end{array}$ \\
\hline 24 & Stress Management & $\begin{array}{l}\text { Stress management in today's world of being a principal (I am seriously looking at getting } \\
\text { out of administration because of the detrimental affect it is having on my health. The } \\
\text { demands are too great! }\end{array}$ \\
\hline \multirow[t]{7}{*}{25} & Technology & 12 \\
\hline & & $\begin{array}{l}\text { Please continue the professional development in technology tools so we can keep up with } \\
\text { the latest gadgets. }\end{array}$ \\
\hline & & Keeping up with technology. \\
\hline & & As much technology as possible. \\
\hline & & How to improve the use of technology in the classroom. \\
\hline & & Technology Integration Specialists in schools at all times. \\
\hline & & How technology applies to the core curriculum and the CSOs. \\
\hline
\end{tabular}




\begin{tabular}{|c|c|c|}
\hline & Category & Quote \\
\hline & & $\begin{array}{l}\text { Professional development that is associated with the new technology innovations such as } \\
\text { student responders, Thinkfinity, blogging for teacher staff development, and any other } \\
\text { activities that would enhance the way that technology is used to enhance student } \\
\text { achievement. }\end{array}$ \\
\hline & & Technology implementation. \\
\hline & & $\begin{array}{l}\text { Effective ongoing training for our teachers and administration that enhances awareness of } \\
\text { new technology. }\end{array}$ \\
\hline & & Assessment technology. \\
\hline & & Technology training and best practices. \\
\hline & & I would like to see how technology is used in successful schools. \\
\hline & & Technology training is helpful since it is ever changing. \\
\hline & & The use and need for technology in core classes. \\
\hline & & More technology and equipment to back it up. \\
\hline & & Technology and the different ways our kids can use it to be successful. \\
\hline & & Help in using $21^{\text {st }}$ technology tools. \\
\hline & & I need as much technology training as I can get. \\
\hline & & I would like to see staff development in the effective use of new technology. \\
\hline & & $\begin{array}{l}\text { More integration of technology into the curriculum. I am fortunate to have } 2 \text { TISs in my } \\
\text { school, but I feel that I need to learn with my staff and be able to support their adventures } \\
\text { into technology. I just don't want to be knowledgeable about technology, I want to } \\
\text { effectively use it and assist my instructors. }\end{array}$ \\
\hline & & $\begin{array}{l}\text { Technology use, new, developing technology and how to incorporate use of that } \\
\text { technology into the classroom for student learning opportunities. }\end{array}$ \\
\hline & & Any type of technology training. \\
\hline 26 & Time Management & $\begin{array}{l}\text { I feel that I have been provided with adequate training. I wish I had more time with the staff } \\
\text { to work through issues. I think the school calendar should include days at the beginning of } \\
\text { the year so that we can have good conversations with all members of the staff. With the } \\
\text { current calendar, teachers are so focused on preparing for their students that they are not } \\
\text { interested in staff development. }\end{array}$ \\
\hline & & $\begin{array}{l}\text { Time for targeted areas of concern that are school based so that staff development has } \\
\text { meaning for our teachers. }\end{array}$ \\
\hline & & $\begin{array}{l}\text { Time to be in my school to actually carry out all of the professional development that we } \\
\text { have already received. The time is needed to make the professional development } \\
\text { sustained, monitor the effects, and make change as needed (sustained and embedded). }\end{array}$ \\
\hline & & More time to work with staff on issues that will improve student achievement. \\
\hline & & $\begin{array}{l}\text { Teachers need more than } 2 \text { or } 3 \text { days of CE to fully understand and implement new } \\
\text { initiatives and processes. I call it drive-thru staff development. }\end{array}$ \\
\hline & & How to find time. \\
\hline 27 & Too Much Already & $\begin{array}{l}\text { I am not sure I have been through so much and we have provided so much to the faculty } \\
\text { and we still meet with frustration. I don't know what will help. However, we are continuing } \\
\text { to move forward. }\end{array}$ \\
\hline & & $\begin{array}{l}\text { How to create time for school-wide planning. We have had many, many, many... sessions } \\
\text { dealing with the importance of staff development. It is time to provide a training to } \\
\text { demonstrate how schools with no staff development funds or extra time in the schedule } \\
\text { can complete adequate and ongoing planning/school improvement activities. }\end{array}$ \\
\hline & & $\begin{array}{l}\text { We need to keep with one program. We keep on changing the direction of how curriculum } \\
\text { should be delivered every five years. }\end{array}$ \\
\hline & & Current topics with follow-up on implementation. \\
\hline & & Balancing what is already on the teacher "plate". \\
\hline 28 & $\begin{array}{l}21^{\text {st }} \text {-Century Leadership } \\
\text { Institute }\end{array}$ & Nothing could beat the 21 st Century Leadership Institute. \\
\hline & & $\begin{array}{l}\text { The Principal's Academy offered by the WVDE has really been great for me. The } \\
\text { professional development concentrated on creating change in our schools, specifically } \\
\text { creating schools compatible for the } 21 \text { st Century. }\end{array}$ \\
\hline & & $\begin{array}{l}\text { The Institute is an excellent way because of the fact we had to go away without family } \\
\text { (that was hard at first), provided critical friends, equipped with technology and expected to } \\
\text { use it, and continuous assignments for ongoing development. }\end{array}$ \\
\hline & & Extended work from the Principal's institute. \\
\hline
\end{tabular}




\begin{tabular}{|c|c|c|}
\hline & Category & Quote \\
\hline & & $\begin{array}{l}\text { I have been very pleased with the WVDE Leadership Institute and the WVDE County } \\
\text { Leadership Conference. The staff development of this quality is what is needed not only } \\
\text { for administrators for all educators. }\end{array}$ \\
\hline & & $\begin{array}{l}\text { To continue support for the Institute and allow the graduates' continued professional } \\
\text { development. }\end{array}$ \\
\hline \multirow[t]{25}{*}{29} & $21^{\text {st }}$-Century Learning & How to evaluate quality $21^{\text {st }}$-century instructional practices. \\
\hline & & Help for teachers with 21 st century skills. \\
\hline & & Student Assessment of 21st Century Skills. \\
\hline & & All staff would benefit from 21st Century Learning Skills. \\
\hline & & Continuous PD on 21st Century skills. \\
\hline & & The ongoing change to 21 st century skills. \\
\hline & & 21 st century strategies - using the tools in a 21 st century class \\
\hline & & How to use 21 st First Century Tools to their greatest advantages. \\
\hline & & Anything on 21st Century instruction. \\
\hline & & $\begin{array}{l}\text { In addition, more time to learn specific practices that will assist in implementation of the } \\
21 \text { st Century initiatives. }\end{array}$ \\
\hline & & Professional development on 21st Century Learning. \\
\hline & & More 21st Century Skills for Teachers. \\
\hline & & 21st Century Skills in the classroom. \\
\hline & & Training that deals with all aspects of 21st Century learning skills. \\
\hline & & Technology and 21st century thinking skills. \\
\hline & & Training teachers in 21st century teaching skills. \\
\hline & & $\begin{array}{l}\text { For teachers and I to be able to see and know how to use more global teaching in the } \\
\text { classroom. }\end{array}$ \\
\hline & & 21st Century Teaching \& Learning Strategies. \\
\hline & & $\begin{array}{l}\text { Teachers have a clear understanding of } 21 \text { st Century learners' brain activity and abilities. } \\
\text { That we can no longer teach students by lining them up in straight rows and giving them } \\
\text { worksheets. }\end{array}$ \\
\hline & & 21st Century Skills that include strategies and methods supported by technology. \\
\hline & & Just keep all principals updated of what is going on in the world. \\
\hline & & $\begin{array}{l}\text { 21st Century Skills and how to support teachers in the classroom trying to implement best } \\
\text { practices. }\end{array}$ \\
\hline & & $\begin{array}{l}\text { Follow up sessions after this academy is over. I would hope that the State Department } \\
\text { doesn't just move on to the next batch of principal and leave us alone. We need to be able } \\
\text { to revisit an intense series of sessions to continue to stay abreast, interested and } \\
\text { enthusiastic. }\end{array}$ \\
\hline & & Continued work in 21st Century Learning skills. \\
\hline & & Continued instruction in 21st Century learning skills. \\
\hline \multirow[t]{2}{*}{30} & WVEIS & $\begin{array}{l}\text { WVEIS contains an immense amount of data. Unfortunately, most principals have not } \\
\text { been trained on how to extract the data and move it into usable formats. }\end{array}$ \\
\hline & & Training on WVEIS with scheduling would be particularly beneficial. \\
\hline
\end{tabular}




\section{Appendix J}

Advance Letter for Survey via Regular Mail

November, 2008

$\begin{array}{ll}\text { [ Name and Address } & \text { ] } \\ {[} & \text { ] }\end{array}$

Dear [ ]

Your name was listed on one of the West Virginia Department of Education (WVDE) web sites as a present or former school principal. It is the principal who often sees the most accurate picture of what is happening in the school. Your professional opinions, therefore, are extremely important to the process of understanding our schools. The better we understand them, the better we can make them.

Within the next few days, you will be receiving an e-mail with a link to a brief questionnaire sent to the following e-mail address: [

].

Your responses to this survey questionnaire will contribute valuable information to the work of school improvement. I urge you to try to find a few minutes in your busy schedule to complete the questionnaire. If you prefer to use a paper copy of the questionnaire, please contact me.

Please note the following:

- This is research being conducted as a dissertation project through West Virginia University, and it has the support of WVDE officials.

- Your responses will be kept anonymous and confidential through the use of an electronic survey. No individual names will be used, and the responses will be studied as group data, not individual data.

- It should take about 15 minutes to complete, and directions will be provided. You are encouraged to answer all the questions, but you may skip any question you do not wish to answer.

- Your participation or lack of participation in this survey will not affect your job or your professional standing in any way.

I hope you will choose to have your opinions included in this state-wide survey. Thank you in advance for your participation.

Sincerely,

Connie L. Myer 


\section{Appendix K - Letter of Support}

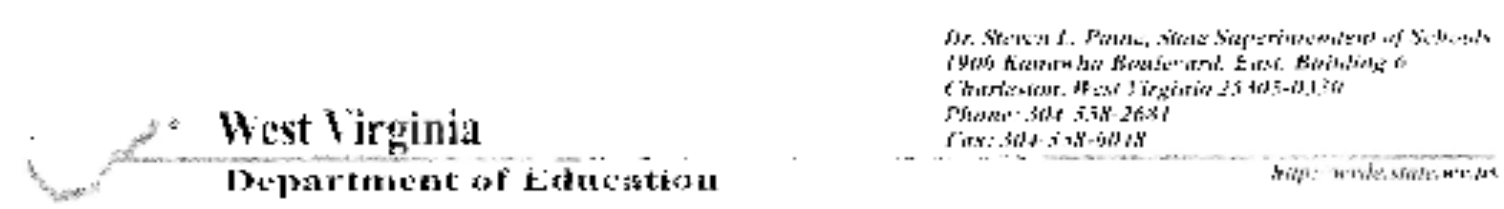

March 202008

Connie Myer. Director

Professional F.ducation Department

Wheeling Jesuit University

316 Washington Avenue

Wheeling, Wv 26003

Dear Ms. Myer:

I am most happy to slpport your dissertation study in the area of the impact of the $21^{\text {sl }}$ Century Leadership Institutes conducted by the Wvest Virginia Department of Education for the state's principals.

As I understand your study: you will be gathering perceptual data from attending and non attending principals and from teachers in the schools of attending and non attending principals to determine where the principals are on the implementation continum of $21^{\text {s. }}$ century teaching and learning. I look forward to reading the results of your study which I see as a potentially important contribution to the work my staft has undertaken to bring about strong $21^{31}$ century leadership for West Virginia s schools.

Please know that you are welcome and encouraged to contact any of my staff invoived with this work. The outstanding educators in the Division of Special ProjectsiSuperintendent's Center for $21^{\text {ts }}$ Century Schools, headed by Dr. Karen I1.iffman, can provide you valuable information about the Leadership Institutes. I know ail of these staff members would be most pleased to discuss their work and prov de you any information you might request.

Do let me know if I can be of any further assistance. Best wishes with your dissertation study!

Sincerely.

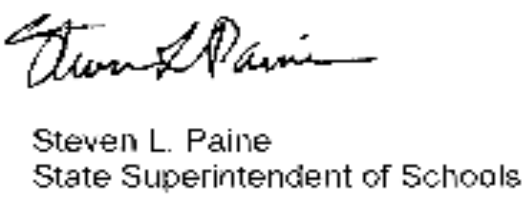

A. F kelriparsilpachl attar

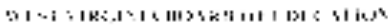

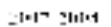

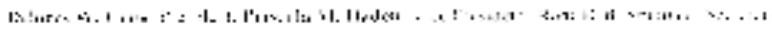

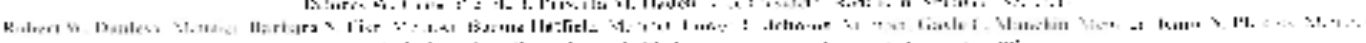

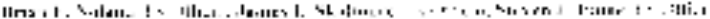

